\title{
MÉTODO PARA ANÁLISE DO CONTORNO DE AGLOMERADOS DE GOTAS DE CHUVA ARTIFICIAL EM IMAGEM DIGITAL
}

Dissertação apresentada à Escola de Engenharia de São Carlos da Universidade de São Paulo, como parte dos requisitos para obtenção do Título de Mestre em Engenharia Elétrica.

Orientador: Prof. Dr. Paulo Estevão Cruvinel

São Carlos

2005 
Dedico este trabalho aos meus amados pais, Aparecida Vieira Koenigkan e Hilton Bittencourt Koenigkan. 


\section{Agradecimentos}

Ao Pai Celestial, por sua constante presença em meu coração;

Aos meus pais e irmão, pelo apoio irrestrito e carinho em todos os momentos desde sempre;

Ao meu orientador Dr. Paulo Estevão Cruvinel, por me ensinar e por sua amizade durante todo o percurso;

A meus grandes amigos Mauricio Fernando Pereira Lima e Marcelo Aparecido Marchiolli, por sua amizade e presença em todas as horas;

Aos professores, pesquisadores, funcionários e colegas da Embrapa Instrumentação e do Departamento de Engenharia Elétrica da EESC USP, pelo apoio recebido;

A equipe do LAC, Profa. Dra. Vilma Alves de Oliveira, Gláucia Maria Bressan e Cláudia Regina Adati, pela cooperação e oportunidades de aprender;

A Thaís Cabrera Galvão Rojas, por seu amor e companheirismo.

A CAPES, pela bolsa concedida; 


\section{Resumo}

Este trabalho apresenta um método para análise do contorno de gotas de chuva artificial em imagem digital, o qual se caracteriza como uma ferramenta para melhor compreensão dos processos agrícolas que envolvem o uso de chuvas artificiais, como a irrigação e a aplicação de defensivos, sendo desenvolvido com o uso de técnicas para análise de formas bidimensionais e processamento de sinais, como representação de formas por contornos paramétricos, análise de Fourier e filtragem gaussiana. Os resultados obtidos demonstram precisão na análise de imagens de aglomerados de gotas, acrescentando as características de descritor apresentadas pela curvatura, assim como a flexibilidade de calibração oferecidas pela abordagem multi-escala adotada, possibilitando a obtenção de erros de medida não maiores que 5\%, para os padrões circulares testados com raios entre 10 e 200 pixels.

Palavras-chave: Processamento de sinais; Análise de curvatura; Gota; Análise do contorno; Imagem digital 


\begin{abstract}
This work presents a method for contour analysis of artificial rain drop based on both digital image and curvature processing. The method is characterized as a tool, which allows a better understanding of the raindrops in irrigation and agrochemicals spraying processes. Its development was based on parametric contours representation of shapes, Fourier analysis, and Gaussian filtering. Results show the suitability of the method, which presents errors smaller than $5 \%$ for curvature determination in the range of the radius variation in betwen 10 and 200 pixels as well as the ability for raindrop clusters analysis.
\end{abstract}

Keywords: Signal processing; Curvature analysis; Drop; Contour analysis; Digital image 


\section{Sumário}

$\begin{array}{ll}\text { Sumário } & 1\end{array}$

$\begin{array}{ll}\text { Lista de figuras } & 3\end{array}$

$\begin{array}{lc}\text { Lista de tabelas } & 8\end{array}$

1 Introdução $\quad 11$

1.1 Introdução . . . . . . . . . . . . . . . . . . . . . . . . . . 11

1.2 Métodos . . . . . . . . . . . . . . . . . . . . . . 12

2 Chuva Artificial e o Estudo do Volume de Gotas $\quad 14$

2.1 Chuva Artificial . . . . . . . . . . . . . . . . . 14

2.2 Importância do Estudo do Volume de Gotas . . . . . . . . . . . . . . . 16

2.3 Principais Métodos para a Determinação do Volume de Gotas . . . . . 17

2.3.1 Descrição dos principais métodos para a determinação do volume de gotas . . . . . . . . . . . . . . . 17

2.4 Informação do Volume de Gotas . . . . . . . . . . . . . . . . . . 19

3 Processamento de Imagens Digitais $\quad 22$

3.1 Imagem, um Modelo . . . . . . . . . . . . . . . . . . . . . 22

3.2 Imagem Digital . . . . . . . . . . . . . . . . . . . . . . 23

3.2.1 Relações entre pixels . . . . . . . . . . . . . . . . . . . . 24

3.2 .2 Cor . . . . . . . . . . . . . . . . 26

3.3 Processamento de Imagem Digital . . . . . . . . . . . . . . . . . . . 28

3.3 .1 Organização típica . . . . . . . . . . . . . . . . . . . . 28

3.3.2 Transformações entre os modelos RGB e YIQ . . . . . . . . . . 30

3.3.3 Limiarização . . . . . . . . . . . . . . . . . . . . . . . 30

3.3.4 Rotulação de regiões disjuntas . . . . . . . . . . . . . . . . . . . . . 31

3.3.5 Extração de contornos paramétricos . . . . . . . . . . . . . 33

4 Curvatura $\quad 37$

4.1 Importância da curvatura . . . . . . . . . . . . . . . . . . 37

4.2 Curvatura Baseada na Medida de Ângulos entre Vetores . . . . . . . . 38

4.2.1 Medida multi-escala de curvatura com a curvatura-c . . . . . . . 40

4.3 Descritores de Formas Baseados em Curvatura . . . . . . . . . . . . . . 40

4.4 Estimativa da Curvatura através da Transformada de Fourier . . . . . . 41

4.4.1 Expressões para a estimativa da curvatura através da transformada de Fourier . . . . . . . . . . . . . . . . . . . . . . 41

4.4.2 Estimativa multi-escala da curvatura através da filtragem gaussiana 42 
4.4.3 Prevenção da contração do contorno causada pela filtragem gaussiana . . . . . . . . . . . . . . . . 43

4.5 Detecção de Vértices a partir da Curvatura . . . . . . . . . . . . . . 46

5 Medida do Volume de Gotas com Análise de Curvatura $\quad 47$

5.1 Amostragem da chuva artificial . . . . . . . . . . . . . . . . 48

5.2 Digitalização da imagem . . . . . . . . . . . . . . . . . . . . . . 48

5.3 Quantização em níveis de cinza . . . . . . . . . . . . . . . . . . 48

5.4 Limiarização . . . . . . . . . . . . . . . . . . . . . 50

5.5 Segmentação e rotulação . . . . . . . . . . . . . . . . . . . . . . . 51

5.6 Extração de contornos . . . . . . . . . . . . . . . . . . . . . . 52

5.6.1 Modificação no algoritmo de extração de contornos . . . . . . . 53

5.7 Identificação de aglomerados de gotas . . . . . . . . . . . . . . 55

5.7 .1 Método de detecção de vértices . . . . . . . . . . . . . . . 55

5.7.2 Aplicação da abordagem multi-escala de estimativa da curvatura na identificação de aglomerados . . . . . . . . . . . . . . . . . . 59

5.8 Estimativa da curvatura dos contornos de gotas . . . . . . . . . . . 60

6 Resultados, Discussões e Conclusões $\quad 62$

6.1 Resultados . . . . . . . . . . . . . . . . . . 62

6.1.1 Rotinas implementadas . . . . . . . . . . . . . . . . . 64

6.1.2 Estudos realizados . . . . . . . . . . . . . . . 70

6.1.3 Estudo de caso com imagens de gotas reais . . . . . . . . . . . . 83

6.2 Discussões . . . . . . . . . . . . . . . . . . . . . . . . 87

6.3 Conclusões . . . . . . . . . . . . . . . . . . . . . . . . . . . . 89

6.4 Trabalhos futuros . . . . . . . . . . . . . . . . . . . . . 89

$\begin{array}{ll}\text { A Formulações de Curvatura } & 90\end{array}$

B Definições Relacionadas a Transformada de Fourier $\quad 94$

$\begin{array}{lll}\text { C Dados complementares dos estudos realizados } & 97\end{array}$

$\begin{array}{ll}\text { D Estudos de caso com amostras de papéis hidrossensíveis } & 109\end{array}$

Referências bibliográficas $\quad 134$ 


\section{Lista de Figuras}

2.1 (a) Pivo central, (b) Aspersor com carretel, (c) Pulverizador costal, (d) Pulverizador autopropelido, (e) Atomizador, (f) Avião agrícola. Fontes: (a) IrrigaFertil - http://irrigafertil.tripod.com.br, (b) Metal Lavras http://www.metallavras.com.br, (c) Plasgot - http://www.plasgot.com, (d) Servspray - http://www.servspray.com.br, (e) Hardi Internatinal http://www.hardi-nozzles.com, (f) Instituto de Tecnologia - UFRRJ http://www.ufrrj.br/institutos/it/it.htm. . . . . . . . . . . .

3.1 (a) Imagem com amostragem de 70 pixels/cm, (b) Imagem com amostragem de 35 pixels $/ \mathrm{cm}$, (c) Imagem com amostragem de 13 pixels $/ \mathrm{cm}$.

3.2 (a) Imagem de uma cena, quantizada em 256 níveis de cinza, (b) Imagem de uma cena, quantizada em 16 níveis de cinza, (c) Imagem de uma cena, quantizada em 4 níveis de cinza. . . . . . . . . . . . . . . . . . .

3.3 (a) Ilustração da vizinhança-de-4 de p, (b) Ilustração da vizinhança-de-8 de p. . . . . . . . . . . . . . . . . . 25

3.4 Diagrama representação o modelo de cor RGB . . . . . . . . . . . . . 27

3.5 Diagrama rpresentando o modelo de cor YIQ . . . . . . . . . . . . . 27

3.6 Diagrama de um sistema típicos de processamento de imagens digitais, segundo Gonzales e Woods. . . . . . . . . . . . . . . . . . .

3.7 (a) Imagem colorida quantizada em 24 bits no sistema de cor RGB, (b) Imagem monocromática quantizada em 256 níveis de cinza, após conversão. 31

3.8 (a) Ilustração dos pixels vizinhos de $(p)$ considerados na análise, no caso de objetos conectados-de-4, (b) Ilustração dos pixels vizinhos de $(p)$ considerados na análise, no caso de objetos conectados-de- 8 . . . . . . . 32

3.9 Forma bidimensional apresentada em uma imagem binária. . . . . . . . 34

3.10 Primeiro passo para extração do contorno paramétrico. . . . . . . . . . 34

3.11 Segundo passo para extração do contorno paramétrico. . . . . . . . . . 35

3.12 Vizinhança-de-8 de p rotulada de 0 a $7 \ldots$. . . . . . . . . . . . . 35

3.13 Extração de contorno de forma com cavidade de um pixel de largura. . 36

3.14 Valores de X e Y do Contorno Paramétrico extraído do objeto apresen-

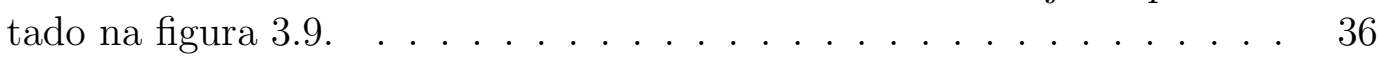

4.1 Contorno paramétrico $C(t) \ldots \ldots \ldots \ldots$

4.2 Vetores $\vec{v}(n)$ e $\vec{w}(n)$ que descrevem o ângulo no ponto $C\left(t_{n}\right) \ldots \ldots$. . . 38

4.3 Vetores $\overrightarrow{v_{i}}(n)$ e $\vec{w}_{i}(n)$ que descrevem o ângulo no ponto $C\left(t_{n}\right) \ldots \ldots$

5.1 Diagrama de blocos do método. . . . . . . . . . . . . . . . . . 47

5.2 Papel hidrossensível com marcas de gotas de água, com dimensões de

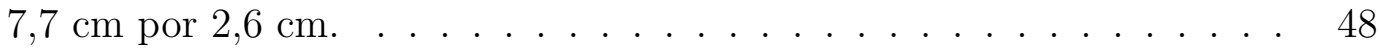


5.3 Diagrama com representação do formato RGB na qual a imagem deve ser digitalizada . . . . . . . . . . . . . . . . . . . . . 49

5.4 Diagrama ilustrando o processo de quantização em níveis de cinza . . . 49

5.5 Diagrama ilustrando o processo de limiarização, para se obter uma imagem binária. . . . . . . . . . . . . . . . . 50

5.6 Diagrama ilustrando o processo de segmentação e rotulação. . . . . . . . 51

5.7 Diagrama ilustrando em destaque a cavidade com um pixel de largura e com mais de um pixel de profundidade. . . . . . . . . . . . . . .

5.8 Diagrama ilustrando contorno de forma com cavidade com um pixel de largura e com mais de um pixel de profundidade. . . . . . . . . . . .

5.9 Picos de curvatura ocasionados por cavidades com um pixel de largura e mais de pixel de profundidade. . . . . . . . . . . . . . . . .

5.10 Diagrama ilustrando um contorno extraído com o algoritmo modificado, de uma forma contendo uma cavidade de um pixel de largura e com mais de um pixel de profundidade.

5.11 Ilustrações de aglomerados com os pontos de separação das gotas em destaque.

5.12 Ilustração do contorno de um aglomerado com pontos de quebra marcados. 57

5.13 Ilustração do contorno suavizado de um aglomerado com pontos de quebra marcados. . . . . . . . . . . . . . . . . . . . . . .

5.14 Gráfico da curvatura do contorno de um aglomerado com pontos de quebra marcados. . . . . . . . . . . . . . . . .

5.15 Gráficos das derivadas primeira e segunda da curvatura do contorno de um aglomerado com pontos de quebra marcados. . . . . . . . . . . 59

5.16 Função gaussiana utilizada como filtro. . . . . . . . . . . . . . . . 60

5.17 Curvatura de um padrão circular, para cada ponto do contorno extraído. 61

6.1 Interface com o usuário desenvolvida para a interação com as rotinas do método para análise do contorno de gotas de chuva artificial em imagem digital. . . . . . . . . . . . . . . . . . .

6.2 (a) Ilustração de aglomerados com percentual de aglomeração igual a 0 \%, (b) Ilustração de aglomerados com percentual de aglomeração igual a $25 \%$, (c) Ilustração de aglomerados com percentual de aglomeração igual a $50 \%$, (d) Ilustração de aglomerados com percentual de aglomeração igual a 75 \%, (e) Ilustração de aglomerados com percentual de aglomeração igual a 100 \%. (O percentual de aglomeração é determinado em relação à sobreposição do diâmetro do menor padrão componente do aglomerado) . . . . . . . . . . . . . . . . . .

6.3 Padrão circular gerado pela rotina de estudo de precisão de medidas sem a inserção de ruído em seu contorno. . . . . . . . . . . . . . . .

6.4 Padrão circular gerado pela rotina de estudo de precisão de medidas com a inserção de ruído randômico com valor máximo de 3 pixels de deslocamento em seu contorno. . . . . . . . . . . . . . . .

6.5 Gráfico com erros na medida do raio por escala, para o valor de nível de ruído 0 no primeiro estudo. . . . . . . . . . . . . . . . . .

6.6 Gráfico com erros na medida do raio por escala, para o valor de nível de ruído 1 no primeiro estudo. . . . . . . . . . . . . . . . . .

6.7 Gráfico com erros na medida do raio por escala, para o valor de nível de ruído 2 no primeiro estudo. . . . . . . . . . . . . . . . . . . 
6.8 Gráfico com erros na medida do raio por escala, para o valor de nível de ruído 3 no primeiro estudo. . . . . . . . . . . . . . . . . . .

6.9 Gráfico com erros na medida do raio por escala, para o valor de nível de ruído 0 no segundo estudo. . . . . . . . . . . . . . . . . . . .

6.10 Gráfico com erros na medida do raio por escala, para o valor de nível de ruído 1 no segundo estudo. . . . . . . . . . . . . . . . . .

6.11 Gráfico com erros na medida do raio por escala, para o valor de nível de ruído 2 no segundo estudo. . . . . . . . . . . . . . . . . .

6.12 Gráfico com erros na medida do raio por escala, para o valor de nível de ruído 3 no segundo estudo. . . . . . . . . . . . . . . . . . . .

6.13 Aspecto predominante dos gráficos de erro da estimativa do raio, realizada com aglomerados no terceiro estudo.

6.14 Primeira amostra do primeiro papel hidrossensível, ampliada 5 vezes em relação ao seu tamanho original. . . . . . . . . . . . . . . .

6.15 Histograma apresentando a distribuição dos tamanhos das gotas contidas na primeira amostra do primeiro papel hidrossensível. . . . . . . . . .

6.16 Segunda amostra do primeiro papel hidrossensível, ampliada 5 vezes em relação ao seu tamanho original. . . . . . . . . . . . . . . . . .

6.17 Histograma apresentando a distribuição dos tamanhos das gotas contidas na segunda amostra do primeiro papel hidrossensível. . . . . . . . . . .

6.18 Terceira amostra do primeiro papel hidrossensível, ampliada 5 vezes em relação ao seu tamanho original. . . . . . . . . . . . . . . . . .

6.19 Histograma apresentando a distribuição dos tamanhos das gotas contidas na terceira amostra do primeiro papel hidrossensível.

A.1 Contorno paramétrico C . . . . . . . . . . . . .

D.1 Primeira amostra do segundo papel hidrossensível, ampliada 5 vezes em relação ao seu tamanho original. . . . . . . . . . . . . . . . . .

D.2 Histograma apresentando a distribuição dos tamanhos das gotas contidas na primeira amostra do segundo papel hidrossensível. . . . . . . . . . .

D.3 Segunda amostra do segundo papel hidrossensível, ampliada 5 vezes em relação ao seu tamanho original. . . . . . . . . . . . . . . . .

D.4 Histograma apresentando a distribuição dos tamanhos das gotas contidas na segunda amostra do segundo papel hidrossensível.

D.5 Terceira amostra do segundo papel hidrossensível, ampliada 5 vezes em relação ao seu tamanho original. . . . . . . . . . . . . . . . . . . . . 112

D.6 Histograma apresentando a distribuição dos tamanhos das gotas contidas na terceira amostra do segundo papel hidrossensível. . . . . . . . . . . . 112

D.7 Primeira amostra do terceiro papel hidrossensível, ampliada 5 vezes em relação ao seu tamanho original. . . . . . . . . . . . . . . . .

D.8 Histograma apresentando a distribuição dos tamanhos das gotas contidas na primeira amostra do terceiro papel hidrossensível. . . . . . . . . . .

D.9 Segunda amostra do terceiro papel hidrossensível, ampliada 5 vezes em relação ao seu tamanho original. . . . . . . . . . . . . . . . . . . . . . 114

D.10 Histograma apresentando a distribuição dos tamanhos das gotas contidas na segunda amostra do terceiro papel hidrossensível. . . . . . . . . . . . 114

D.11 Terceira amostra do terceiro papel hidrossensível, ampliada 5 vezes em relação ao seu tamanho original. . . . . . . . . . . . . . . . . . 
D.12 Histograma apresentando a distribuição dos tamanhos das gotas contidas na terceira amostra do terceiro papel hidrossensível. . . . . . . . . . . .

D.13 Primeira amostra do quarto papel hidrossensível, ampliada 5 vezes em relação ao seu tamanho original. . . . . . . . . . . . . . . . .

D.14 Histograma apresentando a distribuição dos tamanhos das gotas contidas na primeira amostra do quarto papel hidrossensível. . . . . . . . . . . 116

D.15 Segunda amostra do quarto papel hidrossensível, ampliada 5 vezes em relação ao seu tamanho original. . . . . . . . . . . . . . .

D.16 Histograma apresentando a distribuição dos tamanhos das gotas contidas na segunda amostra do quarto papel hidrossensível. . . . . . . . . . . .

D.17 Terceira amostra do quarto papel hidrossensível, ampliada 5 vezes em relação ao seu tamanho original. . . . . . . . . . . . . . . . .

D.18 Histograma apresentando a distribuição dos tamanhos das gotas contidas na terceira amostra do quarto papel hidrossensível. . . . . . . . . . . .

D.19 Primeira amostra do quinto papel hidrossensível, ampliada 5 vezes em relação ao seu tamanho original. . . . . . . . . . . . . . . . .

D.20 Histograma apresentando a distribuição dos tamanhos das gotas contidas na primeira amostra do quinto papel hidrossensível. . . . . . . . . . . .

D.21 Segunda amostra do quinto papel hidrossensível, ampliada 5 vezes em relação ao seu tamanho original. . . . . . . . . . . . . . . . .

D.22 Histograma apresentando a distribuição dos tamanhos das gotas contidas na segunda amostra do quinto papel hidrossensível. . . . . . . . . . . .

D.23 Terceira amostra do quinto papel hidrossensível, ampliada 5 vezes em relação ao seu tamanho original. . . . . . . . . . . . . . . . . .

D.24 Histograma apresentando a distribuição dos tamanhos das gotas contidas na terceira amostra do quinto papel hidrossensível. . . . . . . . . . .

D.25 Primeira amostra do sexto papel hidrossensível, ampliada 5 vezes em relação ao seu tamanho original. . . . . . . . . . . . . . . . . .

D.26 Histograma apresentando a distribuição dos tamanhos das gotas contidas na primeira amostra do sexto papel hidrossensível. . . . . . . . . . . . . 122

D.27 Segunda amostra do sexto papel hidrossensível, ampliada 5 vezes em relação ao seu tamanho original. . . . . . . . . . . . . . . . . .

D.28 Histograma apresentando a distribuição dos tamanhos das gotas contidas na segunda amostra do sexto papel hidrossensível. . . . . . . . . . . . .

D.29 Terceira amostra do sexto papel hidrossensível, ampliada 5 vezes em relação ao seu tamanho original. . . . . . . . . . . . . . . . .

D.30 Histograma apresentando a distribuição dos tamanhos das gotas contidas na terceira amostra do sexto papel hidrossensível. . . . . . . . . . . . .

D.31 Primeira amostra do sétimo papel hidrossensível, ampliada 5 vezes em relação ao seu tamanho original. . . . . . . . . . . . . . . . . . .

D.32 Histograma apresentando a distribuição dos tamanhos das gotas contidas na primeira amostra do sétimo papel hidrossensível. . . . . . . . . . . . 125

D.33 Segunda amostra do sétimo papel hidrossensível, ampliada 5 vezes em relação ao seu tamanho original. . . . . . . . . . . . . . . . . .

D.34 Histograma apresentando a distribuição dos tamanhos das gotas contidas na segunda amostra do sétimo papel hidrossensível. . . . . . . . . . . 126

D.35 Terceira amostra do sétimo papel hidrossensível, ampliada 5 vezes em relação ao seu tamanho original. . . . . . . . . . . . . . . . . . . . 127 
D.36 Histograma apresentando a distribuição dos tamanhos das gotas contidas na terceira amostra do sétimo papel hidrossensível. . . . . . . . . . . .

D.37 Primeira amostra do oitavo papel hidrossensível, ampliada 5 vezes em relação ao seu tamanho original. . . . . . . . . . . . . . . . . . . . . . 128

D.38 Histograma apresentando a distribuição dos tamanhos das gotas contidas na primeira amostra do oitavo papel hidrossensível. . . . . . . . . . . . 128

D.39 Segunda amostra do oitavo papel hidrossensível, ampliada 5 vezes em relação ao seu tamanho original. . . . . . . . . . . . . . . . . . . . . . . . 129

D.40 Histograma apresentando a distribuição dos tamanhos das gotas contidas na segunda amostra do oitavo papel hidrossensível. . . . . . . . . . . . 129

D.41 Terceira amostra do oitavo papel hidrossensível, ampliada 5 vezes em relação ao seu tamanho original. . . . . . . . . . . . . . . . . . . . 130

D.42 Histograma apresentando a distribuição dos tamanhos das gotas contidas na terceira amostra do oitavo papel hidrossensível. . . . . . . . . . . . . 130

D.43 Primeira amostra do nono papel hidrossensível, ampliada 5 vezes em relação ao seu tamanho original. . . . . . . . . . . . . . . . . . . . . . 131

D.44 Histograma apresentando a distribuição dos tamanhos das gotas contidas na primeira amostra do nono papel hidrossensível. . . . . . . . . . . . . 131

D.45 Segunda amostra do nono papel hidrossensível, ampliada 5 vezes em relação ao seu tamanho original. . . . . . . . . . . . . . . . . . . . . . 132

D.46 Histograma apresentando a distribuição dos tamanhos das gotas contidas na segunda amostra do nono papel hidrossensível. . . . . . . . . . . . . 132

D.47 Terceira amostra do nono papel hidrossensível, ampliada 5 vezes em relação ao seu tamanho original. . . . . . . . . . . . . . . . . . . 133

D.48 Histograma apresentando a distribuição dos tamanhos das gotas contidas na terceira amostra do nono papel hidrossensível. . . . . . . . . . . . . 133 


\section{Lista de Tabelas}

2.1 Relacionamento entre o tipo de alvo que se deseja atingir e o tamanho de gota para uma aplicação de defensivos - fonte: FCA - UNESP. . . .

2.2 Classificação de gotas pelo DMV (Fonte: BCPC - Formerly the British Crop Protection Council). . . . . . . . . . . . . . . . .

4.1 Sintese de algumas características geométricas importantes que podem ser extraídas através da análise de curvatura. . . . . . . . . . . .

6.1 Parâmetros de entrada da implementação do método para medida do volume de gotas. . . . . . . . . . . . . . . . . . 64

6.2 Resultados da implementação do método para medida do volume de gotas. 64

6.3 Parâmetros de entrada da rotina para teste de precisão de medida. . . . 65

6.4 Resultados da rotina para teste de precisão de medida. . . . . . . . . . 68

6.5 Parâmetros de entrada da rotina para teste de identificação de aglomerados. . . . . . . . . . . . . . . . . . . 69

6.6 Resultados da rotina para teste de identificação de aglomerados. . . . . 69

6.7 Valores de raios testados no primeiro estudo. . . . . . . . . . . . 70

6.8 Escalas, maiores erros e erros médios, para o valor nível de ruído zero encontrados no primeiro estudo. . . . . . . . . . . . . . 71

6.9 Escalas, maiores erros e erros médios, para o valor nível de ruído 1 encontrados no primeiro estudo. . . . . . . . . . . . . . 72

6.10 Escalas, maiores erros e erros médios para, o valor nível de ruído 2 encontrados no primeiro estudo. . . . . . . . . . . . . 73

6.11 Escalas, maiores erros e erros médios, para o valor nível de ruído 3 encontrados no primeiro estudo. . . . . . . . . . . . . . 74

6.12 Valores de raios testados no segundo estudo. . . . . . . . . . . . . . 75

6.13 Escalas, maiores erros e erros médios, para o valor nível de ruído zero encontrados no segundo estudo. . . . . . . . . . . . . . 75

6.14 Escalas, maiores erros e erros médios, para o valor nível de ruído 1 encontrados no no segundo estudo. . . . . . . . . . . . . 76

6.15 Escalas, maiores erros e erros médios para, o valor nível de ruído 2 encontrados no segundo estudo. . . . . . . . . . . . . . 77

6.16 Escalas, maiores erros e erros médios, para o valor nível de ruído 3 encontrados no segundo estudo. . . . . . . . . . . . . . .

6.17 Percentuais de acerto na identificação dos aglomerados, valores dos maiores erros e erros médios da medida dos raios obtidos no terceiro estudo, para o valor de escala para quebra de aglomerados 0,5 . . . . . . . . .

6.18 Percentuais de acerto na identificação dos aglomerados, valores dos maiores erros e erros médios da medida dos raios obtidos no terceiro estudo, para o valor de escala para quebra de aglomerados $0,6 \ldots$. . . . . . 
6.19 Percentuais de acerto na identificação dos aglomerados, valores dos maiores erros e erros médios da medida dos raios obtidos no terceiro estudo, para o valor de escala para quebra de aglomerados $0,7 \ldots$. . . . . . .

6.20 Percentuais de acerto na identificação dos aglomerados, valores dos maiores erros e erros médios da medida dos raios obtidos no terceiro estudo, para o valor de escala para quebra de aglomerados $0,8 \ldots$. . . . . . .

6.21 Percentuais de acerto na identificação dos aglomerados, valores dos maiores erros e erros médios da medida dos raios obtidos no terceiro estudo, para o valor de escala para quebra de aglomerados 0,9 . . . . . . . .

6.22 Percentuais de acerto na identificação dos aglomerados, valores dos maiores erros e erros médios da medida dos raios obtidos no terceiro estudo, para o valor de escala para quebra de aglomerados 1,0 . . . . . . . . .

6.23 Percentuais de acerto na identificação dos aglomerados, valores dos maiores erros e erros médios da medida dos raios obtidos no terceiro estudo, para o valor de escala para quebra de aglomerados 1,1 . . . . . . . . .

6.24 Percentuais de acerto na identificação dos aglomerados, valores dos maiores erros e erros médios da medida dos raios obtidos no terceiro estudo, para o valor de escala para quebra de aglomerados 1,2 . . . . . . . . .

6.25 Percentuais de acerto na identificação dos aglomerados, valores dos maiores erros e erros médios da medida dos raios obtidos no terceiro estudo, para o valor de escala para quebra de aglomerados $1,3 . \ldots$. . . . . .

6.26 Percentuais de acerto na identificação dos aglomerados, valores dos maiores erros e erros médios da medida dos raios obtidos no terceiro estudo, para o valor de escala para quebra de aglomerados 1,4 . . . . . . . . .

6.27 Percentuais de acerto na identificação dos aglomerados, valores dos maiores erros e erros médios da medida dos raios obtidos no terceiro estudo, para o valor de escala para quebra de aglomerados 1,5 . . . . . . . . .

6.28 valores de DMN e DMV calculados para as amostras analisadas. . . . .

C.1 Valores de raios conhecidos, valores de raios caracterizados e erros na medida dos raio, para a escala 0,5 submetida ao valor de nível de ruído zero, para o primeiro estudo. . . . . . . . . . . . . . .

C.2 Valores de raios conhecidos, valores de raios caracterizados e erros na medida dos raio, para a escala 0,6 submetida ao valor de nível de ruído zero, para o primeiro estudo. . . . . . . . . . . . . .

C.3 Valores de raios conhecidos, valores de raios caracterizados e erros na medida dos raio, para a escala 0,7 submetida ao valor de nível de ruído zero, para o primeiro estudo. . . . . . . . . . . . . . .

C.4 Valores de raios conhecidos, valores de raios caracterizados e erros na medida dos raio, para a escala 0,8 submetida ao valor de nível de ruído zero, para o primeiro estudo. . . . . . . . . . . . . .

C.5 Valores de raios conhecidos, valores de raios caracterizados e erros na medida dos raio, para a escala 0,9 submetida ao valor de nível de ruído zero, para o primeiro estudo. . . . . . . . . . . . . .

C.6 Valores de raios conhecidos, valores de raios caracterizados e erros na medida dos raio, para a escala 1,0 submetida ao valor de nível de ruído zero, para o primeiro estudo. . . . . . . . . . . . . . . . 103 
C.7 Valores de raios conhecidos, valores de raios caracterizados e erros na medida dos raio, para a escala 1,1 submetida ao valor de nível de ruído zero, para o primeiro estudo. . . . . . . . . . . . . . . . . . . . 104

C.8 Valores de raios conhecidos, valores de raios caracterizados e erros na medida dos raio, para a escala 1,2 submetida ao valor de nível de ruído zero, para o primeiro estudo. . . . . . . . . . . . . . . 105

C.9 Valores de raios conhecidos, valores de raios caracterizados e erros na medida dos raio, para a escala 1,3 submetida ao valor de nível de ruído zero, para o primeiro estudo. . . . . . . . . . . . . . 106

C.10 Valores de raios conhecidos, valores de raios caracterizados e erros na medida dos raio, para a escala 1,4 submetida ao valor de nível de ruído zero, para o primeiro estudo. . . . . . . . . . . . . . . 107

C.11 Valores de raios conhecidos, valores de raios caracterizados e erros na medida dos raio, para a escala 1,5 submetida ao valor de nível de ruído zero, para o primeiro estudo. . . . . . . . . . . . . . . 108 


\section{Capítulo 1}

\section{Introdução}

\subsection{Introdução}

A produção agrícola baseia-se fundamentalmente nas relações entre água, solo, planta e atmosfera, sendo que do equilíbrio dessas relações depende o rendimento e a eficiência dessa produção.

No tocante aos fatores climáticos a disponibilidade hídrica assume um papel determinante quanto ao rendimento e à qualidade dos produtos, podendo levar a perdas significativas em razão da deficiência hídrica em fases críticas ou em todo o período de desenvolvimento das culturas, como já verificado na produção de feijão que apresenta perda de produtividade de até 54\% (CALVACHE et al., 1997), na batata com perda de até 70,5\% (BEZERRA et al., 1998), no trigo com perda de até 18\% (RODRIGUES et al., 1998), no café com perda de até 100\% (FERNANDES et al., 2000), no alho a deficiência hídrica pode causar diminuição de até $70 \%$ no tamanho dos bulbos (MAROUELLI et al., 2002) e no arroz cuja perda chega a até $70 \%$ (CRUSCIOL et al., 2003).

A relação entre produtividade e disponibilidade hídrica afirma a importância da irrigação freqüentemente empregada nos métodos de manejo, no entanto para que os objetivos da irrigação sejam atingidos esta deve ser realizada de maneira eficiente e para tanto faz-se necessária a compreensão dos processos empregados, dentre eles o da chuva artificial possibilitando melhorias em relação a fatores como desgaste e selamento do solo.

Além de sua aplicação na irrigação a chuva artificial é largamente utilizada na atividade de aplicação de defensivos agrícolas quando da sua pulverização, sendo que sua aplicação nesta atividade está relacionada a fatores envolvendo os custos da produção agrícola, contaminação do ambiente, produtos agrícolas e profissionais envolvidos.

Por estas razões esforços têm sido empregados no desenvolvimento de métodos e instrumentos que auxiliem no monitoramento e controle das atividades agrícolas que se utilizam de chuvas artificiais. Neste contexto, o estudo do volume de gotas tem grande importância, atuando como descritor para o processo de chuva artificial.

A partir do volume de gotas e de sua distribuição, se pode estimar informações sobre: a uniformidade da deposição da chuva artificial, bem como o seu volume total.

O desenvolvimento de métodos de fácil utilização e que apresentem rapidamente resultados de análises, tende a incentivar sua adoção como meio de monitoramento contínuo, permitindo a intervenção em tempo hábil para a correção de problemas. Também podendo ser utilizadas no desenvolvimento e calibração de melhores equipamentos para produção de chuvas artificiais.

O monitoramento por meio do estudo do volume de gotas e de outras análises, 
de áreas que não deveriam estar sob a ação da atividade de defensivos agrícolas pode servir como estudo do processo de contaminação, ocasionado por aplicações que estejam sendo feitas em áreas próximas.

A seguir são apresentados os métodos empregados no trabalho desenvolvido, sendo este um método para a análise do processo de chuva artificial, baseado nas informações obtidas a partir do estudo do volume de gotas.

\section{$1.2 \quad$ Métodos}

No trabalho realizado a aplicação do processamento de imagens digitais se deu por este apresentar características desejáveis as necessidades da aplicação, uma vez que este propicia precisão da análise e rapidez na obtenção dos resultados (CRUVINEL et al., 1996).

A análise visual automática realizada por meio de técnicas do processamento de imagens digitais, traz além da rapidez de resposta a não subjetividade do resultado, o que não é possível com o uso de métodos onde a medida é realizada manualmente.

Além do uso do processamento de imagens digitais este trabalho baseia-se na análise da informação de curvatura de formas bidimensionais para realizar a medida do volume de gotas de chuva artificial.

A medida de curvatura compreende o conceito do quão curvo é o contorno de uma forma, ou o quanto varia essa medida ao longo da forma analisada, sendo que um importante indicio sobre a eficiência da curvatura na análise visual, está no fato de se tratar de um aspecto muito utilizado pela visão biológica (COSTA; CESAR, 2000).

Nos sistemas de visão por computador, a curvatura pode ser empregada na localização de pontos importantes dentro de uma cena, uma vez que alguns trabalhos mostram que os pontos com alta curvatura tendem a concentrar a informação visual (ATTNEAVE, 1954).

A técnica empregada neste trabalho extrai de imagens digitais a informação da curvatura de contornos de maneira a permitir sua representação como um sinal unidimensional, possibilitando a aplicação de técnicas provenientes da engenharia elétrica para o processamento de sinais, bem como a redução da demanda por recursos computacionais que envolvem capacidade de armazenamento e processamento, essa possível redução do custo computacional do método em relação a abordagens puramente bidimensionais pode facilitar sua transposição para plataformas portáteis bastante úteis para aplicação em campo, que no entanto normalmente não dispõem dos mesmos recursos computacionais das plataformas tradicionais.

A transposição do método para plataformas portáteis permite a realização de análises no campo com precisão até então só obtida em laboratórios, por meio da utilização de técnicas baseadas no uso de laser e câmeras de alta velocidade (CUNHA et al., 2004; KASHDAN et al., 2004; LOVICH et al., 2005; SONG et al., 2005).

Este trabalho está organizado em capítulos, sendo a introdução e a apresentação dos métodos são partes deste primeiro Capítulo, no Capítulo 2 são introduzidos os aspectos referentes a utilização da chuva artificial na agricultura, os possíveis problemas que o mau uso da chuva artificial pode provocar e o estudo do volume de gotas e sua importância; o Capítulo 3, que trata os tópicos referentes ao processamento de imagens desde a apresentação de um modelo para compreensão de imagens digitais e as técnicas empregadas; o Capítulo 4 que trata da medida de curvatura que é introduzida através de uma abordagem baseada na medida de ângulos o que facilita compreensão do 
conceito, sendo também introduzida a abordagem multi-escala baseada em filtragem gaussiana e diferenciação numérica através da transformada de Fourier; o Capítulo 5 , que trata os temas anteriormente introduzidos e adequados de forma a compor um método para a análise do contorno de gotas, sendo apresentados os problemas e soluções desenvolvidas para cada uma das etapas desenvolvidas e finalmente; o Capítulo 6, onde são apresentados os resultados, bem como as conclusões obtidas. 


\section{Capítulo 2}

\section{Chuva Artificial e o Estudo do Volume de Gotas}

\subsection{Chuva Artificial}

A chuva artificial é um processo provocado pelo homem, através do qual se distribui água e ou outro líquido em um ambiente por meio da pulverização de gotas e com objetivo definido.

Como na agricultura o emprego da chuva artificial atende a diferentes objetivos e são utilizados para sua produção diversos tipos de equipamentos como pivôs centrais, aspersores acoplados a carretéis de irrigação, pulverizadores costais, pulverizadores autopropelidos, atomizadores e aviões agrícolas de pulverização, exemplos desses equipamentos podem ser vistos nas figuras: 2.1(a), 2.1(b), 2.1(c), 2.1(d), 2.1(e) e 2.1(f) respectivamente.

Devido a ampla escala de seu uso e a importância das atividades onde a chuva artificial é aplicada, os possíveis problemas decorrentes do seu uso incorreto são merecedores de atenção.

Segundo (RAMOS, 2001), a aplicação de defensivos tal como se prática hoje, não difere essencialmente daquela praticada há 100 anos e se caracteriza por um considerável desperdício de energia e de produto químico. Ramos ilustra que diversos estudos e estatísticas sobre a aplicação de defensivos no Brasil, revelando problemas como:

1. o alto número de pessoas expostas direta ou indiretamente aos defensivos, o que chegou em 1980 a aproximadamente 13,7 milhões de pessoas no Brasil possivelmente submetidas aos efeitos da má aplicação dos defensivos;

2. a inadequação de treinamento e educação dos técnicos e produtores envolvidos no processo, nos mais diversos níveis;

3. as más condições de conservação e regulagem dos equipamentos empregados;

4. a alta ineficiência e o grande desperdício de produtos químicos, causados pelos mais diversos fatores ligados a má qualidade da aplicação de defensivos.

As constatações acima citadas implicam em problemas relacionados a contaminação ambiental, a saúde pública e conseqüentemente aos custos sociais decorrentes, 


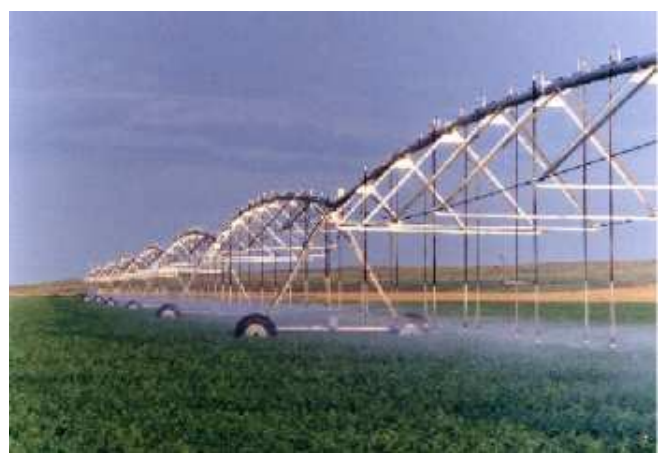

(a)

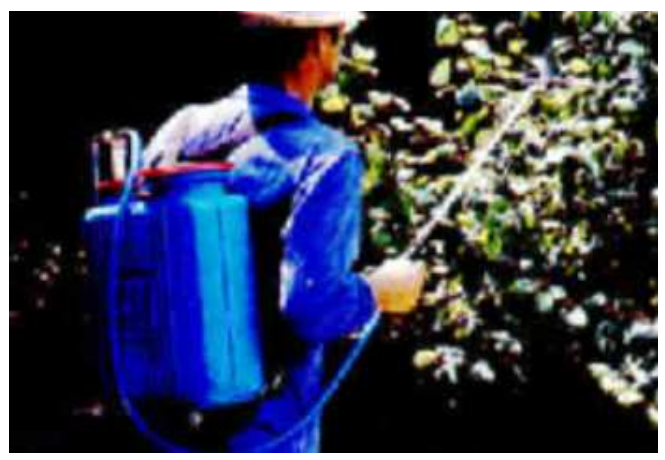

(c)

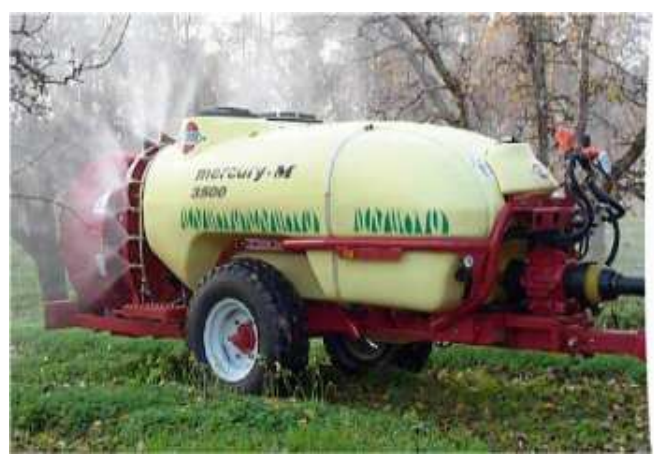

(e)

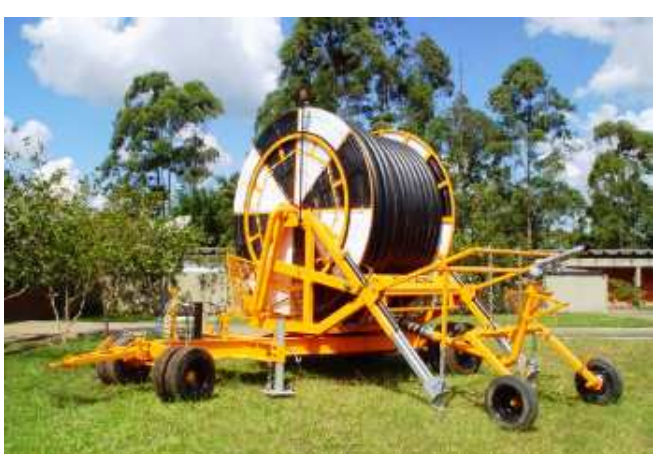

(b)

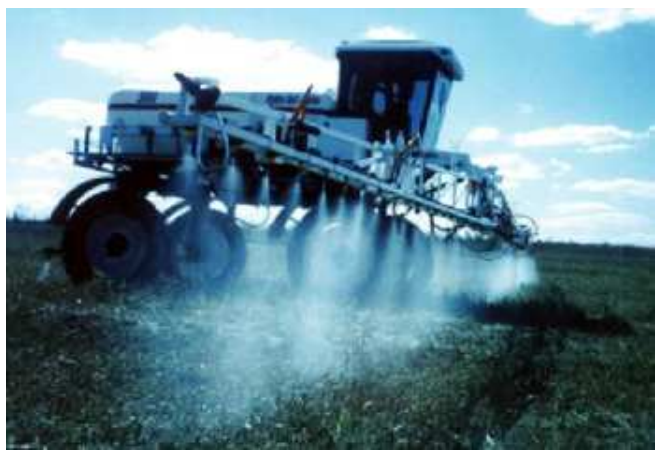

(d)

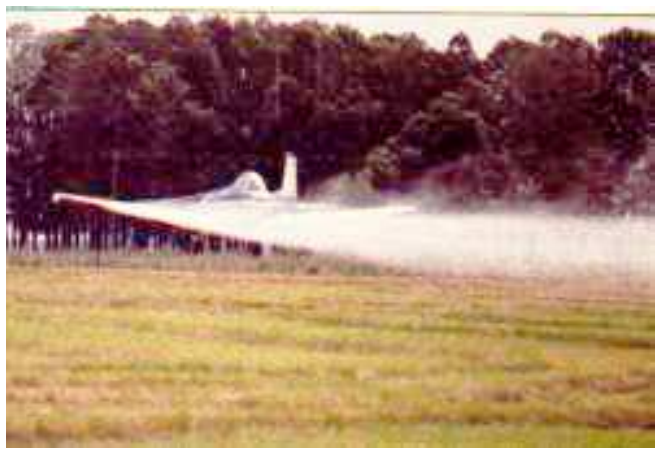

(f)

Figura 2.1: (a) Pivo central, (b) Aspersor com carretel, (c) Pulverizador costal, (d) Pulverizador autopropelido, (e) Atomizador, (f) Avião agrícola. Fontes: (a) IrrigaFertil - http://irrigafertil.tripod.com.br, (b) Metal Lavras - http://www.metallavras.com.br, (c) Plasgot - http://www.plasgot.com, (d) Servspray - http://www.servspray.com.br, (e) Hardi Internatinal - http://www.hardi-nozzles.com, (f) Instituto de Tecnologia UFRRJ - http://www.ufrrj.br/institutos/it/it.htm.

constituindo um exemplo das implicações que podem decorrer da má aplicação de defensivos agrícolas, mostrando a necessidade de trabalhar o problema.

Um trabalho para o aumento na qualidade da aplicação de defensivos agrícolas passa pela melhoria na distribuição e na qualidade da informação para os envolvidos no processo ampliando seu conhecimento sobre o assunto e aperfeiçoando assim seu nível técnico, sendo também necessários trabalhos de desenvolvimento de métodos e instrumentos, que facilitem e permitam a evolução desse conhecimento permitindo assim uma melhor e maior segurança nos processos de aplicação. 


\subsection{Importância do Estudo do Volume de Gotas}

Em processos de irrigação, um aspecto a ser considerado quanto ao volume de gotas geradas é a intensidade com que as gotas se impactam contra o solo, sendo que a geração de gotas com volumes mal dimensionados pode acarretar problemas no solo como selamento da camada superficial, quebra de agregados, conseqüentemente perda de nutrientes e erosão.

Em processos que envolvem a aplicação de defensivos agrícolas, segundo (ANTUNIASSE, 2003) o sucesso da aplicação está ligado aos seguintes fatores:

1. correta seleção dos bicos;

2. correta especificação do volume de calda a ser aplicado, que é o resultado da composição dos defensivos a serem aplicados que podem estar diluídos em água e acrescido a adjuvantes para a modificação de suas características físicas como densidade;

3. parâmetros operacionais, como: a altura e a velocidade do equipamento do qual as gotas serão lançadas;

4. condições ambientais, como: umidade relativa, velocidade do vento e temperatura;

5. momento da aplicação em relação ao ponto ótimo de controle da praga, doença ou planta daninha e a correta identificação de sua localização: sobre ou sob as folhas, dentro ou fora da planta, no solo ou no ar;

6. o tipo de defensivo utilizado se de contato $^{1}$ ou sistêmico ${ }^{2}$.

De diversas formas os fatores acima estão relacionados ao volume de gotas a ser utilizado, pois cada tipo de bico possui diferentes características que o faz gerar uma determinada faixa de tamanhos de gotas e trabalhar a uma certa vazão, quando submetido a uma pressão de trabalho, sendo que estes parâmetros permitem associar volumes de calda aplicados a tamanhos de gota corretos para as necessidades da aplicação.

Dependendo da altura e a velocidade do equipamento do qual as gotas serão lançadas, o uso de gotas excessivamente pequenas pode retardar o tempo de queda das mesmas fazendo com que estas não atinjam o alvo previsto, fator principalmente considerado nas aplicações aéreas.

Ainda o uso de gotas excessivamente pequenas pode facilitar perdas por evaporação ou deriva pelo vento, dependendo das condições ambientais no momento da aplicação. No entanto, quando as características dos equipamentos utilizados e as condições ambientais permitirem o uso de gotas menores pode-se obter uma melhor taxa de cobertura do alvo, bem como uma maior densidade de gotas e uma maior penetração na massa de folhas das plantas, o que é desejável dependendo do tipo do alvo e de defensivo como, por exemplo os de contato.

No uso dos defensivos sistêmicos, pode-se requerer volumes de deposição maiores sobre o alvo o que pode ser conseguido com o uso de gotas com maior volume, que

\footnotetext{
${ }^{1}$ Os defensivos de contato são aqueles que atuam através do contato direto com o alvo que se deseja combater.

${ }^{2}$ Os defensivos sistêmicos são absorvidos pela planta, tornando-a tóxica para algum parasita, seja ela outra planta ou inseto.
} 
também podem ser utilizadas no caso de condições ambientais desfavoráveis até certos limites, visto que, reduzem as perdas por evaporação e deriva pelo vento.

A tabela 2.1, traz a relação entre diversas faixas de tamanhos de gotas e o tipo de alvo aos quais esses tamanhos de gotas mais se adequam.

\begin{tabular}{|c|c|}
\hline Alvo & Diâmetro $(\boldsymbol{\mu m})$ \\
\hline Insetos voadores & $10-50$ \\
\hline Insetos em folhagens & $30-50$ \\
\hline Folhagens & $40-100$ \\
\hline Solo (e/ou para se evitar derivas e perdas) & $250-500$ \\
\hline
\end{tabular}

Tabela 2.1: Relacionamento entre o tipo de alvo que se deseja atingir e o tamanho de gota para uma aplicação de defensivos - fonte: FCA - UNESP.

As relações descritas acima entre volume de gota, tipo de bico, altura e velocidade do equipamento, variáveis ambientais, tipo de alvo e de defensivo, compõem uma complexa relação cuja otimização influência diretamente na eficiência da aplicação. Um exemplo dessa influência é apresentado por Roman (ROMAN et al., 2004), onde a variação de fatores climatológicos sem o ajuste do tamanho de gotas causou variações em torno de $25 \%$ na eficiência da aplicação de herbicida.

Os fatores relacionados a pulverização de defensivos dependentes do volume de gotas e sua relação com a eficiência do processo demonstra a importância e as possíveis aplicações do estudo do volume de gotas bem como sua influência na qualidade da aplicação de defensivos agrícolas.

\subsection{Principais Métodos para a Determinação do Vo- lume de Gotas}

Pesquisadores tem obtido medidas do volume de gotas de chuva desde 1890 e na literatura encontram-se pelo menos sete métodos para a realização desse tipo de medida, obtidas por diferentes autores, dentre os métodos relatados há três técnicas que se utilizam do processamento de imagem.

Assim encontram-se os métodos: método do impulso (SCHLEUSENER, 1967), método mancha (HALL, 1970), método da farinha (KOHL, 1974), método da fotografia (ROELS, 1981), método de imersão (MCCOOL, 1982), método do óleo (EIGEL; MORE, 1983), método com processamento de imagens (CRUVINEL et al., 1996) (CRUVINEL et al., 1999) (PESSOA et al., 1999) (MARTINEZ, 2002) (MARTINEZ; CRUVINEL, 2002) (CRUVINEL et al., 2003).

\subsubsection{Descrição dos principais métodos para a determinação do volume de gotas}

\section{Método do impulso}

Trata-se de um método baseado no uso de sensores piezoelétricos e transdutores de pressão, este método tem sido utilizado com sucesso quando as gotas medidas encontramse dentro de uma mesma faixa de volume. 


\section{Método da mancha}

Baseado na suposição de que a distribuição do volume pode ser obtida pela comparação com gotas de diâmetro conhecidos, o método da mancha requer calibração exaustiva antes de seu uso e seu intervalo de erros está estimado de $6 \%$ a 14\%, para gotas com diâmetros entre $500 \mu \mathrm{m}$ a $5008 \mu \mathrm{m}$.

\section{Método da farinha}

Em uma primeira etapa este método é calibrado através da marcação de uma superfície recoberta com uma camada plana de farinha peneirada e compactada de aproximadamente 2,5mm, por gotas de massas conhecidas, este procedimento cria aglomerados de farinha que são secos em ambiente aberto e posteriormente levados ao forno para finalizar a secagem a $110^{\circ} \mathrm{C}$.

Os aglomerados secos, são pesados e seu peso relacionado ao volume da gota que o formou, este processo de calibração é repetido para diversos volumes de gotas o que leva a obtenção de uma curva de calibração, após a calibração uma nova superfície recoberta com farinha é exposta a chuva e os volumes das gotas podem ser então calculados baseados nas informações levantadas na calibração.

O método apresenta a dificuldade da curva de calibração se alterar de acordo com as características da farinha utilizada.

\section{Método fotográfico}

Com o uso de uma câmera fotográfica dotada de lente reflexiva simples realiza-se a análise manual das gotas, este método traz a vantagem de realizar a medida de forma direta e tem sido utilizado na determinação da expansão individual de gotas sobre uma superfície homogênea.

A desvantagem deste método está no fato do mesmo não apresentar bons resultados na medida da distribuição do volume de gotas em situação reais de uso.

\section{Método da imersão}

Neste método as gotas são depositadas em um recipiente cheio de um líquido que não se mistura com a água, como o óleo por exemplo, feito isso as gotas assumem o formato esférico devido a força de tensão superficial, com o formato esférico torna se possível a medição do diâmetro da gota com o uso de microscópio ou outro dispositivo.

Os principais problemas dessa técnica são: a quebra das gotas devido ao impacto com o líquido e a não penetração de gotas pequenas no liquido, no entanto em laboratórios tem se utilizado com frequência esta técnica para a calibração de equipamentos.

\section{Método do óleo}

O método do óleo baseia-se na premissa de que gotas de água quando suspensas em um líquido menos denso, porém viscoso passam a ter a forma aproximada de uma esfera, isso ocorre devido a distribuição da pressão e as forças de tensão superficiais.

Este método tem sido utilizado, no entanto apresenta as dificuldades inerentes a contagem e medição manual. 


\section{Método com processamento de imagens}

Um dos métodos se baseia no uso de reconhecimento de padrões com análise de correlação no domínio da frequência como uso do processamento digital de imagem.

Algumas vantagens deste método estão na realização das medidas de maneira direta e automática, permitindo a determinação do volume de gotas e sua distribuição.

Os valores de erro apresentados por este método tem sido não maiores que 1,5\%, para gotas com diâmetros entre $100 \mu \mathrm{m}$ e $850 \mu \mathrm{m}$.

Outro utiliza técnicas de morfologia matemática para análise de imagens digitais de gotas, tendo como principais vantagens, aquelas intrinsicas de um método automático baseado em processamento de imagens como, rapidez e não subjetividade.

Também se encontra nesta modalidade um método baseado no uso da transformada de Hough circular em conjunto com técnicas de backmappings, para permitir a medida automática e direta do volume a da distribuição de gotas.

Neste caso o erro médio percentual não maior que $3,61 \%$, para gotas de $1 \mu \mathrm{m}$ a $85.000 \mu \mathrm{m}$ de diâmetro.

\subsection{Informação do Volume de Gotas}

Tendo seu inicio no setor industrial a tendência de automação do controle e coleta de dados, para aferição da qualidade de processos vem sendo transferida para o campo, principalmente sob a ótica de que a propriedade rural opera como parte das chamadas agroindústrias. Essa automação traz vantagens como um possível maior controle dos processos, uma vez que passam a existirem condições de se obter dados com maior qualidade e em maior quantidade, aumentando por exemplo a taxa de amostragem das coletas, devido a maior rapidez na realização de medidas, por outro lado esse significativo aumento na quantidade dos dados disponíveis muitas vezes os tornam incompreensíveis quando observados sem um tratamento prévio que permita, sintetizálos e retirar dos mesmos as informações que representam os parâmetros que interessam nos processos observados.

Trazendo essa discussão para o escopo da medida do volume de gotas de chuva artificial, tem-se que o vetor de dados com os diferentes volumes de gotas de uma amostra necessita de tratamento para que o mesmo possa revelar parâmetros relevantes do processo em questão.

Para a análise de gotas em processos de pulverização há meios de caracterização específicos, os quais consideram um vetor de decisão composto pelos seguintes parâmetros:

\section{Diâmetro Mediano Volumétrico (DMV)}

O diâmetro mediano volumétrico (DMV) é a medida de diâmetro de gota, que divide uma amostra do líquido pulverizado em duas partes de igual volume, a obtenção desse diâmetro se da a partir da amostra analisada ordenada por seus valores de diâmetro, sendo que uma vez estabelecido o DMV este divide a amostra em duas partes onde uma parte possui gotas de diâmetros menores que o DMV e a outra gotas com os diâmetros maiores que o DMV.

Na literatura é comum a classificação de gotas em classes baseadas no DMV, uma dessas classificações é apresentada na tabela 2.2.

\section{Diâmetro Mediano Numérico (DMN)}




\begin{tabular}{|c|c|}
\hline DMV $(\boldsymbol{\mu} m)$ & Classificação \\
\hline$<119$ & Muito fina \\
\hline $119-216$ & Fina \\
\hline $217-353$ & Média \\
\hline $354-464$ & Grossa \\
\hline$>464$ & Muito grossa \\
\hline
\end{tabular}

Tabela 2.2: Classificação de gotas pelo DMV (Fonte: BCPC - Formerly the British Crop Protection Council).

O diâmetro mediano numérico é obtido através da localização da medida do diâmetro de gotas que, a partir da amostra analisada ordenada pelos seus valores de diâmetro de gotas a divide em dois grupos com o mesmo número de gotas.

Com essa divisão, tem-se um grupo com gotas menores que o DMN e outro com gotas maiores que o DMN.

\section{Interpretando DMV e DMN}

A medida de DMV quando observada isoladamente, pode ser fortemente influenciada por poucas gotas de grande diâmetro uma vez que essas podem representar uma grande parte do volume da amostra.

Analogamente com a observação do DMN isolado, corre-se o risco do mesmo ser decisiva mente afetado pela ocorrência numerosa na amostra de gotas de pequeno diâmetro, ema vez que DMV e DMN sofrem grandes influências respectivamente de gotas grandes e pequenas segundo Antuniasse (ANTUNIASSE, 2003), desaconselha-se o uso isolado dessas medidas, sendo uma boa maneira de utilização dessas medidas está no cálculo da razão das mesmas, pois se todas as gotas tiverem o mesmo tamanho, DMV e DMN terão o mesmo valor levando sua razão a apresentar valor 1 .

A partir dessa constatação tem-se que quanto maior a não uniformidade dos diâmetros de gotas, mais a razão entre DMV e DMN se afasta do valor 1.

\section{Espectro de Gotas (EG)}

O espectro de gotas (EG), representa a distribuição dos diferentes diâmetros ocorridos em uma amostra, a partir do EG pode-se aferir a homogeneidade da pulverização quanto ao volume das gotas, sendo que quanto menor a amplitude do EG maior será a homogeneidade.

Uma forma objetiva de traduzir o EG como medida da uniformidade da aplicação é através da determinação de sua extensão e amplitude relativa.

Para tal, levanta-se a partir da amostra ordenada pelo diâmetro de gotas: $D_{v} 0,1$, $D_{v} 0,5$ e $D_{v} 0,9$, sendo que estes são respectivamente os Diâmetros que dividem a amostra ordenada pelo diâmetro das gotas em: 10\%, 50\% e 90\%, do volume acumulativo do líquido aplicado, a determinação desses valores se da de forma semelhante ao cálculo do DMV que aparece aqui como $D_{v} 0,5$.

A determinação da extensão se da pela diferença entre $D_{v} 0,9$ e $D_{v} 0,1$ conforme (2.1), já a amplitude relativa é expressa pela razão entre a extensão e o $D_{v} 0,5$ como pode ser visto em (2.2). 


$$
\begin{aligned}
\text { Extensão } & =D_{v} 0,9-D_{v} 0,1 \\
\text { Amplitude Relativa } & =\frac{\text { Extensão }}{D_{v} 0,5}
\end{aligned}
$$

A extensão (2.1) representa a variação do diâmetro das gotas sofrida por $80 \%$ do volume da pulverização.

A amplitude relativa (2.2) pode ser útil como uma medida independente de escala para a comparação entre pulverizações, sendo que sua proximidade de zero indica uma maior uniformidade na aplicação, uma vez que seu valor igual a zero indica que todas as gotas da amostra possuem o mesmo diâmetro.

\section{Densidade de Gotas (DG)}

A densidade de gotas (DG) é a medida do número de gotas depositadas por unidade de área em uma pulverização e é geralmente expressa em gotas $/ \mathrm{cm}^{2}$, assumindo que a distribuição das gotas seja uniforme torna-se possível o cálculo da DG a partir dos parâmetros volume aplicado V (l/ha) e o diâmetro de gota d $(\mu \mathrm{m})$, como mostrado em (2.3).

$$
\mathrm{DG}=\frac{60 \times 100^{3} \times \mathrm{V}}{\pi \times \mathrm{d}}
$$

\section{Faixa de Deposição (FD)}

A faixa de deposição (FD) é a extensão da largura na qual o líquido pulverizado se deposita podendo ser classificada em FD real e FD relativa, sendo que considerase FD real, a faixa onde se depositou o volume total da pulverização enquanto a FD relativa, considera apenas a faixa onde foram atingidos os valores mínimos de deposição para que a aplicação analisada surta efeito com eficácia.

O cálculo da FD relativa se da através do coeficiente de variação do depósito ao longo da FD real, sendo que pode-se obter a FD através da densidade de gotas ou seja, pelo volume depositado de principio ativo por unidade de superfície.

\section{Potencial Risco de Deriva (PRD)}

O potencial risco de deriva $(\mathrm{PRD})$ representa o percentual de gotas com diâmetro menores que 150, que por seu tamanho reduzido apresentam maior risco de deriva, a ocorrência de gotas com diâmetros menores que esse aumenta rapidamente com a diminuição do DMV, como exemplo temos os percentuais de sua ocorrência: $5 \%$, $10 \%$ e $22 \%$ para os valores $400 \boldsymbol{\mu} m, 300 \boldsymbol{\mu} m$ e $200 \boldsymbol{\mu} m$ de DMV respectivamente.

No próximo capítulo são apresentados os tópicos sobre imagens digitais, como sequência das técnicas utilizadas no desenvolvimento do trabalho. 


\section{Capítulo 3}

\section{Processamento de Imagens Digitais}

\subsection{Imagem, um Modelo}

Segundo o modelo definido em Gonzales e Woods (GONZALEZ; WOODS, 1993), uma imagem pode ser modelada uma função intensidade luminosa bidimensional, denotada por $f(x, y)$, em que o valor ou amplitude nas coordenadas espaciais $(x, y)$ denota a intensidade da imagem naquelas coordenadas. Uma vez que luz é uma forma de energia, $f(x, y)$ deve ser não negativa e finita, ou seja:

$$
0<f(x, y)<\infty
$$

As imagens percebidas pela visão humana por exemplo, são o resultado da reflexão da luz nos objetos e $f(x, y)$ essencialmente pode ser caracterizada por duas componentes:

- quantidade de luz incidente nos objetos da cena, chamada de iluminância.

- percentual de luz refletida pelo objetos da cena, chamada de reflectância.

As seguintes relações e limites teóricos podem ser estabelecidos representando a iluminância por $i(x, y)$ e a reflectância por $r(x, y)$ :

$$
\begin{array}{r}
f(x, y)=i(x, y) . r(x, y) \\
0<i(x, y)<\infty \\
0<r(x, y)<1
\end{array}
$$

A partir de (3.2), (3.3) e (3.4), observa-se que os valores $f(x, y)$ podem ser encarados como decorrentes do percentual de luz refletida pelos objetos da cena.

Tratando de imagens monocromáticas, chama-se o conjunto de valores assumidos por $f(x, y)$ de níveis de cinza, os quais podem variar continuamente do nível preto ao nível branco. 


\subsection{Imagem Digital}

Partindo do modelo de imagem apresentado tem-se como representação digital de uma imagem $\mathrm{f}(\mathrm{x}, \mathrm{y})$, um conjunto de amostras igualmente espaçadas e arranjadas na forma de uma matriz $M \times N$ que pode ser visto:

$$
f(x, y) \simeq\left(\begin{array}{cccc}
f(0,0) & f(0,1) & \ldots & f(0, M-1) \\
f(1,0) & f(1,1) & \ldots & f(1, M-1) \\
\vdots & \vdots & \ddots & \vdots \\
f(N-1,0) & f(N-1,1) & \ldots & f(N-1, M-1)
\end{array}\right)
$$

A matriz apresentada em (3.5) é denominada imagem digital e cada um de seus elementos representa um pixel que é o nome dado a cada elemento constituinte da imagem (discreta), sendo que a razão do número de pixels que constituem uma imagem digital e a área da cena representada, define a amostragem da imagem ou resolução espacial R da imagem digital, essa razão está definida por:

$$
R=\frac{\text { Número de Pixels }}{\text { Unidade de área }}
$$

A informação de brilho, ou seja os valores assumidos por $f(x, y)$ também são discretizados para que sejam representados de forma digital, este processo é chamado quantização em níveis de cinza e define o número $G$ máximo de níveis de cinza que os elementos da matriz poderão assumir.

A fidelidade com que uma imagem digital pode representar uma imagem $f(x, y)$, está estreitamente ligada as suas taxas de amostragem e a quantização em níveis de cinza da mesma, a medida em que as taxas de amostragem e valores de quantização são diminuídas a fidelidade com que a imagem digital representa $f(x, y)$ se degrada.

O uso de taxas de amostragem da imagem (resolução espacial) aquém do necessário pode acarretar na não representação de detalhes finos da cena, além de tornar visível o efeito da discretização de $f(x, y)$, dando aos objetos da cena o aspecto de serrilhamento em suas bordas, as figuras 3.1(a), 3.1(b) e 3.1(c), mostram imagens ampliadas obtidas de um mesmo objeto, utilizando-se uma mesma câmera e conservando a posição da câmera em relação ao objeto. Essas imagens obtidas taxas de amostragem respectivamente de 70 pixels $/ \mathrm{cm}, 35$ pixels $/ \mathrm{cm}$ e 13 pixels $/ \mathrm{cm}$ ilustram que na medida em que as taxas de amostragem caem tornam-se mais visíveis os efeitos do serrilhamento das bordas.

No caso da quantização de níveis de cinza em escalas com amplitudes abaixo do necessário, os efeitos provocados são a não representação de algumas variações de intensidades dos pixels, podendo vir a criar falsas bordas e com isso uma representação infiel da cena na imagem.

As figuras 3.2(a), 3.2(b) e 3.2(c), mostram uma mesma imagem de uma cena, quantizada nas escalas 25616 e 4 níveis de cinza pode-se observar que na medida em que diminui o número de níveis de cinza utilizados na imagem os efeitos da quantização em escalas com amplitudes menores tornam-se visíveis os efeitos que levam ao o surgimento de falsas bordas em regiões homogêneas. 


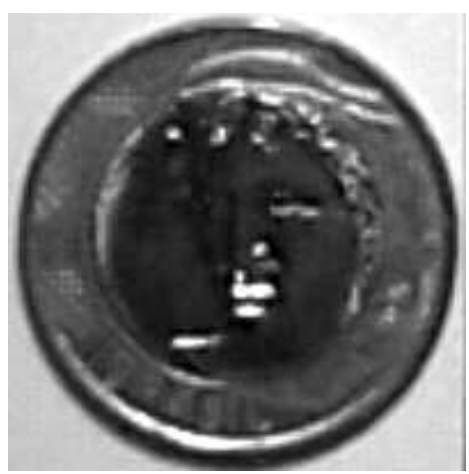

(a)

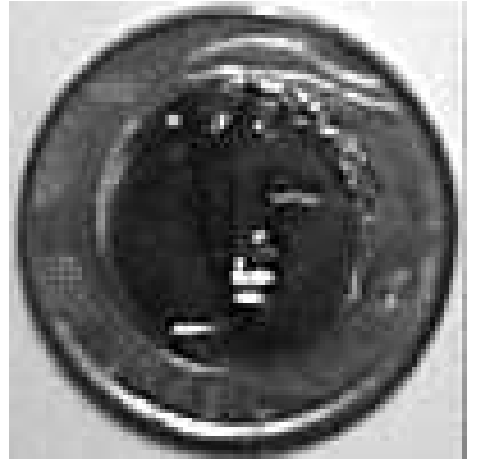

(b)

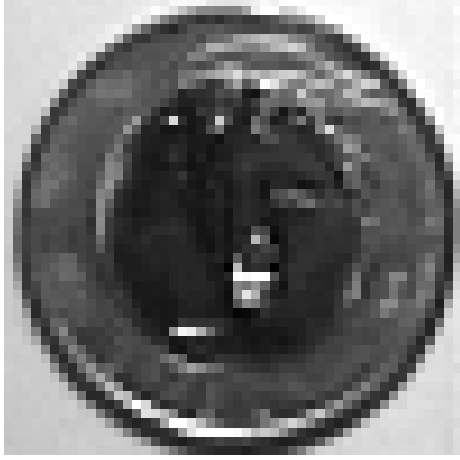

(c)

Figura 3.1: (a) Imagem com amostragem de 70 pixels/cm, (b) Imagem com amostragem de 35 pixels $/ \mathrm{cm}$, (c) Imagem com amostragem de 13 pixels $/ \mathrm{cm}$.

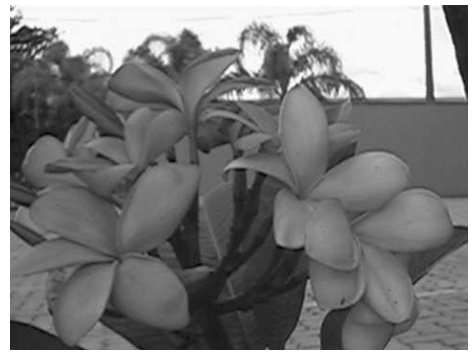

(a)

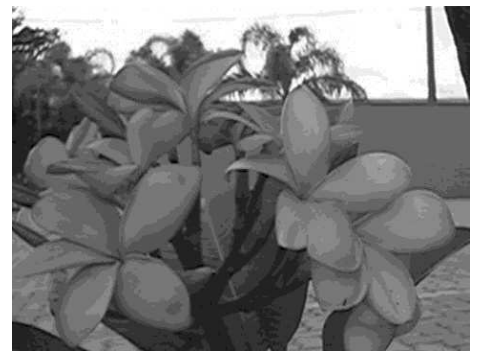

(b)

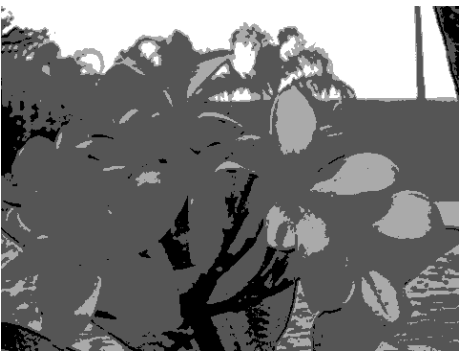

(c)

Figura 3.2: (a) Imagem de uma cena, quantizada em 256 níveis de cinza, (b) Imagem de uma cena, quantizada em 16 níveis de cinza, (c) Imagem de uma cena, quantizada em 4 níveis de cinza.

\subsubsection{Relações entre pixels}

\section{Vizinhança}

Para a extração de informações em imagens digitais é necessário o estabelecimento do conceito de vizinhança onde, sendo $p$ um pixel de coordenada $(x, y)$ o mesmo possui horizontalmente e verticalmente quatro vizinhos, cujas coordenadas podem ser vistas em (3.7), sendo que caso $p$ seja um pixel pertencente a borda da imagem, alguns de seus vizinhos pode se localizar fora da imagem digital.

$$
(x+1, y),(x-1, y),(x, y+1),(x, y-1) .
$$

O conjunto dos vizinhos verticais e horizontais de $p$ é chamado de vizinhança-de-4 de $p$ é denotado por $N_{4}(p)$ e cada pixel desse conjunto está a uma unidade de distância de $p$, conforme ilustrado na figura 3.3(a).

O conjunto dos quatro vizinhos diagonais de $p$ é denotado por $N_{D}(p)$ e suas coordenadas podem ser vistas em (3.8).

$$
(x+1, y+1),(x-1, y-1),(x-1, y+1),(x+1, y-1) .
$$




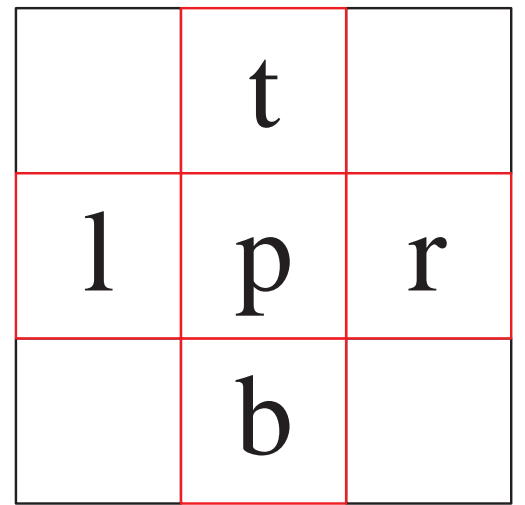

(a)

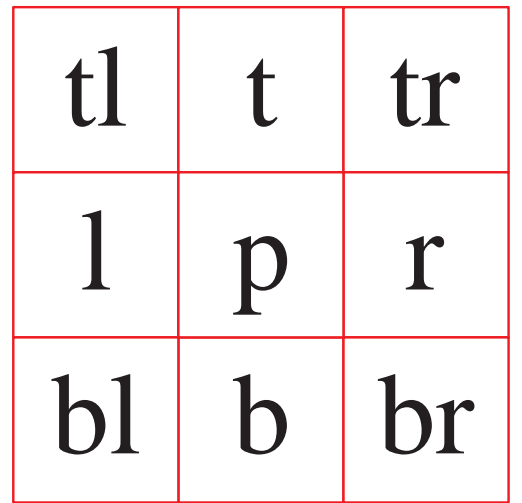

(b)

Figura 3.3: (a) Ilustração da vizinhança-de-4 de p, (b) Ilustração da vizinhança-de-8 de p.

O conjunto dos pixels de $N_{4}(p)$ e $N_{D}(p)$, é chamado de vizinhança-de-8 de $p$ e é denotado por $N_{8}(p)$, este conjunto está ilustrado na figura 3.3(b).

\section{Conectividade}

O conceito de conectividade entre pixels tem sua importância na identificação de bordas e elementos de regiões em uma imagem.

A conexão entre dois pixels $p$ e $q$ se da quando estes são de alguma forma adjacentes e seus níveis de cinza satisfazem algum critério de similaridade, o critério utilizado para a verificação da similaridade de níveis de cinza entre pixels no caso de uma imagem binária pode ser definida pelo conjunto $V=\{1\}$, para conectividade de pixels de valor 1 .

Tratando-se de uma imagem quantizada em níveis de cinza o critério $V$ utilizado pode-ser estabelecido pela igualdade entre os níveis dos pixels, como na equação (3.9), apresentam-se abaixo alguns possíveis tipos de conectividade:

$$
V=\{\operatorname{Nível~de~} \operatorname{cinza}(p)=\text { Nível de } \operatorname{cinza}(q)\} \text {. }
$$

conectividade-de-4: pixels $p$ e $q$ com valores pertencentes ao conjunto $V$ e $q$ pertencente ao conjunto $N_{4}(p)$.

conectividade-de-8: pixels $p$ e $q$ com valores pertencentes ao conjunto $V$ e $q$ pertencente ao conjunto $N_{8}(p)$.

conectividade-de-m (conectividade mista): pixels $p$ e $q$ com valores pertencentes ao conjunto $V$ e $q$ pertencente ao conjunto $N_{4}(p)$ ou $q$ pertencente ao conjunto $N_{D}(p)$ e o conjunto $N_{4}(p) \cap N_{4}(q)$ for vazio.

A conectividade-de-m tem a propriedade de substituir a conectividade-de- 8 eliminando a conexão entre pixels por mais de um caminho. 


\subsubsection{Cor}

Normalmente são utilizadas três características para distinguir uma cor da outra, estas características são:

Brilho: indica a noção acromática de intensidade de luz, tratando-se de um descritor subjetivo e sendo praticamente impossível de ser medido.

Matiz: trata-se de um atributo associado com o comprimento de onda dominante em uma mistura de ondas de luz, representando a cor dominante percebida por um observador.

Saturação: refere-se o grau de pureza relativo ou seja, a quantidade de luz branca misturada com um matiz, sendo que a saturação é inversamente proporcional a quantidade de luz branca adicionada.

O matiz e a saturação em conjunto são denominados cromaticidade, sendo que para se caracterizar uma cor são necessárias informações sobre seu brilho e cromaticidade.

Para que se possa utilizar cores em imagens digitais, são utilizados os chamados modelos de cores que tem por objetivo facilitar a especificação da informação de cor de maneira padronizada e com aceitação geral.

São brevemente descritos aqui dois dos diversos modelos de cores normalmente utilizados em imagens digitais.

\section{Modelo de cor RGB}

No modelo RGB 3.4, as cores aparecem representadas por seus componentes primários: $(R)$ vermelho, $(G)$ verde e $(B)$ azul, neste modelo as proporções em que essas componentes primárias são aplicadas caracterizam a cor e assume-se que estes valores estejam normalizados no intervalo de $[0,1]$. Um diagrama de representação do modelo de cor RGB pode ser visto na figura 3.4.

Atualmente a maioria dos dispositivos de captura de imagens como câmeras tem como modelo nativo para cores o RGB, o que o torna mais valioso ainda para o processamento de imagens digitais.

\section{Modelo de cor YIQ}

O modelo YIQ 3.5 codifica a informação de cor em termos de (Y) iluminância e (IQ) traz a informação de cromaticidade, estas características tornam o modelo IYQ compatível com sistemas de monocromáticos uma vez que a componente Y trata de forma desacoplada a parte acromática da informação podendo ser utilizada para a conversão de imagens coloridas em imagens monocromáticas, como as quantizadas em níveis de cinza. Um diagrama de representação do modelo de cor RGB pode ser visto na figura 3.5 . 
- Níveis de cinza

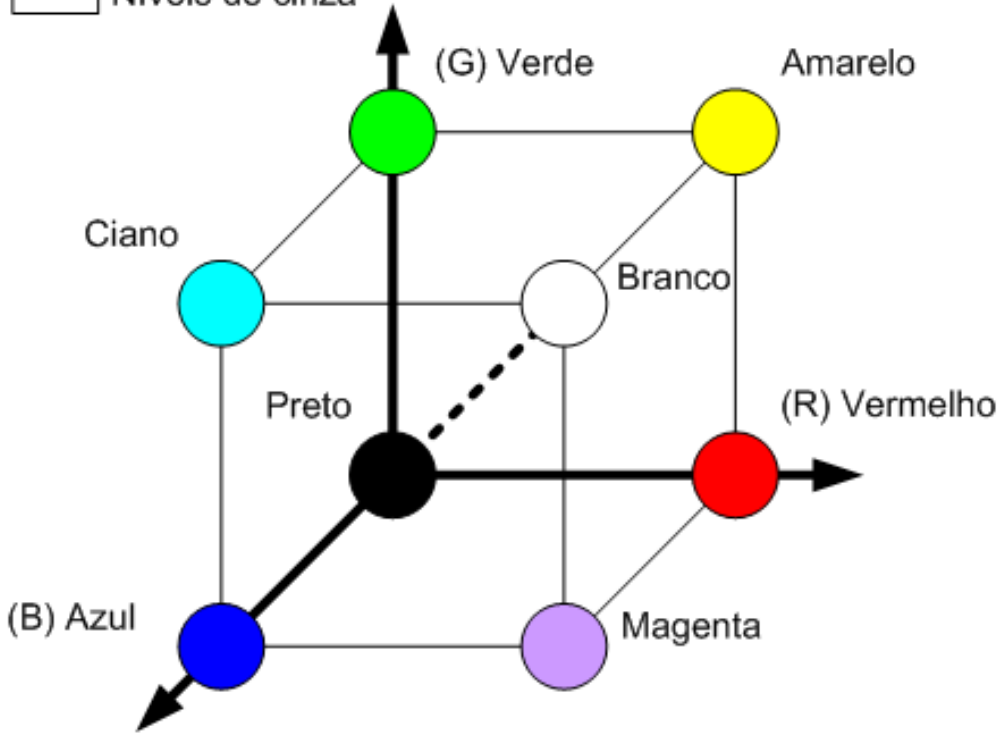

Figura 3.4: Diagrama representação o modelo de cor RGB

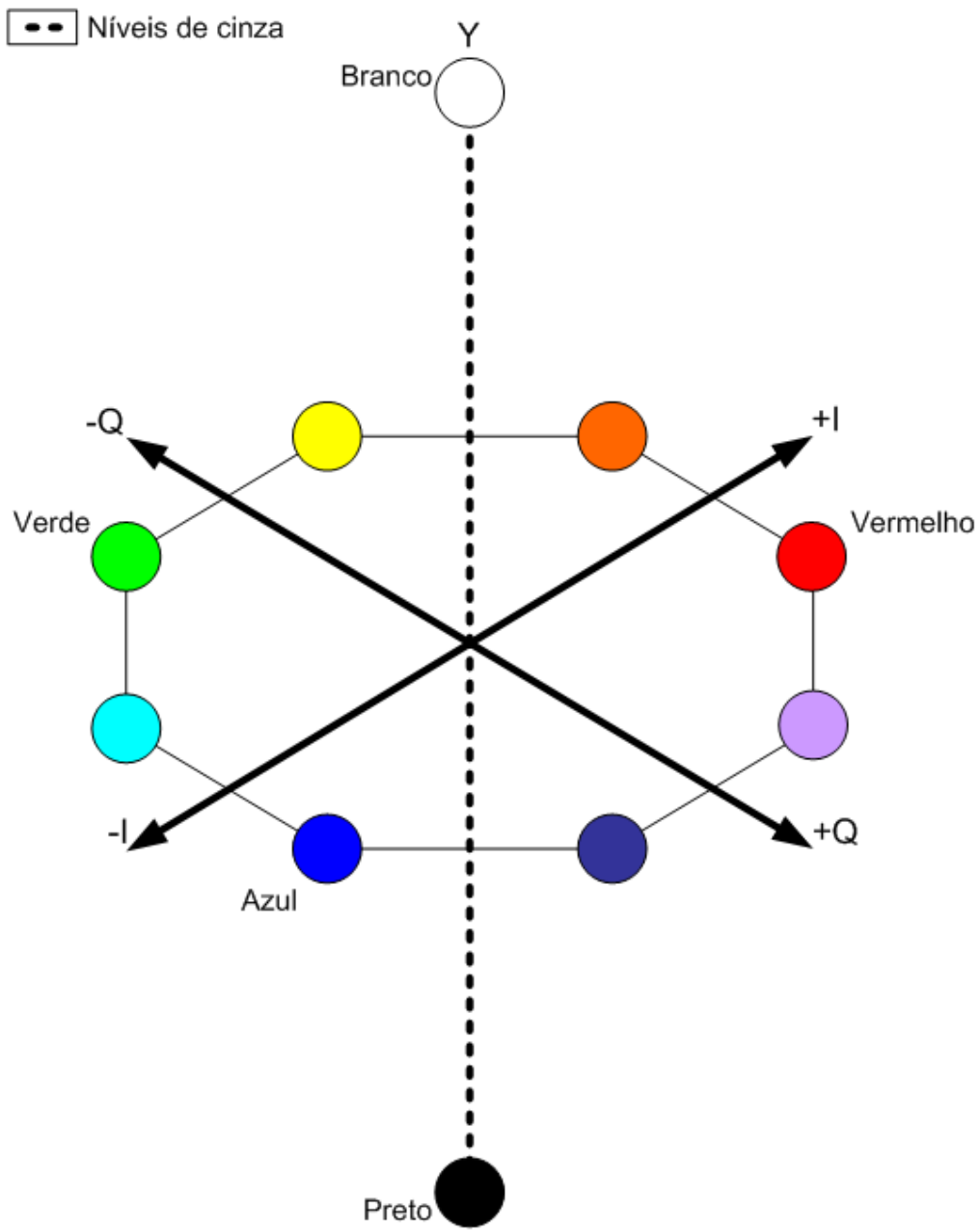

Figura 3.5: Diagrama rpresentando o modelo de cor YIQ 


\subsection{Processamento de Imagem Digital}

\subsubsection{Organização típica}

O processamento de imagens digitais possui dois grandes ramos de aplicação, sendo que o primeiro e maior destes faz uso de técnicas que buscam adequar uma imagem digital para que esta seja visualizada por um ser humano. Este tipo de aplicação pode ser necessário quando uma imagem for corrompida por ruído durante sua aquisição ou transmissão, a necessidade dessa adequação pode ainda advir da necessidade de ressaltar certos aspectos da imagem para auxiliar sua análise, como uma imagem radiológica, que pode ser melhorada facilitando o diagnóstico do médico (GONZALEZ; WOODS, 1993).

O segundo ramo é aquele que busca extrair informações de imagens para a análise automática por computador, sendo que este ramo possui aplicações nas mais diversas áreas como: indústria, saúde e agricultura.

O tipo de informação possível de obter a partir da análise de imagens são bastante diversificadas, como dimensão e cor.

Existe até mesmo a possibilidade da aferição de grandezas relacionadas ao movimento como direção, velocidade e aceleração de um objeto na cena, no caso do processamento de imagens de vídeo.

Dentre as vantagens do uso de processamento digital de imagens em análises visuais automáticas a que mais se destaca em relação a análise visual feita por humanos é a não subjetividade da análise automática, uma vez que esta está imune a fatores como o estresse, em contra ponto a análise visual automática por computador no estágio atual está ainda distante de conseguir lidar facilmente com o grande número de informações que uma imagem pode conter, tarefa essa desempenhada com facilidade e eficiência por seres humanos e outros seres biológicos dotados de visão cotidianamente.

Ao se observar a natureza torna-se claro o quanto a análise visual ou visão é uma tarefa melhor desempenhada por seres biológicos, apesar da diversidade de aplicações possíveis para o processamento de imagens digitais existem alguns componentes e passos típicos que um sistema de processamento de imagens digitais em sua maioria realiza, esses componentes e passos típicos realizados por um sistema de processamento de imagens digitais e a forma como estão organizados estão ilustrados na figura 3.6.

Quanto aos blocos que compõem o diagrama apresentado na figura 3.6, tem-se que um sistema de processamento de imagens pode compreender:

Domínio do problema: o domínio do problema consiste na natureza da cena que será representada na imagem, essa cena deve conter a informação necessária para o tratamento do problema e a produção do resultado esperado pelo sistema.

Como exemplo num sistema de reconhecimento automático do grau de amadurecimento de frutas, o domínio do problema é a própria fruta ou parte dela que na cena pode surgir isolada ou junto a própria planta onde se encontra a fruta sob análise e outros elementos.

Base de conhecimento: a base de conhecimento é a forma codificada do conhecimento que se tem sobre o domínio do problema.

$\mathrm{Na}$ base de conhecimento podem estar armazenadas dentre outras informações: características que possam auxiliar a identificar em que parte da imagem está a região de interesse da aplicação ou até mesmo padrões para serem localizados dentro da imagem que está sendo analisada.

No exemplo do sistema de reconhecimento automático do grau de amadureci- 


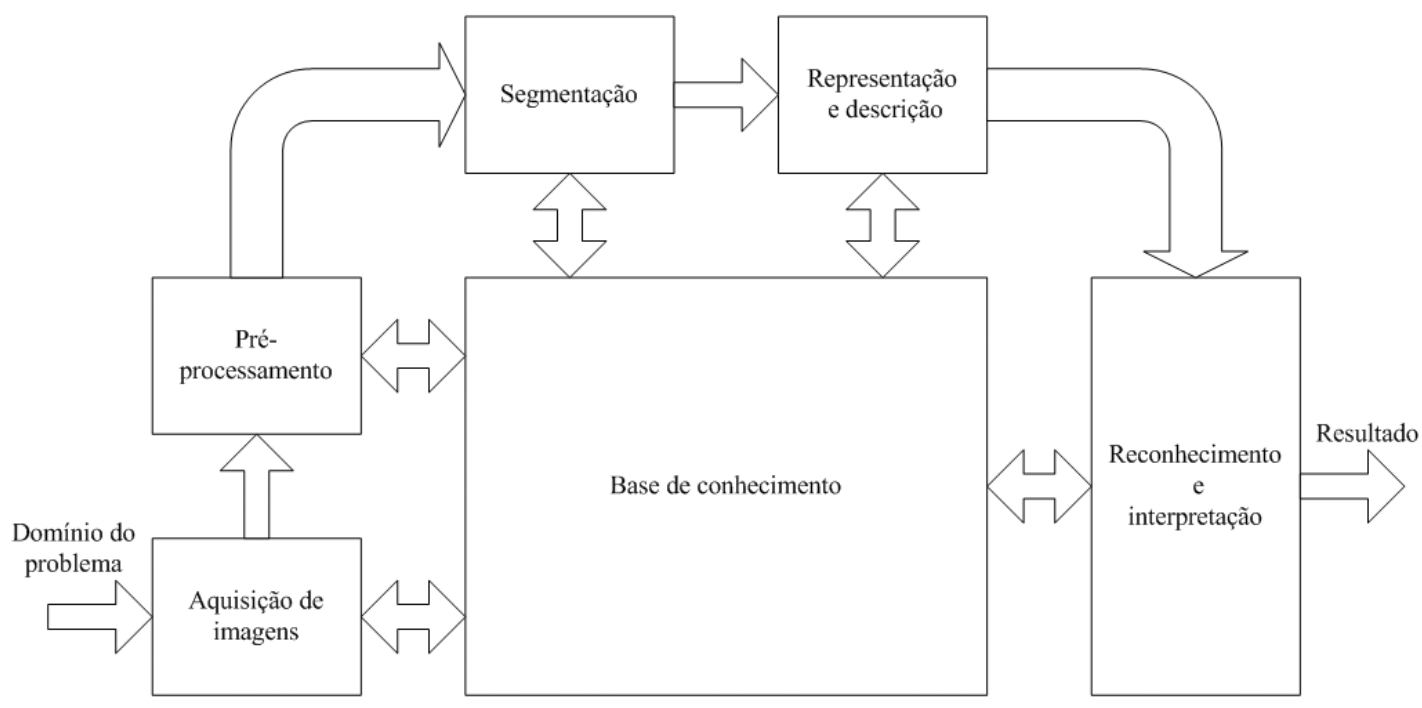

Figura 3.6: Diagrama de um sistema típicos de processamento de imagens digitais, segundo Gonzales e Woods.

mento de frutas, as informações que comporiam a base de conhecimento poderiam ser características comuns as frutas cor, formato ou a posição da área que deve ser verificada em relação a fruta, essa base de conhecimento poderia ainda conter padrões de cores que indicariam diferentes graus de amadurecimento.

Além de servir a cada módulo do sistema a base de conhecimento possui também a atribuição de controlar a interação entre os módulos, servindo como ponto de troca de informações entre eles que permitam um melhor funcionamento individual de cada módulo.

Aquisição de imagens: a aquisição da imagem é o passo onde a cena é captada e representada por meio de uma imagem e isto é realizado com o uso de algum dispositivo de imageamento, sendo que os mais comuns são: scanner e câmera.

A correta determinação dos parâmetros de aquisição é decisiva para a qualidade do resultado gerado pelo sistema, pois estes parâmetros devem estar afinados com a natureza do problema de forma que as taxas de amostragem, quantização e demais parâmetros da aquisição, sejam suficientes para que a imagem obtida represente de forma razoavelmente fiel o domínio do problema.

Pré-processamento: este passo consiste em realizar operações que resultem na alteração da imagem adquirida de forma a aumentar a qualidade do resultado que será obtido, neste passo a imagem é adequada para os próximos do sistema, tipicamente as operações realizadas nesse passo são as de: equalização e filtragem da imagem.

Segmentação: a segmentação consiste em dividir a imagem em regiões com significado para a aplicação em curso de forma a separá-la por exemplo em objetos que serão processados individualmente nos próximos passos, a segmentação automática é uma das mais árduas tarefas a serem implementadas em um sistema de processamento de imagens digitais, no entanto uma segmentação confiável e resistentes e tolerante a falhas é um fator decisivo na obtenção de bons resultados.

Representação e descrição: representar os dados da imagem de forma adequada e de modo a enfatizar as características importantes para a obtenção do resultado esperado, bem como descrever através de atributos que tragam a tona informações 
de interesse da aplicação é do que trata este passo, algumas formas tradicionais de descrever objetos que compõem uma imagem são através de: contornos de formas e quantidade de pixels existentes em regiões homogêneas.

Reconhecimento e interpretação: a definição desse passo pode se dada pelo seus objetivos, onde o reconhecimento deve identificar e rotular os objetos da imagem fazendo uso das informações fornecidas pelos seus descritores, a interpretação cabe atribuir significado aos objetos reconhecidos de forma a torná-la compatível com o uso que dela será feito no contexto do problema.

Resultado: o resultado é a informação objetivada pelo sistema, lançando mão novamente do exemplo do sistema de reconhecimento automático do grau de amadurecimento de frutas o resultado poderia ser um valor dentro de uma escala previamente estabelecida de graus de amadurecimento.

Na implementação de um sistema de processamento de imagens digitais e de seus módulos componentes, diversas técnicas e algoritmos podem ser empregados, a seguir estão descritas algumas desses.

\subsubsection{Transformações entre os modelos RGB e YIQ}

A transformação das componentes RGB em componentes YIQ é definida por (3.10) e a obtenção das componentes RGB a partir de YIQ se dá por sua inversa.

$$
\left[\begin{array}{l}
Y \\
I \\
Q
\end{array}\right]=\left[\begin{array}{ccc}
0.299 & 0.587 & 0.114 \\
0.596 & -0.275 & -0.321 \\
0.212 & -0.523 & 0.311
\end{array}\right]\left[\begin{array}{c}
R \\
G \\
B
\end{array}\right]
$$

Como ressaltado em 3.2.2 uma característica interessante do modelo de cor YIQ está no fato da informação de iluminância e cromaticidade serem tratadas de forma desacoplada, esta característica do modelo YIQ permite sua utilização para a conversão de imagens coloridas em imagens monocromáticas, isto pode ser feito através do uso da informação de $(Y)$ iluminância, esse tipo de conversão utiliza os sequintes passos para a obtenção de uma imagem $(G)$ monocromática em níveis de cinza a partir de uma imagem $(I)$ colorida que utiliza o modelo de cor RGB, de tal forma que:

1. aplicar na imagem $(I)$ colorida RGB a transformação das componentes RGB em componentes YIQ, descrita na equação (3.10).

2. utilizar os valores da componente $(Y)$ da imagem obtida no passo anterior, como níveis de cinza para gerar uma nova imagem $(G)$;

A figura 3.7(b), apresenta o resultado do algoritmo de conversão aplicado em uma imagem RGB quantizada em 24 bits no sistema RGB que pode ser vista na figura $3.7(\mathrm{a})$.

\subsubsection{Limiarização}

Uma etapa importante no processamento de imagens digitais é a segmentação e o processo de limiarização é uma importantes abordagem a ser considerada nessa etapa. Supondo que uma imagem digital de uma cena tenha objetos que estejam sendo iluminados sobre um fundo escuro, de forma que os níveis de cinza dos pixels dos objetos 


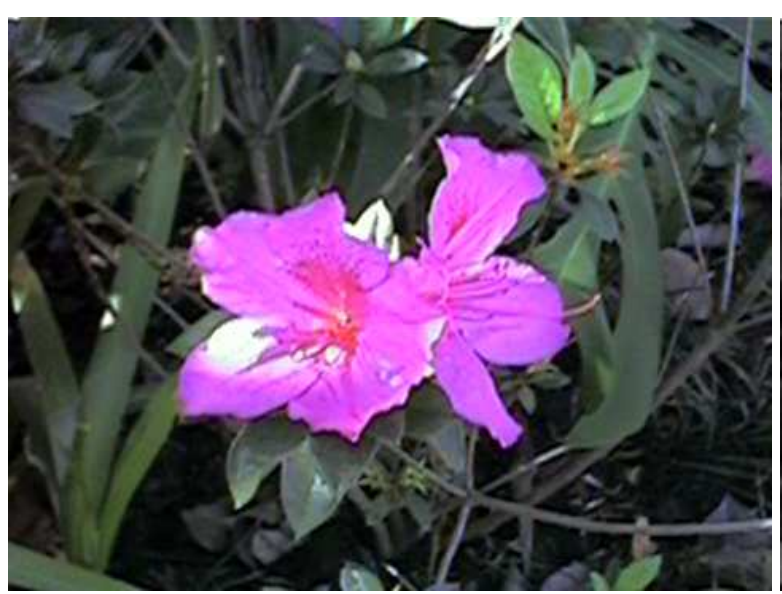

(a)

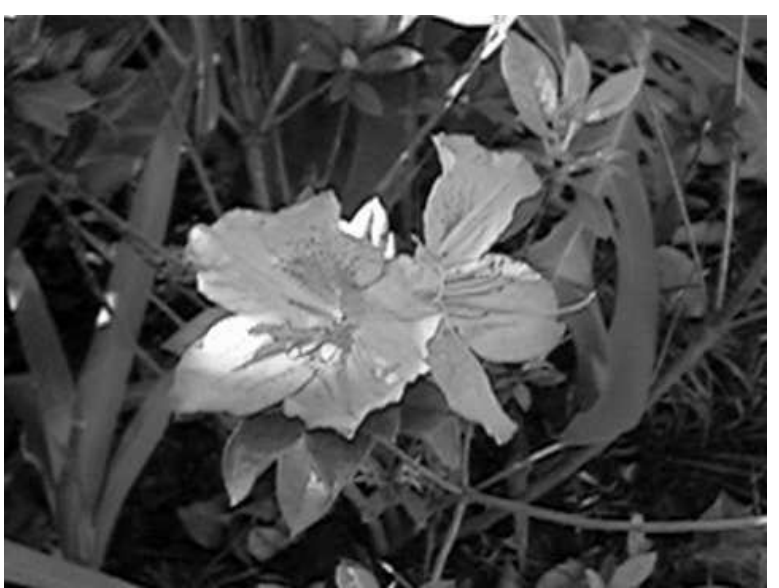

(b)

Figura 3.7: (a) Imagem colorida quantizada em 24 bits no sistema de cor RGB, (b) Imagem monocromática quantizada em 256 níveis de cinza, após conversão.

e do fundo formem dois grupos dominantes, uma maneira simples de separa-los do fundo é através do uso de um limiar $T$ que separe da melhor forma possível os grupos. Neste contexto considera-se como sendo $f(x, y)>T$, pixels constituintes dos objetos representados na imagem e $f(x, y) \leq T$ pixels que pertencem ao fundo.

Uma imagem limiarizada $g(x, y)$ pode ser definida como em (3.11).

$$
g(x, y)=\left\{\begin{array}{l}
0 \text { se } f(x, y) \leq T \\
1 \text { se } f(x, y)>T
\end{array}\right.
$$

Quando for necessária a separação da imagem em mais de dois grupos dominantes, podem ser utilizados mais do que um único limiar, também é possível utilizar um limiar dinâmico que tenha seu valor estabelecido por uma função $p(x, y)$ que atenda as necessidades da aplicação, como exemplo: o nível de cinza médio numa vizinhança centrada em $(x, y)$.

No caso do uso de um limiar dinâmico, a limiarização pode ser visto como uma função T da forma apresentada em (3.12), onde $f(x, y)$ é denota o nível de cinza do ponto $(x, y)$ e $p(x, y)$ uma função que caracterize alguma propriedade desse ponto que possa determinar o limiar que será utilizado.

$$
T=T[x, y, p(x, y), f(x, y)]
$$

Quando $T$ depender apenas de $f(x, y)$ este será chamado global e quando depender de $f(x, y)$ e de $p(x, y)$ será chamado dinâmico.

\subsubsection{Rotulação de regiões disjuntas}

O processo de rotulação de componentes conectados permite enumerar as regiões disjuntas formadas por pixels conectados em uma imagem binária, este processo é de 
grande utilidade para aplicações automáticas de processamento digital de imagens, este processo se da a partir de uma imagem binária e pode ser realizado observando os seguintes conceitos e seguindo os seguintes passos.

A imagem é totalmente varrida da esquerda para a direita e de cima para baixo e se o pixel analisado for de borda os valores de seus vizinhos que estejam fora da imagem serão considerados como zero.

No caso da utilização da vizinhança do tipo conectados-de-4, se $p$ for o pixel atual do processo de varredura, o sentido da varredura garante que os vizinhos $(t)$ superior e (l) esquerdo de $p$ já terão sido analisados e nos passos do processo esses serão os pixels vizinhos considerados na análise, conforme ilustrado na figura 3.8(a).

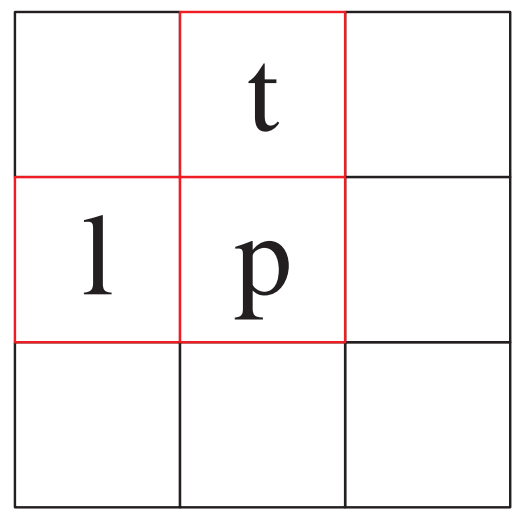

(a)

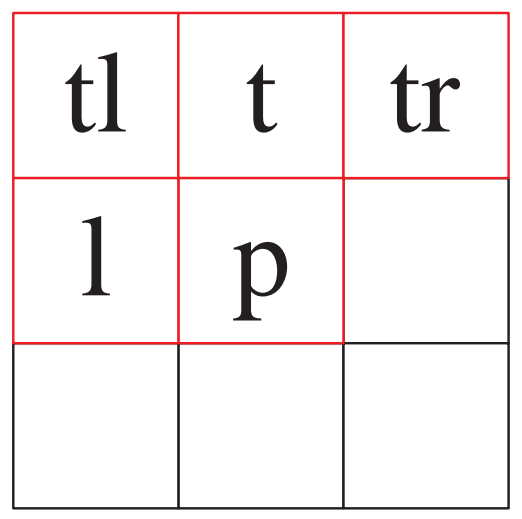

(b)

Figura 3.8: (a) Ilustração dos pixels vizinhos de $(p)$ considerados na análise, no caso de objetos conectados-de-4, (b) Ilustração dos pixels vizinhos de $(p)$ considerados na análise, no caso de objetos conectados-de-8.

No caso da utilização da vizinhança do tipo conectados-de-8, se $p$ for o pixel atual do processo de varredura, o sentido da varredura garante que os vizinhos $(t)$ superior, $(l)$ esquerdo e os dois diagonais superiores $(t l)$ e $(t r)$ de $p$ já terão sido analisados e nos passos do processo esses serão os pixels vizinhos considerados na análise, conforme ilustrado na figura 3.8(b).

Tendo em vista os conceitos apresentados a rotulação é realizada seguindo os seguintes passos para todos os pixels da imagem:

1. se o valor de $p$ é 0 , então a análise segue para o próximo pixel da varredura;

2. se o valor de $p$ é 1 , então serão examinados os vizinhos considerados para o tipo de conexão em uso;

3. se todos os vizinhos forem $0, p$ receberá um novo rótulo;

4. se apenas um dos vizinhos for $1, p$ receberá o mesmo rótulo que este vizinho;

5. se mais de um vizinho for 1 e todos estes tiverem o mesmo rótulo, $p$ receberá o mesmo rótulo que estes vizinhos;

6. se mais de um vizinho for 1 e nem todos estes tiverem o mesmo rótulo, $p$ receberá um novo rótulo e os valores do rótulo de $p$ e dos rótulos dos vizinhos de $p$ serão 
armazenados como um novo item de uma lista para utilização após essa etapa do processo.

Ao final da primeira varredura da imagem, uma segunda varredura deve ser realizada, pois a lista de rótulos criada no passo 6 da primeira varredura indica que $p$ une as regiões das quais os vizinhos que já possuíam rótulos diferentes fazem parte, sendo assim todos pixels com rótulos na lista devem ser rotulados com um único rótulo, para cada item da lista e feitas as unificações necessárias as regiões disjuntas estarão devidamente rotuladas.

\subsubsection{Extração de contornos paramétricos}

Certas abordagens representam contornos de formas através de imagens binárias, no entanto esse tipo de tratamento apresenta algumas desvantagens como o consumo excessivo de espaço para armazenar o contorno e a não identificação direta de elementos da forma que uma abordagem interessante para a representação de contornos de formas, se da através dos contornos paramétricos que não apresenta as desvantagens acima citadas.

O conceito de contorno paramétrico é análogo ao da representação paramétrica de curvas em geometria diferencial, onde a curva é descrita em função de um único parâmetro $(t)$. Pode-se enfocar esta abordagem como se o contorno paramétrico $C(t)$ descrevesse a trajetória bidimensional de uma partícula através de sua posição $(x, y)$ a cada instante $t$, sendo assim para cada $t$ será definida uma posição $(x, y)$ e ao considerar um intervalo para $t=\{0,1,2, \ldots, n-1\}$ tem-se um vetor $C(t)$ de pares ordenados $(x, y)$, conforme visto em (3.13).

$$
C(t)=\left\{\left(x_{0}, y_{0}\right) ;\left(x_{1}, y_{1}\right) ;\left(x_{2}, y_{2}\right) ; \ldots ;\left(x_{n-1}, y_{n-1}\right)\right\}
$$

\section{Extração de contornos}

Um método pode ser implementado para extrair contornos externos de uma forma bidimensional representada em uma imagem binária, convencionada de forma que o fundo seja branco 1 e o objeto preto 0 , como ilustrado na figura 3.9.

A partir da imagem binária o método executa um primeiro passo no qual a imagem é totalmente varrida da esquerda para a direita e de cima para baixo em busca do primeiro pixel de valor 0 , ou seja pertencente ao objeto, conforme ilustra a figura 3.10 .

Uma vez encontrado o primeiro pixel do objeto, o pixel imediatamente a sua esquerda é adotado como o primeiro elemento do contorno, sendo este o pixel marcado na figura 3.11, na cor verde.

O segundo passo, consiste em circundar o objeto, levantando seu contorno pixel a pixel, o objeto é circundado a partir do pixel inicial e só termina quando este mesmo seja revisitado.

A vizinhança-de-8 de cada pixel do contorno levantado é varrida no sentido antihorário, seguindo a ordem dos vizinhos ilustrada na figura 3.12. Com essa varredura 


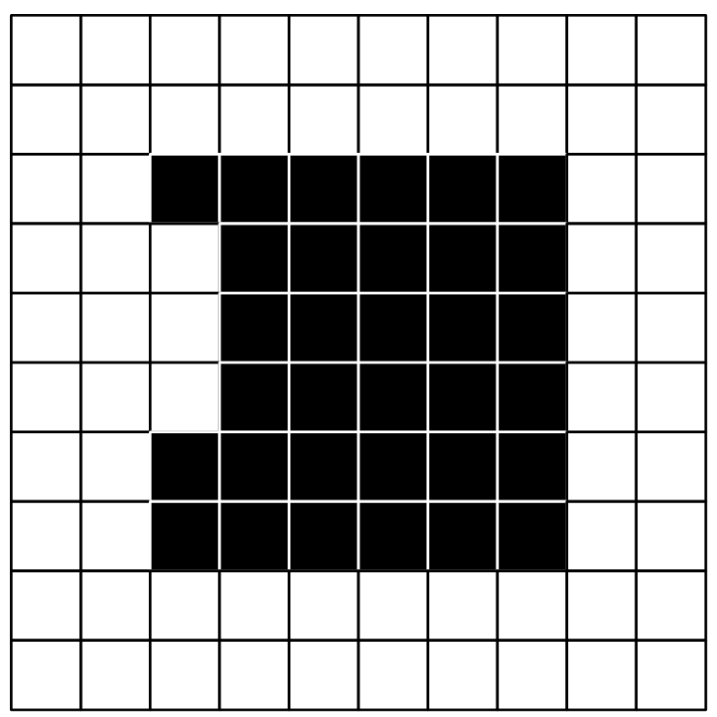

Figura 3.9: Forma bidimensional apresentada em uma imagem binária.

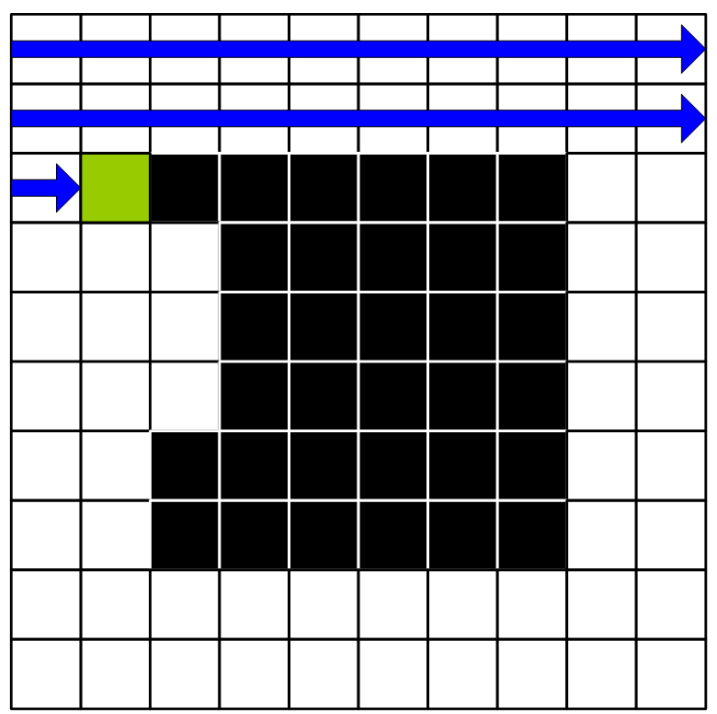

Figura 3.10: Primeiro passo para extração do contorno paramétrico.

de vizinhança o contorno do objeto é também levantado no sentido anti-horário, assim como ilustrado na figura 3.11.

A varredura da vizinhança dos pixels do contorno sofre uma única exceção que ocorre durante a avaliação do primeiro pixel do contorno levantado, pois para este o algoritmo necessita testar apenas os vizinhos de 4 a 7 , uma vez que já o foram durante a varredura linha a linha do primeiro passo.

Apesar do pixel 4 também já haver sido testado no passo anterior, este deve ser verificado, pois o objeto pode estar logo abaixo do pixel 4. Sendo assim:

O pixel 4 será candidato a pixel do contorno, caso ele seja branco e o pixel 5 preto.

O pixel 5 será candidato a pixel do contorno, caso ele seja branco e o pixel 6 preto. 


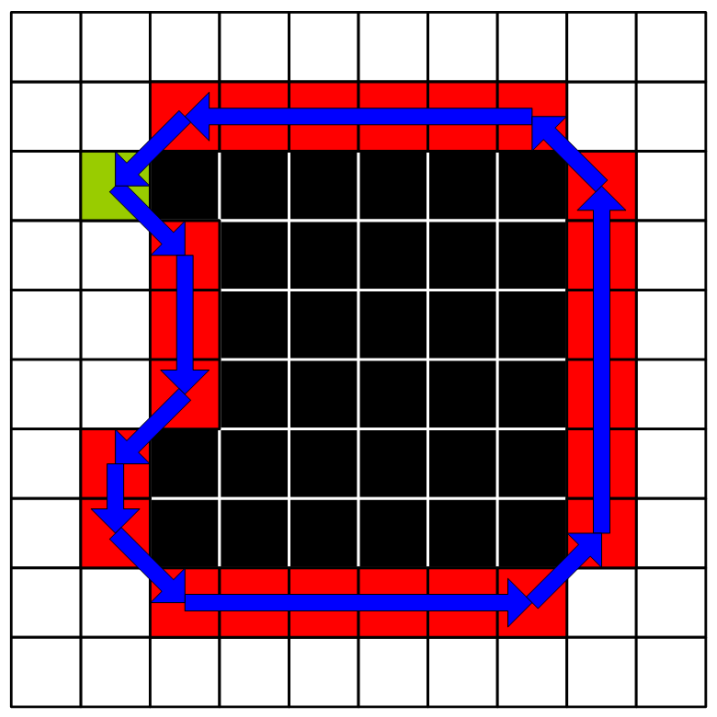

Figura 3.11: Segundo passo para extração do contorno paramétrico.

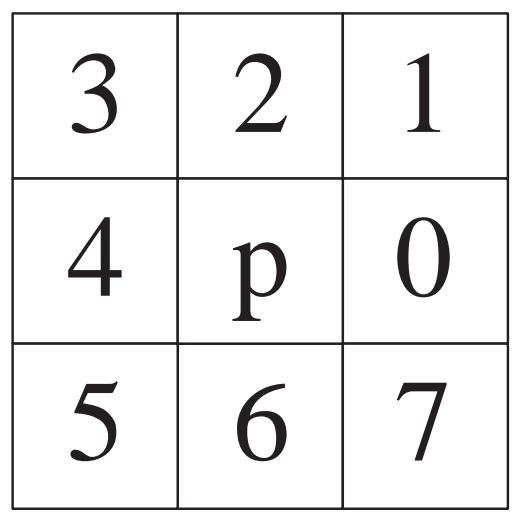

Figura 3.12: Vizinhança-de-8 de p rotulada de 0 a 7.

O pixel 6 será candidato a pixel do contorno, caso ele seja branco e o pixel 7 preto.

O pixel 7 será candidato a pixel do contorno, caso ele seja branco e o pixel 0 preto.

O primeiro pixel encontrado que satisfaz as condições acima será o próximo pixel do contorno.

Após o segundo pixel $p$ do contorno ter sido encontrado o algoritmo continua de forma análoga, mas a partir de então considerando toda a vizinhança de zero a sete.

Para os próximos passos duas variáveis são importantes: $C[n]$ o pixel corrente do contorno, a direção a partir do pixel anterior para o pixel atual $d_{p c}$ e sua direção $d_{c p}$ inversa. Essa informação é utilizada para determinar qual será o primeiro pixel da vizinhança a ser verificado pelo algoritmo nas subsequentes repetições do segundo passo do algoritmo.

É importante notar que um pixel anterior já assumido como parte do contorno deve poder ser um candidato a próximo pixel, pois assim o algoritmo poderá entrar e 
sair de cavidades da forma com um pixel de largura, como exemplificado na figura 3.13, caso essa regra não seja verificada o algoritmo não teria pixels candidatos a integrantes do contorno após alcançar o fim deste tipo de cavidade.

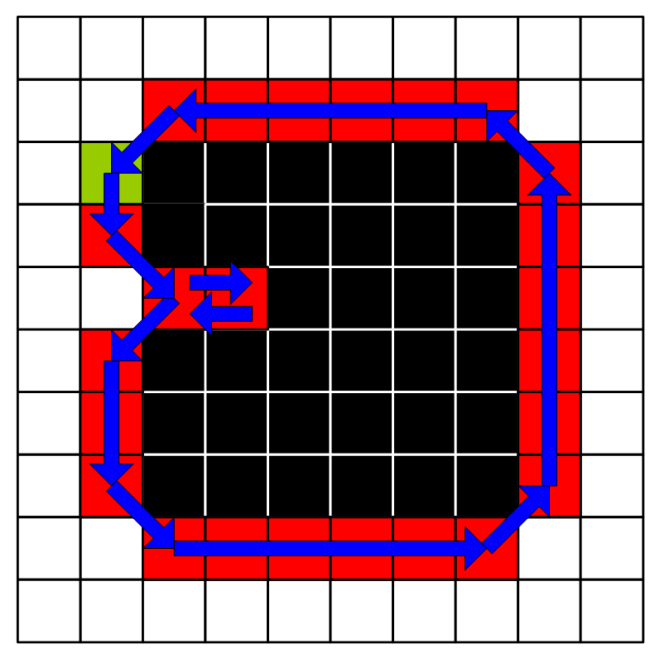

Figura 3.13: Extração de contorno de forma com cavidade de um pixel de largura.

Vale a pena ressaltar que o pixel anterior só poderá ser assumido como próximo pixel quando, não mais houver candidatos, pois caso contrário o algoritmo poderia entrar numa situação de "looping", do tipo: proximo, anterior, proximo, ...

Após a finalização do algoritmo obtém-se como resultado um vetor ordenado com as coordenadas do contorno da forma bidimensional análisada os valores das componentes x e y desse vetor podem ser vistos na figura 3.14, que mostra os valores do contorno extraído pelo algoritmo a partir da forma apresentada na figura 3.9.

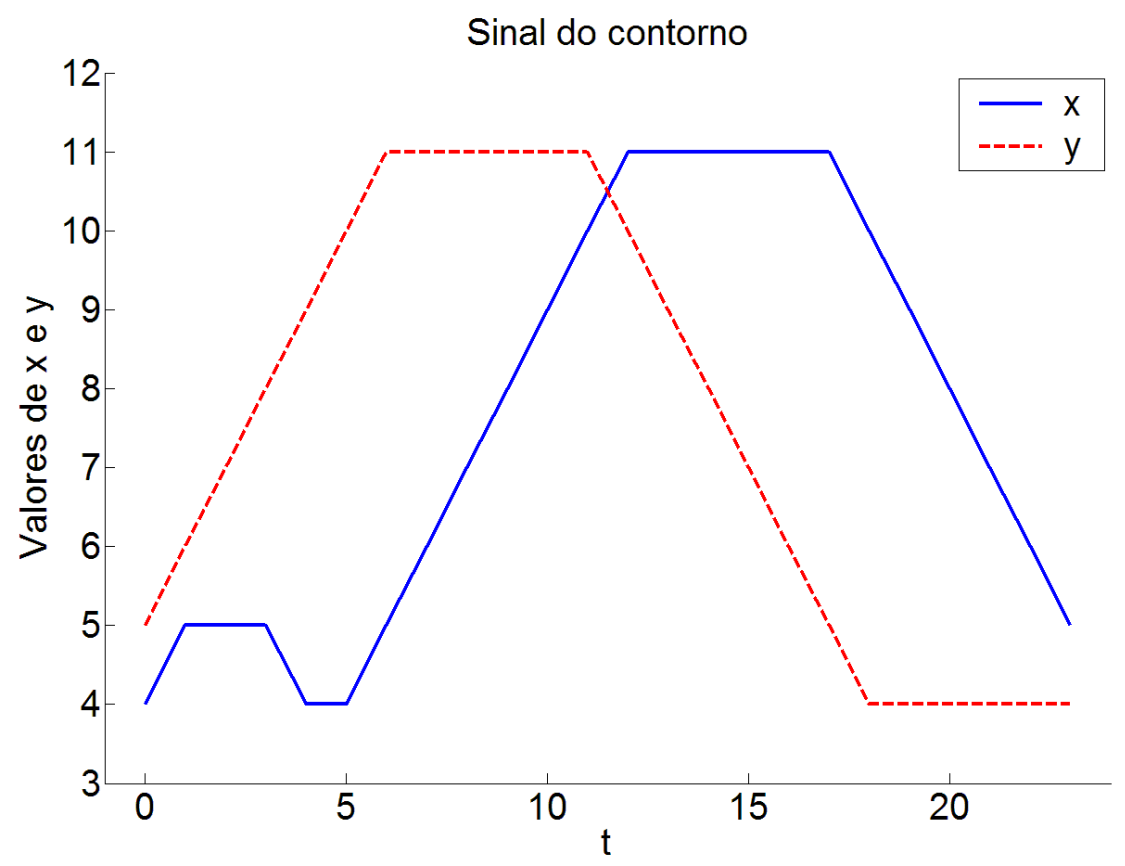

Figura 3.14: Valores de X e Y do Contorno Paramétrico extraído do objeto apresentado na figura 3.9 . 


\section{Capítulo 4}

\section{Curvatura}

\subsection{Importância da curvatura}

A medida de curvatura compreende o conceito do quão curvo é o contorno de uma forma, ou o quanto varia essa medida ao longo da forma analisada.

Trabalhando com esse atributo visual, Attneave mostrou em seus experimentos (ATTNEAVE, 1954), que a informação da curvatura é um aspecto importante explorado pela visão humana para lidar com grandes volumes de informação visual, uma vez que pontos de alta-curvatura tendem a concentrar a informação de uma cena a curvatura pode ser utilizada para localizar pontos importantes de uma imagem (CARMONAPOYATO et al., 2005; SABER et al., 2005).

Esses pontos podem ser traduzidos do contorno de formas como algumas primitivas geométricas que normalmente indicam atributos relevantes da forma análisada e que podem ser localizadas através da análise da curvatura, a tabela 4.1 adaptada por Costa e Cesar (COSTA; CESAR, 2000), traz uma síntese dessas primitivas e sua interpretação do ponto de vista da curvatura.

\begin{tabular}{|c|c|}
\hline Curvatura & $\begin{array}{c}\text { Aspecto geométrico } \\
\text { (seguindo padrão anti-horário) }\end{array}$ \\
\hline Máxima valor absoluto de curvatura (local) & Canto genérico \\
\hline Máxima curvatura positiva (local) & Canto convexo \\
\hline Mínima curvatura negativa (local) & Canto côncavo \\
\hline Curvatura constante e igual a zero & Segmento de reta \\
\hline Curvatura constante e diferente de zero & Segmento de circulo \\
\hline Cruzamento do zero & Ponto de inflexão \\
\hline Média de valores absolutos & $\begin{array}{c}\text { Complexidade da forma, } \\
\text { ou }\end{array}$ \\
quadrados de altas curvaturas & \\
\hline
\end{tabular}

Tabela 4.1: Sintese de algumas características geométricas importantes que podem ser extraídas através da análise de curvatura. 


\subsection{Curvatura Baseada na Medida de Ângulos en- tre Vetores}

Em imagens digitais pode-se trabalhar com formas bidimensionais através do seu contorno paramétrico $C(t)$, como o ilustrado na figura4.1.

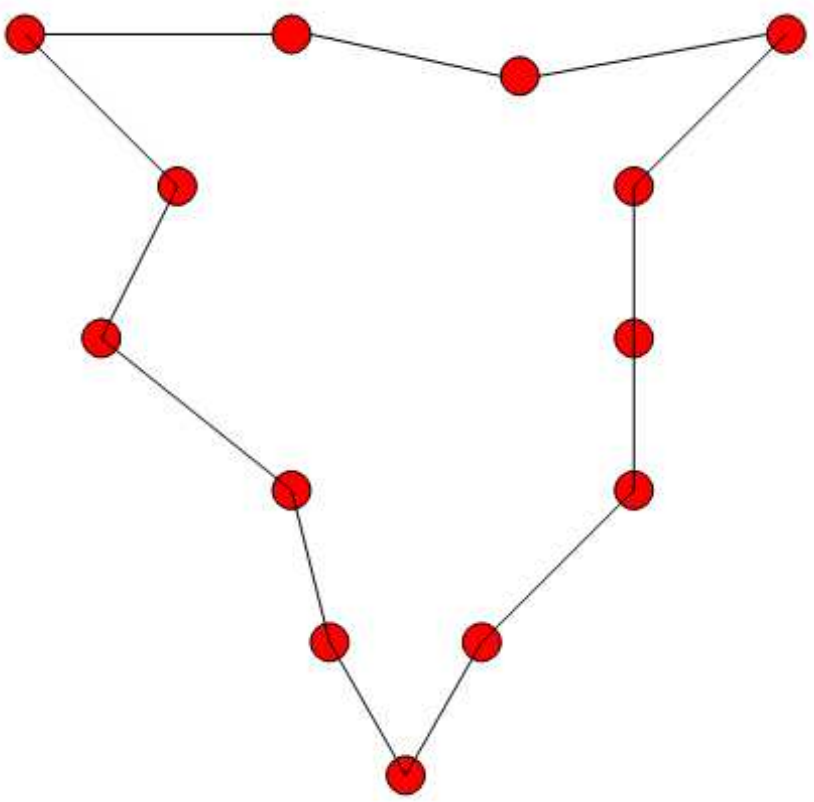

Figura 4.1: Contorno paramétrico $C(t)$

A partir de um ponto comum $C\left(t_{n}\right)$ de um contorno paramétrico $C(t)$ pode se definir dois vetores $v \overrightarrow{(n)}$ e $\overrightarrow{w(n)}$, como os ilustrados na figura 4.2. Sendo que a medida do ângulo descrito por estes vetores é uma abordagem simples para medida da curvatura, descrevendo o quanto a mesma vária a cada ponto do contorno.

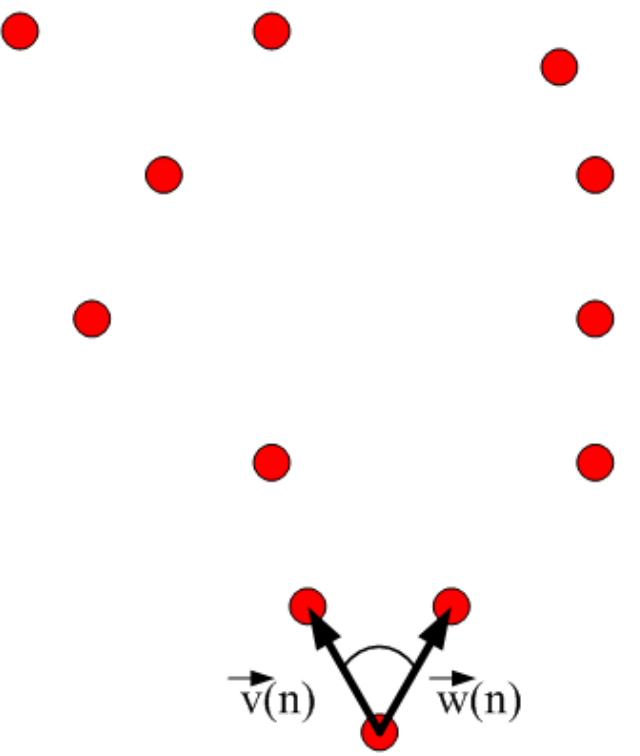

Figura 4.2: Vetores $\vec{v}(n)$ e $\vec{w}(n)$ que descrevem o ângulo no ponto $C\left(t_{n}\right)$. 
Um variação da abordagem baseada na medida de ângulo entre vetores está no uso dos seguintes vetores $\overrightarrow{v_{i}}(n)$ e $\overrightarrow{w_{i}}(n)$ definidos respectivamente nas equações $(4.1)$ e (4.2), estes vetores podem ser definidos entre $C\left(t_{n}\right)$ e seus i-ésimos vizinhos para a esquerda e para a direita.

$$
\begin{aligned}
\vec{v}_{i}(n) & =(x(n)-x(n-i), y(n)-y(n-i)) \\
\vec{w}_{i}(n) & =(x(n)-x(n+i), y(n)-y(n+i))
\end{aligned}
$$

OS vetores $\overrightarrow{v_{i}}(n)$ e $\vec{w}_{i}(n)$ ilustrados na figura 4.3 , determinados pela variação acima descrita do método baseado na medida de ângulo serão utilizados para introduzir o conceito de análise multi-escala da curvatura.

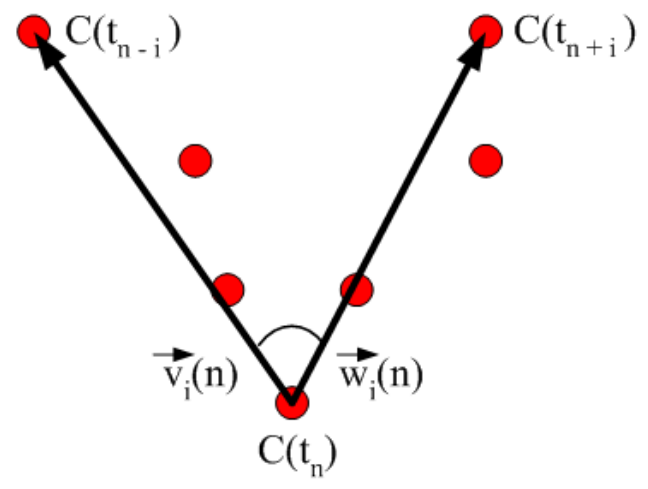

Figura 4.3: Vetores $\vec{v}_{i}(n)$ e $\vec{w}_{i}(n)$ que descrevem o ângulo no ponto $C\left(t_{n}\right)$.

O ângulo descrito entre os vetores $\overrightarrow{v_{i}}(n)$ e $\vec{w}_{i}(n)$ originados em um ponto comum $C\left(t_{n}\right)$, podem ser utilizados na obtenção de informações relevantes sobre a forma análisada através da deteção de pontos de alta curvatura, um modelo digital para detecção deste tipo de ponto, foi proposto por Johnston e Rosenfeld (JOHNSTON; ROSENFELD, 1973), onde a estimativa da curvatura é obtida por (4.3):

$$
r_{i}(n)=\frac{\overrightarrow{v_{i}}(n) \cdot \vec{w}_{i}(n)}{\left|\overrightarrow{v_{i}}(n)\right| \cdot\left|\vec{w}_{i}(n)\right|}
$$

No modelo de Rosenfeld, tem-se então que $r_{i}(n)$ é o co-seno do ângulo entre os vetores $\overrightarrow{v_{i}}(n)$ e $\vec{w}_{i}(n)$, logo está limitado aos seguintes valores $-1 \leq r_{i}(n) \leq 1$.

Sendo que quando o ângulo entre os vetores for de $180^{\circ}$ tem-se $r_{i}(n)=-1$, ou seja um segmento de reta em $C\left(t_{n}\right)$. 
Por sua vez para $0^{\circ}$ (Menor ângulo possível) tem-se $r_{i}(n)=1$ ou seja, um ponto de alta curvatura em $C\left(t_{n}\right)$.

Neste sentido, $r_{i}(n)$ pode ser utilizado como uma medida capaz de localizar pontos de alta curvatura ao longo do contorno de uma forma bidimensional.

\subsubsection{Medida multi-escala de curvatura com a curvatura-c}

Um mesmo padrão de forma pode surgir na natureza em diferentes escalas e por vezes a análise de formas deve extrair informações desse tipo de padrão, para isso o fator escala deve ser considerado definindo assim uma análise Multi-Escala.

O método da Medida de curvatura-c ou c-Measure proposta por Larry Davis em 1977 é um dos primeiros trabalhos importantes relacionados ao paradigma de análise Multi-Escala (DAVIS, 1977).

Davis partiu do modelo digital de pontos de alta curvatura (JOHNSTON; ROSENFELD, 1973), onde são tomados os vetores $\overrightarrow{v_{i}}(n)$ e $\overrightarrow{v_{i}}(n)$ definidos entre o n-ésimo ponto $C\left(t_{n}\right)$ de um contorno até o i-ésimo ponto $C\left(t_{n-i}\right)$, respectivamente para um sentido do contorno e até o i-ésimo ponto $C\left(t_{n+i}\right)$ para o outro.

$\mathrm{Na}$ medida em que i aumenta uma maior vizinhança no contorno é levada em conta para a estimativa de $r_{i}(n)$, co-seno do ângulo entre os vetores acima citados, ou seja, o ângulo é estimado em uma maior escala espacial.

Escalas maiores tornam a curvatura mais tolerante a ruídos, mas menos precisa, quanto a pequenas estruturas no contorno.

Dentro deste contexto Davis desenvolveu um método descritivo hierárquico baseado na evolução de $r_{i}(n)$ à medida que i varia.

Uma forma alternativa de implementação, para obtenção da medida de curvatura, pode ser obtida levando-se em conta não somente as extremidades $C\left(t_{n-i}\right)$ e $C\left(t_{n+i}\right)$, mas também todos os pontos entre estes, neste caso isto pode ser feito através do cálculo do co-seno do ângulo entre os vetores resultantes da soma dos vetores obtidos entre $C\left(t_{n}\right)$ e os pontos de $C(t)$ mais próximos $C\left(t_{n-i}\right)$ e $C\left(t_{n+i}\right)$.

\subsection{Descritores de Formas Baseados em Curvatura}

Enquanto a curvatura por si só pode ser utilizada como um vetor de características, está abordagem apresenta algumas desvantagens como o fato do sinal da curvatura ser muito longo (envolvendo milhares de pontos, dependendo do contorno) e altamente redundante, para contornar este problema uma vez estimada a curvaura, os descritores de forma apresentados a seguir podem ser utilizados.

\section{Amostragem da curvatura}

Ao invés de utilizar todos os valores de curvatura obtidos ao longo do contorno, é possível amostrá-la de maneira a obter um conjunto menor de valores.

\section{Estatísticas da curvatura}

O histograma de curvaturas pode prover uma série de medidas globais úteis como: curvatura média, mediana, variância, desvio padrão, entropia e outros. 


\section{Pontos de máximo, mínimo e de inflexão}

O fato de que nem todos os pontos ao longo do contorno são igualmente importantes motiva-se a análise dos pontos dominantes com máxima curvatura positiva, mínima curvatura negativa ou pontos de inflexão, o número destes pontos, sua posição ao longo do contorno e seus valores de curvatura, os quais podem ser utilizados como medidas de formas.

\section{Energia de dobramento}

Em análise de formas a energia de dobramento ou energia de fronteira foi introduzida por Young (BOWIE, 1974) e (BOWIE; YOUNG, 1977), onde é utilizada como uma medida global de complexidade do contorno.

A energia de contorno pode ser compreendida como a quantidade de energia necessária para transformar um dado contorno fechado em uma circunferência, seu estado de maior simplicidade e de menor energia.

Como medida de complexidade de formas a energia de dobramento apresenta como características interesssantes a invariabilidade a rotação, translação e reflexão.

Por conter tais características a importância da energia de dobramento é ressaltada por Cesar em (CESAR, 1997), onde a mesma é apresentada sob três formas distintas Energia de dobramento média, energia de dobramento multi-escala e energia de dobramento multi-escala normalizada.

A partir de um contorno $C(t)$, contendo $n$ pontos tem-se que a forma de energia de dobramento média é uma das formas a qual se apresenta a energia de dobramento é calculada através da equação 4.4 , onde $P$ é o perímetro do contorno analisado e $k(t)$ a curvatura calcula para cada ponto de $C(t)$ :

$$
B=\frac{1}{P} \sum_{1}^{n} k(t)^{2} d t
$$

A energia de dobramento média, representa a complexidade global do contorno, possuindo sensibilidade para detectar os efeitos de processos de suavização que o contorno possa sofrer em decorrência da aplicação de filtragem em seu sinal, o que a torna adequada para o emprego neste trabalho, no processo de prevenção de contração de contornos que será visto nas próximas seções.

\subsection{Estimativa da Curvatura através da Transfor- mada de Fourier}

\subsubsection{Expressões para a estimativa da curvatura através da transformada de Fourier}

A partir de $C(t)$ um contorno paramétrico como o descrito em (3.13), pode-se estimar a sua curvatura a partir de (4.5) na forma: 


$$
k(t)=\frac{\dot{x}(t) \ddot{y}(t)-\ddot{x}(t) \dot{y}(t)}{\left(\dot{x}(t)^{2}+\dot{y}(t)^{2}\right)^{\frac{3}{2}}}
$$

A equação acima pode ser trabalhada a partir de um sinal complexo $u(t)$ definido na equação (4.6) como:

$$
u(t)=x(t)+i y(t)
$$

A partir deste sinal complexo a curvatura pode ser obtida com o uso da equação (4.7), onde $\ddot{u}^{*}$ é o conjugado complexo de $\ddot{u}$, de forma que:

$$
k(t)=\frac{-\operatorname{Im}\left\{\dot{u}(t) \ddot{u}^{*}(t)\right\}}{|\dot{u}(t)|^{3}}
$$

A estimativa da curvatura $k(t)$ utiliza as derivadas primeira $\dot{x}(t)$ e $\dot{y}(t)$ e segunda $\ddot{x}(t)$ e $\ddot{y}(t)$ de $x(t)$ e $y(t)$. Pode-se para essa estimativa se fazer uso da propriedade da derivada de Fourier para funções de banda limitada (PAPOULIS, 1962), sendo que as derivadas obtidas através da aplicação da propriedade da derivada de Fourier podem ser substituídas nas equações (4.5) e (4.7) utilizadas no calculo da curvatura $k(t)$.

\subsubsection{Estimativa multi-escala da curvatura através da filtra- gem gaussiana}

O processo de diferenciação numérica envolvido na estimativa da curvatura $k(t)$ atua como um filtro passa-altas aumentando a influência do ruído no sinal.

Uma forma de controlar essa influência se da através da incorporação de um filtro passa-baixas aplicado após o processo de diferenciação. Cesar em 1997 adotou filtro Gaussiano para este fim e a incorporação de um esquema multi-escala de curvatura foi introduzido (CESAR, 1997).

Sendo $G(f)$ uma função gaussiana e $\tau$ o valor da variância com a qual é calculada, pode-se controlar a largura de banda de um filtro Gaussiano $G(f)$ através de seu parâmetro $\tau$, a medida que este parâmetro varia uma porção diferente do espectro é levada em consideração, uma possivel formulação de gaussiana é apresentada na formula 4.8 .

$$
G(f)=\frac{1}{\tau \sqrt{2 \pi}} \exp \left(\frac{-f^{2}}{2 \tau^{2}}\right)
$$

O aumento do valor de $\tau$ causa um aumento na largura de banda de $G(f)$ e a diminuição do valor de $\tau$ diminui a largura de banda do filtro. 
Quanto menor a largura de banda do filtro $G(f)$, mais suavizado será o sinal convoluido com o mesmo, pois uma porção maior das componentes de alta freqüência do sinal será desconsiderada.

A variação da largura de banda do filtro gaussiano no espaço freqüência é inversamente proporcional a escala com que a curvatura será estimada, uma vez que em escalas maiores onde a largura de banda do filtro é menor detalhes finos do contorno serão suavizados, sendo o inverso também verdadeiro, por essa razão denota-se o fator escala como a e sua relação com o filtro gaussiano é apresentada na equação (4.9).

$$
a=\frac{1}{\tau}
$$

A proposta apresentada por Cesar em 1997 (CESAR, 1997), consiste na construção de um banco de filtros $G_{\frac{1}{a}}(f)$ em diferentes escalas o que permite o calculo da curvatura em diferentes escalas a partir de um mesmo sinal.

Supondo um banco de filtros $G_{\frac{1}{a}}(f)$ com escala $a=1,2, \ldots, E$, sua aplicação pode ser descrita como:

$$
\begin{aligned}
& U_{\frac{1}{a}}(f)=U(f) G_{\frac{1}{a}}(f) \\
& \dot{U}_{\frac{1}{a}}(f)=\dot{U}(f) G_{\frac{1}{a}}(f) \\
& \ddot{U}_{\frac{1}{a}}(f)=\ddot{U}(f) G_{\frac{1}{a}}(f)
\end{aligned}
$$

O processo de filtragem para a estimativa da curvatura a partir de $x(t)$ e $y(t)$ é feito de forma análoga.

\subsubsection{Prevenção da contração do contorno causada pela filtra- gem gaussiana}

Segundo (CESAR; COSTA, 1996) a filtragem gaussiana altera a amplitude espectral de Contornos, causando a contração dos mesmos na medida em que a escala do filtro aumenta.

Essa contração afeta os resultados obtidos a partir desses contornos e para contornar este problema foram desenvolvidos alguns métodos por estes autores em 1996 e 1997 (CESAR; COSTA, 1996) e (CESAR; COSTA, 1997).

\section{Prevenção da contração do contorno através da conservação de energia}

A energia total de um contorno é definida por (CESAR; COSTA, 1997), de forma que:

$$
E=\int|U(f)|^{2} d f
$$


O processo de filtragem gaussiana altera a energia do contorno, e traz a definição da energia total de um contorno suavizado por um filtro $G_{\frac{1}{a}}(f)$, de forma que:

$$
E(a)=\int\left|U_{\frac{1}{a}}(f)\right|^{2} d f
$$

Uma vez calculada as energias do contorno original e do suavizado a correção da contração pode ser feita multiplicando-se os sinais do contorno suavizado envolvidos na estimativa da curvatura pelo coeficiente $\Omega(a)$ definido por:

$$
\Omega(a)=\sqrt{\frac{E}{E(a)}}
$$

Assim, a obtenção dos sinais corrigidos a partir dos sinais suavizados podem ser vistos como:

$$
\begin{aligned}
& u(t, a)=u(t, a) \Omega(a) \\
& \dot{u}(t, a)=\dot{u}(t, a) \Omega(a) \\
& \ddot{u}(t, a)=\ddot{u}(t, a) \Omega(a)
\end{aligned}
$$

Segundo Cesar (CESAR; COSTA, 1997), os bons resultados alcançados com a prevenção da contração do contorno se devem ao fato da maior porção da energia de contornos típicos estar concentrada nas componentes de baixa frequência o que impede uma grande degradação dos mesmos no processo de filtragem.

\section{Prevenção da contração do contorno através da conservação do perímetro}

A idéia deste método se baseia na analogia de que o processo de suavização do contorno é equivalente ao de se desdobrar um arame inicialmente dobrado no formato do contorno original. Seguindo essa idéia tem-se que o perímetro do contorno deve ser conservado uma vez que ao desdobrar um arame seu comprimento não muda.

Assim, definindo-se o perímetro $L$ de uma curva $u(t)$ como:

$$
L=\int|\dot{u}(t)| d t
$$

onde $u(t)$ uma curva discreta pode-se assim calcular o perímetro da mesma, através dos somatórios apresentados em (4.20) ou (4.21). 


$$
L=\sum_{n=0}^{N-1}|u(n)-u(n-1)|
$$

$\mathrm{Ou}$

$$
L=\frac{2 \pi}{N} \sum_{n=0}^{N-1}|\dot{u}(n)|
$$

De forma análoga, o perímetro $L(a)$ é calculado para a curva suavizada $u(t, a)$, ou seja:

$$
L(a)=\int|\dot{u}(t, a)| d t
$$

Da mesma forma pode-se calcular o perímetro para a curva discreta suavizada $u(t, a)$ estimando a primeira derivada por diferenças sucessivas, como:

$$
L(a)=\sum_{n=0}^{N-1}|u(n, a)-u(n-1, a)|
$$

O próximo passo consiste no cálculo do fator de normalização $P(a)$, definido como:

$$
P(a)=\sqrt{\frac{L}{L(a)}}
$$

O fator de normalização $P(a)$ é definido pela razão do perímetro do contorno original pelo contorno suavizado e sua aplicação se da com a sua multiplicação pelo sinais envolvidos no calculo da curvatura $k(t)$, como:

$$
\begin{aligned}
& u(t, a)=u(t, a) L(a) \\
& \dot{u}(t, a)=\dot{u}(t, a) L(a) \\
& \ddot{u}(t, a)=\ddot{u}(t, a) L(a)
\end{aligned}
$$




\subsection{Detecção de Vértices a partir da Curvatura}

Vértices estão normalmente associados com valores absolutos de alta curvatura. Sendo que uma abordagem direta para a detecção de vértices se da pelo estabelecimento de um valor de limite $T$ na curvatura onde se assume que todos valores acima desse valor $T$ são vértices.

Essa abordagem simples apresenta duas desvantagens principais, além de sofrer os problemas intrínsecos de um método global para determinação de pontos de máximo, ou seja:

1. pontos de alta curvatura tendem a ter em sua vizinhança outros pontos que também excedem o valor $T$, formando assim grupos de vértices. Este problema pode ser solucionado encontrando o ponto de máxima curvatura local e definindoo como única aresta dentro dos limites de sua vizinhança;

2. enquanto arestas verdadeiras são definidas considerando o conhecimento global que se tem sobre a curva, a curvatura é por si só uma medida local, esta característica da curvatura pode levar à determinação de falsos vértices. Este problema pode ser contornado verificando se o angulo formado pelos segmentos de reta aproximados, que se estendem deste falso vértice até os vértices vizinhos a ele onde ocorre um valor menor que $\mathrm{T}$.

O problema da detecção de vértices está intimamente relacionado com a escala espacial das variações do contorno.

Uma abordagem alternativa é apresentada em 1995 (CESAR; COSTA, 1995), a qual considerou que um ponto $P$ do contorno só é visto como um vértice, se as seguintes condições sejam simultaneamente verificadas:

$$
\begin{array}{r}
\frac{d|k(P)|}{d t}=0 \\
k(P)>T \\
\frac{d^{2}|k(P)|}{d t^{2}}<0
\end{array}
$$

Assim pelas condições, tem se que primeira derivada da curvatura absoluta passa por zero em $P$ (curvatura absoluta é o valor da curvatura tomada em módulo $|k(t)|$ ) e a curvatura excede o limiar $T$ em $P$, bem como que a segunda derivada da curvatura absoluta em $P$ é negativa.

Após a apresentação das técnicas empregadas no trabalho, o texto tem sequência com a descrição da forma como estas foram adequadas para compor o método de análise dos contornos de gotas de chuva artificial. 


\section{Capítulo 5}

\section{Medida do Volume de Gotas com Análise de Curvatura}

O método desenvolvido está organizado em oito etapas como pode ser visto no diagrama de blocos na figura 5.1, sendo que as seis primeiras etapas do algoritmo tratam a informação de maneira bidimensional, ou seja, envolvem o processamento de imagens.

Por sua vez as duas últimas etapas do método são compostas pelo processamento do sinal unidimensional dos contornos.

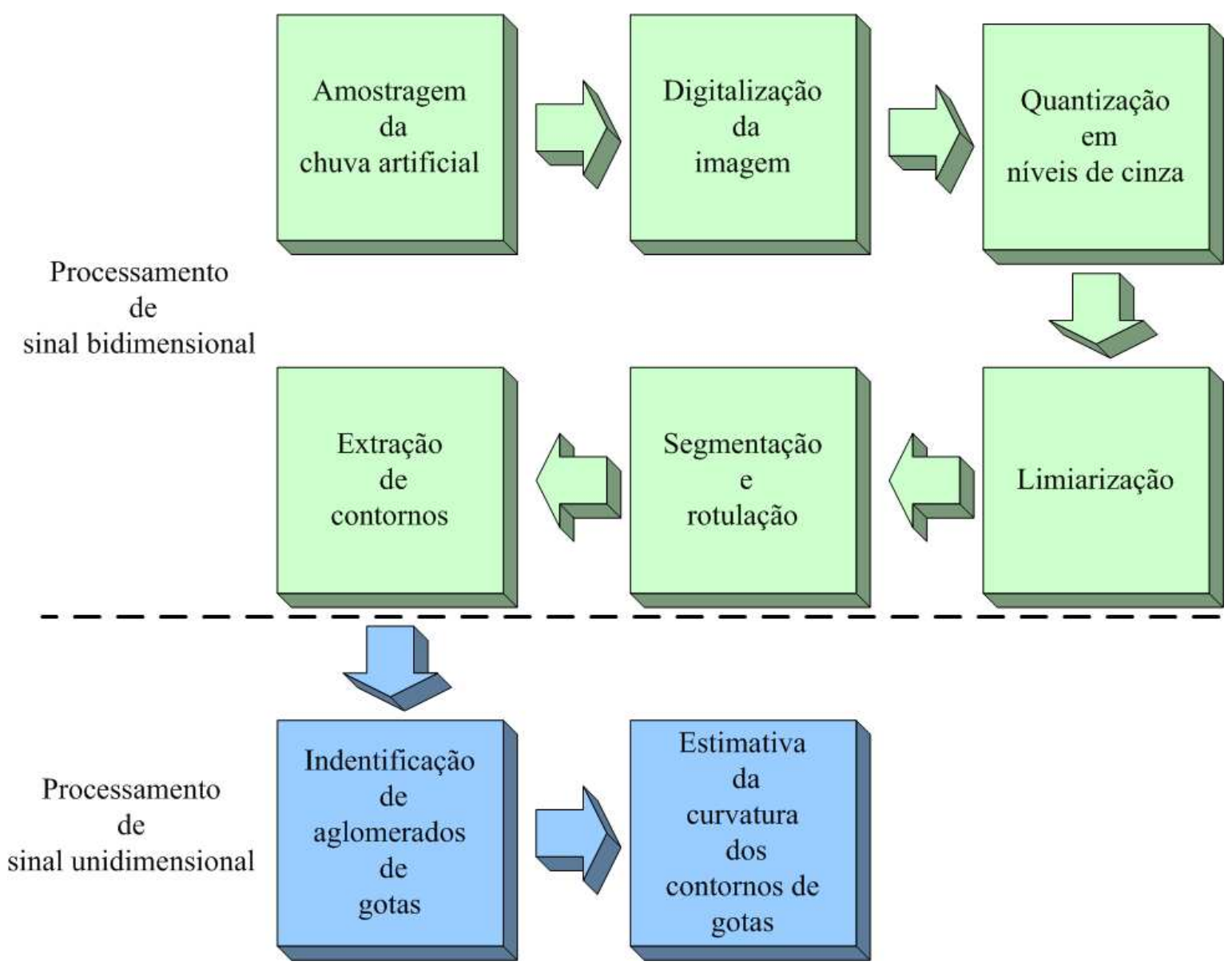

Figura 5.1: Diagrama de blocos do método. 


\subsection{Amostragem da chuva artificial}

Para a medida de gotas de chuva artificial através da análise da curvatura de contornos é preciso realizar a amostragem da chuva artificial analisada. Uma das formas de se realizar essa amostragem é obtida com o uso de papéis hidrossensíveis.

Este tipo de papel foi desenvolvido para análise de gotas com contagem manual. O papel hidrossensível antes de entrar em contato com água possui uma coloração amarela bastante viva, tornando-se azul nas regiões onde ocorre contato com a água, como pode ser visto na figura 5.2 (RAMOS et al., 2004).

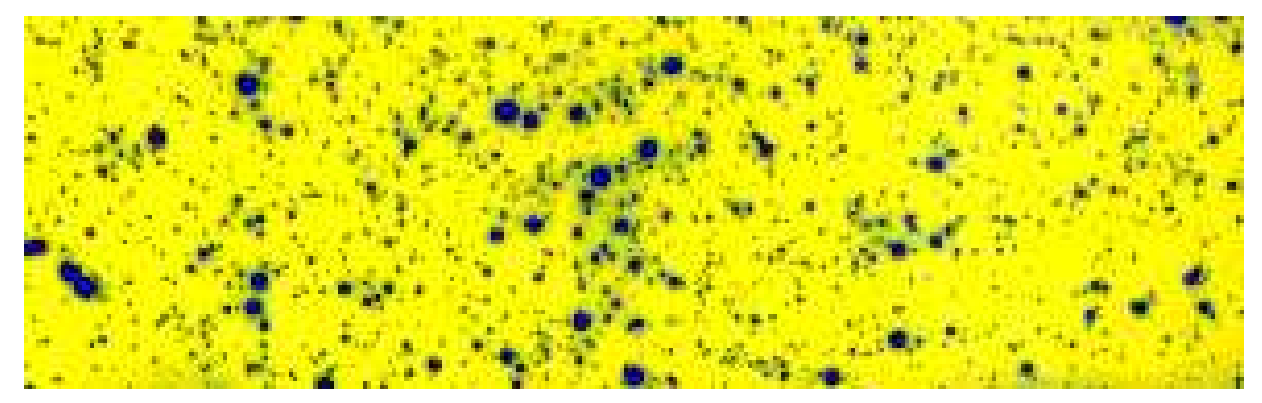

Figura 5.2: Papel hidrossensível com marcas de gotas de água, com dimensões de 7,7 $\mathrm{cm}$ por $2,6 \mathrm{~cm}$.

Na sua utilização os papéis são distribuídos nas áreas onde se pretende aplicar a chuva artificial que se deseja amostrar.

\subsection{Digitalização da imagem}

Para que a informação coletada nos papéis possa ser processada, esses devem ser digitalizados o que pode ser realizado com o auxilio de um equipamento de digitalização de imagens como um scanner, sendo que a digitalização deve ser realizada com uma quantização de cores de 24 bits para representação no modelo de cores RGB, conforme ilustrado no diagrama da figura 5.3 Deve ser observada uma resolução espacial mínima necessária para a correta representação dos menores objetos que se deseja identificar na cena.

\subsection{Quantização em níveis de cinza}

Após a digitalização, tem-se inicio as etapas seguintes do processamento da imagem obtida com a adequação do seu formato para o processamento que se inicia com a conversão da imagem colorida para níveis de cinza. Este processo é realizado através da conversão da imagem do sistema RGB para YIQ utilizando-se a transformação apropriada e fazendo-se uso apenas da informação de iluminância ${ }^{1}$ em Y e descartando os valores de IQ que contém a informação de crominância ${ }^{1}$, obtendo-se então a imagem em níveis de cinza, como ilustra o diagrama da figura 5.4.

\footnotetext{
${ }^{1}$ Quantidade de luz que incide nos objetos de uma cena.

${ }^{1}$ Faixa do espectro de luz refletida pelos objetos de uma cena.
} 


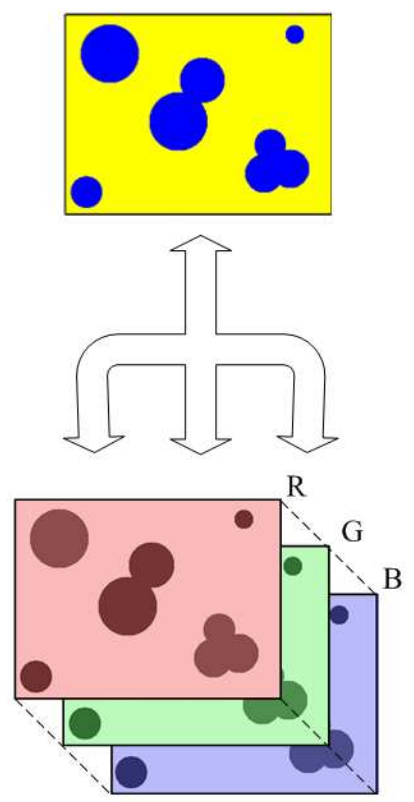

Figura 5.3: Diagrama com representação do formato RGB na qual a imagem deve ser digitalizada

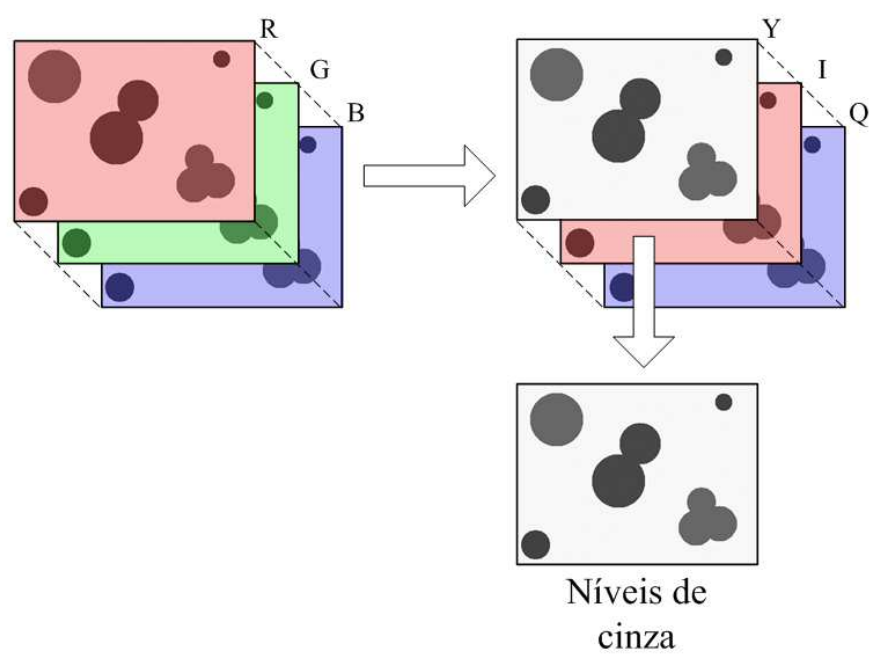

Figura 5.4: Diagrama ilustrando o processo de quantização em níveis de cinza 


\subsection{Limiarização}

Uma vez obtida a imagem em níveis de cinza pode-se dar inicio ao processo de limiarização, onde um limiar é utilizado para dividir os níveis de cinza da imagem em dois grupos. A divisão é realizada de forma que os pixels pertencentes as manchas de gotas no papel componham o primeiro grupo, sendo que esse pixels originalmente eram os de cor azul na imagem colorida e os níveis mais escuros na imagem em níveis de cinza. Por sua vez o segundo grupo será composto pelos pixels que originalmente apresentavam a cor amarela na imagem RGB e os níveis mais claros na imagem em níveis de cinza.

O primeiro grupo de pixels da nova imagem será representado pelo valor 1 enquanto o segundo grupo será representado pelo valor 0, compondo dessa forma uma imagem binária, cujos valores são representados pelos níveis preto e branco, como representado no diagrama da figura 5.5.

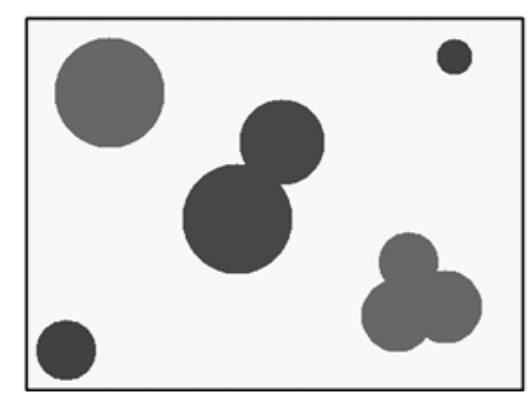

Níveis de cinza

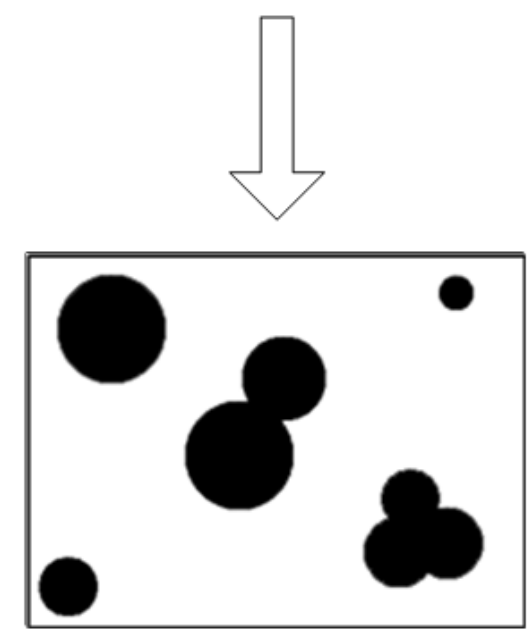

Imagem binária

Figura 5.5: Diagrama ilustrando o processo de limiarização, para se obter uma imagem binária.

A imagem binária obtida no processo anterior de certa maneira apresenta uma primeira segmentação onde os objetos foram separados do fundo da imagem, ou seja, as marcas de gotas na imagem do papel hidrossensível já podem ser diferenciadas das regiões do papel hidrossensível que não foram molhadas pelas gotas de chuva artificial. 


\subsection{Segmentação e rotulação}

O processo seguinte tem por objetivo segmentar as regiões que representam as gotas e que não estejam conectadas diretamente por vizinhança entre pixels que as compõem, para tal utiliza-se o método de separação de regiões disjuntas, neste processo é empregada o algoritmo de rotulação de regiões disjuntas.

O resultado desse processo é uma lista de imagens, sendo que cada imagem contém uma das regiões que representam aglomerados ou gotas como ilustrado no diagrama da figura 5.6, onde ainda os rótulos atribuidos estão representados em pseudo-cores.

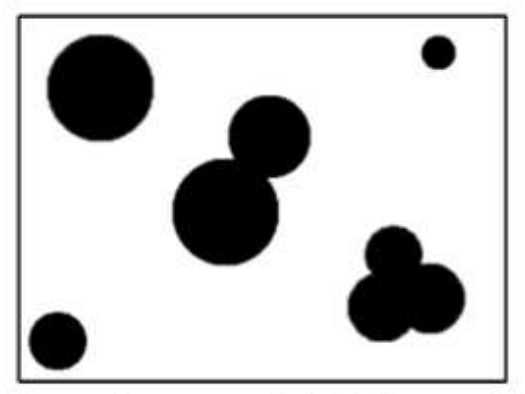

Imagem binária

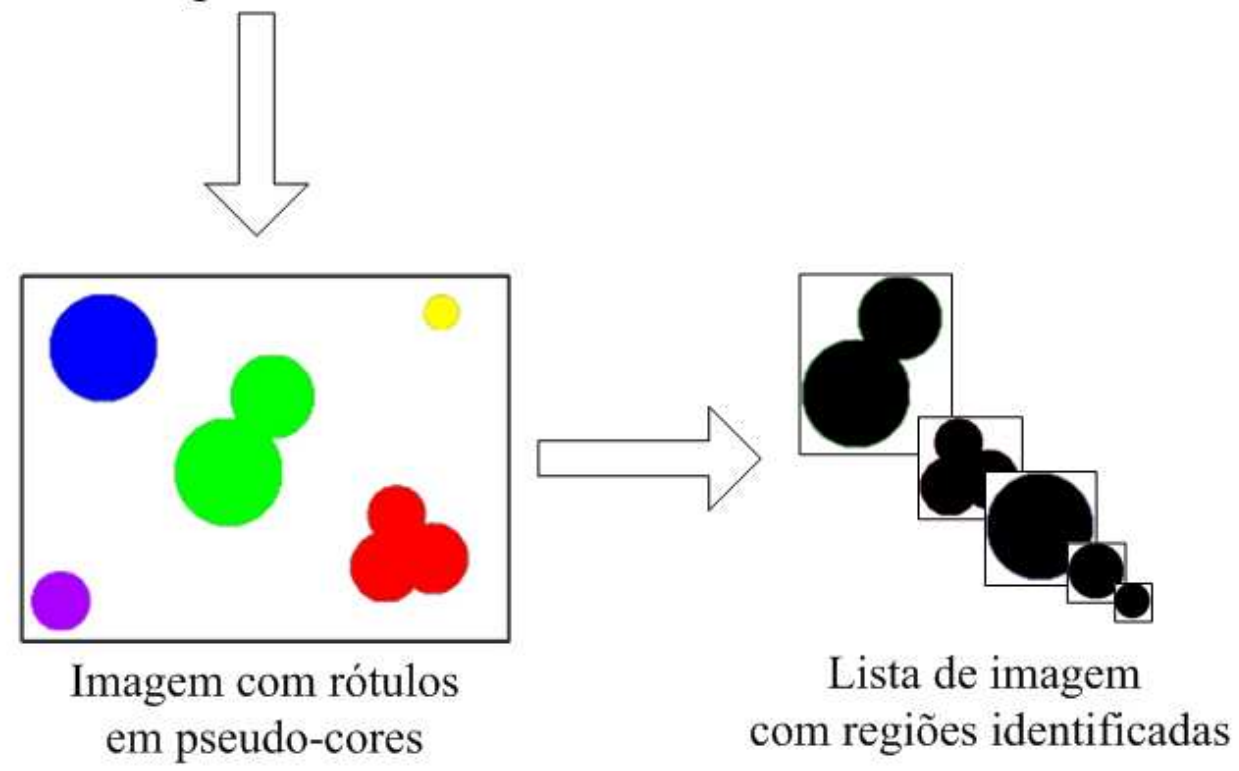

Figura 5.6: Diagrama ilustrando o processo de segmentação e rotulação.

Nesse ponto do processamento tem-se dois tipos de regiões identificadas, o primeiro tipo de região foi produzido por uma única gota que marcou o papel de forma a não se justapor ou sobrepor parcialmente um outra marca de gota. Já o segundo tipo é formado por marcas de gotas aglomeradas as quais precisam ser identificadas para que a estimativa do volume das gotas possa ser feita de maneira correta.

Para realizar a separação desses aglomerados será utilizada a informação da curvatura e para que essa possa ser estimada é necessária a extração do contorno de cada uma das regiões presentes nas imagens. 


\subsection{Extração de contornos}

O processo que da seqüência ao método, utiliza-se do algoritmo de extração de contornos paramétricos.

A forma que normalmente os aglomerados de gotas assumem favorecem o aparecimento em seus contornos de cavidades com um pixel de largura e mais de um pixel de profundidade, na região onde os contornos das gotas que formam o aglomerado se unem, como ilustra o diagrama na figura 5.7, esse tipo de formação faz com que o algoritmo crie um contorno que após entrar nesse tipo de cavidade retorna pelos mesmos pixels, conforme ilustrado no diagrama da figura 5.8.

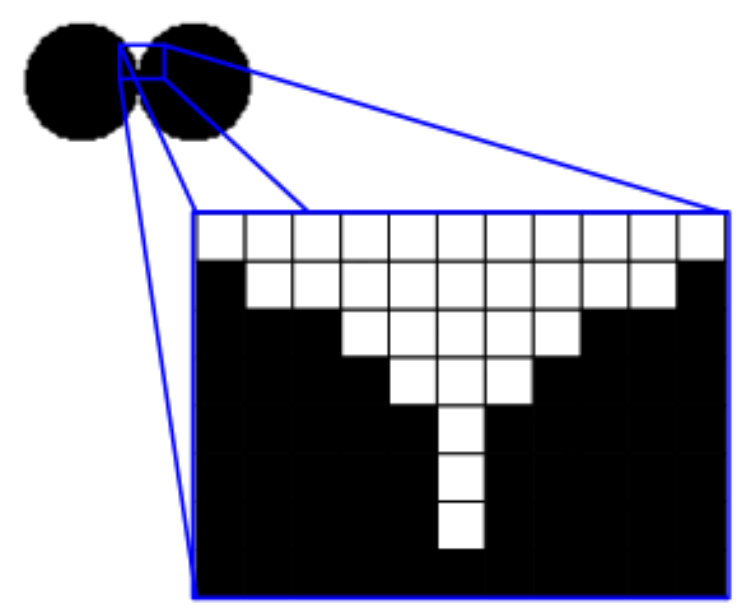

Figura 5.7: Diagrama ilustrando em destaque a cavidade com um pixel de largura e com mais de um pixel de profundidade.

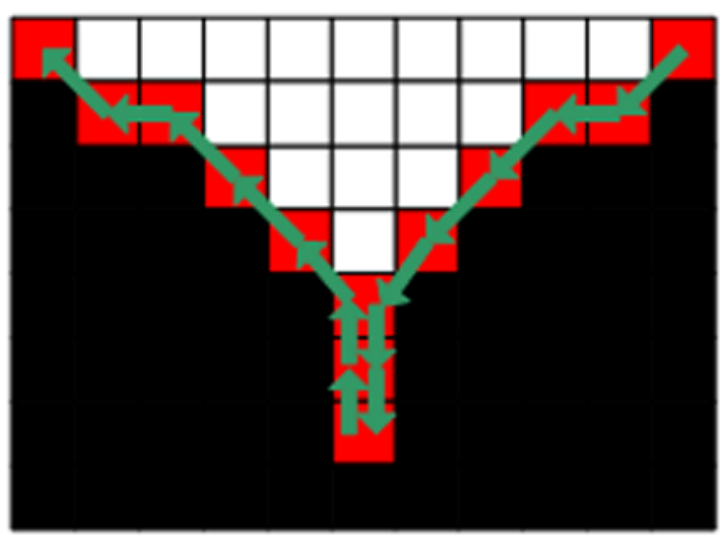

Figura 5.8: Diagrama ilustrando contorno de forma com cavidade com um pixel de largura e com mais de um pixel de profundidade.

Essa configuração do contorno cria um ponto de alta curvatura nessa região, como pode ser visto no gráfico da figura 5.9, Esse ponto de alta curvatura acaba por mascarar a curvatura negativa que normalmente caracterizaria esse trecho do contorno.

Em virtude da ocorrência desse tipo de formação o algoritmo de extração de contornos paramétricos utilizado no método possui uma modificação, para evitar que tal situação ocorra. 


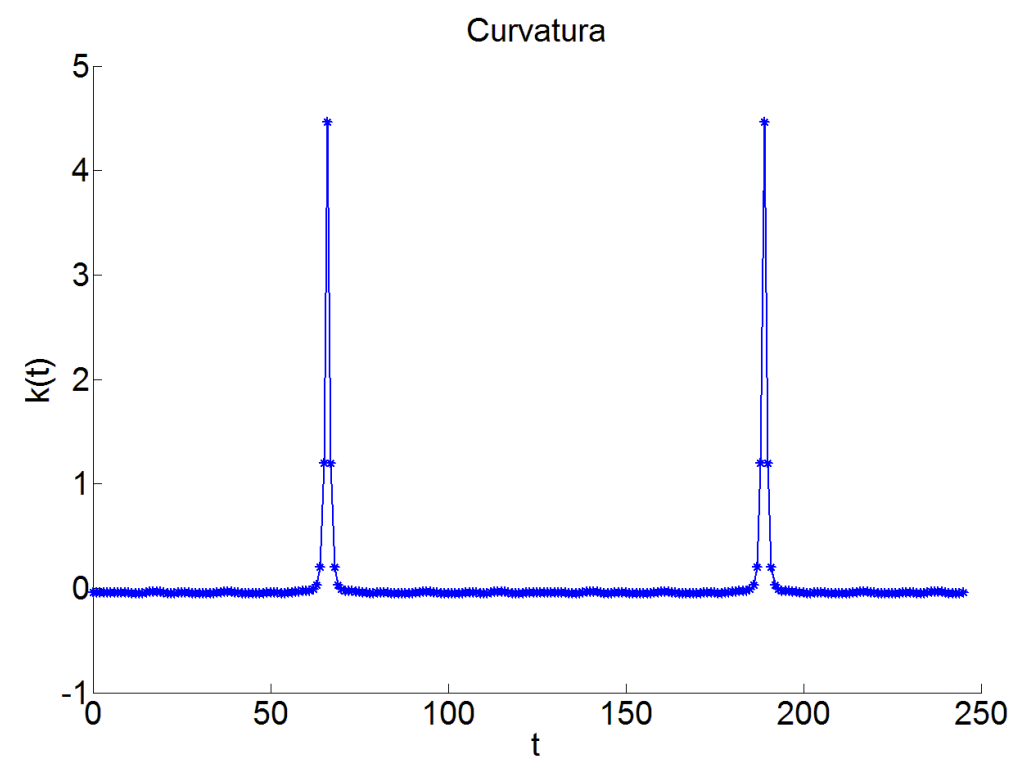

Figura 5.9: Picos de curvatura ocasionados por cavidades com um pixel de largura e mais de pixel de profundidade.

\subsubsection{Modificação no algoritmo de extração de contornos}

Como resultado da execução padrão do algoritmo de extração de contornos apresentado na seção 3.3.5, tem-se uma lista com os pixels que constituem o contorno.

A partir dessa lista de pixels o algoritmo modificado realiza os seguintes passos:

- identificar e anotar os pixels onde ocorreram mudanças de direção de 180॰;

- remover do contorno o pixel $\mathbf{p}$ anotado;

- remover do contorno os pixels repetidos, a exceção do pixel repetido mais afastado de $\mathbf{p}$

Após a execução destes passos obtem-se como resultado um contorno semelhante ao ilustrado no diagrama da figura 5.10.

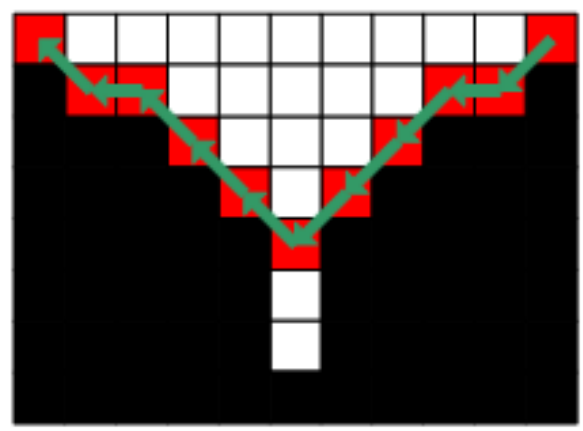

Figura 5.10: Diagrama ilustrando um contorno extraído com o algoritmo modificado, de uma forma contendo uma cavidade de um pixel de largura e com mais de um pixel de profundidade. 


\section{Algoritmo modificado para extração do contorno}

Para apresentação do algoritmo modificado são deinidas as seguintes variáveis:

- Den a direção do pixel corrente para o próximo do contorno;

- Dcp a direção do pixel corrente para o anterior do contorno;

- Pc as coordenadas do pixel corrente;

- PI a lista de pontos de inversão;

- Inverter a função que retorna a direção oposta a uma direção pasada como parâmetro;

- EP o número de pontos repetidos.

Definidas as variáveis empregadas, tem-se o algoritmo modificado:

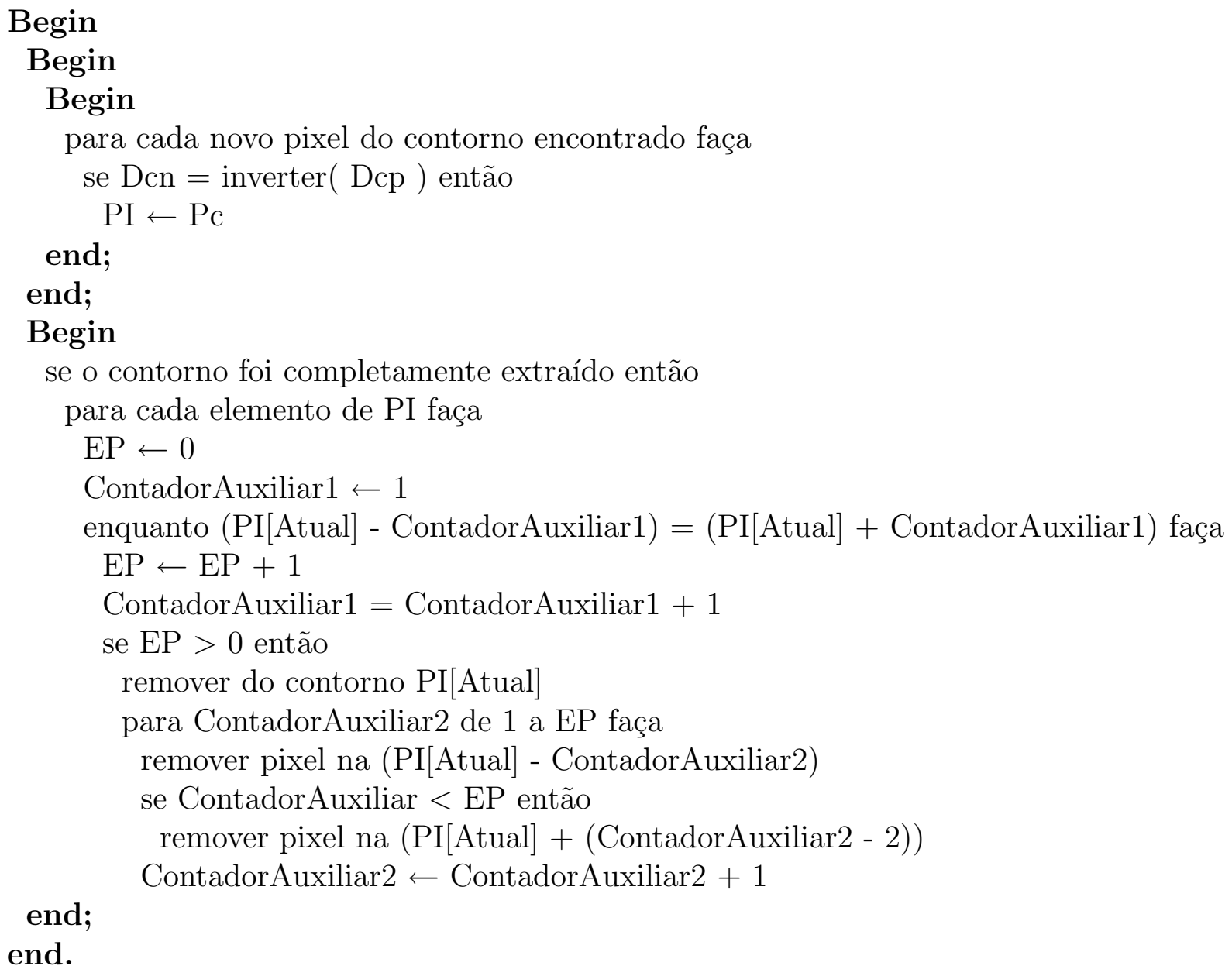




\subsection{Identificação de aglomerados de gotas}

Uma vez que os contornos das regiões foi extraído o método tem seqüência com o reconhecimento de quais regiões são formadas simplesmente por uma gota e quais são aglomerados de gotas, mais do que isso, é necessária a identificação dos pontos no contorno onde essas gotas se unem.

Esse tipo de análise é importante, pois se esses aglomerados não forem identificados, podem ser confundidos com gotas de tamanho maior, comprometendo assim os resultados da análise do volume das gotas.

Ao observar o contornos das regiões marcadas no papel por gotas, nota-se que as gotas não aglomeradas formam padrões circulares, enquanto os aglomerados de gotas possuem ao longo do contorno pontos onde a tendência de direção do contorno sofre uma abrupta mudança de sentido, que se inverte, como pode ser observado nas ilustrações da figura 5.11.
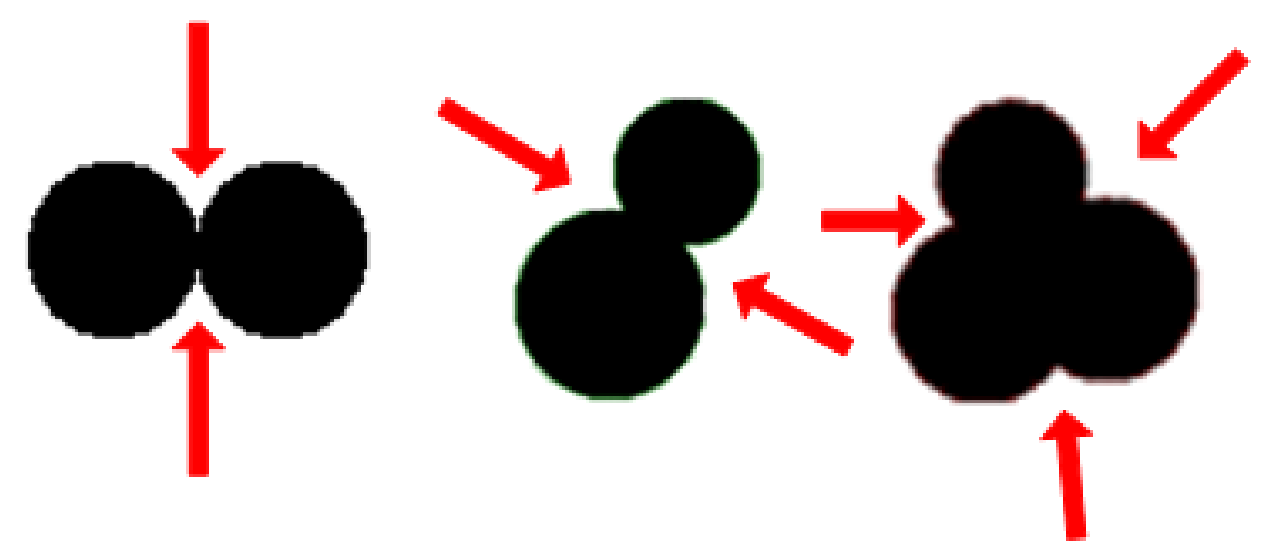

Figura 5.11: Ilustrações de aglomerados com os pontos de separação das gotas em destaque.

Os pontos de inversão no sentido do contorno são os pontos onde os contornos das gotas que constituem os aglomerados se unem, sendo que ao calcularmos a curvatura para o contorno nesses pontos esta torna-se negativa, sendo que esses pontos de curvatura negativa podem ser utilizados para a correta identificação dos aglomerados.

\subsubsection{Método de detecção de vértices}

O ponto de curvatura negativa que caracteriza os pontos de quebra dos aglomerados tendem a agrupar pontos de curvatura negativa, que com o uso de um simples limiar negativo para sua identificação poderiam levar ao reconhecimento de falsos pontos de quebra. Para evitar esse tipo de problema uma solução consiste na utilização de uma variação do método de detecção de vértices.

O método originalmente utiliza-se da análise de três parâmetros para identificação de vértices sendo que, assumindo um limiar $\mathrm{T}$ e um ponto $\mathrm{P}$ do contorno $C(t)$ é 
considerado um vértice caso:

1. ocorra o cruzamento por zero na primeira derivada do módulo da curvatura em $\mathrm{P}$ indicando um ponto de inflexão;

2. a curvatura exceda um limiar $\mathrm{T}$ no ponto $\mathrm{P}$;

3. a segunda derivada do módulo da curvatura assuma um valor negativo em $\mathrm{P}$ indicando um ponto de máximo local.

Definindo que $k(P), \frac{d|k(P)|}{d t}$ e $\frac{d^{2}|k(P)|}{d t^{2}}$, são respectivamente a curvatura, a primeira derivada do módulo da curvatura e a segunda derivada do módulo da curvatura em $\mathrm{P}$, as regras acima são traduzidas pelas seguintes equações:

$$
\begin{aligned}
\frac{d|k(P)|}{d t} & =0 \\
k(P) & >T \\
\frac{d^{2}|k(P)|}{d t^{2}} & <0
\end{aligned}
$$

\section{Modificação no método de detecção de vértices}

A variação do método para detecção de vértices, permite a identificação de um ponto $P$ pertencente a um contorno $C(t)$, como um ponto de quebra de aglomerado partindo-se da definição de um limiar T e verificando-se as seguintes regras em P que é considerado ponto de quebra de aglomerado caso:

1. ocorra o cruzamento por zero na primeira derivada da curvatura no ponto indicando um ponto de inflexão;

2. o valor da curvatura está abaixo de um limiar;

3. a segunda derivada da curvatura assuma um valor positivo no ponto indicando um ponto de mínimo local, ou seja, o ponto onde a curvatura apresenta um valor mais negativo.

As regras acima são traduzidas pelas seguintes equações, onde $k(P), \frac{d k(P)}{d t} \mathrm{e} \frac{d^{2} k(P)}{d t^{2}}$, são respectivamente a curvatura, a primeira derivada da curvatura e a segunda derivada da curvatura em $\mathrm{P}$ :

$$
\begin{aligned}
\frac{d k(P)}{d t} & =0 \\
k(P) & <T \\
\frac{d^{2} k(P)}{d t^{2}} & >0
\end{aligned}
$$


O emprego do método possibilita identificar um único ponto na região de curvaturas negativas, sendo este um ponto de mínimo local que representa o local de união das gotas que formam o aglomerado.

Um exemplo dos sinais analisados para a identificação de aglomerados de gotas pode ser visto nas figuras 5.12 que ilustra o contorno de um aglomerado com os pontos de quebra detectados, a figura 5.15 ilustra o contorno do aglomerado suavizado pela filtragem gaussiana acentuada que tem o objetivo de facilitar o reconhecimento dos pontos de quebra de aglomerados.

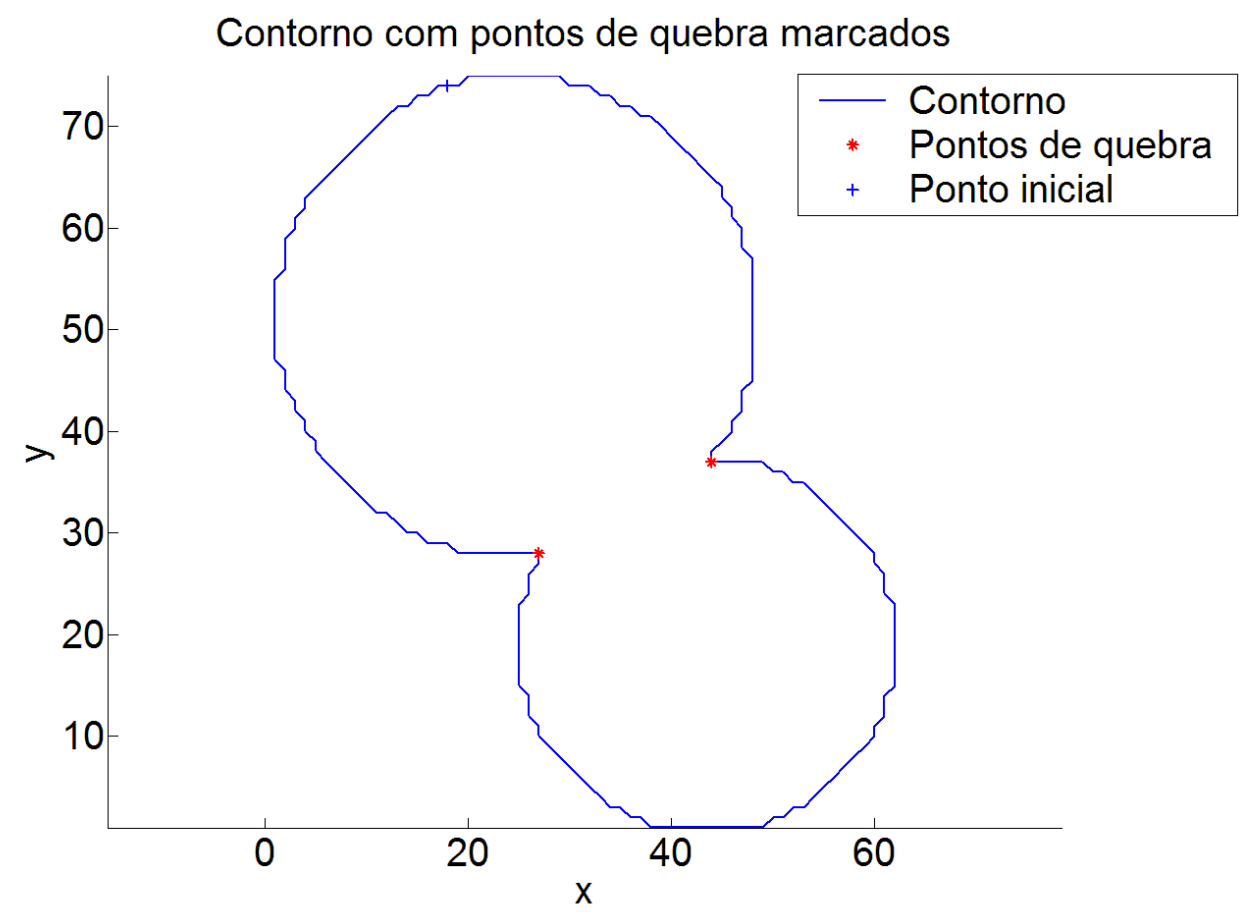

Figura 5.12: Ilustração do contorno de um aglomerado com pontos de quebra marcados.

Os demais sinais verificados na correta identificação dos aglomerados podem ser vistos nas figuras 5.14 e 5.15, que apresentam respectivamente o gráfico da curvatura do aglomerado e respectivamente o gráfico das derivadas primeira e segunda da curvatura, ambos possuem os pontos de quebra do aglomerado marcados. 


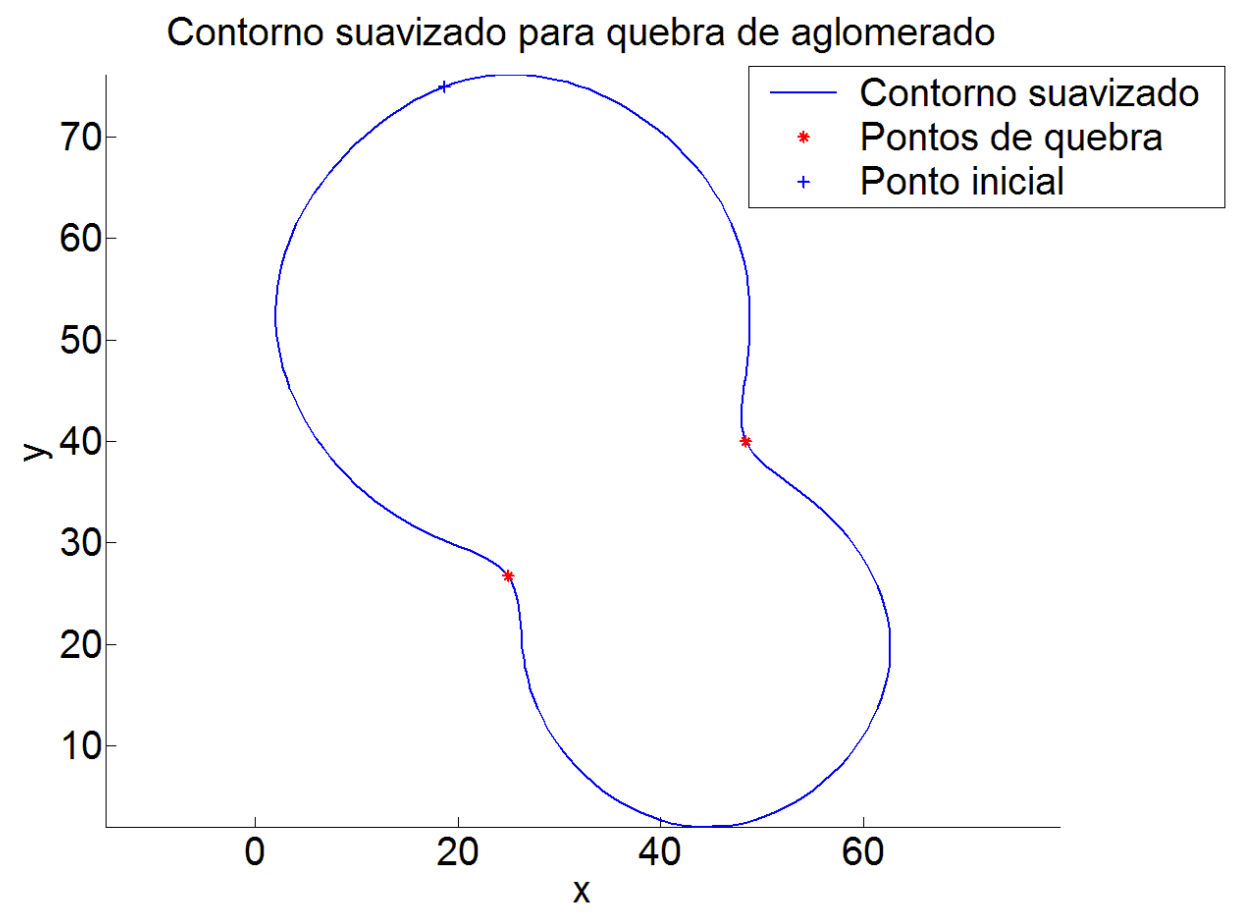

Figura 5.13: Ilustração do contorno suavizado de um aglomerado com pontos de quebra marcados.

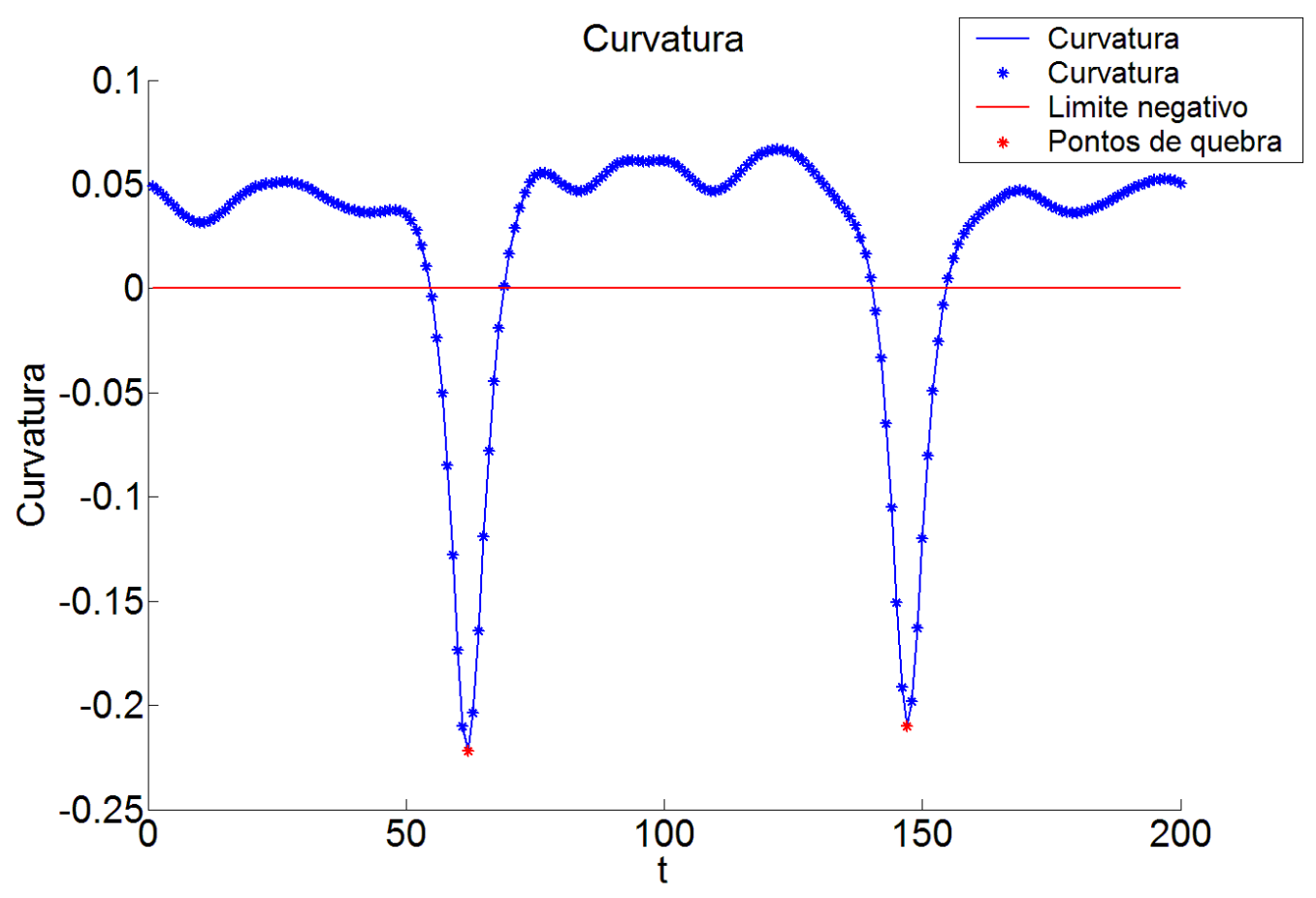

Figura 5.14: Gráfico da curvatura do contorno de um aglomerado com pontos de quebra marcados. 


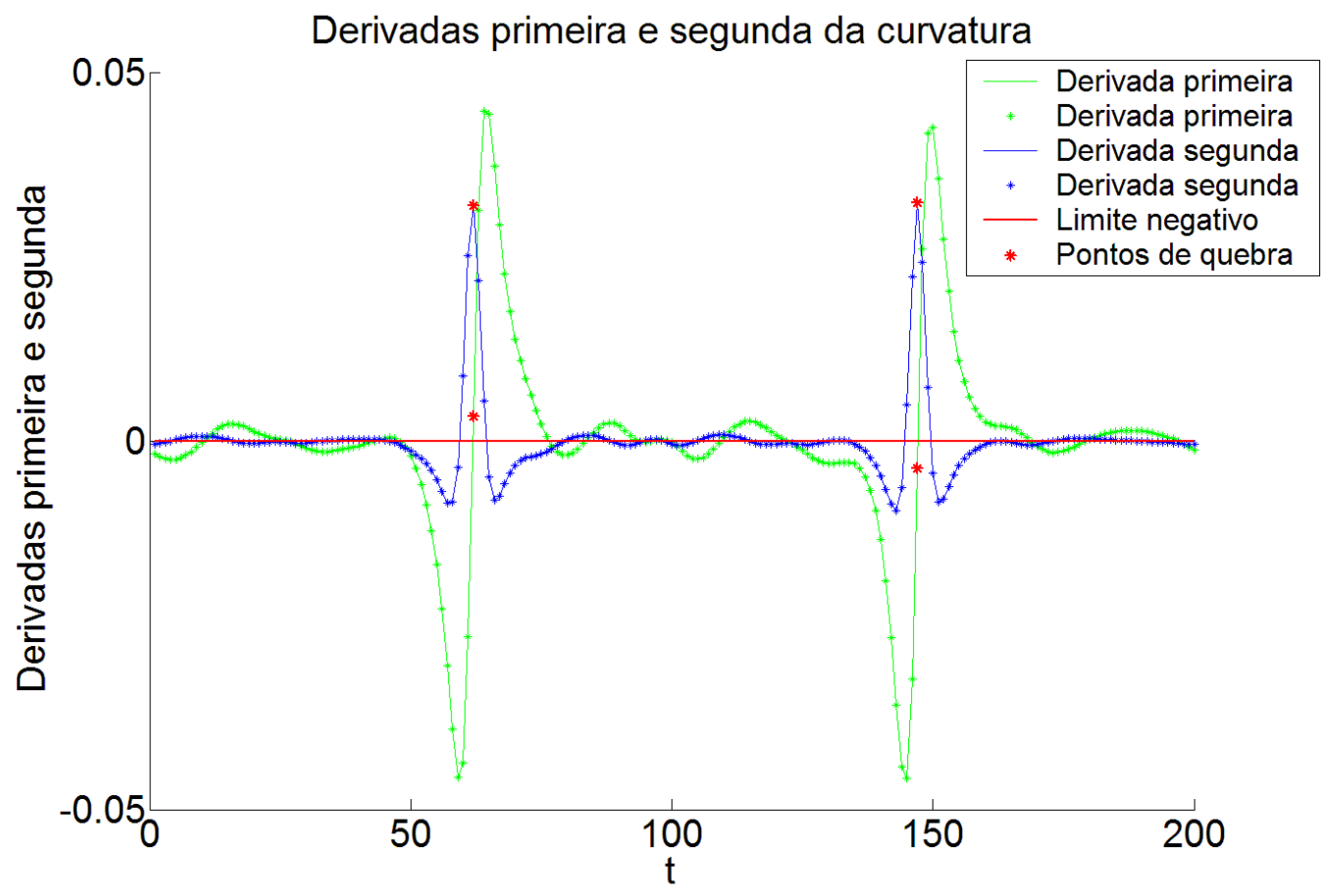

Figura 5.15: Gráficos das derivadas primeira e segunda da curvatura do contorno de um aglomerado com pontos de quebra marcados.

\subsubsection{Aplicação da abordagem multi-escala de estimativa da curvatura na identificação de aglomerados}

Uma outra questão a ser trabalhada para a correta identificação dos aglomerados consiste em conseguir diferenciar os pontos de curvatura negativa, que indicam a quebra dos aglomerados, de outros valores de curvatura negativa que ocorrem no contorno.

Estes outros valores de curvatura negativa, podem ser decorrência do fato de tratar-se de um contorno extraído de uma forma bidimensional representada em uma imagem digital, logo discreta ou ainda criados pelo processo de diferenciação numérica utilizado para a estimativa da curvatura que atua como um filtro passa-altas no sinal.

Seja qual for a origem desses pontos de curvatura negativa a solução adotada para resolver este problema na identificação dos aglomerados, consiste em trabalhar com o parâmetro de escala, introduzido com a abordagem de curvatura multi-escala, uma vez que o aumento da escala torna a curvatura menos sensível a detalhes finos do contorno.

A variação do fator escala, atua sobre a largura de banda do filtro gaussiano que em freqüência possui uma relação inversa com o fator escala, sendo que quanto maior a escala, menor a largura do filtro o que faz com que uma porção menor do espectro do sinal do contorno seja considerado. Um exemplo de gráfico de uma função gaussiana pode ser visto na figura 5.16.

A porção do espectro desconsiderada consiste nas freqüências mais altas o que suaviza o contorno. Esta suavização com o correto ajuste do fator escala permite um realce nos pontos de curvatura negativa que indicam a quebra dos aglomerados em relação ao restante dos pontos do contorno. Além de servir de ajuste para que o método identifique como aglomerados apenas gotas que tenham sobreposição até um limite definido pelo usuário. 


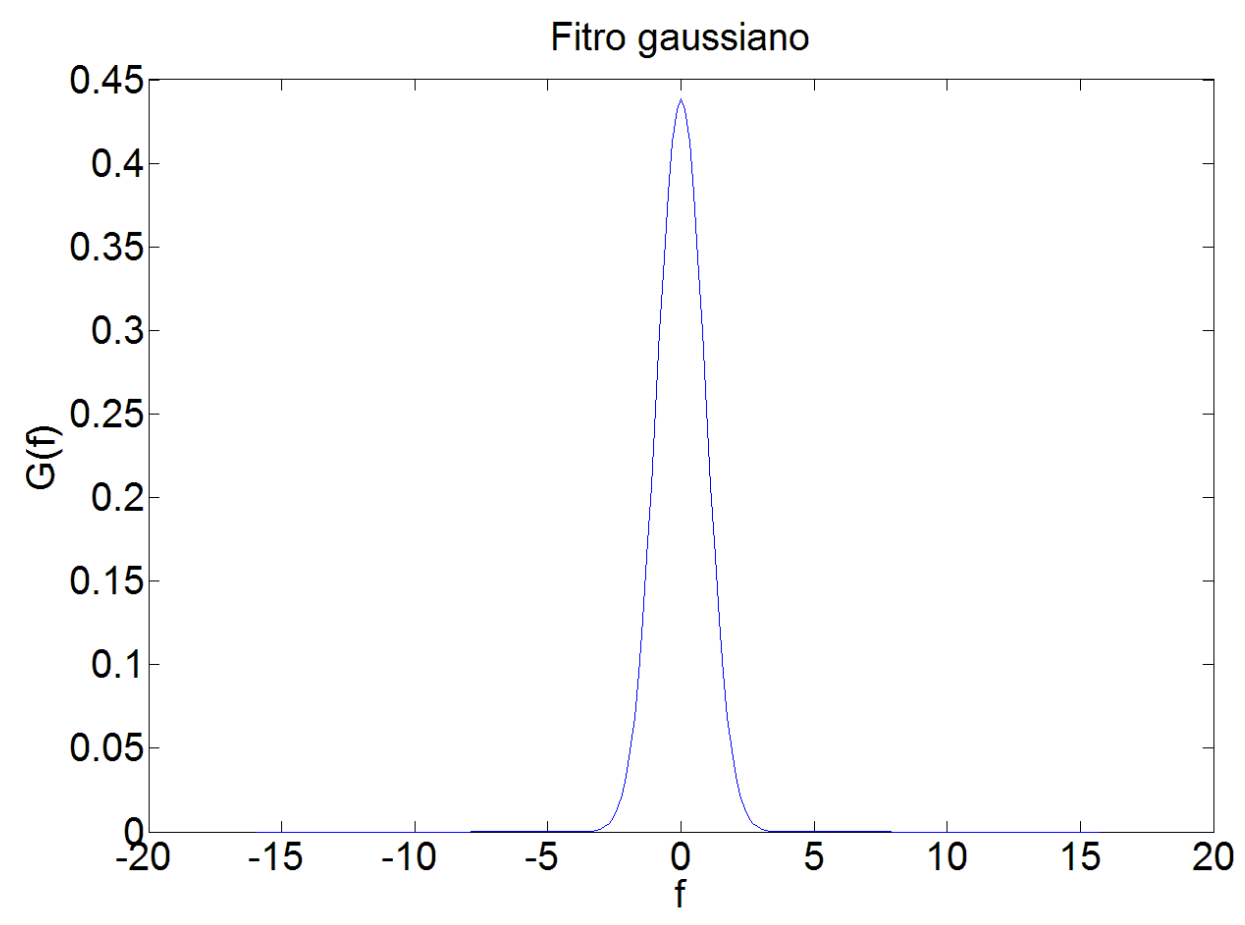

Figura 5.16: Função gaussiana utilizada como filtro.

Na observação de contornos e suas medidas de curvatura nos pontos de quebra dos aglomerados, com diferentes níveis de sobreposição das gotas verifica-se a seguinte relação, quanto mais as gotas estão sobrepostas menos negativa se apresenta a curvatura, com base nesse fato se pode trabalhar com o parâmetro escala para calibrar a sensibilidade do método ao grau de aglomeração das gotas, para a identificação das regiões como gotas ou aglomerados.

Para calibrar a sensibilidade do método à aglomeração das gotas são realizados ensaios com padrões circulares de tamanhos conhecidos com um nível de sobreposição também conhecido, com diversos valores de escala para identificar os valores que representam a sensibilidade desejada do método para a aplicação pretendida.

Uma vez que o parâmetro escala para o ajuste da sensibilidade do sistema a aglomeração de gotas foi definido, tem-se contornos de cada uma das gotas identificadas ou trechos de contornos de gotas que puderam ser identificadas em aglomerados. Com essas informações o método tem seqüência com a estimativa da curvatura para cada um desses contornos.

\subsection{Estimativa da curvatura dos contornos de gotas}

A estimativa da curvatura do contorno dos padrões circulares criados pelas gotas é utilizada para a estimativa do volume, seu uso baseia-se na relação inversa entre a curvatura e raio. Os padrões circulares das marcas das gotas está relacionado ao volume da gota em questão. Tendo em vista as relações acima, a precisão da estimativa das curvaturas determina a precisão da medida do volume das gotas.

No processo de estimativa da curvatura mais uma vez faz-se uso da abordagem multi-escala, pois a variação do fator escala influência na precisão da medida da curvatura, pois em baixas escalas existe uma grande oscilação no sinal da curvatura que torna-se mais sensível a detalhes do contorno, no entanto a adoção de escalas muito 
altas implicam numa filtragem excessiva do contorno o que acaba por interferir na precisão da medida da mesma forma, um exemplo de gráfico de curvatura de um padrão circular pode ser visto na figura 5.17.

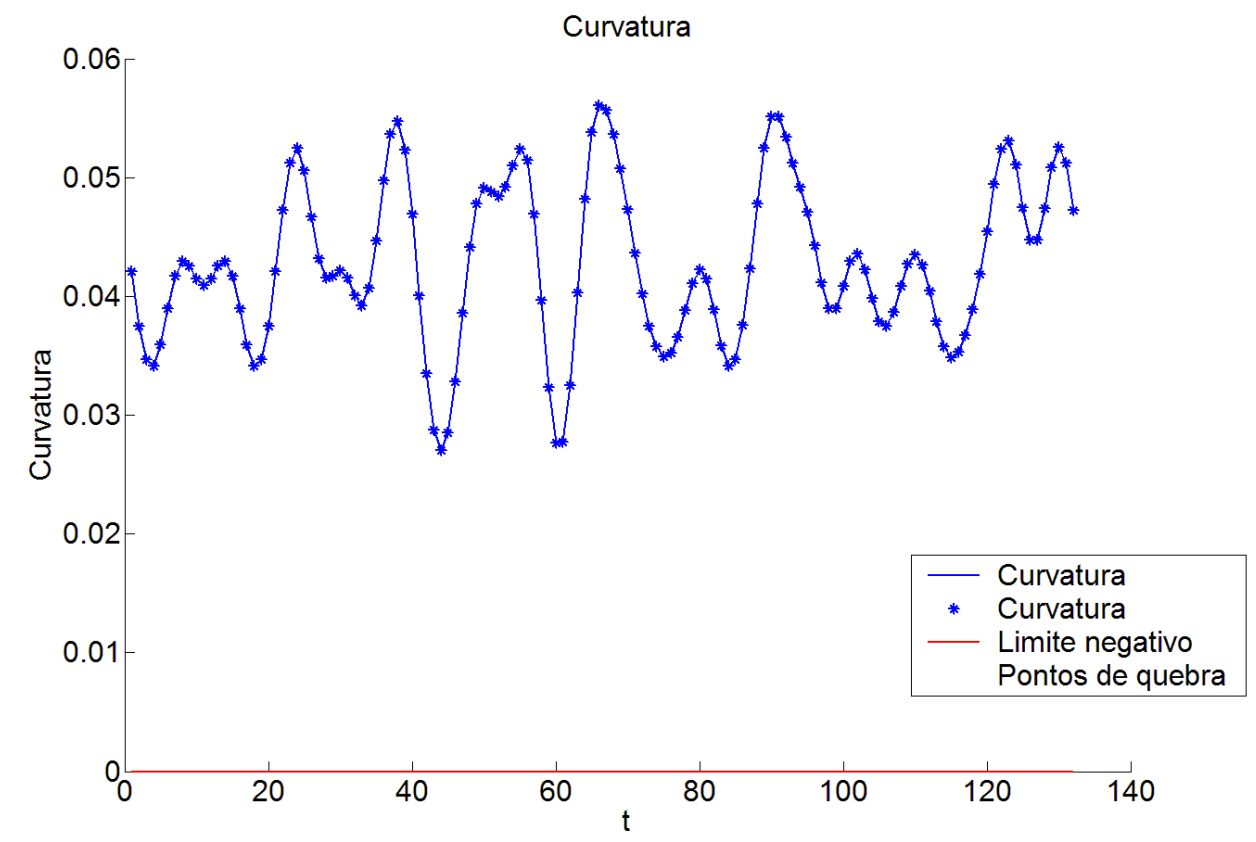

Figura 5.17: Curvatura de um padrão circular, para cada ponto do contorno extraído.

Para a correta escolha da escala que propicie um nível desejável de precisão na medida da curvatura a técnica adotada consiste novamente na avaliação de resultados de ensaios com padrões circulares em uma faixa de tamanhos conhecidos, cujas curvaturas são estimadas em diferentes escalas tornando possível a avaliação do erro na medida.

$\mathrm{Na}$ estimativa das curvaturas dos contornos de gotas que se encontram aglomeradas um cuidado adicional é tomado visando a melhora na precisão da medida, como já dito anteriormente os pontos de curvatura negativa que identificam os pontos de quebra de aglomerados tendem a concentrar ao seu redor pontos de curvatura negativa que poderiam influenciar na estimativa da curvatura dessas gotas, para amenizar o efeito desses pontos um percentual dos pontos do contorno de cada uma dessas gotas na periferia dos pontos de quebra são desconsiderados no cálculo da curvatura.

Após a estimativa das curvaturas dos contornos de gotas o raio médio pode ser estimado através do calculo da curvatura média desses contornos, como definido na equação (5.7). Por sua vez a estimativa do volume das gotas é obtida com a aproximação da gota pode uma esfera, cujo volume depende do raio da mesma que é representado pelo raio médio obtido a partir da análise do contorno da marca da gota feita em papel hidrossensível.

$$
\text { Raio médio }=\frac{1}{\text { Curvatura média }}
$$

Após a apresentação das técnicas empregadas para formar o método para análise do contorno de gotas de chuva artificial em imagens, são apresentados no próximo capítulo os resultados e conclusões obtidos. 


\section{Capítulo 6}

\section{Resultados, Discussões e Conclusões}

\subsection{Resultados}

Os resultados obtidos consistem de um protótipo do método para a análise do contorno de gotas de chuva artificial em imagem digital, implementado através da codificação de rotinas com o uso do ambiente de desenvolvimento MATLAB, desenvolvido pela MathWorks em sua versão 6.5 - Release 13.

A ferramenta de desenvolvimento utilizada, tem como a principais características a capacidade de manipulação de matrizes o que a torna adequada ao desenvolvimento de aplicações de processamento de imagens digitais, bem como é dotada de uma ampla biblioteca de pacotes que podem ser utilizados.

As rotinas implementadas, permitem a execução de todo o método desde sua etapa de processamento de dados bidimensionais ou seja, das imagens. Além de abranger a etapa do processamento de dados unidimensionais de contornos e curvatura.

A implementação é composta também de uma interface gráfica com o usuário, constituindo um sistema que permite o uso interativo das rotinas desenvolvidas, com a possibilidade de mudança durante a execução dos parâmetros de ajuste do método, o que auxilia na experimentação dos parâmetros e compreensão dos processos envolvidos, um exemplo desta interface pode ser vista na figura 6.1.

Para que esses resultados fossem avaliados foram também implementadas no mesmo ambiente, rotinas auxiliares para calibração do método quanto a sensibilidade para detecção de aglomerados, bem como a escolha do parâmetro escala que propicie o grau de precisão pretendido.

Além das implementações foram realizados estudos de dois tipos principais com o uso das rotinas implementadas, o primeiro teve como objetivos analisar a precisão do método na medida de tamanho de padrões circulares, sua tolerância a ruídos e deformidades nas formas dos padrões e calibrar o método indicando a melhor escala de medida a ser adotada para a faixa de tamanhos de padrões analisada.

O segundo tipo de estudo realizado objetivou analisar a capacidade do método em identificar aglomerados de gotas, sua precisão na medida do tamanho das gotas que constituem os aglomerados, bem como verificar a influência do fator escala na identificação de aglomerados. 


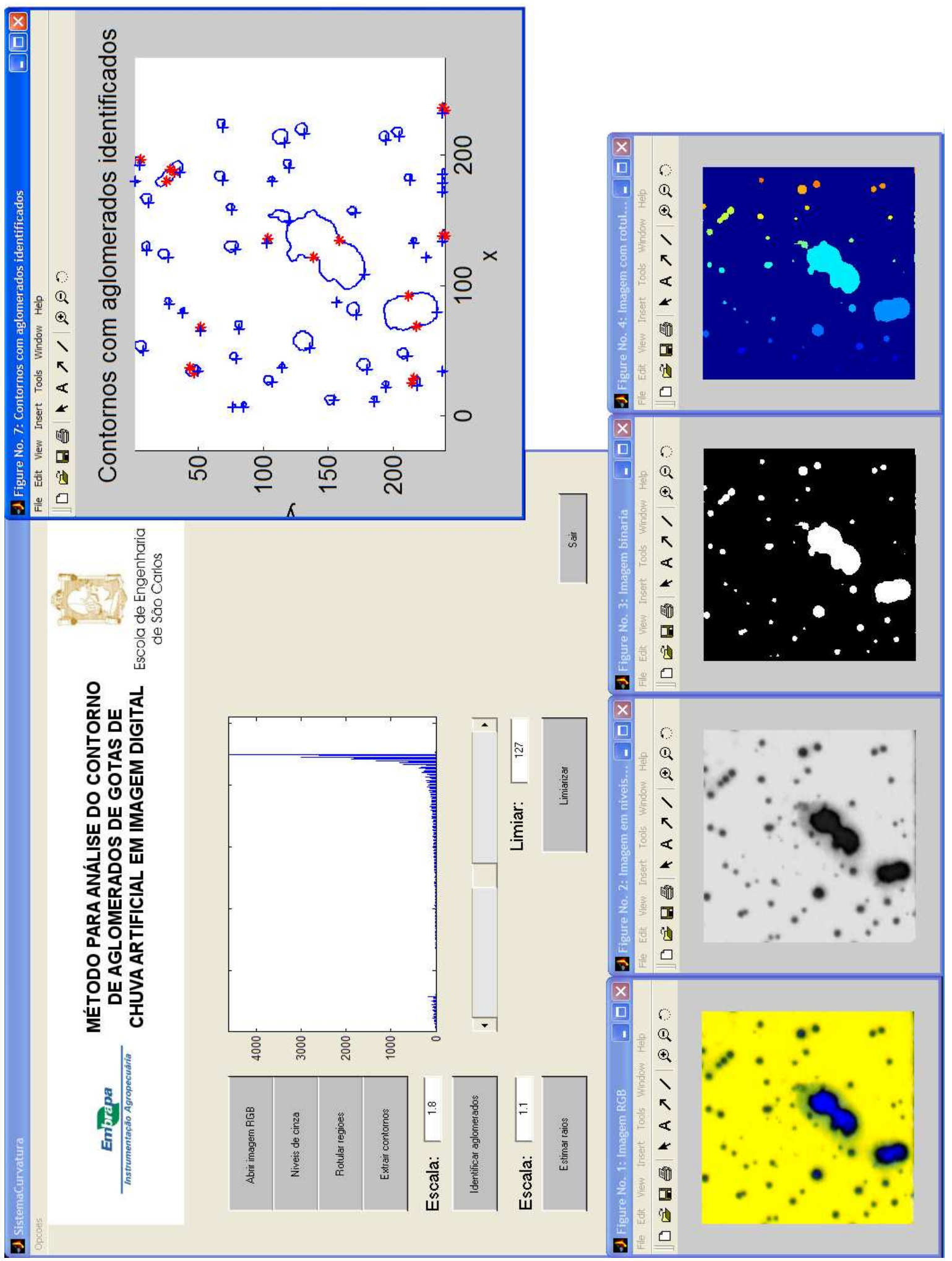

Figura 6.1: Interface com o usuário desenvolvida para a interação com as rotinas do método para análise do contorno de gotas de chuva artificial em imagem digital. 


\subsubsection{Rotinas implementadas}

A implementação das rotinas diretamente ligadas com o método para medida do volume de gotas realizada tem como entradas os parâmetros listados na tabela 6.1.

\begin{tabular}{|l|}
\hline Implementação do método para medida do volume de gotas \\
Parâmetros de entrada \\
\hline Imagem de papel hidrossensível \\
\hline Escala para quebra de aglomerados \\
\hline Escala para estimativa da curvatura \\
\hline
\end{tabular}

Tabela 6.1: Parâmetros de entrada da implementação do método para medida do volume de gotas.

A descrição dos parâmetros de entrada da implementação do método para medida do volume de gotas, se constituem na forma:

1. A imagem do papel hidrossensível deve ser quantizada em 24 bits de cor no modelo RGB constituindo o principal parâmetro;

2. A escala para quebra de aglomerados, será utilizada pelo método durante a identificação dos possíveis aglomerados que a imagem possa conter;

3. A escala para estimativa da curvatura, por sua vez será aplicada na estimativa da curvatura para o cálculo do raio médio das gotas.

Os resultados da implementação do método para medida do volume de gotas encontram-se listadas na tabela 6.2.

\begin{tabular}{|l|}
\hline $\begin{array}{l}\text { Implementação do método para medida do volume de gotas } \\
\text { Resultados }\end{array}$ \\
\hline Numero de aglomerados identificados \\
\hline Número de gotas identificadas em cada aglomerado \\
\hline Raio médio para cada gota identificada \\
\hline Imagens com regiões \\
\hline Contornos de aglomerados e gotas \\
\hline Pontos de quebra de aglomerados \\
\hline Curvaturas dos contornos \\
\hline
\end{tabular}

Tabela 6.2: Resultados da implementação do método para medida do volume de gotas.

A descrição dos resultados da implementação do método para medida do volume de gotas, se constituem na forma:

1. O numero de aglomerados identificados, refere-se ao número de regiões analisadas que foram identificadas como aglomerados de gotas pelo método;

2. O número de gotas identificadas em cada aglomerado, indica para cada uma das regiões o número de gotas que constituem o aglomerado;

3. O raio médio para cada gota identificada é retornado, tenham sido estas reconhecidas em aglomerados ou individualmente e é expresso em pixels; 
4. As imagens com regiões são partes da imagem original passada para processamento, sendo que cada uma dessas partes contem uma região identificada, podendo a mesma ser um aglomerado ou uma gota identificada individualmente;

5. Os Contornos de aglomerados e gotas retornados em conjunto com os pontos de quebra dos contornos, identificam cada trecho do contorno pertencente a uma gota;

6. Os pontos de quebra de aglomerados identificam os intervalos de cada contorno que pertencem a cada uma das gotas identificadas.

Uma das rotinas auxiliares implementadas permite a produção de padrões circulares mediante a entrada do raio em pixels que se deseja a criação do padrão, e seu retorno consiste no padrão circular desejado que é empregado na avaliação e calibração do método.

A partir da rotina auxiliar de produção de padrões circulares foi implementada uma rotina para a produção de aglomerados de padrões circulares. Os parâmetros de entrada dessa rotina consistem dos raios que constituem o aglomerado, bem como o percentual de aglomeração do mesmo. O percentual de aglomeração representa a porcentagem de sobreposição do diâmetro do menor padrão circular componente dos aglomerados e a figura 6.2 apresenta aglomerados com diferentes percentuais de aglomeração.

A rotina de estudo de precisão de medida tem seus parâmetros de entrada listados na tabela 6.3.

\begin{tabular}{|l|}
\hline Rotina para teste de precisão de medida \\
Parâmetros de entrada \\
\hline Faixa de níveis de ruído analisada \\
\hline Faixa de escalas para estimativa da curvatura analisada \\
\hline Faixa de raios analisada \\
\hline
\end{tabular}

Tabela 6.3: Parâmetros de entrada da rotina para teste de precisão de medida.

A descrição dos parâmetros de entrada da rotina para teste de precisão de medida, se constituem na forma:

1. A faixa de níveis de ruído analisada, identifica quais níveis de ruído serão aplicados durante a execução da rotina, este nível de ruído indica um valor de deslocamento máximo em pixels que um ponto do contorno pode sofrer, sendo que esse deslocamento é gerado por uma função geradora de valores randômicos, permitindo assim o teste da tolerância do método a possíveis imperfeições das formas analisadas;

Na figura 6.3, pode ser visto um padrão circular gerado pela rotina de estudo de precisão de medidas sem a inserção de ruído em seu contorno, apresentando uma forma de maior regularidade em relação a da figura 6.4 que por sua vez mostra um padrão circular gerado pela rotina de estudo de precisão de medidas com a inserção de ruído randômico com valor máximo de 3 pixels de deslocamento em seu contorno.

2. A faixa de escalas para estimativa da curvatura analisada representa os valores que assumidos durante a execução da rotina pelo parâmetro escala utilizado na estimativa da curvatura para a obtenção do raio médio de cada gota; 


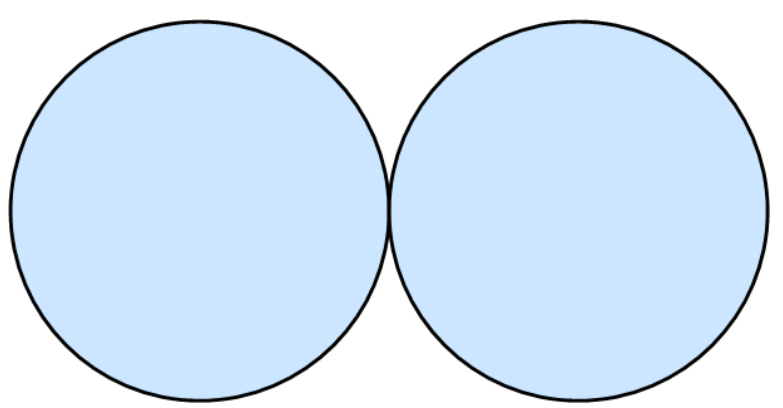

(a)

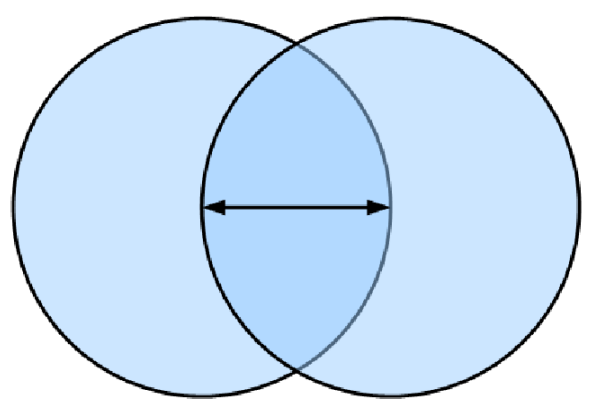

(c)

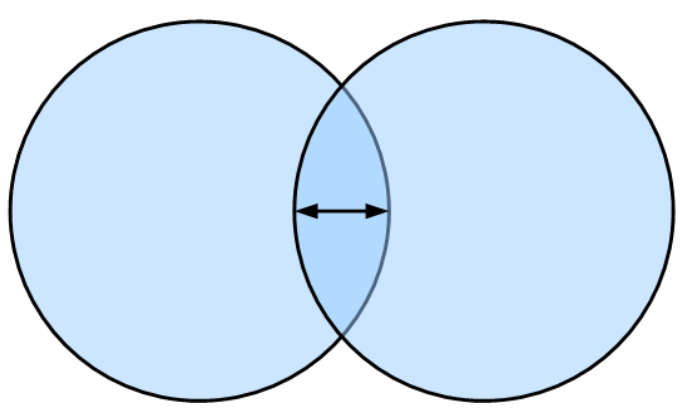

(b)

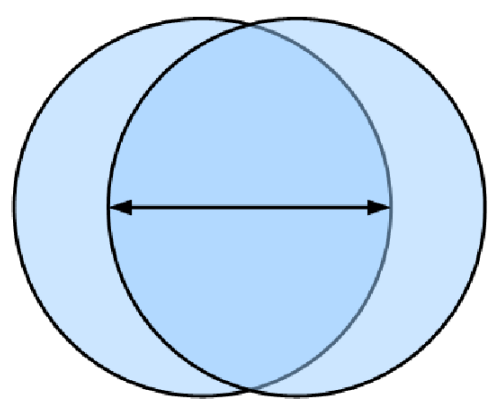

(d)

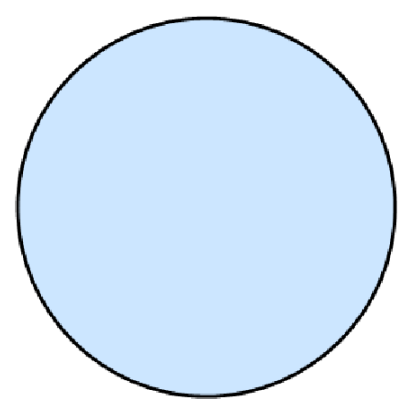

(e)

Figura 6.2: (a) Ilustração de aglomerados com percentual de aglomeração igual a 0 \%, (b) Ilustração de aglomerados com percentual de aglomeração igual a $25 \%$, (c) Ilustração de aglomerados com percentual de aglomeração igual a 50 \%, (d) Ilustração de aglomerados com percentual de aglomeração igual a 75 \%, (e) Ilustração de aglomerados com percentual de aglomeração igual a 100 \%. (O percentual de aglomeração é determinado em relação à sobreposição do diâmetro do menor padrão componente do aglomerado) 


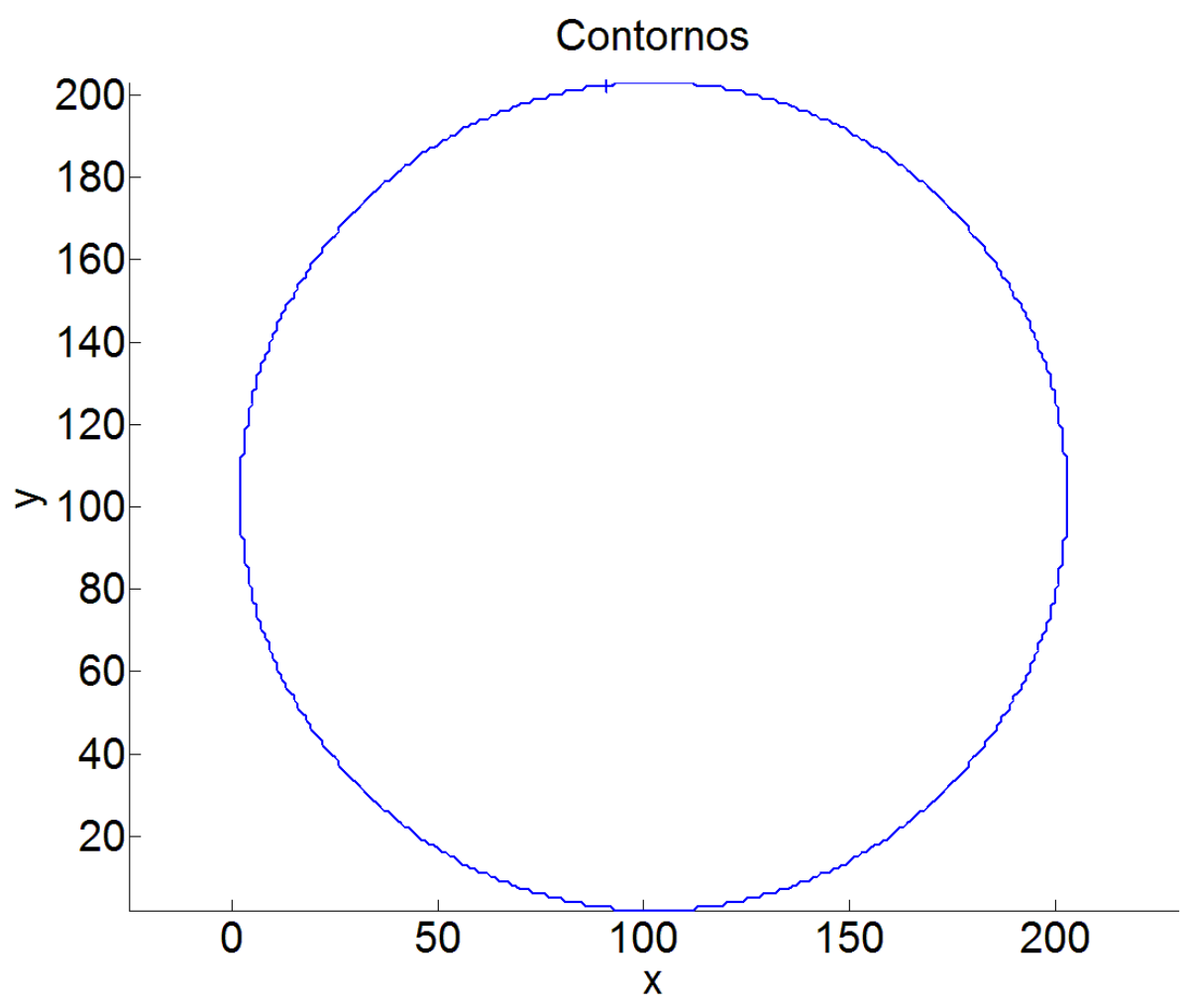

Figura 6.3: Padrão circular gerado pela rotina de estudo de precisão de medidas sem a inserção de ruído em seu contorno.

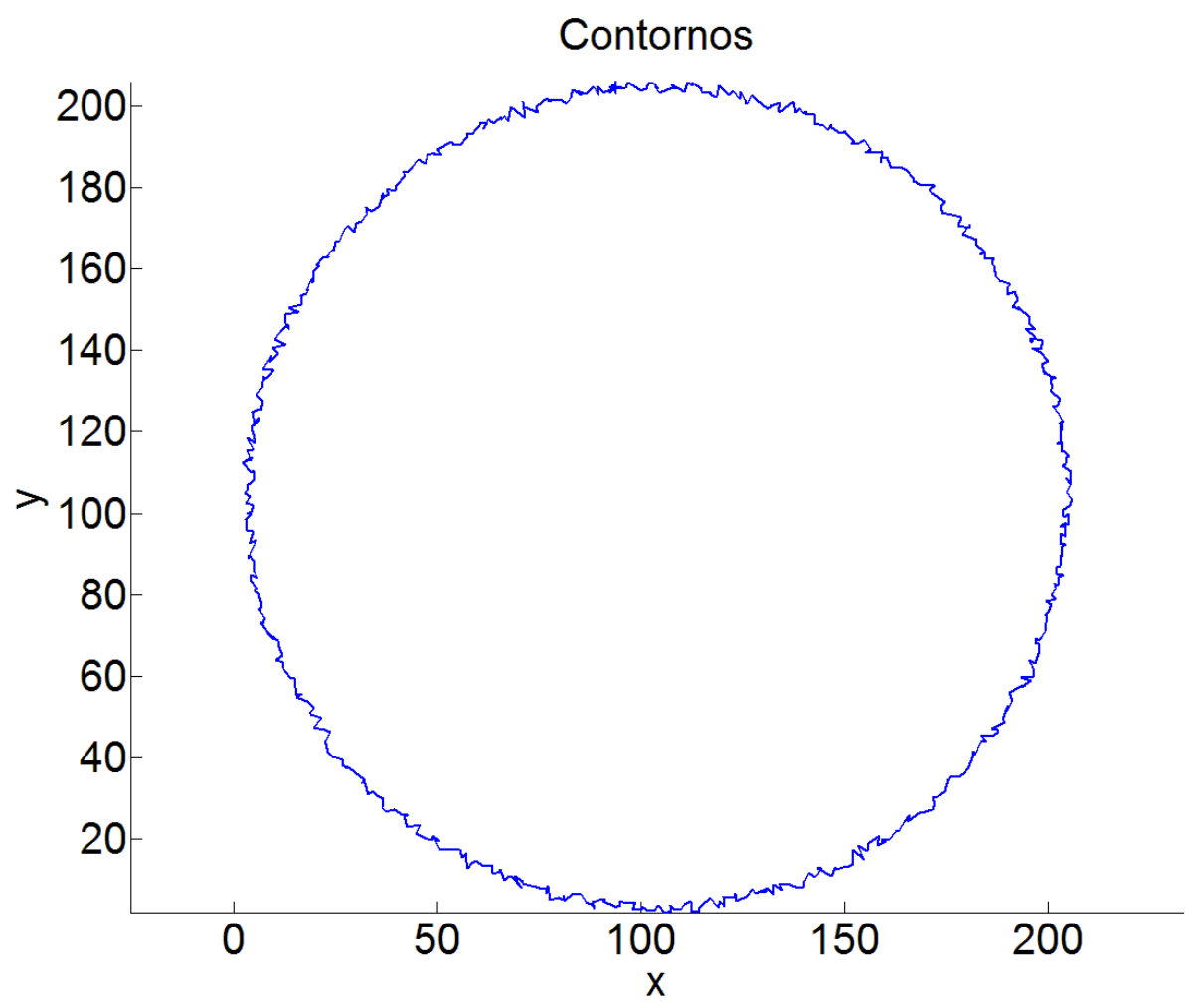

Figura 6.4: Padrão circular gerado pela rotina de estudo de precisão de medidas com a inserção de ruído randômico com valor máximo de 3 pixels de deslocamento em seu contorno. 
3. A faixa de raios analisada identifica os valores de raios de padrões circulares que serão produzidos e avaliados durante a execução da rotina e é expressa em pixels;

Os resultados retornados pela rotina de teste de precisão de medida encontram-se listadas na tabela 6.4 .

\begin{tabular}{|l|}
\hline $\begin{array}{l}\text { Rotina para teste de precisão de medida } \\
\text { Resultados }\end{array}$ \\
\hline Raio médio \\
\hline Erro de medida \\
\hline Maior erro \\
\hline Erro médio \\
\hline Escalas ordenadas pelo maior erro de medida \\
\hline Escalas ordenadas pelo erro médio de medida \\
\hline
\end{tabular}

Tabela 6.4: Resultados da rotina para teste de precisão de medida.

A descrição dos resultados da implementação da rotina para teste de precisão de medida, se constituem na forma:

1. O raio médio é retornado pela rotina para cada nível de ruído, escala e raios avaliados, sendo expresso em pixels;

2. O erro de medida indica quão distante foi a estimativa do raios médio em relação ao verdadeiro raio do padrão circular produzido, sendo retornado para cada nível de ruído, escala e raios avaliados;

3. O maior erro de medida é retornado para cada nível de ruído e escala;

4. O erro médio de medida é retornado para cada nível de ruído e escala;

5. A escalas ordenadas pelo maior erro de medida são retornadas para cada nível de ruído analisado, sendo uma informação bastante útil na identificação da escala adequada para estimativa da curvatura.

6. A escalas ordenadas pelo erro médio de medida são também retornadas para cada nível de ruído analisado, sendo uma informação utilizada na identificação da escala adequada para estimativa da curvatura.

A rotina para teste de identificação de aglomerados tem seus parâmetros de entrada listados na tabela 6.5.

A descrição dos parâmetros de entrada da rotina para teste de identificação de aglomerados, se constituem na forma:

1. A faixa de níveis de ruído analisada, identifica quais níveis de ruído serão aplicados durante a execução da rotina, este nível de ruído indica um valor de deslocamento máximo em pixels que um ponto do contorno pode sofrer, sendo que esse deslocamento é gerado por uma função geradora de valores randômicos, permitindo assim o teste da tolerância do método a possíveis imperfeições das formas analisadas; 


\begin{tabular}{|l|}
\hline $\begin{array}{l}\text { Rotina para teste de identificação de aglomerados } \\
\text { Parâmetros de entrada }\end{array}$ \\
\hline Faixa de níveis de ruído analisada \\
\hline Faixa de escalas para quebra de aglomerados analisada \\
\hline Faixa de percentuais de aglomeração analisada \\
\hline Faixa de raios analisada \\
\hline Escala para estimativa da curvatura analisada \\
\hline
\end{tabular}

Tabela 6.5: Parâmetros de entrada da rotina para teste de identificação de aglomerados.

2. A faixa de escalas para quebra de aglomerados analisada representa os valores que assumidos durante a execução da rotina o parâmetro escala ajusta a sensibilidade do método na identificação de aglomerados;

3. A faixa de raios analisada identifica os valores de raios de padrões circulares componentes dos aglomerados que serão produzidos e avaliados durante a execução da rotina e é expressa em pixels, os raios são combinados um a um durante a execução da rotina;

4. A faixa de percentuais de aglomeração analisada, representa os valores que serão assumidos na execução da rotina para produção dos aglomerados de padrões circulares que são produzidos, sendo este parâmetro compatível com o percentual de aglomeração da rotina de produção de aglomerados, identificando o percentual de raio sobreposto dos padrões circulares componentes do aglomerado;

5. A escala para estimativa da curvatura analisada representa o valor assumido durante a execução da rotina pelo parâmetro escala utilizado na estimativa da curvatura para a obtenção do raio médio de cada padrão circular componente dos aglomerados analisados;

A rotina para teste de identificação de aglomerados tem seus resultados listados na tabela 6.6 .

\begin{tabular}{|l|}
\hline $\begin{array}{l}\text { Rotina para teste de identificação de aglomerados } \\
\text { Resultados }\end{array}$ \\
\hline Número de aglomerados analisados \\
\hline Percentual de identificação de aglomerados \\
\hline Erro de medida por padrão circular \\
\hline Maiores erros de medida \\
\hline Erros médios de medida \\
\hline
\end{tabular}

Tabela 6.6: Resultados da rotina para teste de identificação de aglomerados.

A descrição dos resultados da rotina para teste de identificação de aglomerados, se constituem na forma:

1. O número de aglomerados analisados totaliza o número de combinação realizadas com os valores de raios utilizados na composição dos aglomerados analisados;

2. O percentual de identificação de aglomerados representa a correta identificação dos aglomerados analisados pelo método quanto ao número de gotas que os 
compõem, sendo retornado para cada nível de ruído, escala de identificação de aglomerados e percentual de aglomeração;

3. O erro de medida por padrão circular indica quão distante foi a estimativa do raios médio em relação aos verdadeiros raios dos padrões circulares componentes dos aglomerados sendo retornado para cada nível de ruído, escala e combinação de raios analisada;

4. Os maiores erros de medida são retornados para cada nível de ruído, escala e raios analisados;

5. Os erros médios de medida são retornados para cada nível de ruído, escala e raios analisados.

Os Erros de medida utilizados em todas as rotinas são definidos em função do Raio conhecido sendo este o utilizado na produção das formas analisadas e do raio caracterizado através da curvatura média, sendo descrito na forma:

$$
\text { Erro }=\frac{\mid \text { Raio conhecido }- \text { Raio caracterizado } \mid}{\text { Raio conhecido }}
$$

\subsubsection{Estudos realizados}

\section{Pimeiro estudo}

No primeiro estudo foram realizadas medidas de padrões circulares, sendo este estudo realizado com os parâmetros:

- Nível de ruído de com valores de 0 a 3 pixels, com variação de 1 pixel;

- Escalas com valores de 0,5 a 1,5, com variação de 0,1.

Para estes níveis de ruído foram testados os valores de raio apresentados na tabela 6.7

\begin{tabular}{|c|c|}
\hline Intervalo (pixels) & Variação (pixels) \\
\hline 1 a 9 & 1 \\
\hline 10 a 30 & 10 \\
\hline 31 а 39 & 1 \\
\hline 40 a 70 & 10 \\
\hline 71 a 79 & 1 \\
\hline 80 а 140 & 10 \\
\hline 141 а 149 & 1 \\
\hline 150 а 200 & 10 \\
\hline
\end{tabular}

Tabela 6.7: Valores de raios testados no primeiro estudo. 
Os valores de maior erro e erro médio, obtidos no primeiro estudo para os valores de escalas de 0,5 a 1,5, com a aplicação do nível de ruído zero, estão apresentados na tabela 6.8.

\begin{tabular}{rrrr}
\hline Escala & Maior erro & Erro médio & Desvio padrão \\
\hline 1,5 & 0,8032 & 0,0327 & 0,1131 \\
1,4 & 0,8180 & 0,0328 & 0,1150 \\
1,3 & 0,8328 & 0,0330 & 0,1169 \\
1,2 & 0,8474 & 0,0333 & 0,1188 \\
1,1 & 0,8616 & 0,0336 & 0,1207 \\
1,0 & 0,8754 & 0,0342 & 0,1226 \\
0,9 & 0,8885 & 0,0352 & 0,1246 \\
0,8 & 0,9007 & 0,0371 & 0,1275 \\
0,7 & 0,9120 & 0,0408 & 0,1341 \\
0,6 & 0,9222 & 0,0488 & 0,1576 \\
0,5 & 1,7866 & 0,0704 & 0,2677 \\
\hline
\end{tabular}

Tabela 6.8: Escalas, maiores erros e erros médios, para o valor nível de ruído zero encontrados no primeiro estudo.

Os valores de erros do primeiro estudo para cada raio analisado nas diferentes escalas, com a aplicação do nível de ruído zero, podem ser vistos na figura 6.5.

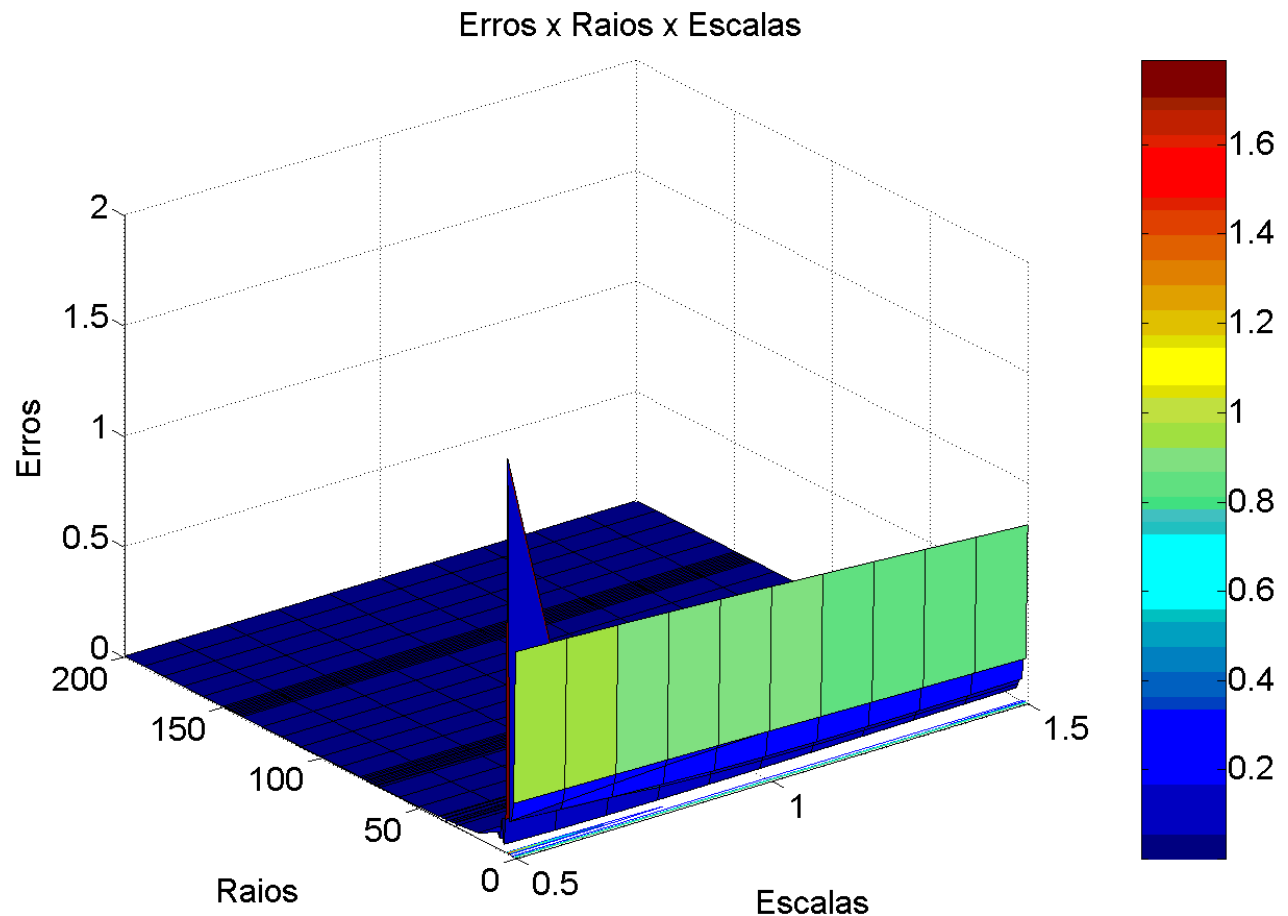

Figura 6.5: Gráfico com erros na medida do raio por escala, para o valor de nível de ruído 0 no primeiro estudo. 
Os valores de maior erro e erro médio, obtidos no primeiro estudo para os valores de escala de 0,5 a 1,5, com a aplicação do nível de ruído 1, estão apresentados na tabela 6.9 .

\begin{tabular}{rrrr}
\hline Escala & Maior erro & Erro médio & Desvio padrão \\
\hline 1,5 & 0,2326 & 0,0177 & 0,0437 \\
1,1 & 0,3540 & 0,0229 & 0,0614 \\
0,9 & 0,5549 & 0,0283 & 0,0850 \\
0,7 & 0,5886 & 0,0543 & 0,1371 \\
1,2 & 0,6646 & 0,0263 & 0,0918 \\
0,5 & 0,7082 & 0,0506 & 0,1284 \\
1,4 & 0,7162 & 0,0358 & 0,1243 \\
1,0 & 0,7380 & 0,0382 & 0,1296 \\
1,3 & 1,3139 & 0,0371 & 0,1760 \\
0,6 & 1,9751 & 0,0773 & 0,3143 \\
0,8 & 3,6414 & 0,1252 & 0,5534 \\
\hline
\end{tabular}

Tabela 6.9: Escalas, maiores erros e erros médios, para o valor nível de ruído 1 encontrados no primeiro estudo.

Os valores de erros do primeiro estudo para cada raio analisado nas diferentes escalas, com a aplicação do nível de ruído 1, podem ser vistos na figura 6.6.

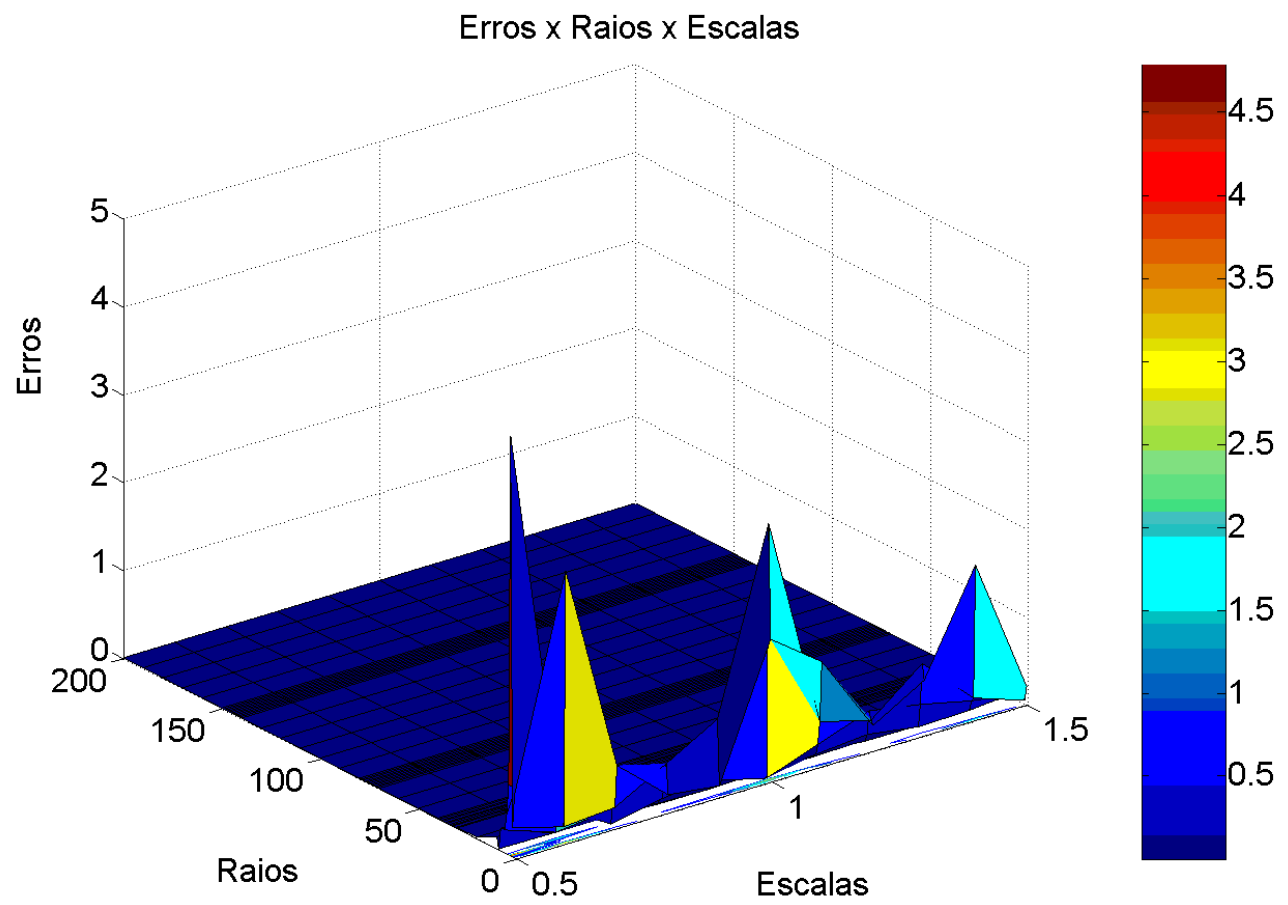

Figura 6.6: Gráfico com erros na medida do raio por escala, para o valor de nível de ruído 1 no primeiro estudo. 
Os valores de maior erro e erro médio, obtidos no primeiro estudo para os valores de escala de 0,5 a 1,5, com a aplicação do nível de ruído 2 , estão apresentados na tabela 6.10 .

\begin{tabular}{rrrr}
\hline Escala & Maior erro & Erro médio & Desvio padrão \\
\hline 1,5 & 1,0673 & 0,0459 & 0,1883 \\
0,8 & 1,6276 & 0,1198 & 0,3810 \\
1,4 & 2,0088 & 0,0481 & 0,2687 \\
1,3 & 2,1290 & 0,0934 & 0,3713 \\
1,2 & 2,1725 & 0,0890 & 0,3765 \\
1,0 & 5,5320 & 0,1568 & 0,7887 \\
1,1 & 8,0421 & 0,2409 & 1,1308 \\
0,7 & 9,1830 & 0,3289 & 1,3471 \\
0,5 & 16,6141 & 0,4434 & 2,2317 \\
0,6 & 105,3405 & 2,0783 & 14,0700 \\
0,9 & 186,0051 & 3,5966 & 24,8565 \\
\hline
\end{tabular}

Tabela 6.10: Escalas, maiores erros e erros médios para, o valor nível de ruído 2 encontrados no primeiro estudo.

Os valores de erros do primeiro estudo para cada raio analisado nas diferentes escalas, com a aplicação do nível de ruído 2, podem ser vistos na figura 6.7.

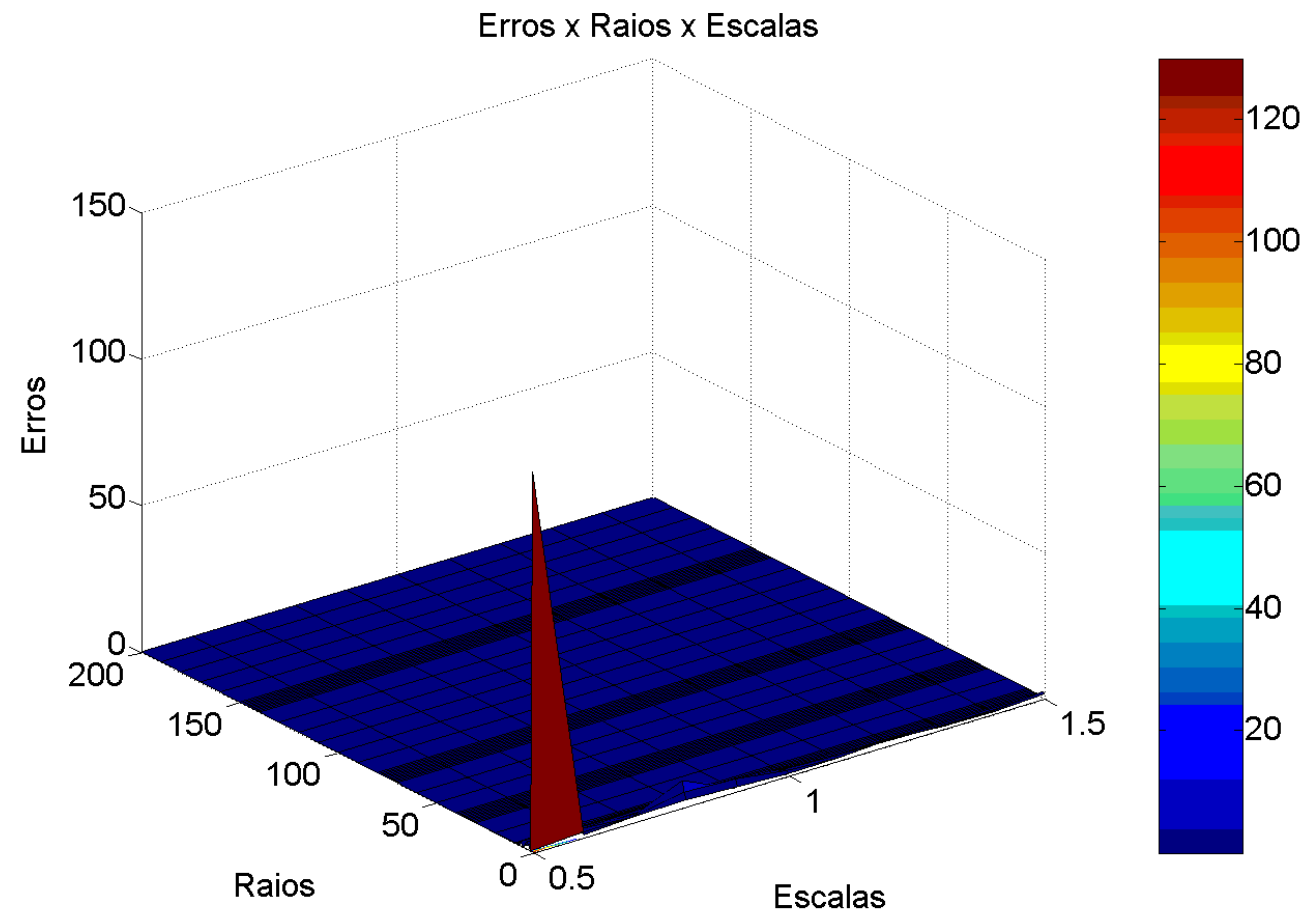

Figura 6.7: Gráfico com erros na medida do raio por escala, para o valor de nível de ruído 2 no primeiro estudo. 
Os valores de maior erro e erro médio, obtidos no primeiro estudo para os valores de escala de 0,5 a 1,5, com a aplicação do nível de ruído 3, estão apresentados na tabela 6.11 .

\begin{tabular}{rrrr}
\hline Escala & Maior erro & Erro médio & Desvio padrão \\
\hline 1,5 & 1,7930 & 0,0581 & 0,2590 \\
0,7 & 1,9977 & 0,1725 & 0,4552 \\
1,4 & 2,6647 & 0,0940 & 0,4232 \\
0,9 & 2,7160 & 0,1269 & 0,4294 \\
0,8 & 2,7775 & 0,1546 & 0,5194 \\
1,3 & 3,3871 & 0,1228 & 0,5041 \\
1,2 & 8,8065 & 0,3605 & 1,6430 \\
0,6 & 9,4394 & 0,3351 & 1,3410 \\
1,1 & 11,9202 & 0,2772 & 1,5970 \\
1,0 & 13,5099 & 0,3816 & 1,9209 \\
0,5 & 63,9356 & 1,3763 & 8,5371 \\
\hline
\end{tabular}

Tabela 6.11: Escalas, maiores erros e erros médios, para o valor nível de ruído 3 encontrados no primeiro estudo.

Os valores de erros do primeiro estudo para cada raio analisado nas diferentes escalas, com a aplicação do nível de ruído 3, podem ser vistos na figura 6.8.

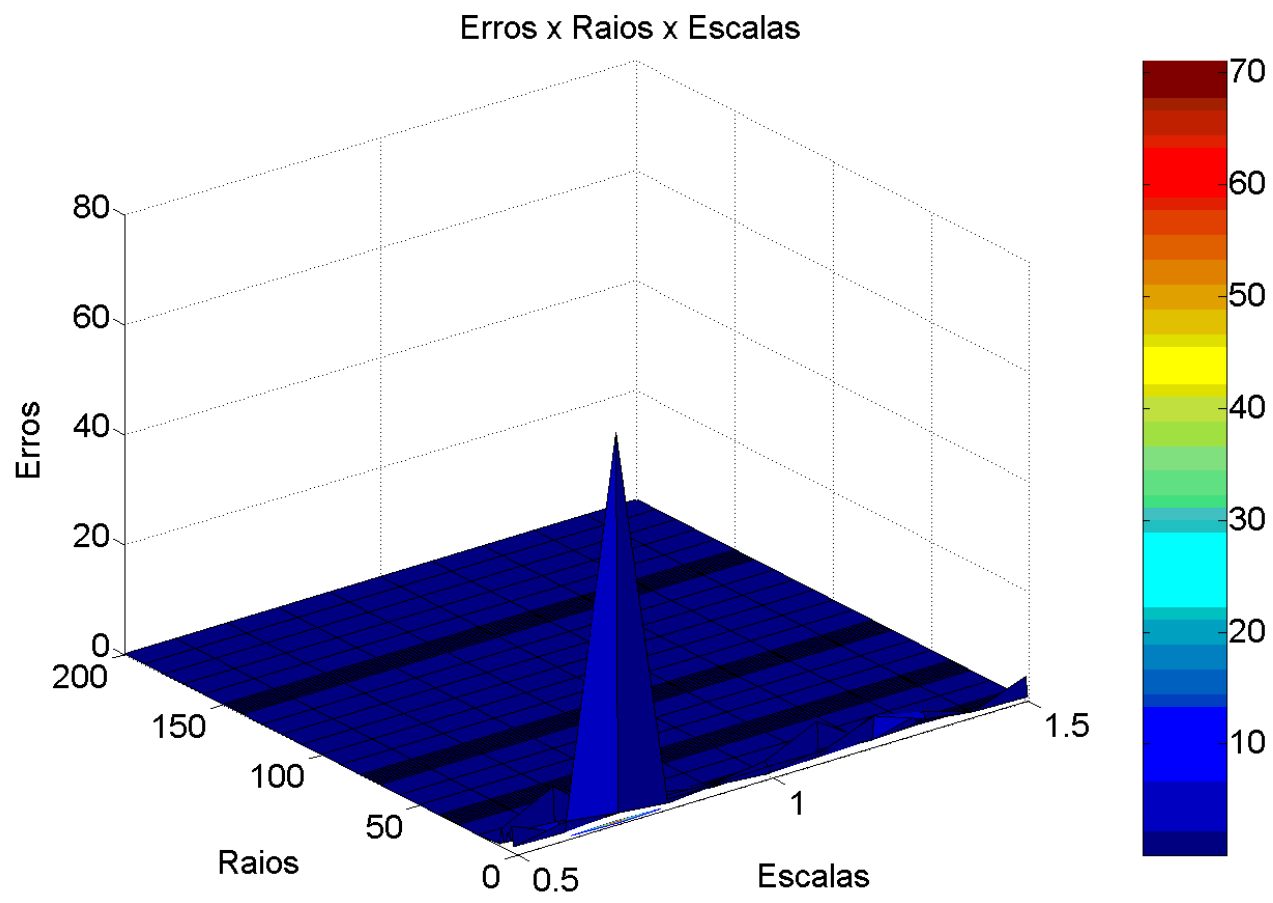

Figura 6.8: Gráfico com erros na medida do raio por escala, para o valor de nível de ruído 3 no primeiro estudo. 


\section{Segundo estudo}

No segundo estudo foram realizadas medidas de padrões circulares, sendo este estudo realizado com os parâmetros:

- Nível de ruído de com valores de 0 a 3 pixels, com variação de 1 pixel;

- Escalas com valores de 0.5 a 1,5 , com variação de 0,1 .

Para estes níveis de ruído foram testados os valores de raio apresentados na tabela 6.12

\begin{tabular}{|c|c|}
\hline Intervalo (pixels) & Variação (pixels) \\
\hline 10 a 30 & 10 \\
\hline 31 a 39 & 1 \\
\hline 40 a 70 & 10 \\
\hline 71 a 79 & 1 \\
\hline 80 a 140 & 10 \\
\hline 141 a 149 & 1 \\
\hline 150 a 200 & 10 \\
\hline
\end{tabular}

Tabela 6.12: Valores de raios testados no segundo estudo.

Os valores de maior erro e erro médio, obtidos no segundo estudo para os valores de escala de 0,5 a 1,5, com a aplicação do nível de ruído zero, estão apresentados na tabela 6.13.

\begin{tabular}{rrrr}
\hline Escala & Maior erro & Erro médio & Desvio padrão \\
\hline 1,1 & 0,0441 & 0,0046 & 0,0075 \\
1,0 & 0,0442 & 0,0047 & 0,0075 \\
1,2 & 0,0443 & 0,0046 & 0,0075 \\
1,3 & 0,0447 & 0,0046 & 0,0075 \\
0,9 & 0,0447 & 0,0049 & 0,0076 \\
1,4 & 0,0450 & 0,0046 & 0,0076 \\
1,5 & 0,0454 & 0,0046 & 0,0076 \\
0,8 & 0,0463 & 0,0051 & 0,0077 \\
0,7 & 0,0496 & 0,0054 & 0,0081 \\
0,6 & 0,0567 & 0,0058 & 0,0089 \\
0,5 & 0,0735 & 0,0063 & 0,0111 \\
\hline
\end{tabular}

Tabela 6.13: Escalas, maiores erros e erros médios, para o valor nível de ruído zero encontrados no segundo estudo. 
Os valores de erros do segundo estudo para cada raio analisado nas diferentes escalas, com a aplicação do nível de ruído zero, podem ser vistos na figura 6.9.

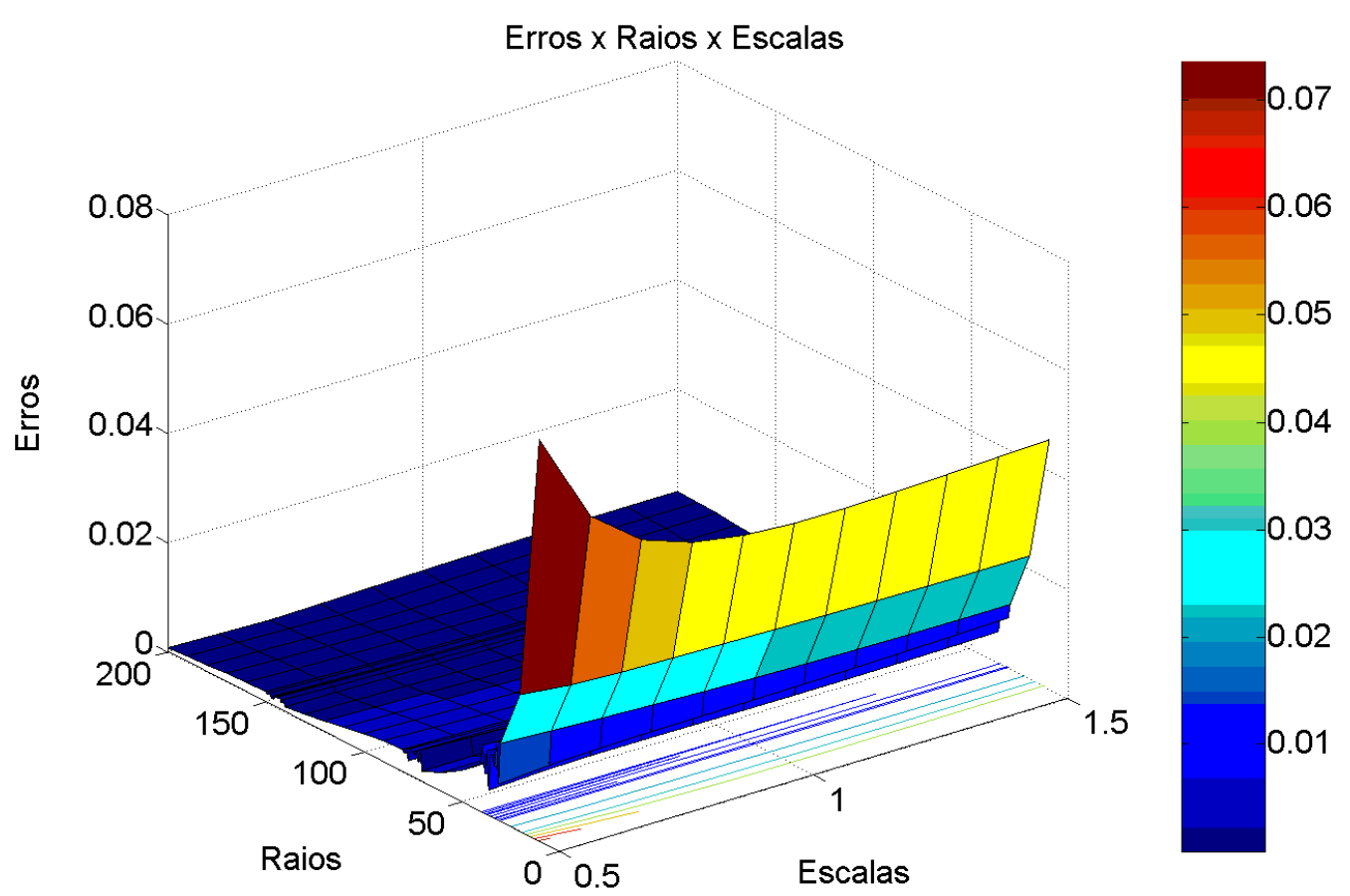

Figura 6.9: Gráfico com erros na medida do raio por escala, para o valor de nível de ruído 0 no segundo estudo.

Os valores de maior erro e erro médio, obtidos no segundo estudo para os valores de escala de 0,5 a 1,5, com a aplicação do nível de ruído 1, estão apresentados na tabela 6.14 .

\begin{tabular}{rrrr}
\hline Escala & Maior erro & Erro médio & Desvio padrão \\
\hline 0,7 & 0,0255 & 0,0047 & 0,0052 \\
0,9 & 0,0319 & 0,0044 & 0,0061 \\
1,2 & 0,0341 & 0,0042 & 0,0061 \\
1,1 & 0,0376 & 0,0044 & 0,0066 \\
0,6 & 0,0429 & 0,0053 & 0,0073 \\
1,3 & 0,0431 & 0,0045 & 0,0073 \\
1,5 & 0,0463 & 0,0046 & 0,0077 \\
0,8 & 0,0474 & 0,0050 & 0,0079 \\
1,4 & 0,0476 & 0,0046 & 0,0079 \\
1,0 & 0,0507 & 0,0049 & 0,0084 \\
0,5 & 0,3002 & 0,0104 & 0,0434 \\
\hline
\end{tabular}

Tabela 6.14: Escalas, maiores erros e erros médios, para o valor nível de ruído 1 encontrados no no segundo estudo. 
Os valores de erros do segundo estudo para cada raio analisado nas diferentes escalas, com a aplicação do nível de ruído 1, podem ser vistos na figura 6.10.

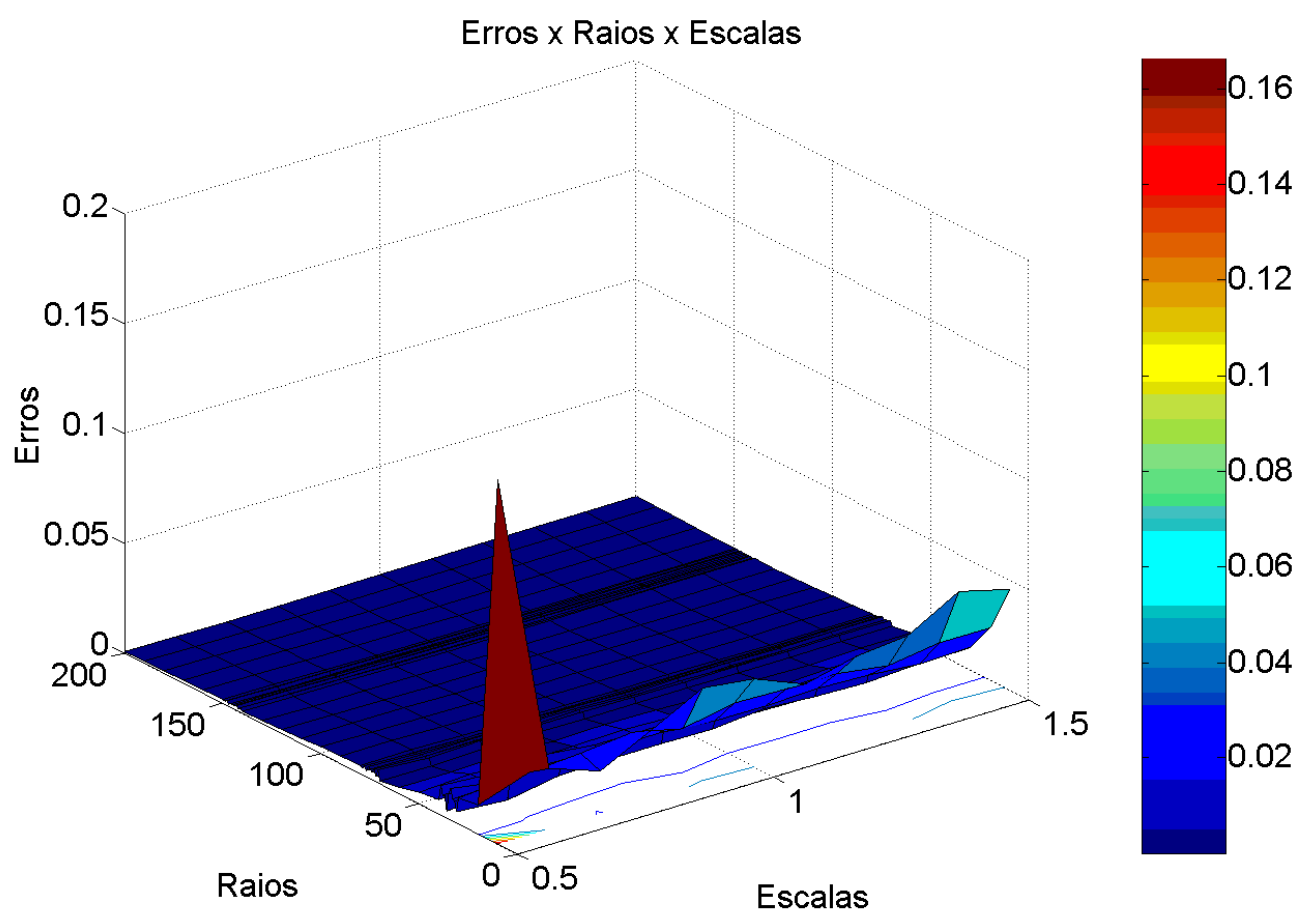

Figura 6.10: Gráfico com erros na medida do raio por escala, para o valor de nível de ruído 1 no segundo estudo.

Os valores de maior erro e erro médio, obtidos no segundo estudo para os valores de escala de 0,5 a 1,5, com a aplicação do nível de ruído 2 , estão apresentados na tabela 6.15 .

\begin{tabular}{rrrr}
\hline Escala & Maior erro & Erro médio & Desvio padrão \\
\hline 0,8 & 0,0150 & 0,0041 & 0,0043 \\
1,0 & 0,0232 & 0,0041 & 0,0050 \\
1,2 & 0,0338 & 0,0042 & 0,0062 \\
0,7 & 0,0340 & 0,0046 & 0,0062 \\
1,3 & 0,0354 & 0,0043 & 0,0065 \\
1,5 & 0,0432 & 0,0046 & 0,0074 \\
1,4 & 0,0557 & 0,0048 & 0,0090 \\
1,1 & 0,0737 & 0,0051 & 0,0111 \\
0,6 & 0,0835 & 0,0058 & 0,0121 \\
0,9 & 0,0866 & 0,0058 & 0,0131 \\
0,5 & 0,3565 & 0,0113 & 0,0516 \\
\hline
\end{tabular}

Tabela 6.15: Escalas, maiores erros e erros médios para, o valor nível de ruído 2 encontrados no segundo estudo. 
Os valores de erros do segundo estudo para cada raio analisado nas diferentes escalas, com a aplicação do nível de ruído 2, podem ser vistos na figura 6.11.

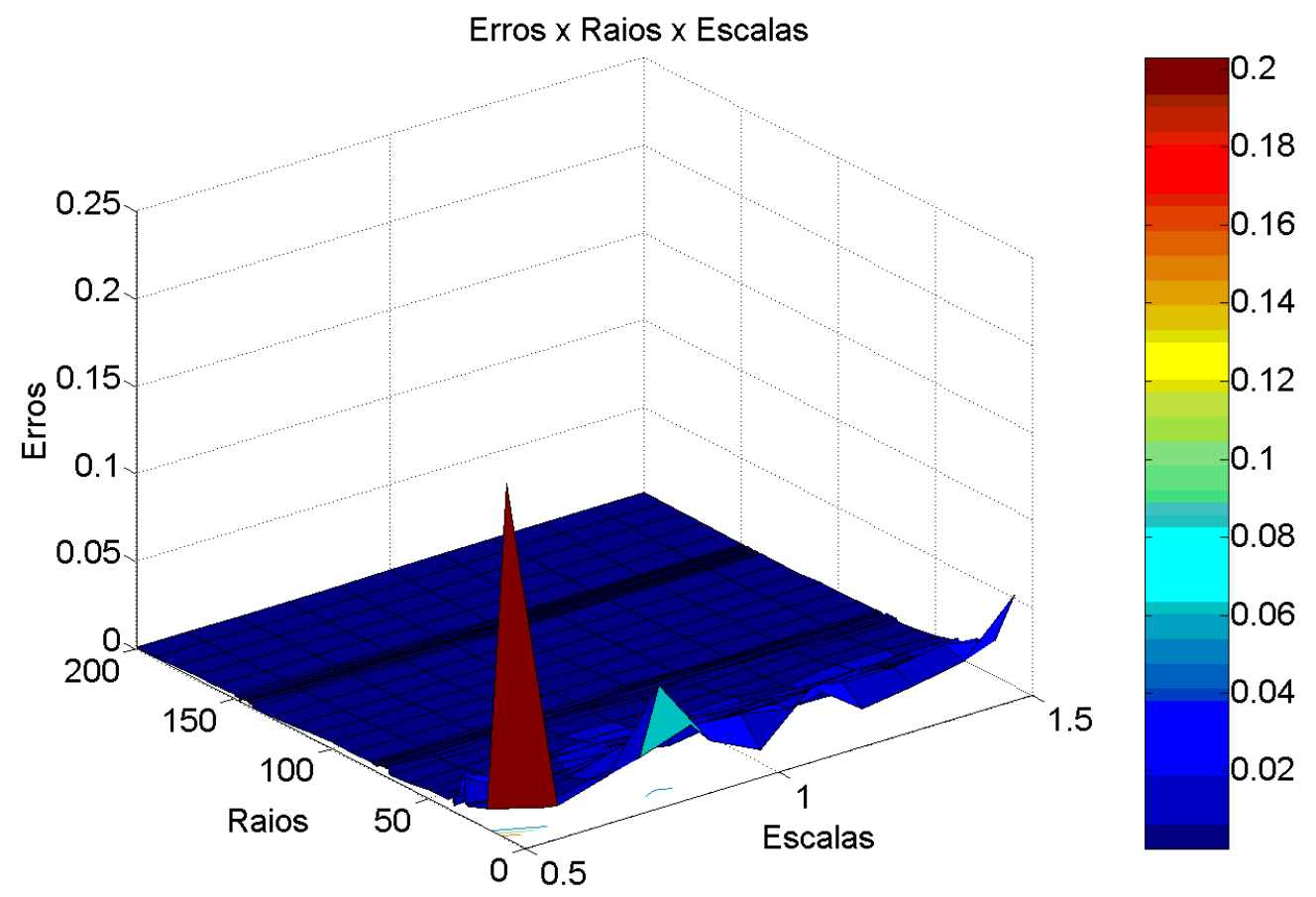

Figura 6.11: Gráfico com erros na medida do raio por escala, para o valor de nível de ruído 2 no segundo estudo.

Os valores de maior erro e erro médio, obtidos no segundo estudo para os valores de escala de 0,5 a 1,5, com a aplicação do nível de ruído 3, estão apresentados na tabela 6.16 .

\begin{tabular}{rrrr}
\hline Escala & Maior erro & Erro médio & Desvio padrão \\
\hline 0.9 & 0.0178 & 0.0034 & 0.0039 \\
1.5 & 0.0231 & 0.0039 & 0.0050 \\
1.4 & 0.0360 & 0.0044 & 0.0068 \\
1.3 & 0.0425 & 0.0043 & 0.0071 \\
0.8 & 0.0562 & 0.0052 & 0.0090 \\
1.0 & 0.0664 & 0.0050 & 0.0101 \\
0.7 & 0.0678 & 0.0055 & 0.0106 \\
1.1 & 0.0693 & 0.0051 & 0.0105 \\
1.2 & 0.0740 & 0.0053 & 0.0114 \\
0.6 & 0.2244 & 0.0097 & 0.0341 \\
0.5 & 0.7527 & 0.0218 & 0.1095 \\
\hline
\end{tabular}

Tabela 6.16: Escalas, maiores erros e erros médios, para o valor nível de ruído 3 encontrados no segundo estudo. 
Os valores de erros do segundo estudo para cada raio analisado nas diferentes escalas, com a aplicação do nível de ruído 3, podem ser vistos na figura 6.12.

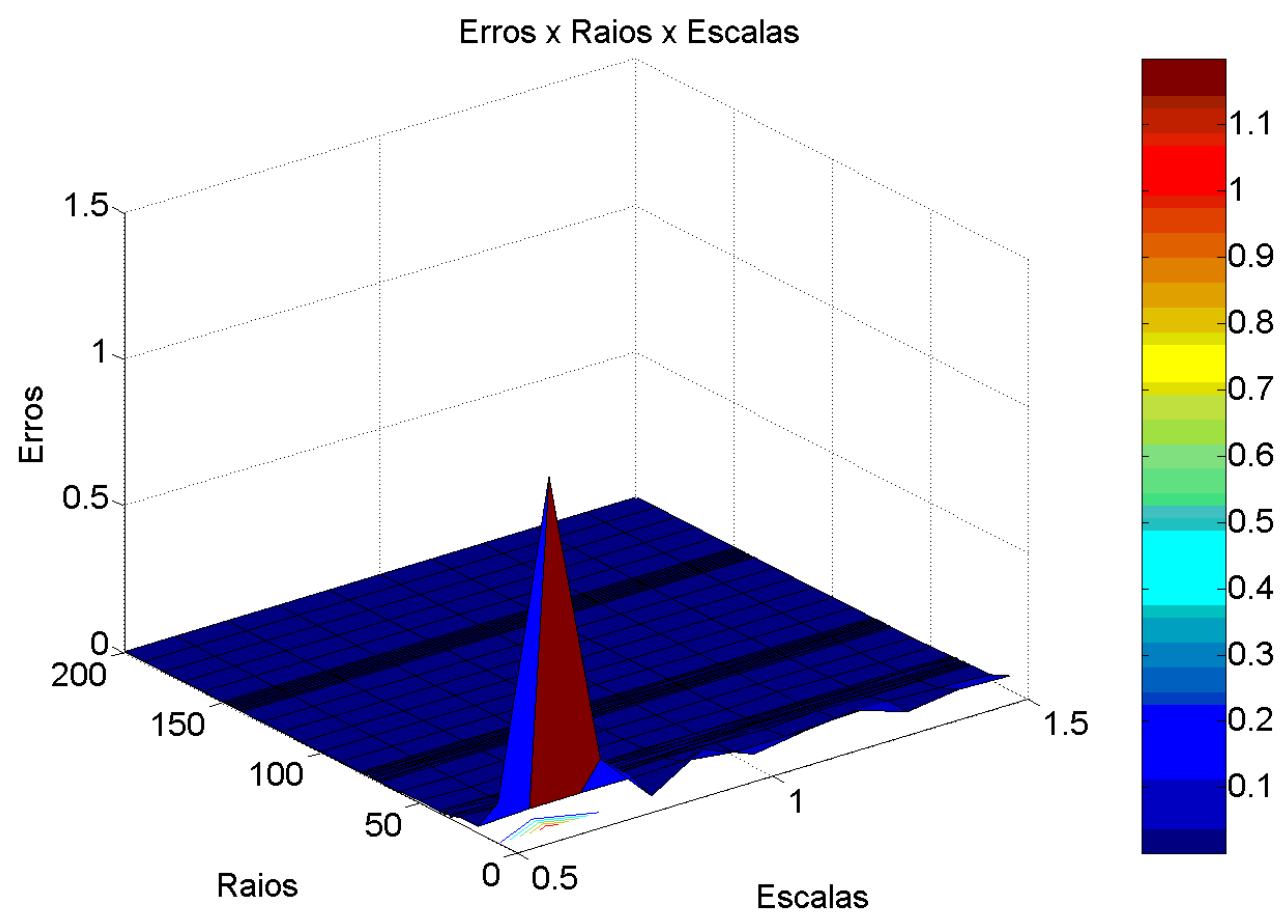

Figura 6.12: Gráfico com erros na medida do raio por escala, para o valor de nível de ruído 3 no segundo estudo.

O segundo estudo realizado difere do primeiro no fato de não incluir em suas análises os valores de raios menores que 10, o que permite uma melhor observação da variação do erro na caracterização dos raios, bem como a influência do nível de ruído inserido e do fator escala adotado, uma vez que os altos valores de erro dos menores raios ocultam os demais resultados.

\section{Terceiro estudo}

No terceiro estudo foram realizadas análises de aglomerados de padrões circulares, sendo este estudo realizado com os parâmetros:

- Escalas para quebra de aglomerados com valores de 0,5 a 1,5, com variação de 0,1

- Percentuais de aglomeração de 0 a 100, com variação de 25;

- Escala de medida igual a 1,1;

- Combinação de valores de raio de 10 a 100, com variação de 10. 
Nas tabelas de 6.17 a 6.27 , estão apresentados respectivamente para as escalas para quebra de aglomerados de 0,5 a 1,5, os percentuais de objetos que foram identificados como aglomerados, os valores de maior erro e erro médio, para cada raio quando existirem objetos identificados como aglomerados, sendo que estes resultados são apresentados para cada percentual de aglomeração.

\begin{tabular}{|c|c|c|c|c|c|c|c|}
\hline $\begin{array}{r}\text { Percentual } \\
\text { de } \\
\text { aglomeracão }\end{array}$ & $\begin{array}{r}\text { Reconhecido } \\
\text { como } \\
\text { aglomerado }\end{array}$ & $\begin{array}{r}\text { Maior } \\
\text { erro } \\
\text { raio } 1\end{array}$ & $\begin{array}{l}\text { Erro } \\
\text { médio } \\
\text { raio } 1\end{array}$ & $\begin{array}{l}\text { Desvio } \\
\text { padrão } \\
\text { raio } 2\end{array}$ & $\begin{array}{r}\text { Maior } \\
\text { erro } \\
\text { raio 2 }\end{array}$ & $\begin{array}{l}\text { Erro } \\
\text { médio } \\
\text { raio } 2\end{array}$ & $\begin{array}{l}\text { Desvio } \\
\text { padrão } \\
\text { raio } 2\end{array}$ \\
\hline $0 \%$ & $97 \%$ & 0,8952 & 0,2869 & 0,2841 & 9.0084 & 1,1936 & 1,6158 \\
\hline $25 \%$ & $100 \%$ & 1,0997 & 0,2627 & 0,2994 & 9,0264 & 1,1198 & 1,6816 \\
\hline $50 \%$ & $98 \%$ & 2,4605 & 0,3036 & 0,4033 & 9,0336 & 1,0476 & 1,7333 \\
\hline $75 \%$ & $96 \%$ & 5,2144 & 0,4310 & 0,7903 & 9,0374 & 0,9722 & 1,7461 \\
\hline $100 \%$ & $0 \%$ & - & 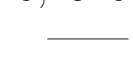 & 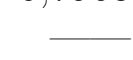 & 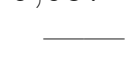 & $\underline{-}$ & 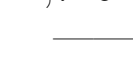 \\
\hline
\end{tabular}

Tabela 6.17: Percentuais de acerto na identificação dos aglomerados, valores dos maiores erros e erros médios da medida dos raios obtidos no terceiro estudo, para o valor de escala para quebra de aglomerados 0,5 .

\begin{tabular}{|c|c|c|c|c|c|c|c|}
\hline $\begin{array}{r}\text { Percentual } \\
\text { de } \\
\text { aglomeração }\end{array}$ & $\begin{array}{r}\text { Reconhecido } \\
\text { como } \\
\text { aglomerado }\end{array}$ & $\begin{array}{r}\text { Maior } \\
\text { erro } \\
\text { raio } 1\end{array}$ & $\begin{array}{r}\text { Erro } \\
\text { médio } \\
\text { raio } 1\end{array}$ & $\begin{array}{r}\text { Desvio } \\
\text { padrão } \\
\text { raio } 2\end{array}$ & $\begin{array}{r}\text { Maior } \\
\text { erro } \\
\text { raio } 2\end{array}$ & $\begin{array}{r}\text { Erro } \\
\text { médio } \\
\text { raio } 2\end{array}$ & $\begin{array}{r}\text { Desvio } \\
\text { padrão } \\
\text { raio } 2\end{array}$ \\
\hline $0 \%$ & $98 \%$ & 0,8950 & 0,2846 & 0,2835 & 9,0084 & 1,1752 & 1,6137 \\
\hline $25 \%$ & $100 \%$ & 1,0997 & 0,2626 & 0,2992 & 9,0264 & 1,1200 & 1,6820 \\
\hline $50 \%$ & $100 \%$ & 2,5513 & 0,3042 & 0,4067 & 9,0336 & 1,0422 & 1,7162 \\
\hline $75 \%$ & $100 \%$ & 5,2144 & 0,4217 & 0,7838 & 9,0404 & 0,9467 & 1,7171 \\
\hline $100 \%$ & $0 \%$ & - & - & - & - & - & - \\
\hline
\end{tabular}

Tabela 6.18: Percentuais de acerto na identificação dos aglomerados, valores dos maiores erros e erros médios da medida dos raios obtidos no terceiro estudo, para o valor de escala para quebra de aglomerados 0,6 .

\begin{tabular}{|c|c|c|c|c|c|c|c|}
\hline $\begin{array}{r}\text { Percentual } \\
\text { de } \\
\text { aglomeração }\end{array}$ & $\begin{array}{r}\text { Reconhecido } \\
\text { como } \\
\text { aglomerado }\end{array}$ & $\begin{array}{r}\text { Maior } \\
\text { erro } \\
\text { raio } 1\end{array}$ & $\begin{array}{r}\text { Erro } \\
\text { médio } \\
\text { raio } 1\end{array}$ & $\begin{array}{r}\text { Desvio } \\
\text { padrão } \\
\text { raio } 2\end{array}$ & $\begin{array}{r}\text { Maior } \\
\text { erro } \\
\text { raio 2 }\end{array}$ & $\begin{array}{r}\text { Erro } \\
\text { médio } \\
\text { raio } 2\end{array}$ & $\begin{array}{l}\text { Desvio } \\
\text { padrão } \\
\text { raio } 2\end{array}$ \\
\hline $0 \%$ & $99 \%$ & 0,8904 & 0,2813 & 0,2837 & 9,0084 & 1,1566 & 1,6117 \\
\hline $25 \%$ & $100 \%$ & 1,1789 & 0,2633 & 0,3014 & 9,0296 & 1,1207 & 1,6821 \\
\hline $50 \%$ & $100 \%$ & 2,5513 & 0,3061 & 0,4106 & 9,0367 & 1,0429 & 1,7148 \\
\hline $75 \%$ & $97 \%$ & 4,3944 & 0,3800 & 0,6379 & 8,0411 & 0,8799 & 1,5287 \\
\hline $100 \%$ & $0 \%$ & & & & & & \\
\hline
\end{tabular}

Tabela 6.19: Percentuais de acerto na identificação dos aglomerados, valores dos maiores erros e erros médios da medida dos raios obtidos no terceiro estudo, para o valor de escala para quebra de aglomerados 0,7 . 


\begin{tabular}{|c|c|c|c|c|c|c|c|}
\hline $\begin{array}{r}\text { Percentual } \\
\text { de } \\
\text { aglomeração }\end{array}$ & $\begin{array}{r}\text { Reconhecido } \\
\text { como } \\
\text { aglomerado }\end{array}$ & $\begin{array}{r}\text { Maior } \\
\text { erro } \\
\text { raio } 1\end{array}$ & $\begin{array}{l}\text { Erro } \\
\text { médio } \\
\text { raio } 1\end{array}$ & $\begin{array}{r}\text { Desvio } \\
\text { padrão } \\
\text { raio } 2\end{array}$ & $\begin{array}{r}\text { Maior } \\
\text { erro } \\
\text { raio } 2\end{array}$ & $\begin{array}{r}\text { Erro } \\
\text { médio } \\
\text { raio } 2\end{array}$ & $\begin{array}{l}\text { Desvio } \\
\text { padrão } \\
\text { raio } 2\end{array}$ \\
\hline $0 \%$ & $99 \%$ & 0,8904 & 0,2809 & 0,2838 & 9,0084 & 1,1500 & 1,6132 \\
\hline $25 \%$ & $100 \%$ & 1,1789 & 0,2635 & 0,3026 & 9,0296 & 1,1219 & 1,6824 \\
\hline $50 \%$ & $100 \%$ & 2,6513 & 0,3097 & 0,4222 & 9,0397 & 1,0414 & 1,7148 \\
\hline $75 \%$ & $93 \%$ & 2,5749 & 0,3063 & 0,3881 & 6,0307 & 0,7532 & 1,1973 \\
\hline $100 \%$ & $0 \%$ & & & & & & \\
\hline
\end{tabular}

Tabela 6.20: Percentuais de acerto na identificação dos aglomerados, valores dos maiores erros e erros médios da medida dos raios obtidos no terceiro estudo, para o valor de escala para quebra de aglomerados 0,8 .

\begin{tabular}{rrrrrrrr}
\hline $\begin{array}{r}\text { Percentual } \\
\text { de }\end{array}$ & $\begin{array}{r}\text { Reconhecido } \\
\text { como }\end{array}$ & $\begin{array}{r}\text { Maior } \\
\text { erro }\end{array}$ & $\begin{array}{r}\text { Erro } \\
\text { médio }\end{array}$ & $\begin{array}{r}\text { Desvio } \\
\text { padrão } \\
\text { aio 2 }\end{array}$ & $\begin{array}{r}\text { Maior } \\
\text { erro } \\
\text { raio 2 }\end{array}$ & $\begin{array}{r}\text { Erro } \\
\text { médio } \\
\text { raio 2 }\end{array}$ & $\begin{array}{r}\text { Desvio } \\
\text { padrão } \\
\text { raio 2 }\end{array}$ \\
aglomeração & aglomerado & raio 1 & raio 1 & raio & 1,1315 & 1,6110 \\
$25 \%$ & $100 \%$ & 0,8904 & 0,2780 & 0,2835 & 9,0116 & 1,131 \\
$50 \%$ & $100 \%$ & 1,2648 & 0,2646 & 0,3056 & 9,0327 & 1,1243 & 1,6821 \\
$75 \%$ & $100 \%$ & 2,7604 & 0,3130 & 0,4318 & 9,0427 & 1,0387 & 1,7142 \\
$100 \%$ & $89 \%$ & 1,1404 & 0,2617 & 0,2731 & 4,2141 & 0,6597 & 0,9746 \\
\hline
\end{tabular}

Tabela 6.21: Percentuais de acerto na identificação dos aglomerados, valores dos maiores erros e erros médios da medida dos raios obtidos no terceiro estudo, para o valor de escala para quebra de aglomerados 0,9 .

\begin{tabular}{rrrrrrrr}
\hline $\begin{array}{r}\text { Percentual } \\
\text { de }\end{array}$ & $\begin{array}{r}\text { Reconhecido } \\
\text { como }\end{array}$ & $\begin{array}{r}\text { Maior } \\
\text { erro }\end{array}$ & $\begin{array}{r}\text { Erro } \\
\text { médio } \\
\text { aglo }\end{array}$ & $\begin{array}{r}\text { Desvio } \\
\text { padrão } \\
\text { raio 2 }\end{array}$ & $\begin{array}{r}\text { Maior } \\
\text { erro } \\
\text { raio 2 }\end{array}$ & $\begin{array}{r}\text { Erro } \\
\text { médio } \\
\text { raio 2 }\end{array}$ & $\begin{array}{r}\text { Desvio } \\
\text { padrão } \\
\text { raio 2 }\end{array}$ \\
\hline $0 \%$ & $100 \%$ & 0,8901 & 0,2781 & 0,2832 & 9,0116 & 1,1256 & 1,6125 \\
$25 \%$ & $100 \%$ & 1,3577 & 0,2669 & 0,3095 & 9,0357 & 1,1237 & 1,6824 \\
$50 \%$ & $98 \%$ & 2,1902 & 0,2872 & 0,3621 & 8,4009 & 0,9700 & 1,5405 \\
$75 \%$ & $83 \%$ & 0,6448 & 0,2224 & 0,2285 & 3,2013 & 0,5582 & 0,7647 \\
$100 \%$ & $0 \%$ & - & - & - & - & - & \\
\hline
\end{tabular}

Tabela 6.22: Percentuais de acerto na identificação dos aglomerados, valores dos maiores erros e erros médios da medida dos raios obtidos no terceiro estudo, para o valor de escala para quebra de aglomerados 1,0.

\begin{tabular}{|c|c|c|c|c|c|c|c|}
\hline $\begin{array}{r}\text { Percentual } \\
\text { de } \\
\text { aglomeração }\end{array}$ & $\begin{array}{r}\text { Reconhecido } \\
\text { como } \\
\text { aglomerado }\end{array}$ & $\begin{array}{r}\text { Maior } \\
\text { erro } \\
\text { raio } 1\end{array}$ & $\begin{array}{r}\text { Erro } \\
\text { médio } \\
\text { raio } 1\end{array}$ & $\begin{array}{r}\text { Desvio } \\
\text { padrão } \\
\text { raio } 2\end{array}$ & $\begin{array}{r}\text { Maior } \\
\text { erro } \\
\text { raio 2 }\end{array}$ & $\begin{array}{l}\text { Erro } \\
\text { médio } \\
\text { raio } 2\end{array}$ & $\begin{array}{r}\text { Desvio } \\
\text { padrão } \\
\text { raio } 2\end{array}$ \\
\hline $0 \%$ & $100 \%$ & 0,8854 & 0,2781 & 0,2828 & 9,0149 & 1,1222 & 1,6132 \\
\hline $25 \%$ & $100 \%$ & 1,4576 & 0,2694 & 0,3149 & 9,0388 & 1,1286 & 1,6941 \\
\hline $50 \%$ & $96 \%$ & 1,6896 & 0,2658 & 0,3135 & 7,0527 & 0,9020 & 1,3540 \\
\hline $75 \%$ & $77 \%$ & 0,6089 & 0,1950 & 0,2131 & 2,5102 & 0,4814 & 0,6164 \\
\hline $100 \%$ & $0 \%$ & & & & & & 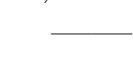 \\
\hline
\end{tabular}

Tabela 6.23: Percentuais de acerto na identificação dos aglomerados, valores dos maiores erros e erros médios da medida dos raios obtidos no terceiro estudo, para o valor de escala para quebra de aglomerados 1,1 . 


\begin{tabular}{rrrrrrrr}
\hline $\begin{array}{r}\text { Percentual } \\
\text { de }\end{array}$ & $\begin{array}{r}\text { Reconhecido } \\
\text { como }\end{array}$ & $\begin{array}{r}\text { Maior } \\
\text { erro }\end{array}$ & $\begin{array}{r}\text { Erro } \\
\text { médio }\end{array}$ & $\begin{array}{r}\text { Desvio } \\
\text { padrão } \\
\text { raio 2 }\end{array}$ & $\begin{array}{r}\text { Maior } \\
\text { erro } \\
\text { raio 2 }\end{array}$ & $\begin{array}{r}\text { Erro } \\
\text { médio } \\
\text { raio 2 }\end{array}$ & $\begin{array}{r}\text { Desvio } \\
\text { padrão } \\
\text { raio 2 }\end{array}$ \\
\hline aglomeração & aglomerado & raio 1 & raio 1 & raio & 1,28140 \\
$25 \%$ & $100 \%$ & 0,8848 & 0,2780 & 0,2827 & 9,0149 & 1,1212 & 1,6140 \\
$50 \%$ & $100 \%$ & 1,4576 & 0,2697 & 0,3149 & 9,0388 & 1,1423 & 1,7183 \\
$75 \%$ & $92 \%$ & 0,7192 & 0,2332 & 0,2586 & 5,0527 & 0,7915 & 1,0829 \\
$100 \%$ & $59 \%$ & 0,5822 & 0,1877 & 0,1993 & 2,1966 & 0,4309 & 0,4904 \\
\hline
\end{tabular}

Tabela 6.24: Percentuais de acerto na identificação dos aglomerados, valores dos maiores erros e erros médios da medida dos raios obtidos no terceiro estudo, para o valor de escala para quebra de aglomerados 1,2 .

\begin{tabular}{|c|c|c|c|c|c|c|c|}
\hline $\begin{array}{r}\text { Percentual } \\
\text { de }\end{array}$ & $\begin{array}{r}\text { Reconhecido } \\
\text { como }\end{array}$ & $\begin{array}{r}\text { Maior } \\
\text { erro }\end{array}$ & $\begin{array}{r}\text { Erro } \\
\text { médio }\end{array}$ & $\begin{array}{l}\text { Desvio } \\
\text { padrão }\end{array}$ & $\begin{array}{r}\text { Maior } \\
\text { erro }\end{array}$ & $\begin{array}{r}\text { Erro } \\
\text { médio }\end{array}$ & $\begin{array}{l}\text { Desvio } \\
\text { padrão }\end{array}$ \\
\hline aglomeração & aglomerado & raio 1 & raio 1 & raio 2 & raio 2 & raio 2 & raio 2 \\
\hline $0 \%$ & $100 \%$ & 0,8798 & 0,2786 & 0,2820 & 9,0181 & 1,1188 & 1,6152 \\
\hline $25 \%$ & $98 \%$ & 1,0380 & 0,2548 & 0,2921 & 8,5669 & 1,0751 & 1,5577 \\
\hline $50 \%$ & $90 \%$ & 0,7103 & 0,2234 & 0,2511 & 4,3542 & 0,7511 & 0,9992 \\
\hline $75 \%$ & $20 \%$ & 0,4069 & 0,1309 & 0,1362 & 0,7873 & 0,2717 & 0,2154 \\
\hline $100 \%$ & $0 \%$ & - & - & & - & - & \\
\hline
\end{tabular}

Tabela 6.25: Percentuais de acerto na identificação dos aglomerados, valores dos maiores erros e erros médios da medida dos raios obtidos no terceiro estudo, para o valor de escala para quebra de aglomerados 1,3.

\begin{tabular}{rrrrrrrr}
\hline $\begin{array}{r}\text { Percentual } \\
\text { de }\end{array}$ & $\begin{array}{r}\text { Reconhecido } \\
\text { como }\end{array}$ & $\begin{array}{r}\text { Maior } \\
\text { erro }\end{array}$ & $\begin{array}{r}\text { Erro } \\
\text { médio } \\
\text { aglo }\end{array}$ & $\begin{array}{r}\text { Desvio } \\
\text { padrão } \\
\text { raio 2 }\end{array}$ & $\begin{array}{r}\text { Maior } \\
\text { erro } \\
\text { raio 2 }\end{array}$ & $\begin{array}{r}\text { Erro } \\
\text { médio } \\
\text { raio 2 }\end{array}$ & $\begin{array}{r}\text { Desvio } \\
\text { padrão } \\
\text { raio 2 }\end{array}$ \\
\hline $0 \%$ & $100 \%$ & 0,8798 & 0,2781 & 0,2821 & 9,0214 & 1,1191 & 1,6167 \\
$25 \%$ & $96 \%$ & 0,8073 & 0,2421 & 0,2797 & 7,0478 & 1,0007 & 1,3622 \\
$50 \%$ & $90 \%$ & 0,7103 & 0,2235 & 0,2506 & 4,3409 & 0,7490 & 1,0059 \\
$75 \%$ & $0 \%$ & - & - & - & - & - & - \\
$100 \%$ & $0 \%$ & - & - & - & - & - & - \\
\hline
\end{tabular}

Tabela 6.26: Percentuais de acerto na identificação dos aglomerados, valores dos maiores erros e erros médios da medida dos raios obtidos no terceiro estudo, para o valor de escala para quebra de aglomerados 1,4 .

\begin{tabular}{|c|c|c|c|c|c|c|c|}
\hline $\begin{array}{r}\text { Percentual } \\
\text { de } \\
\text { aglomeração }\end{array}$ & $\begin{array}{r}\text { Reconhecido } \\
\text { como } \\
\text { aglomerado }\end{array}$ & $\begin{array}{r}\text { Maior } \\
\text { erro } \\
\text { raio } 1\end{array}$ & $\begin{array}{r}\text { Erro } \\
\text { médio } \\
\text { raio } 1\end{array}$ & $\begin{array}{r}\text { Desvio } \\
\text { padrão } \\
\text { raio } 2\end{array}$ & $\begin{array}{r}\text { Maior } \\
\text { erro } \\
\text { raio } 2\end{array}$ & $\begin{array}{r}\text { Erro } \\
\text { médio } \\
\text { raio } 2\end{array}$ & $\begin{array}{r}\text { Desvio } \\
\text { padrão } \\
\text { raio } 2\end{array}$ \\
\hline $0 \%$ & $100 \%$ & 0,8738 & 0,2788 & 0,2817 & 9,0246 & 1,1193 & 1,6171 \\
\hline $25 \%$ & $94 \%$ & 0,7967 & 0,2314 & 0,2712 & 6,0264 & 0,9389 & 1,2157 \\
\hline $50 \%$ & $84 \%$ & 0,7000 & 0,2004 & 0,2375 & 3,3095 & 0,6424 & 0,7876 \\
\hline $75 \%$ & $0 \%$ & & & & & & \\
\hline $100 \%$ & $0 \%$ & - & - & ${ }^{-}$ & 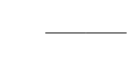 & - & 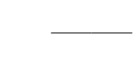 \\
\hline
\end{tabular}

Tabela 6.27: Percentuais de acerto na identificação dos aglomerados, valores dos maiores erros e erros médios da medida dos raios obtidos no terceiro estudo, para o valor de escala para quebra de aglomerados 1,5. 
A figura 6.13, ilustra o aspecto predominante dos gráficos de erro, da estimativa do raio dos padrões circulares, dos aglomerados avaliados no terceiro estudo. Ao analisar os valores de erro na figura, percebe-se que os maiores valores de erro se concentraram, nas combinações com maior diferença entre os valores de raios dos padrões circulares componentes do aglomerado, enquanto o erro na medida dos aglomerados, para valores de raios semelhantes manteve-se em patamares menores.

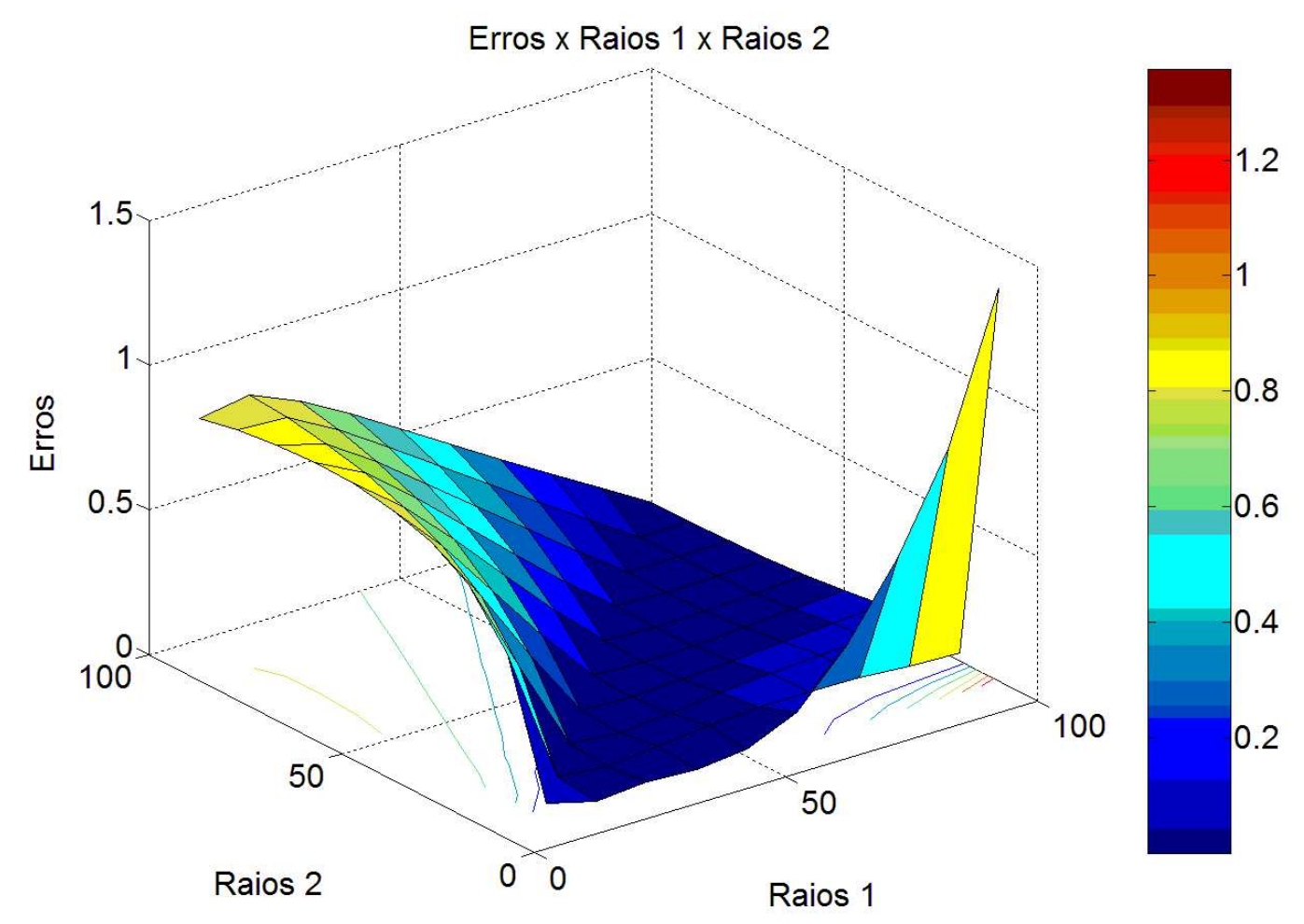

Figura 6.13: Aspecto predominante dos gráficos de erro da estimativa do raio, realizada com aglomerados no terceiro estudo.

\subsubsection{Estudo de caso com imagens de gotas reais}

Como estudo de caso o método desenvolvido foi aplicado em vinte e sete amostras de 1 $\mathrm{cm}^{2}$ provenientes de imagens de nove papéis hidrossensíveis, as marcas de gotas nestes papéis foram obtidas a partir de sua exposição a um sistema de irrigação por aspersão o que forneceu tipos variados de gotas para as análises.

A digitalização das amostras foi realizada com uso de um scanner configurado para a resolução de 300 DPI.

A aplicação do método permitiu a obtenção dos histogramas das distribuições dos tamanhos das gotas, bem como o cálculo do DMV e DMN das amostras.

Seguem os resultados das análises realizadas nas amostras do papel hidrossensível \#1 como exemplo, sendo que os demais resultados das análises realizadas nos demais papéis podem ser encontradas no apêndice D. 


\section{Estudo de caso com amostras do papel hidrossensível \#1}

\section{Primeira amostra}

A figura 6.14 apresenta a imagem da primeira amostra do primeiro papel hidrossensível, ampliada 5 vezes em relação ao seu tamanho original.

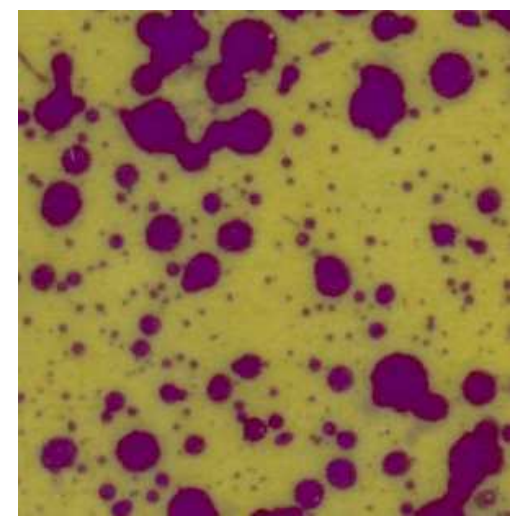

Figura 6.14: Primeira amostra do primeiro papel hidrossensível, ampliada 5 vezes em relação ao seu tamanho original.

Na figura 6.15 pode ser visto o histograma apresentando a distribuição dos tamanhos das gotas contidas na primeira amostra do primeiro papel hidrossensível.

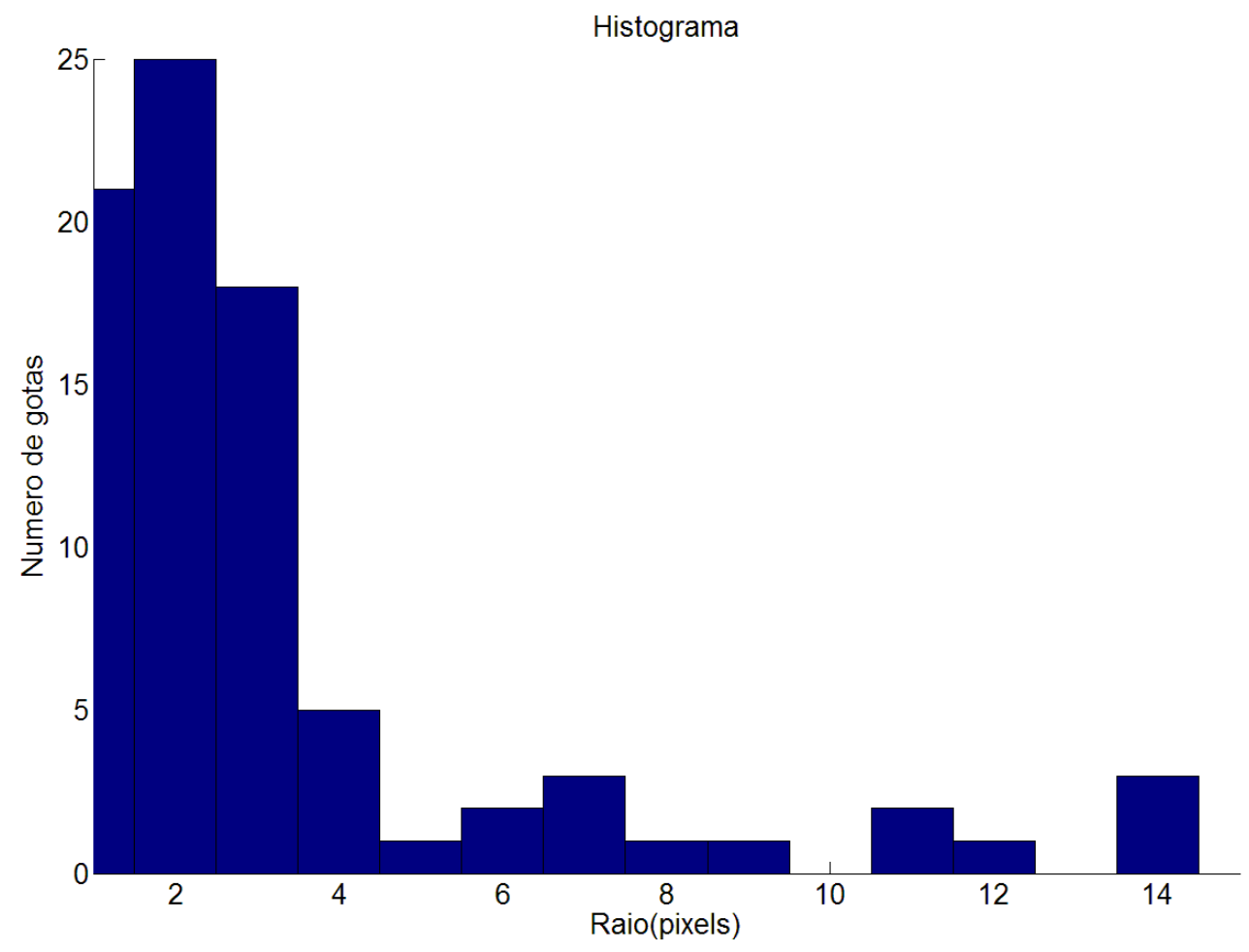

Figura 6.15: Histograma apresentando a distribuição dos tamanhos das gotas contidas na primeira amostra do primeiro papel hidrossensível. 


\section{Segunda amostra}

A figura 6.16 apresenta a imagem da segunda amostra do primeiro papel hidrossensível, ampliada 5 vezes em relação ao seu tamanho original.

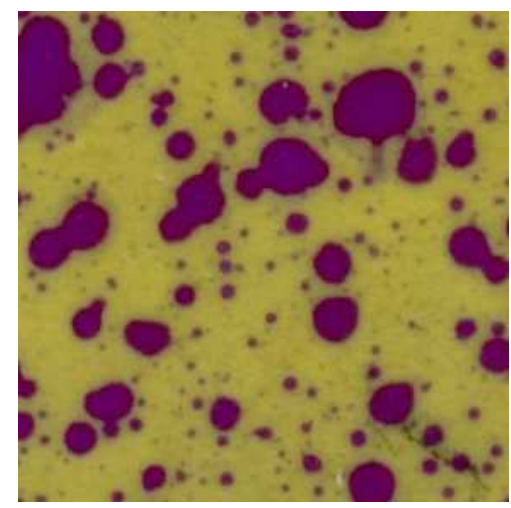

Figura 6.16: Segunda amostra do primeiro papel hidrossensível, ampliada 5 vezes em relação ao seu tamanho original.

Na figura 6.17 pode ser visto o histograma apresentando a distribuição dos tamanhos das gotas contidas na segunda amostra do primeiro papel hidrossensível.

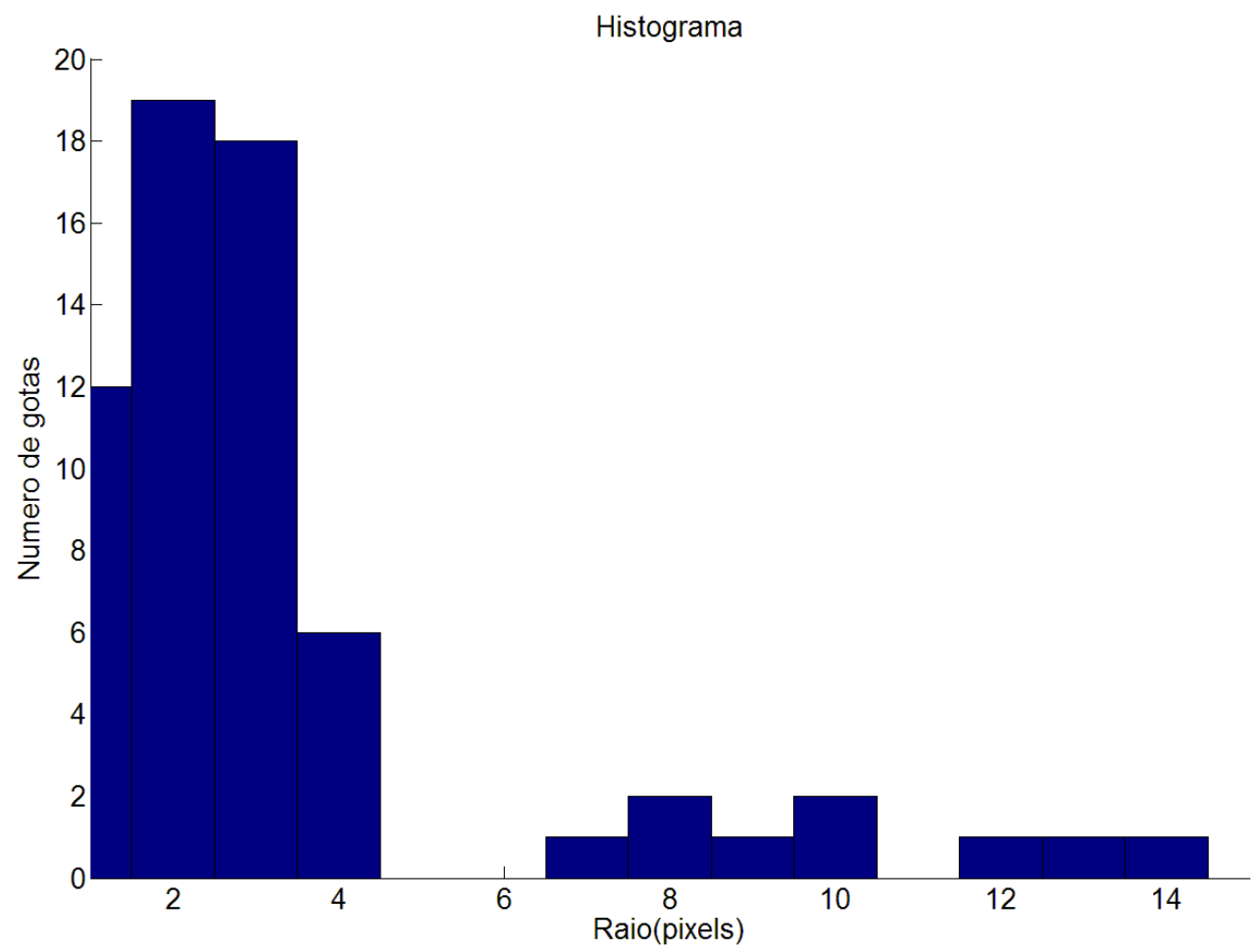

Figura 6.17: Histograma apresentando a distribuição dos tamanhos das gotas contidas na segunda amostra do primeiro papel hidrossensível. 


\section{Terceira amostra}

A figura 6.18 apresenta a imagem da terceira amostra do primeiro papel hidrossensível, ampliada 5 vezes em relação ao seu tamanho original.

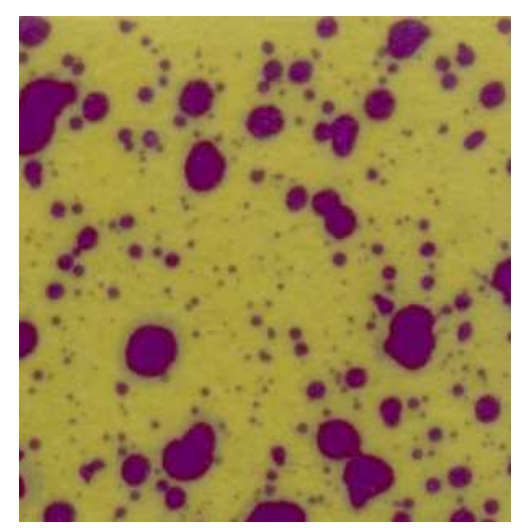

Figura 6.18: Terceira amostra do primeiro papel hidrossensível, ampliada 5 vezes em relação ao seu tamanho original.

Na figura 6.19 pode ser visto o histograma apresentando a distribuição dos tamanhos das gotas contidas na terceira amostra do primeiro papel hidrossensível.

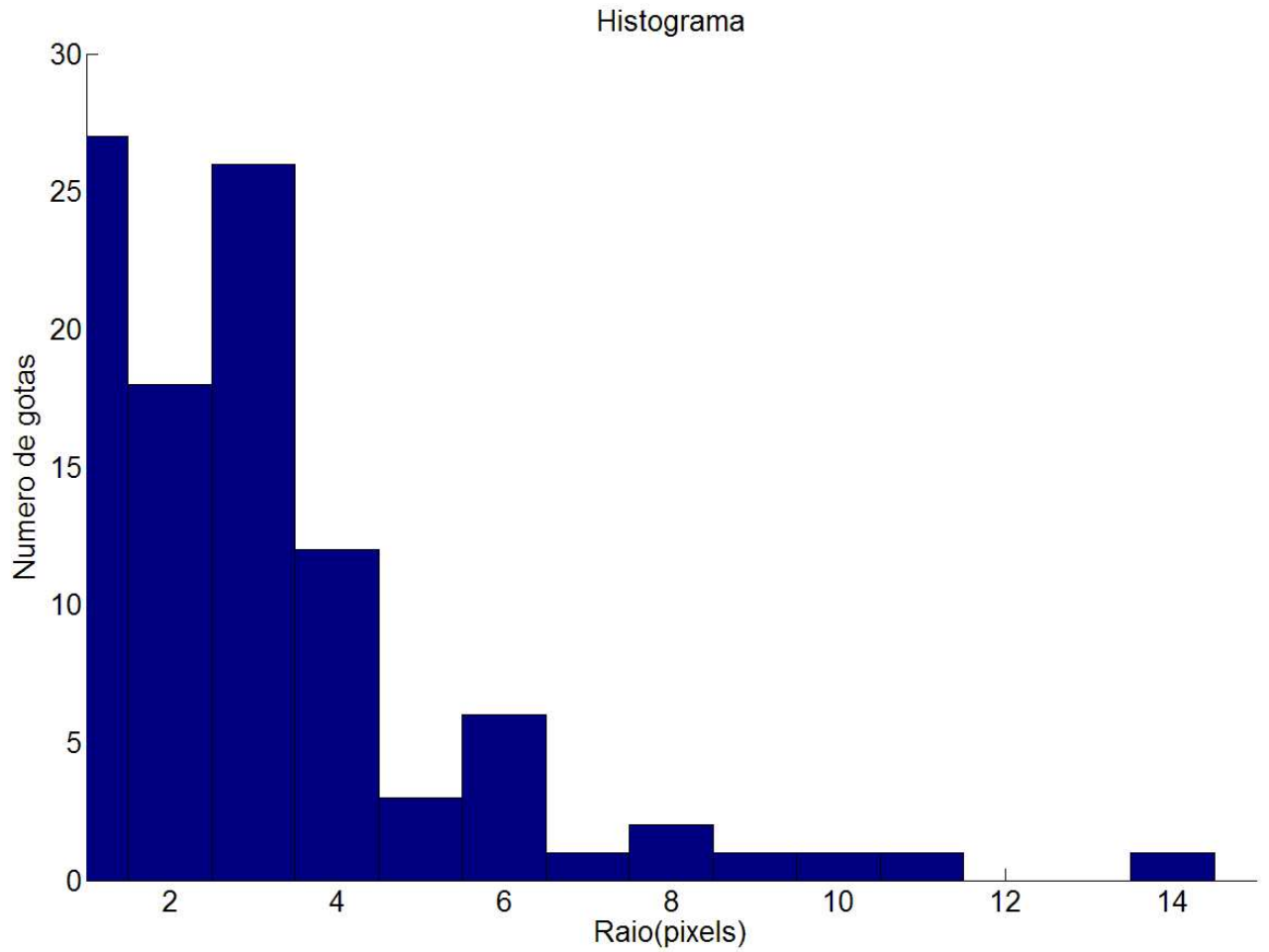

Figura 6.19: Histograma apresentando a distribuição dos tamanhos das gotas contidas na terceira amostra do primeiro papel hidrossensível. 


\section{Valores de DMN e DMV das amostras}

A tabela 6.28 contém os valores de Diâmetro mediano numérico (DMN) e Diâmetro mediano volumétrico (DMV) calculados para as amostras analisadas conforme apresentado na seção 2.4 .

\begin{tabular}{|c|c|c|c|}
\hline $\begin{array}{c}\text { Papel } \\
\text { hidrosenssível }\end{array}$ & Amostra & $\begin{array}{r}\text { DMN } \\
\text { (pixels) }\end{array}$ & $\begin{array}{r}\text { DMV } \\
\text { (pixels) }\end{array}$ \\
\hline \multirow{3}{*}{1} & 1 & 5 & 9 \\
\hline & 2 & 5 & 8 \\
\hline & 3 & 6 & 8 \\
\hline \multirow{3}{*}{2} & 1 & 4 & 6 \\
\hline & 2 & 4 & 6 \\
\hline & 3 & 4 & 6 \\
\hline \multirow{3}{*}{3} & 1 & 5 & 11 \\
\hline & 2 & 6 & 8 \\
\hline & 3 & 5 & 7 \\
\hline \multirow{3}{*}{4} & 1 & 6 & 7 \\
\hline & 2 & 5 & 7 \\
\hline & 3 & 6 & 7 \\
\hline \multirow{3}{*}{5} & 1 & 4 & 7 \\
\hline & 2 & 4 & 6 \\
\hline & 3 & 4 & 7 \\
\hline \multirow{3}{*}{6} & 1 & 5 & 7 \\
\hline & 2 & 5 & 7 \\
\hline & 3 & 5 & 7 \\
\hline \multirow{3}{*}{7} & 1 & 6 & 8 \\
\hline & 2 & 5 & 7 \\
\hline & 3 & 6 & 11 \\
\hline \multirow{3}{*}{8} & 1 & 5 & 6 \\
\hline & 2 & 5 & 6 \\
\hline & 3 & 5 & 6 \\
\hline \multirow{3}{*}{9} & 1 & 6 & 8 \\
\hline & 2 & 6 & 7 \\
\hline & 3 & 8 & 30 \\
\hline
\end{tabular}

Tabela 6.28: valores de DMN e DMV calculados para as amostras analisadas.

\subsection{Discussões}

Com base nos resultados obtidos no primeiro teste apresentado, foi possível avaliar que os erros de medida dos padrões circulares concentraram-se, na faixa de $80 \%$ para os menores valores de raios e foram de até $5 \%$ para raios maiores que 10 pixels. A verificação deste resultado pode ser feita através da observação comparativa dos gráficos de erro por raio e escala, bem como verificado nas tabelas do primeiro e segundo estudo realizados. Adicionalmente, a observação dos baixos valores de desvio padrão na tabela 6.13, indicam o comportamento estável da medida nos diversos testes realizados atestando a qualidade dos dados obtidos. 
Sobre este resultado é possível dizer que a concentração dos maiores erros na medida nos menores valores de raios se deve principalmente ao pequeno número de pixels presentes no contorno e utilizados para o calculo do raio.

No segundo estudo foram inseridos diferentes níveis de ruído ao sinal do contorno dos padrões circulares, este procedimento teve como objetivo simular as imperfeições freqüentemente presentes em marcas de gotas reais, permitindo assim a avaliação da tolerância do método a presença dessas imperfeições na medida.

Os resultados obtidos no segundo estudo mostraram que quando ajustado para trabalhar com valores maiores de escala o método apresenta maior robustez na realização de medidas na presença de ruído o que pode ser observado com a comparação dos valores presentes nas tabelas de erros para diferentes escalas e níveis de ruído. Como exemplo pode-se tomar os valores de erros de medidas obtidos para as escalas 0,5 e 1,5 , sendo que a primeira apresenta uma variação de mais de $10 \%$ no erro entre as medidas realizadas na presença de ruído e as realizadas na ausencia do mesmo, no entanto para o segundo e maior valor de escala os valores de erros praticamente não sofrem variação com a inserção do ruído no sinal do contorno.

O resultado obtido referente ao estudo da tolerância a ruído se deve a relação inversa entre a escala e a largura de banda do filtro gaussiano empregado no método, que para escalas menores considera uma porção maior das altas freqüências do sinal do contorno, levando o método a considerar até mesmo pequenas imperfeições do contorno na medida.

As constatações acima confirmam a idéia de que a escala com que a medida é feita serve de parâmetro para a calibração do método, para uma determinada faixa de tamanho de gotas. Sendo que para a faixa de valores de raios de 10 a 200 pixels é possível conservar o erro na medida do raios abaixo de $5 \%$.

A análise dos resultados do terceiro estudo denota que os erros concentram-se nos casos em que os aglomerados são formados por gotas com valores de raios muito diferentes, como pode ser visto na figura 6.13. Este fato decorre da maior precisão na localização do posicionamento dos pontos de quebra de aglomerados formados por padrões de tamanhos similares. Sendo este um indicativo da faixa ótima de operação do método em relação à faixa de tamanho de gotas a ser analisada.

A partir da análise da coluna com os percentuais dos objetos identificados corretamente como aglomerados, nas tabelas do terceiro estudo, verifica-se a capacidade do método em reconhecer com até $100 \%$ de precisão a presença dos aglomerados. Este resultado aumenta a precisão na medida dos raios e por sua vez dos descritores da chuva artificial como DMV e DMN, os quais não sofreriam a influência dos valores de falsas gotas que na verdade se tratariam de aglomerados.

Continuando a avaliação dos resultados obtidos no terceiro estudo, a utilização do fator escala para calibrar a sensibilidade do método sobre quais objetos devem ser identificados como aglomerados ou gotas, confirmou-se. Uma vez que os resultados mostraram que a variação do fator de escala atua como um ajuste do método, que de acordo com o valor desse parâmetro passa a reconhecer como um aglomerado objetos com até um determinado percentual de aglomeração. Por exemplo, o valor de escala 1,1 que para a faixa de valores de raios analisada, ajusta o método de forma que este reconheça corretamente a totalidade dos aglomerados com até $75 \%$ de percentual de aglomeração e ao mesmo tempo reconheceu corretamente como uma única gota o total de padrões gerados com 100\% de sobreposição.

A aplicação do método nas amostras obtidas a partir de imagens de gotas reais, propiciou a obtenção da distribuição do tamanho das gotas representadas através de 
histogramas, bem como o cálculo de DMV e DMN condizentes com as amostras como pode ser visto na tabela 6.28, onde os valores de DMV e DMN apresentam maiores diferenças para amostras de papéis com menor uniformidade na distribuição dos tamanhos das gotas, enquanto que para as amostras onde a distribuição do tamanho das gotas apresentou maior uniformidade, observa-se valores próximos entre DMV e DMN, como no caso do oitavo papel analisado.

Ainda quanto a aplicação do método em imagens de gotas reais, a observação da alta concentração dos valores nos histogramas das figuras D.20, D.22 e D.24 das amostras do quinto papel hidrossensível, denota a tolerância do método a grande presença de aglomerados nas amostras, não permitindo que influenciem erroneamente na medida.

\subsection{Conclusões}

- A aplicação da análise de curvatura, adotada pelo método apresentado neste trabalho proporcionou precisão na medida de padrões circulares, os erros encontrados são menores que 5\% para padrões com raios de 10 a 200 pixels;

- Quanto ao aspecto da identificação dos aglomerados de gotas, o método desenvolvido foi capaz de reconhecer com 100\% de precisão aglomerados com até $75 \%$ de sobreposição, o que caracterizou o método de forma significativa, por atingir um dos pontos de maior complexidade na medida do tamanho de gotas;

- A abordagem multi-escala empregada no trabalho, mostrou-se capaz de permitir o ajuste do método para o trabalho de maneira ótima dentro da faixa de tamanho de gotas que se deseja analisar, bem como permitiu ajuste da sensibilidade na identificação de aglomerados de gotas;

- A robustez do método foi verificada, pois este conservou sua precisão na medida mesmo na presença de ruído nos sinais aferidos, mostrando-se adequado para utilização mesmo em marcas de gotas que apresentaram imperfeições em seus contornos;

- O método desenvolvido contribui para a melhoria dos métodos existentes, proporcionando o aumento na precisão das medidas envolvidas no estudo do volume de gotas de chuva artificial, com especial atenção para o aspecto da correta identificação de aglomerados de gotas de chuva artificial em imagem digital.

\subsection{Trabalhos futuros}

- O desenvolvimento de métodos com técnica mista para a medida do volume de gotas, onde a análise da curvatura pode ser empregada na identificação dos aglomerados e uma outra técnica na medida das gotas que os compõem.

- A utilização da capacidade dos contornos paramétricos em representar formas bidimensionais, bem como a da análise da curvatura em identificar quais pontos do contorno concentram mais informação, para o desenvolvimento de sistemas de armazenamento de dados compostos por formas bidimensionais com menor custo a maior eficiência. 


\section{Apêndice A}

\section{Formulações de Curvatura}

\section{A Curvatura de um contorno paramétrico}

Seguindo a dedução do equacionamento da curvatura apresentada em (FELINTO, 2001), partindo de $s \in\left[t_{0}, n-1\right]$ e de um contorno fechado simples regular $C(t)=\{x(t), y(t)\}$, conforme ilustrado na figura A.1.

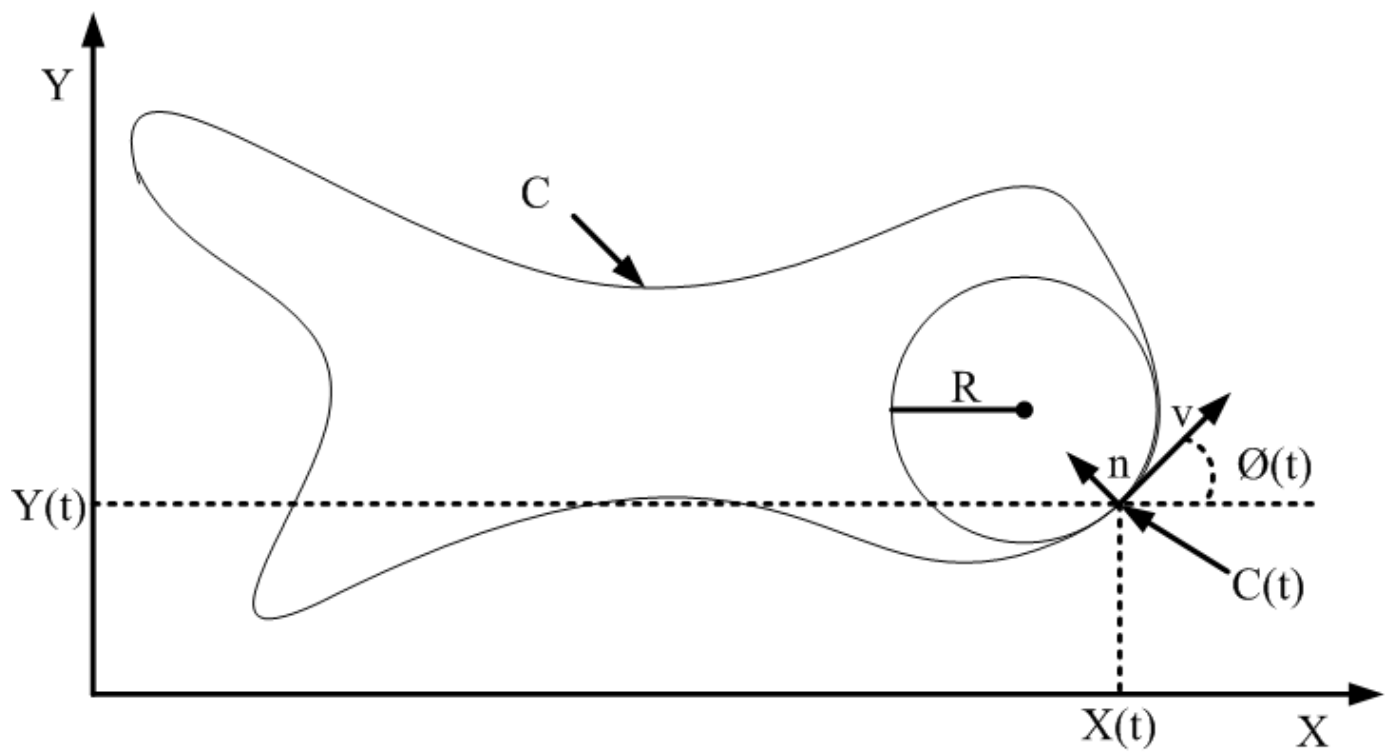

Figura A.1: Contorno paramétrico C.

Tem-se que:

$C$ denota o contorno.

$x(t)$ denota a coordenada $x$ do ponto $t$ do contorno.

$y(t)$ denota a coordenada $y$ do ponto $t$ do contorno.

$\vec{u}_{x}=(1,0)$ e $\vec{u}_{x}=(0,1)$ denotam vetores unitários.

A derivada primeira de $C$ num ponto de $t$ representa o vetor tangente $\vec{v}$ sendo assim, temos que:

$$
\vec{v}=\frac{\partial}{\partial t} \overrightarrow{C(t)}=\frac{\partial}{\partial t} x(t) \vec{u}_{x}+\frac{\partial}{\partial t} y(t) \vec{u}_{y}=\dot{x}(t) \vec{u}_{x}+\dot{y}(t) \vec{u}_{y}
$$

Um vetor unitário na mesma direção de $\vec{v}$ é definido por: 


$$
\frac{\vec{v}}{|\vec{v}|}=\frac{\dot{x}(t)}{\left[\dot{x}^{2}(t)+\dot{y}^{2}(t)\right]^{\frac{1}{2}}} \vec{u}_{x}+\frac{\dot{x}(t)}{\left[\dot{x}^{2}(t)+\dot{y}^{2}(t)\right]^{\frac{1}{2}}} \vec{u}_{y}=\cos (\phi(t)) \vec{u}_{x}+\operatorname{sen}(\phi(t)) \vec{u}_{y}
$$

$\phi(t)$ denota o ângulo formado pelo vetor unitário $\vec{u}_{x}$ e $\vec{v}$.

A partir de da equação (A.2), tem se que:

$$
\phi(t)=\arctan \left(\frac{\dot{y}(t)}{\dot{x}(t)}\right)
$$

O comprimento do arco de uma curva é descrito por:

$$
\frac{d s}{d t}=|\vec{v}|
$$

Sendo que $\frac{d s}{d t}$ é a variação do comprimento de arco dividida pela variação de $t$. Tomando as equações (A.1) e (A.4), se obtém:

$$
d s=\left(\sqrt{\dot{x}^{2}+\dot{y}^{2}}\right) d t
$$

Observa-se que quando o arco $C$ torna-se mais curvo, os vetores tangentes mudam de direção mais rapidamente, ou seja a taxa de variação em módulo $\left(\left|\frac{d \phi(s)}{d s}\right|\right)$, em relação ao comprimento de arco é maior conforme definido em (OTTERLOO, 1991; MUNEM; FOULIS, 1982).

Denotando essa taxa de variação nomeada de curvatura, por $k$, tem-se por definição que:

$$
k=\frac{d \phi(s)}{d s}
$$

Aplicando a derivada em relação ao comprimento do arco em (A.2) e com o uso de (A.6), temos que:

$$
\begin{aligned}
\frac{\vec{v}}{d s \mid} & =\frac{d}{d s}\left[\cos (\phi(s)) \vec{u}_{x}+\operatorname{sen}(\phi(s)) \vec{u}_{y}\right] \\
& =\frac{d \phi(s)}{d s}\left[-\operatorname{sen}(\phi(s)) \vec{u}_{x}+\cos (\phi(s)) \vec{u}_{y}\right] \\
& =k\left[-\operatorname{sen}(\phi(s)) \vec{u}_{x}+\cos (\phi(s)) \vec{u}_{y}\right] \\
& =k \vec{n}
\end{aligned}
$$


Temos que $\vec{n}$ é um vetor unitário ortogonal a $\vec{v}$, sendo assim $\vec{n}$ aponta todo o tempo para a concavidade da curva.

Partindo de (A.7) e fazendo uso de (A.5) e (A.2), tem-se que:

$$
\begin{aligned}
& \frac{\frac{\vec{v}}{|\vec{v}|}}{d s}= \\
& \frac{\vec{v}}{d t \mid} \times \frac{d t}{d s}= \\
& \begin{aligned}
\frac{d}{d t}\left[\frac{\dot{x}(t) \vec{u}_{x}+\dot{y}(t) \vec{u}_{y}}{\sqrt{\dot{x}(t)^{2}+\dot{y}(t)^{2}}}\right] \times \frac{1}{\sqrt{\dot{x}(t)^{2}+\dot{y}(t)^{2}}} & = \\
{\left[\frac{\dot{x}(t) \ddot{y}(t)+\ddot{x}(t) \dot{y}(t)}{\left[\dot{x}(t)^{2}+\dot{y}(t)^{2}\right]^{\frac{3}{2}}}\left(-\dot{y}(t) \vec{u}_{x}+\dot{x}(t) \vec{u}_{y}\right)\right] \times \frac{1}{\sqrt{\dot{x}(t)^{2}+\dot{y}(t)^{2}}} } & = \\
{\left[\frac{\dot{x}(t) \ddot{y}(t)+\ddot{x}(t) \dot{y}(t)}{\left[\dot{x}(t)^{2}+\dot{y}(t)^{2}\right]^{\frac{3}{2}}}\right] \times \frac{\left(-\dot{y}(t) \vec{u}_{x}+\dot{x}(t) \vec{u}_{y}\right)}{\frac{1}{\sqrt{\dot{x}(t)^{2}+\dot{y}(t)^{2}}}} } & =k \vec{n}
\end{aligned} \\
& \begin{aligned}
\frac{d}{d t}\left[\frac{\dot{x}(t) \vec{u}_{x}+\dot{y}(t) \vec{u}_{y}}{\sqrt{\dot{x}(t)^{2}+\dot{y}(t)^{2}}}\right] \times \frac{1}{\sqrt{\dot{x}(t)^{2}+\dot{y}(t)^{2}}} & = \\
{\left[\frac{\dot{x}(t) \ddot{y}(t)+\ddot{x}(t) \dot{y}(t)}{\left[\dot{x}(t)^{2}+\dot{y}(t)^{2}\right]^{\frac{3}{2}}}\left(-\dot{y}(t) \vec{u}_{x}+\dot{x}(t) \vec{u}_{y}\right)\right] \times \frac{1}{\sqrt{\dot{x}(t)^{2}+\dot{y}(t)^{2}}} } & = \\
{\left[\frac{\dot{x}(t) \ddot{y}(t)+\ddot{x}(t) \dot{y}(t)}{\left[\dot{x}(t)^{2}+\dot{y}(t)^{2}\right]^{\frac{3}{2}}}\right] \times \frac{\left(-\dot{y}(t) \vec{u}_{x}+\dot{x}(t) \vec{u}_{y}\right)}{\frac{1}{\sqrt{\dot{x}(t)^{2}+\dot{y}(t)^{2}}}} } & =k \vec{n}
\end{aligned} \\
& \begin{aligned}
\frac{d}{d t}\left[\frac{\dot{x}(t) \vec{u}_{x}+\dot{y}(t) \vec{u}_{y}}{\sqrt{\dot{x}(t)^{2}+\dot{y}(t)^{2}}}\right] \times \frac{1}{\sqrt{\dot{x}(t)^{2}+\dot{y}(t)^{2}}} & = \\
{\left[\frac{\dot{x}(t) \ddot{y}(t)+\ddot{x}(t) \dot{y}(t)}{\left[\dot{x}(t)^{2}+\dot{y}(t)^{2}\right]^{\frac{3}{2}}}\left(-\dot{y}(t) \vec{u}_{x}+\dot{x}(t) \vec{u}_{y}\right)\right] \times \frac{1}{\sqrt{\dot{x}(t)^{2}+\dot{y}(t)^{2}}} } & = \\
{\left[\frac{\dot{x}(t) \ddot{y}(t)+\ddot{x}(t) \dot{y}(t)}{\left[\dot{x}(t)^{2}+\dot{y}(t)^{2}\right]^{\frac{3}{2}}}\right] \times \frac{\left(-\dot{y}(t) \vec{u}_{x}+\dot{x}(t) \vec{u}_{y}\right)}{\frac{1}{\sqrt{\dot{x}(t)^{2}+\dot{y}(t)^{2}}}} } & =k \vec{n}
\end{aligned}
\end{aligned}
$$

A partir da equação (A.8), tem-se que:

$$
\begin{aligned}
& k(t)=\frac{\dot{x}(t) \ddot{y}(t)+\ddot{x}(t) \dot{y}(t)}{\left[\dot{x}(t)^{2}+\dot{y}(t)^{2}\right]^{\frac{3}{2}}} \\
& \vec{n}(t)=\frac{\left(-\dot{y}(t) \vec{u}_{x}+\dot{x}(t) \vec{u}_{y}\right)}{\frac{1}{\sqrt{\dot{x}(t)^{2}+\dot{y}(t)^{2}}}}
\end{aligned}
$$

\section{A Curvatura a partir de um sinal complexo}

A estimativa da curvatura $k(t)$, a partir do sinal complexo $u(t)$ apresentado na equação (A.11), é feita com o uso da expressão (A.14).

$$
u(t)=x(t)+i y(t)
$$

Uma vez que a partir da verificação da equação (A.12), cuja parte imaginária coincide com o numerador da fórmula da curvatura (A.9) quando multiplicada por -1 : 


$$
\dot{u}(t) \ddot{u}^{*}(t)=\dot{x}(t) \dot{y}(t)+\ddot{x}(t) \ddot{y}(t)-i(\dot{x}(t) \ddot{y}(t)+\ddot{x}(t) \dot{y}(t))
$$

E com a relação apresentada na equação (A.13), que equivale ao denominador da fórmula (A.9).

$$
\begin{aligned}
|\dot{u}(t)|^{3} & =\left(\sqrt{\dot{x}(t)^{2}+\dot{y}(t)^{2}}\right)^{3} \\
\left(\sqrt{\dot{x}(t)^{2}+\dot{y}(t)^{2}}\right)^{3} & =\left(\dot{x}(t)^{2}+\dot{y}(t)^{2}\right)^{\frac{3}{2}} \\
|\dot{u}(t)|^{3} & =\left(\dot{x}(t)^{2}+\dot{y}(t)^{2}\right)^{\frac{3}{2}}
\end{aligned}
$$

Substituindo (A.12) e (A.13) em (A.9),obtém-se:

$$
k(t)=-\frac{\operatorname{Im}\left\{\dot{u}(t) \ddot{u}^{*}(t)\right\}}{|\dot{u}(t)|^{3}}
$$




\section{Apêndice B}

\section{Definições Relacionadas a Transformada de Fourier}

\section{A transformada de Fourier de um sinal contínuo}

Uma definição da Transformada de Fourier de um sinal contínuo unidimensional $u(t)$ (BRIGHAM, 1974)(PAPOULIS, 1962), é apresentada na equação (B.1).

$$
U(f)=F\{u(t)\}=\int_{-\infty}^{\infty} u(t) e^{-i 2 \pi f t} d t
$$

Sendo que, a variável $f$ representa frequência, o domínio comum de Fourier.

Se apresenta na equação (B.2), uma definição da Transformada Inversa de Fourier, ou seja:

$$
u(t)=F\{U(f)\}^{-1}=\int_{-\infty}^{\infty} U(f) e^{i 2 \pi f t} d f
$$

Se faz importante observar que uma condição suficiente para que exista a Transformada de Fourier de um sinal é que o sinal seja integrável, ou seja:

$$
\int_{-\infty}^{\infty}|u(t)| d t<\infty
$$

\section{A transformada discreta de Fourier}

A Transformada Discreta de Fourier e sua Inversa (BRIGHAM, 1974) (PAPOULIS, 1962), são definidas como: 


$$
\begin{aligned}
U(S) & =\sum_{n=0}^{N-1} u(n) e^{-i 2 \pi n \frac{s}{N}} d f \text { para }, s=0,1, \ldots, N-1 \\
u(n) & =\sum_{n=0}^{N-1} U(s) e^{i 2 \pi n \frac{s}{N}} d f \text { para }, n=0,1, \ldots, N-1
\end{aligned}
$$

\section{A propriedade das derivadas de Fourier}

A propriedade das derivadas de Fourier, é dada por:

$$
\frac{d^{(n)} u}{d t^{(n)}} \Leftrightarrow(i 2 \pi f)^{n} U(f)
$$

Esta propriedade pode ser utilizada primeiramente aplicando-se a transformada de Fourier denotada por $F$ em $x(t)$ e $y(t)$.

$$
\begin{aligned}
& X(f)=F\{x(t)\} \\
& Y(f)=F\{y(t)\}
\end{aligned}
$$

A partir dos sinais da transformada de Fourier de $x(t)$ e $y(t)$ respectivamente, a propriedade da derivada de Fourier é aplicada como descrito para obtenção das derivadas primeira e segunda da transformada da Fourier.

$$
\begin{aligned}
\dot{X}(f) & =i 2 \pi f X(f) \\
\dot{Y}(f) & =i 2 \pi f Y(f) \\
\ddot{X}(f) & =-(2 \pi f) X(f) \\
\ddot{Y}(f) & =-(2 \pi f) Y(f)
\end{aligned}
$$

Para finalmente obter-se as derivadas primeira $\dot{x}(t)$ e $\dot{y}(t)$ e segunda $\ddot{x}(t)$ e $\ddot{y}(t)$, aplica-se a transformada inversa de Fourier denotada por $F^{-1}$ nos sinais das transformadas de Fourier das derivadas primeira e segunda, de forma que:

$$
\begin{aligned}
& \dot{x}(t)=F^{-1}\{\dot{X}(f)\} \\
& \dot{y}(t)=F^{-1}\{\dot{Y}(f)\} \\
& \ddot{x}(t)=F^{-1}\{\ddot{X}(f)\} \\
& \ddot{y}(t)=F^{-1}\{\ddot{Y}(f)\}
\end{aligned}
$$


Para estimativa das derivadas primeira e segunda os mesmos passos seguidos para $x(t)$ e $y(t)$ podem ser executados para o sinal complexo $u(t)$ obtido com a equação (4.6), de forma que:

$$
\begin{aligned}
U(f) & =F\{u(t)\} \\
\dot{U}(f) & =i 2 \pi f U(f) \\
\ddot{U}(f) & =-(2 \pi f) U(f) \\
\dot{u}(t) & =F^{-1}\{\dot{U}(f)\} \\
\ddot{u}(t) & =F^{-1}\{\ddot{U}(f)\}
\end{aligned}
$$

\section{A convolução no domínio da frequência}

A convolução de um sinal $\mathrm{u}(\mathrm{t})$ com $\mathrm{g}(\mathrm{t})$ ambos no dominio do tempo, é definida como:

$$
v(t)=u(t) * g(t)=\int_{-\infty}^{\infty} u(\tau) g(t-\tau) d \tau
$$

O teorema que relaciona a convolução de dois sinais com suas respectivas Transformadas de Fourier, pode ser representado pela equação (B.23), ou seja a operação de convolução no dominio do tempo implica em uma operação de multiplicação das transformadas de Fourier dos sinais envolvidos.

$$
u(t) * g(t)=F^{-1}\{U(f) G(f)\}
$$


Apêndice $C$

Dados complementares dos estudos realizados 
Os valores de raios conhecidos, valores de raios caracterizados e erros na medida dos raio, para a escala 0,5 , submetida ao valor de nível de ruído zero, para o primeiro estudo são apresentados na tabela C.1.

\begin{tabular}{|c|c|c|c|c|c|}
\hline $\begin{array}{r}\text { Raio } \\
\text { conhecido }\end{array}$ & $\begin{array}{r}\text { Raios } \\
\text { caracterizado }\end{array}$ & Erro & $\begin{array}{r}\text { Raio } \\
\text { conhecido }\end{array}$ & $\begin{array}{r}\text { Raio } \\
\text { caracterizado }\end{array}$ & Erro \\
\hline 1 & 1,931 & 0,931 & 74 & 74,305 & 0,004 \\
\hline 2 & 2,480 & 0,240 & 75 & 75,335 & 0,004 \\
\hline 3 & 3,475 & 0,158 & 76 & 76,371 & 0,005 \\
\hline 4 & 4,597 & 0,149 & 77 & 77,191 & 0,002 \\
\hline 5 & 13,933 & 1,787 & 78 & 78,345 & 0,004 \\
\hline 6 & 6,905 & 0,151 & 79 & 79,275 & 0,003 \\
\hline 7 & 7,225 & 0,032 & 80 & 80,322 & 0,004 \\
\hline 8 & 9,164 & 0,145 & 90 & 90,341 & 0,004 \\
\hline 9 & 9,449 & 0,050 & 100 & 100,323 & 0,003 \\
\hline 10 & 10,735 & 0,074 & 110 & 110,286 & 0,003 \\
\hline 20 & 20,500 & 0,025 & 120 & 120,226 & 0,002 \\
\hline 30 & 30,428 & 0,014 & 130 & 130,168 & 0,001 \\
\hline 31 & 31,205 & 0,007 & 140 & 140,113 & 0,001 \\
\hline 32 & 32,453 & 0,014 & 141 & 141,272 & 0,002 \\
\hline 33 & 33,314 & 0,010 & 142 & 142,171 & 0,001 \\
\hline 34 & 34,371 & 0,011 & 143 & 143,306 & 0,002 \\
\hline 35 & 35,391 & 0,011 & 144 & 144,233 & 0,002 \\
\hline 36 & 36,166 & 0,005 & 145 & 145,254 & 0,002 \\
\hline 37 & 37,432 & 0,012 & 146 & 146,246 & 0,002 \\
\hline 38 & 38,274 & 0,007 & 147 & 147,148 & 0,001 \\
\hline 39 & 39,481 & 0,012 & 148 & 148,283 & 0,002 \\
\hline 40 & 40,352 & 0,009 & 149 & 149,203 & 0,001 \\
\hline 50 & 50,282 & 0,006 & 150 & 150,266 & 0,002 \\
\hline 60 & 60,206 & 0,003 & 160 & 160,264 & 0,002 \\
\hline 70 & 70,130 & 0,002 & 170 & 170,252 & 0,001 \\
\hline 71 & 71,391 & 0,006 & 180 & 180,198 & 0,001 \\
\hline 72 & 72,228 & 0,003 & 190 & 190,176 & 0,001 \\
\hline 73 & 73,366 & 0,005 & 200 & 200,121 & 0,001 \\
\hline
\end{tabular}

Tabela C.1: Valores de raios conhecidos, valores de raios caracterizados e erros na medida dos raio, para a escala 0,5 submetida ao valor de nível de ruído zero, para o primeiro estudo. 
Os valores de raios conhecidos, valores de raios caracterizados e erros na medida dos raio, para a escala 0,6 , submetida ao valor de nível de ruído zero, para o primeiro estudo são apresentados na tabela C.2.

\begin{tabular}{|c|c|c|c|c|c|}
\hline $\begin{array}{r}\text { Raio } \\
\text { conhecido }\end{array}$ & $\begin{array}{r}\text { Raio } \\
\text { caracterizado }\end{array}$ & Erro & $\begin{array}{r}\text { Raio } \\
\text { conhecido }\end{array}$ & $\begin{array}{r}\text { Raio } \\
\text { caracterizado }\end{array}$ & Erro \\
\hline 1 & 1,922 & 0,922 & 74 & 74,284 & 0,004 \\
\hline 2 & 2,472 & 0,236 & 75 & 75,324 & 0,004 \\
\hline 3 & 3,517 & 0,172 & 76 & 76,348 & 0,005 \\
\hline 4 & 4,536 & 0,134 & 77 & 77,186 & 0,002 \\
\hline 5 & 8,580 & 0,716 & 78 & 78,313 & 0,004 \\
\hline 6 & 6,802 & 0,134 & 79 & 79,263 & 0,003 \\
\hline 7 & 7,185 & 0,026 & 80 & 80,304 & 0,004 \\
\hline 8 & 8,702 & 0,088 & 90 & 90,305 & 0,003 \\
\hline 9 & 9,304 & 0,034 & 100 & 100,290 & 0,003 \\
\hline 10 & 10,567 & 0,057 & 110 & 110,258 & 0,002 \\
\hline 20 & 20,480 & 0,024 & 120 & 120,195 & 0,002 \\
\hline 30 & 30,413 & 0,014 & 130 & 130,141 & 0,001 \\
\hline 31 & 31,225 & 0,007 & 140 & 140,093 & 0,001 \\
\hline 32 & 32,428 & 0,013 & 141 & 141,223 & 0,002 \\
\hline 33 & 33,323 & 0,010 & 142 & 142,136 & 0,001 \\
\hline 34 & 34,385 & 0,011 & 143 & 143,261 & 0,002 \\
\hline 35 & 35,375 & 0,011 & 144 & 144,191 & 0,001 \\
\hline 36 & 36,184 & 0,005 & 145 & 145,216 & 0,001 \\
\hline 37 & 37,409 & 0,011 & 146 & 146,194 & 0,001 \\
\hline 38 & 38,284 & 0,007 & 147 & 147,119 & 0,001 \\
\hline 39 & 39,461 & 0,012 & 148 & 148,237 & 0,002 \\
\hline 40 & 40,336 & 0,008 & 149 & 149,159 & 0,001 \\
\hline 50 & 50,279 & 0,006 & 150 & 150,219 & 0,001 \\
\hline 60 & 60,204 & 0,003 & 160 & 160,215 & 0,001 \\
\hline 70 & 70,131 & 0,002 & 170 & 170,199 & 0,001 \\
\hline 71 & 71,363 & 0,005 & 180 & 180,141 & 0,001 \\
\hline 72 & 72,224 & 0,003 & 190 & 190,120 & 0,001 \\
\hline 73 & 73,339 & 0,005 & 200 & 200,066 & 0,000 \\
\hline
\end{tabular}

Tabela C.2: Valores de raios conhecidos, valores de raios caracterizados e erros na medida dos raio, para a escala 0,6 submetida ao valor de nível de ruído zero, para o primeiro estudo. 
Os valores de raios conhecidos, valores de raios caracterizados e erros na medida dos raio, para a escala 0,7 , submetida ao valor de nível de ruído zero, para o primeiro estudo são apresentados na tabela C.3.

\begin{tabular}{|c|c|c|c|c|c|}
\hline $\begin{array}{r}\text { Raio } \\
\text { conhecido }\end{array}$ & $\begin{array}{r}\text { Raio } \\
\text { caracterizado }\end{array}$ & Erro & $\begin{array}{r}\text { Raio } \\
\text { conhecido }\end{array}$ & $\begin{array}{r}\text { Raio } \\
\text { caracterizado }\end{array}$ & Erro \\
\hline 1 & 1,912 & 0,912 & 74 & 74,260 & 0,004 \\
\hline 2 & 2,463 & 0,232 & 75 & 75,311 & 0,004 \\
\hline 3 & 3,556 & 0,185 & 76 & 76,325 & 0,004 \\
\hline 4 & 4,480 & 0,120 & 77 & 77,176 & 0,002 \\
\hline 5 & 6,775 & 0,355 & 78 & 78,285 & 0,004 \\
\hline 6 & 6,640 & 0,107 & 79 & 79,248 & 0,003 \\
\hline 7 & 7,162 & 0,023 & 80 & 80,285 & 0,004 \\
\hline 8 & 8,575 & 0,072 & 90 & 90,274 & 0,003 \\
\hline 9 & 9,266 & 0,030 & 100 & 100,259 & 0,003 \\
\hline 10 & 10,496 & 0,050 & 110 & 110,229 & 0,002 \\
\hline 20 & 20,471 & 0,024 & 120 & 120,161 & 0,001 \\
\hline 30 & 30,399 & 0,013 & 130 & 130,112 & 0,001 \\
\hline 31 & 31,236 & 0,008 & 140 & 140,067 & 0,000 \\
\hline 32 & 32,413 & 0,013 & 141 & 141,176 & 0,001 \\
\hline 33 & 33,329 & 0,010 & 142 & 142,098 & 0,001 \\
\hline 34 & 34,384 & 0,011 & 143 & 143,219 & 0,002 \\
\hline 35 & 35,360 & 0,010 & 144 & 144,149 & 0,001 \\
\hline 36 & 36,191 & 0,005 & 145 & 145,177 & 0,001 \\
\hline 37 & 37,393 & 0,011 & 146 & 146,145 & 0,001 \\
\hline 38 & 38,289 & 0,008 & 147 & 147,087 & 0,001 \\
\hline 39 & 39,443 & 0,011 & 148 & 148,193 & 0,001 \\
\hline 40 & 40,319 & 0,008 & 149 & 149,116 & 0,001 \\
\hline 50 & 50,274 & 0,005 & 150 & 150,173 & 0,001 \\
\hline 60 & 60,198 & 0,003 & 160 & 160,168 & 0,001 \\
\hline 70 & 70,126 & 0,002 & 170 & 170,148 & 0,001 \\
\hline 71 & 71,337 & 0,005 & 180 & 180,084 & 0,000 \\
\hline 72 & 72,215 & 0,003 & 190 & 190,065 & 0,000 \\
\hline 73 & 73,314 & 0,004 & 200 & 200,010 & 0,000 \\
\hline
\end{tabular}

Tabela C.3: Valores de raios conhecidos, valores de raios caracterizados e erros na medida dos raio, para a escala 0,7 submetida ao valor de nível de ruído zero, para o primeiro estudo. 
Os valores de raios conhecidos, valores de raios caracterizados e erros na medida dos raio, para a escala 0,8 , submetida ao valor de nível de ruído zero, para o primeiro estudo são apresentados na tabela C.4.

\begin{tabular}{|c|c|c|c|c|c|}
\hline $\begin{array}{r}\text { Raio } \\
\text { conhecido }\end{array}$ & $\begin{array}{r}\text { Raio } \\
\text { caracterizado }\end{array}$ & Erro & $\begin{array}{r}\text { Raio } \\
\text { conhecido }\end{array}$ & $\begin{array}{r}\text { Raio } \\
\text { caracterizado }\end{array}$ & Erro \\
\hline 1 & 1,901 & 0,901 & 74 & 74,236 & 0,003 \\
\hline 2 & 2,454 & 0,227 & 75 & 75,297 & 0,004 \\
\hline 3 & 3,589 & 0,196 & 76 & 76,304 & 0,004 \\
\hline 4 & 4,433 & 0,108 & 77 & 77,164 & 0,002 \\
\hline 5 & 6,011 & 0,202 & 78 & 78,260 & 0,003 \\
\hline 6 & 6,512 & 0,085 & 79 & 79,232 & 0,003 \\
\hline 7 & 7,154 & 0,022 & 80 & 80,267 & 0,003 \\
\hline 8 & 8,548 & 0,068 & 90 & 90,247 & 0,003 \\
\hline 9 & 9,269 & 0,030 & 100 & 100,231 & 0,002 \\
\hline 10 & 10,463 & 0,046 & 110 & 110,200 & 0,002 \\
\hline 20 & 20,466 & 0,023 & 120 & 120,130 & 0,001 \\
\hline 30 & 30,387 & 0,013 & 130 & 130,084 & 0,001 \\
\hline 31 & 31,242 & 0,008 & 140 & 140,040 & 0,000 \\
\hline 32 & 32,401 & 0,013 & 141 & 141,133 & 0,001 \\
\hline 33 & 33,332 & 0,010 & 142 & 142,062 & 0,000 \\
\hline 34 & 34,380 & 0,011 & 143 & 143,179 & 0,001 \\
\hline 35 & 35,347 & 0,010 & 144 & 144,110 & 0,001 \\
\hline 36 & 36,191 & 0,005 & 145 & 145,141 & 0,001 \\
\hline 37 & 37,379 & 0,010 & 146 & 146,100 & 0,001 \\
\hline 38 & 38,291 & 0,008 & 147 & 147,054 & 0,000 \\
\hline 39 & 39,429 & 0,011 & 148 & 148,151 & 0,001 \\
\hline 40 & 40,304 & 0,008 & 149 & 149,075 & 0,001 \\
\hline 50 & 50,269 & 0,005 & 150 & 150,131 & 0,001 \\
\hline 60 & 60,190 & 0,003 & 160 & 160,123 & 0,001 \\
\hline 70 & 70,119 & 0,002 & 170 & 170,099 & 0,001 \\
\hline 71 & 71,315 & 0,004 & 180 & 180,030 & 0,000 \\
\hline 72 & 72,204 & 0,003 & 190 & 190,012 & 0,000 \\
\hline 73 & 73,292 & 0,004 & 200 & 199,957 & 0,000 \\
\hline
\end{tabular}

Tabela C.4: Valores de raios conhecidos, valores de raios caracterizados e erros na medida dos raio, para a escala 0,8 submetida ao valor de nível de ruído zero, para o primeiro estudo. 
Os valores de raios conhecidos, valores de raios caracterizados e erros na medida dos raio, para a escala 0,9 , submetida ao valor de nível de ruído zero, para o primeiro estudo são apresentados na tabela C.5.

\begin{tabular}{|c|c|c|c|c|c|}
\hline $\begin{array}{r}\text { Raio } \\
\text { conhecido }\end{array}$ & $\begin{array}{r}\text { Raio } \\
\text { caracterizado }\end{array}$ & Erro & $\begin{array}{r}\text { Raio } \\
\text { conhecido }\end{array}$ & $\begin{array}{r}\text { Raio } \\
\text { caracterizado }\end{array}$ & Erro \\
\hline 1 & 1,889 & 0,888 & 74 & 74,213 & 0,003 \\
\hline 2 & 2,444 & 0,222 & 75 & 75,284 & 0,004 \\
\hline 3 & 3,615 & 0,205 & 76 & 76,285 & 0,004 \\
\hline 4 & 4,397 & 0,099 & 77 & 77,152 & 0,002 \\
\hline 5 & 5,675 & 0,135 & 78 & 78,239 & 0,003 \\
\hline 6 & 6,435 & 0,072 & 79 & 79,215 & 0,003 \\
\hline 7 & 7,158 & 0,023 & 80 & 80,249 & 0,003 \\
\hline 8 & 8,541 & 0,068 & 90 & 90,224 & 0,002 \\
\hline 9 & 9,280 & 0,031 & 100 & 100,205 & 0,002 \\
\hline 10 & 10,448 & 0,045 & 110 & 110,173 & 0,002 \\
\hline 20 & 20,462 & 0,023 & 120 & 120,101 & 0,001 \\
\hline 30 & 30,376 & 0,013 & 130 & 130,057 & 0,000 \\
\hline 31 & 31,245 & 0,008 & 140 & 140,013 & 0,000 \\
\hline 32 & 32,393 & 0,012 & 141 & 141,094 & 0,001 \\
\hline 33 & 33,335 & 0,010 & 142 & 142,029 & 0,000 \\
\hline 34 & 34,376 & 0,011 & 143 & 143,143 & 0,001 \\
\hline 35 & 35,336 & 0,010 & 144 & 144,074 & 0,001 \\
\hline 36 & 36,189 & 0,005 & 145 & 145,108 & 0,001 \\
\hline 37 & 37,368 & 0,010 & 146 & 146,061 & 0,000 \\
\hline 38 & 38,293 & 0,008 & 147 & 147,023 & 0,000 \\
\hline 39 & 39,416 & 0,011 & 148 & 148,113 & 0,001 \\
\hline 40 & 40,291 & 0,007 & 149 & 149,038 & 0,000 \\
\hline 50 & 50,263 & 0,005 & 150 & 150,093 & 0,001 \\
\hline 60 & 60,182 & 0,003 & 160 & 160,083 & 0,001 \\
\hline 70 & 70,113 & 0,002 & 170 & 170,054 & 0,000 \\
\hline 71 & 71,296 & 0,004 & 180 & 179,982 & 0,000 \\
\hline 72 & 72,194 & 0,003 & 190 & 189,964 & 0,000 \\
\hline 73 & 73,272 & 0,004 & 200 & 199,909 & 0,000 \\
\hline
\end{tabular}

Tabela C.5: Valores de raios conhecidos, valores de raios caracterizados e erros na medida dos raio, para a escala 0,9 submetida ao valor de nível de ruído zero, para o primeiro estudo. 
Os valores de raios conhecidos, valores de raios caracterizados e erros na medida dos raio, para a escala 1,0, submetida ao valor de nível de ruído zero, para o primeiro estudo são apresentados na tabela C.6.

\begin{tabular}{|c|c|c|c|c|c|}
\hline $\begin{array}{r}\text { Raio } \\
\text { conhecido }\end{array}$ & $\begin{array}{r}\text { Raio } \\
\text { caracterizado }\end{array}$ & Erro & $\begin{array}{r}\text { Raio } \\
\text { conhecido }\end{array}$ & $\begin{array}{r}\text { Raio } \\
\text { caracterizado }\end{array}$ & Erro \\
\hline 1 & 1,875 & 0,875 & 74 & 74,195 & 0,003 \\
\hline 2 & 2,434 & 0,217 & 75 & 75,273 & 0,004 \\
\hline 3 & 3,633 & 0,211 & 76 & 76,268 & 0,004 \\
\hline 4 & 4,373 & 0,093 & 77 & 77,141 & 0,002 \\
\hline 5 & 5,537 & 0,107 & 78 & 78,221 & 0,003 \\
\hline 6 & 6,394 & 0,066 & 79 & 79,201 & 0,003 \\
\hline 7 & 7,170 & 0,024 & 80 & 80,234 & 0,003 \\
\hline 8 & 8,539 & 0,067 & 90 & 90,204 & 0,002 \\
\hline 9 & 9,291 & 0,032 & 100 & 100,183 & 0,002 \\
\hline 10 & 10,442 & 0,044 & 110 & 110,149 & 0,001 \\
\hline 20 & 20,458 & 0,023 & 120 & 120,077 & 0,001 \\
\hline 30 & 30,367 & 0,012 & 130 & 130,033 & 0,000 \\
\hline 31 & 31,248 & 0,008 & 140 & 139,988 & 0,000 \\
\hline 32 & 32,386 & 0,012 & 141 & 141,061 & 0,000 \\
\hline 33 & 33,336 & 0,010 & 142 & 142,000 & 0,000 \\
\hline 34 & 34,373 & 0,011 & 143 & 143,111 & 0,001 \\
\hline 35 & 35,328 & 0,009 & 144 & 144,044 & 0,000 \\
\hline 36 & 36,186 & 0,005 & 145 & 145,080 & 0,001 \\
\hline 37 & 37,357 & 0,010 & 146 & 146,028 & 0,000 \\
\hline 38 & 38,295 & 0,008 & 147 & 146,995 & 0,000 \\
\hline 39 & 39,406 & 0,010 & 148 & 148,080 & 0,001 \\
\hline 40 & 40,282 & 0,007 & 149 & 149,006 & 0,000 \\
\hline 50 & 50,258 & 0,005 & 150 & 150,060 & 0,000 \\
\hline 60 & 60,175 & 0,003 & 160 & 160,047 & 0,000 \\
\hline 70 & 70,107 & 0,002 & 170 & 170,016 & 0,000 \\
\hline 71 & 71,280 & 0,004 & 180 & 179,941 & 0,000 \\
\hline 72 & 72,184 & 0,003 & 190 & 189,921 & 0,000 \\
\hline 73 & 73,256 & 0,004 & 200 & 199,867 & 0,001 \\
\hline
\end{tabular}

Tabela C.6: Valores de raios conhecidos, valores de raios caracterizados e erros na medida dos raio, para a escala 1,0 submetida ao valor de nível de ruído zero, para o primeiro estudo. 
Os valores de raios conhecidos, valores de raios caracterizados e erros na medida dos raio, para a escala 1,1, submetida ao valor de nível de ruído zero, para o primeiro estudo são apresentados na tabela C.7.

\begin{tabular}{|c|c|c|c|c|c|}
\hline $\begin{array}{r}\text { Raio } \\
\text { conhecido }\end{array}$ & $\begin{array}{r}\text { Raio } \\
\text { caracterizado }\end{array}$ & Erro & $\begin{array}{r}\text { Raio } \\
\text { conhecido }\end{array}$ & $\begin{array}{r}\text { Raio } \\
\text { caracterizado }\end{array}$ & Erro \\
\hline 1 & 1,862 & 0,862 & 74 & 74,180 & 0,002 \\
\hline 2 & 2,424 & 0,212 & 75 & 75,264 & 0,004 \\
\hline 3 & 3,644 & 0,215 & 76 & 76,254 & 0,003 \\
\hline 4 & 4,359 & 0,090 & 77 & 77,133 & 0,002 \\
\hline 5 & 5,489 & 0,098 & 78 & 78,208 & 0,003 \\
\hline 6 & 6,375 & 0,062 & 79 & 79,189 & 0,002 \\
\hline 7 & 7,186 & 0,027 & 80 & 80,221 & 0,003 \\
\hline 8 & 8,539 & 0,067 & 90 & 90,188 & 0,002 \\
\hline 9 & 9,301 & 0,033 & 100 & 100,165 & 0,002 \\
\hline 10 & 10,441 & 0,044 & 110 & 110,129 & 0,001 \\
\hline 20 & 20,454 & 0,023 & 120 & 120,057 & 0,000 \\
\hline 30 & 30,359 & 0,012 & 130 & 130,013 & 0,000 \\
\hline 31 & 31,251 & 0,008 & 140 & 139,967 & 0,000 \\
\hline 32 & 32,382 & 0,012 & 141 & 141,033 & 0,000 \\
\hline 33 & 33,338 & 0,010 & 142 & 141,976 & 0,000 \\
\hline 34 & 34,372 & 0,011 & 143 & 143,085 & 0,001 \\
\hline 35 & 35,322 & 0,009 & 144 & 144,019 & 0,000 \\
\hline 36 & 36,185 & 0,005 & 145 & 145,056 & 0,000 \\
\hline 37 & 37,349 & 0,009 & 146 & 146,001 & 0,000 \\
\hline 38 & 38,296 & 0,008 & 147 & 146,972 & 0,000 \\
\hline 39 & 39,399 & 0,010 & 148 & 148,052 & 0,000 \\
\hline 40 & 40,275 & 0,007 & 149 & 148,980 & 0,000 \\
\hline 50 & 50,254 & 0,005 & 150 & 150,033 & 0,000 \\
\hline 60 & 60,170 & 0,003 & 160 & 160,018 & 0,000 \\
\hline 70 & 70,103 & 0,001 & 170 & 169,983 & 0,000 \\
\hline 71 & 71,268 & 0,004 & 180 & 179,907 & 0,001 \\
\hline 72 & 72,177 & 0,002 & 190 & 189,886 & 0,001 \\
\hline 73 & 73,243 & 0,003 & 200 & 199,832 & 0,001 \\
\hline
\end{tabular}

Tabela C.7: Valores de raios conhecidos, valores de raios caracterizados e erros na medida dos raio, para a escala 1,1 submetida ao valor de nível de ruído zero, para o primeiro estudo. 
Os valores de raios conhecidos, valores de raios caracterizados e erros na medida dos raio, para a escala 1,2, submetida ao valor de nível de ruído zero, para o primeiro estudo são apresentados na tabela C.8.

\begin{tabular}{|c|c|c|c|c|c|}
\hline $\begin{array}{r}\text { Raio } \\
\text { conhecido }\end{array}$ & $\begin{array}{r}\text { Raio } \\
\text { caracterizado }\end{array}$ & Erro & $\begin{array}{r}\text { Raio } \\
\text { conhecido }\end{array}$ & $\begin{array}{r}\text { Raio } \\
\text { caracterizado }\end{array}$ & Erro \\
\hline 1 & 1,847 & 0,847 & 74 & 74,170 & 0,002 \\
\hline 2 & 2,414 & 0,207 & 75 & 75,257 & 0,003 \\
\hline 3 & 3,650 & 0,217 & 76 & 76,243 & 0,003 \\
\hline 4 & 4,354 & 0,089 & 77 & 77,127 & 0,002 \\
\hline 5 & 5,479 & 0,096 & 78 & 78,198 & 0,003 \\
\hline 6 & 6,367 & 0,061 & 79 & 79,179 & 0,002 \\
\hline 7 & 7,205 & 0,029 & 80 & 80,211 & 0,003 \\
\hline 8 & 8,539 & 0,067 & 90 & 90,175 & 0,002 \\
\hline 9 & 9,311 & 0,035 & 100 & 100,151 & 0,002 \\
\hline 10 & 10,443 & 0,044 & 110 & 110,113 & 0,001 \\
\hline 20 & 20,450 & 0,023 & 120 & 120,042 & 0,000 \\
\hline 30 & 30,353 & 0,012 & 130 & 129,998 & 0,000 \\
\hline 31 & 31,256 & 0,008 & 140 & 139,951 & 0,000 \\
\hline 32 & 32,380 & 0,012 & 141 & 141,012 & 0,000 \\
\hline 33 & 33,340 & 0,010 & 142 & 141,958 & 0,000 \\
\hline 34 & 34,371 & 0,011 & 143 & 143,065 & 0,000 \\
\hline 35 & 35,318 & 0,009 & 144 & 143,999 & 0,000 \\
\hline 36 & 36,186 & 0,005 & 145 & 145,038 & 0,000 \\
\hline 37 & 37,343 & 0,009 & 146 & 145,981 & 0,000 \\
\hline 38 & 38,298 & 0,008 & 147 & 146,954 & 0,000 \\
\hline 39 & 39,393 & 0,010 & 148 & 148,030 & 0,000 \\
\hline 40 & 40,272 & 0,007 & 149 & 148,960 & 0,000 \\
\hline 50 & 50,251 & 0,005 & 150 & 150,012 & 0,000 \\
\hline 60 & 60,167 & 0,003 & 160 & 159,994 & 0,000 \\
\hline 70 & 70,101 & 0,001 & 170 & 169,958 & 0,000 \\
\hline 71 & 71,258 & 0,004 & 180 & 179,881 & 0,001 \\
\hline 72 & 72,171 & 0,002 & 190 & 189,858 & 0,001 \\
\hline 73 & 73,234 & 0,003 & 200 & 199,805 & 0,001 \\
\hline
\end{tabular}

Tabela C.8: Valores de raios conhecidos, valores de raios caracterizados e erros na medida dos raio, para a escala 1,2 submetida ao valor de nível de ruído zero, para o primeiro estudo. 
Os valores de raios conhecidos, valores de raios caracterizados e erros na medida dos raio, para a escala 1,3, submetida ao valor de nível de ruído zero, para o primeiro estudo são apresentados na tabela C.9.

\begin{tabular}{|c|c|c|c|c|c|}
\hline $\begin{array}{r}\text { Raio } \\
\text { conhecido }\end{array}$ & $\begin{array}{r}\text { Raio } \\
\text { caracterizado }\end{array}$ & Erro & $\begin{array}{r}\text { Raio } \\
\text { conhecido }\end{array}$ & $\begin{array}{r}\text { Raio } \\
\text { caracterizado }\end{array}$ & Erro \\
\hline 1 & 1,833 & 0,833 & 74 & 74,164 & 0,002 \\
\hline 2 & 2,405 & 0,202 & 75 & 75,253 & 0,003 \\
\hline 3 & 3,651 & 0,217 & 76 & 76,236 & 0,003 \\
\hline 4 & 4,356 & 0,089 & 77 & 77,124 & 0,002 \\
\hline 5 & 5,483 & 0,097 & 78 & 78,192 & 0,002 \\
\hline 6 & 6,366 & 0,061 & 79 & 79,173 & 0,002 \\
\hline 7 & 7,225 & 0,032 & 80 & 80,205 & 0,003 \\
\hline 8 & 8,540 & 0,067 & 90 & 90,167 & 0,002 \\
\hline 9 & 9,321 & 0,036 & 100 & 100,142 & 0,001 \\
\hline 10 & 10,447 & 0,045 & 110 & 110,102 & 0,001 \\
\hline 20 & 20,448 & 0,022 & 120 & 120,032 & 0,000 \\
\hline 30 & 30,350 & 0,012 & 130 & 129,988 & 0,000 \\
\hline 31 & 31,262 & 0,008 & 140 & 139,940 & 0,000 \\
\hline 32 & 32,380 & 0,012 & 141 & 140,998 & 0,000 \\
\hline 33 & 33,343 & 0,010 & 142 & 141,946 & 0,000 \\
\hline 34 & 34,371 & 0,011 & 143 & 143,051 & 0,000 \\
\hline 35 & 35,317 & 0,009 & 144 & 143,987 & 0,000 \\
\hline 36 & 36,188 & 0,005 & 145 & 145,026 & 0,000 \\
\hline 37 & 37,340 & 0,009 & 146 & 145,967 & 0,000 \\
\hline 38 & 38,301 & 0,008 & 147 & 146,942 & 0,000 \\
\hline 39 & 39,389 & 0,010 & 148 & 148,015 & 0,000 \\
\hline 40 & 40,270 & 0,007 & 149 & 148,946 & 0,000 \\
\hline 50 & 50,251 & 0,005 & 150 & 149,997 & 0,000 \\
\hline 60 & 60,166 & 0,003 & 160 & 159,978 & 0,000 \\
\hline 70 & 70,101 & 0,001 & 170 & 169,941 & 0,000 \\
\hline 71 & 71,252 & 0,004 & 180 & 179,863 & 0,001 \\
\hline 72 & 72,169 & 0,002 & 190 & 189,838 & 0,001 \\
\hline 73 & 73,229 & 0,003 & 200 & 199,786 & 0,001 \\
\hline
\end{tabular}

Tabela C.9: Valores de raios conhecidos, valores de raios caracterizados e erros na medida dos raio, para a escala 1,3 submetida ao valor de nível de ruído zero, para o primeiro estudo. 
Os valores de raios conhecidos, valores de raios caracterizados e erros na medida dos raio, para a escala 1,4, submetida ao valor de nível de ruído zero, para o primeiro estudo são apresentados na tabela C.10.

\begin{tabular}{|c|c|c|c|c|c|}
\hline $\begin{array}{r}\text { Raio } \\
\text { conhecido }\end{array}$ & $\begin{array}{r}\text { Raio } \\
\text { caracterizado }\end{array}$ & Erro & $\begin{array}{r}\text { Raio } \\
\text { conhecido }\end{array}$ & $\begin{array}{r}\text { Raio } \\
\text { caracterizado }\end{array}$ & Erro \\
\hline 1 & 1,818 & 0,818 & 74 & 74,162 & 0,002 \\
\hline 2 & 2,396 & 0,198 & 75 & 75,251 & 0,003 \\
\hline 3 & 3,651 & 0,217 & 76 & 76,232 & 0,003 \\
\hline 4 & 4,362 & 0,091 & 77 & 77,125 & 0,002 \\
\hline 5 & 5,491 & 0,098 & 78 & 78,190 & 0,002 \\
\hline 6 & 6,368 & 0,061 & 79 & 79,171 & 0,002 \\
\hline 7 & 7,245 & 0,035 & 80 & 80,202 & 0,003 \\
\hline 8 & 8,541 & 0,068 & 90 & 90,163 & 0,002 \\
\hline 9 & 9,331 & 0,037 & 100 & 100,137 & 0,001 \\
\hline 10 & 10,450 & 0,045 & 110 & 110,096 & 0,001 \\
\hline 20 & 20,447 & 0,022 & 120 & 120,028 & 0,000 \\
\hline 30 & 30,348 & 0,012 & 130 & 129,984 & 0,000 \\
\hline 31 & 31,269 & 0,009 & 140 & 139,935 & 0,000 \\
\hline 32 & 32,381 & 0,012 & 141 & 140,990 & 0,000 \\
\hline 33 & 33,347 & 0,011 & 142 & 141,940 & 0,000 \\
\hline 34 & 34,373 & 0,011 & 143 & 143,042 & 0,000 \\
\hline 35 & 35,317 & 0,009 & 144 & 143,980 & 0,000 \\
\hline 36 & 36,193 & 0,005 & 145 & 145,019 & 0,000 \\
\hline 37 & 37,338 & 0,009 & 146 & 145,960 & 0,000 \\
\hline 38 & 38,305 & 0,008 & 147 & 146,936 & 0,000 \\
\hline 39 & 39,387 & 0,010 & 148 & 148,006 & 0,000 \\
\hline 40 & 40,271 & 0,007 & 149 & 148,939 & 0,000 \\
\hline 50 & 50,252 & 0,005 & 150 & 149,988 & 0,000 \\
\hline 60 & 60,168 & 0,003 & 160 & 159,969 & 0,000 \\
\hline 70 & 70,104 & 0,001 & 170 & 169,931 & 0,000 \\
\hline 71 & 71,249 & 0,004 & 180 & 179,852 & 0,001 \\
\hline 72 & 72,169 & 0,002 & 190 & 189,827 & 0,001 \\
\hline 73 & 73,227 & 0,003 & 200 & 199,776 & 0,001 \\
\hline
\end{tabular}

Tabela C.10: Valores de raios conhecidos, valores de raios caracterizados e erros na medida dos raio, para a escala 1,4 submetida ao valor de nível de ruído zero, para o primeiro estudo. 
Os valores de raios conhecidos, valores de raios caracterizados e erros na medida dos raio, para a escala 1,5, submetida ao valor de nível de ruído zero, para o primeiro estudo são apresentados na tabela C.11.

\begin{tabular}{|c|c|c|c|c|c|}
\hline $\begin{array}{r}\text { Raio } \\
\text { conhecido }\end{array}$ & $\begin{array}{r}\text { Raio } \\
\text { caracterizado }\end{array}$ & Erro & $\begin{array}{r}\text { Raio } \\
\text { conhecido }\end{array}$ & $\begin{array}{r}\text { Raio } \\
\text { caracterizado }\end{array}$ & Erro \\
\hline 1 & 1,803 & 0,803 & 74 & 74,163 & 0,002 \\
\hline 2 & 2,388 & 0,194 & 75 & 75,253 & 0,003 \\
\hline 3 & 3,649 & 0,216 & 76 & 76,232 & 0,003 \\
\hline 4 & 4,371 & 0,093 & 77 & 77,129 & 0,002 \\
\hline 5 & 5,498 & 0,100 & 78 & 78,191 & 0,002 \\
\hline 6 & 6,372 & 0,062 & 79 & 79,172 & 0,002 \\
\hline 7 & 7,265 & 0,038 & 80 & 80,202 & 0,003 \\
\hline 8 & 8,543 & 0,068 & 90 & 90,162 & 0,002 \\
\hline 9 & 9,341 & 0,038 & 100 & 100,136 & 0,001 \\
\hline 10 & 10,454 & 0,045 & 110 & 110,094 & 0,001 \\
\hline 20 & 20,446 & 0,022 & 120 & 120,029 & 0,000 \\
\hline 30 & 30,348 & 0,012 & 130 & 129,985 & 0,000 \\
\hline 31 & 31,277 & 0,009 & 140 & 139,936 & 0,000 \\
\hline 32 & 32,384 & 0,012 & 141 & 140,988 & 0,000 \\
\hline 33 & 33,352 & 0,011 & 142 & 141,941 & 0,000 \\
\hline 34 & 34,376 & 0,011 & 143 & 143,040 & 0,000 \\
\hline 35 & 35,320 & 0,009 & 144 & 143,980 & 0,000 \\
\hline 36 & 36,199 & 0,006 & 145 & 145,019 & 0,000 \\
\hline 37 & 37,338 & 0,009 & 146 & 145,959 & 0,000 \\
\hline 38 & 38,310 & 0,008 & 147 & 146,936 & 0,000 \\
\hline 39 & 39,387 & 0,010 & 148 & 148,003 & 0,000 \\
\hline 40 & 40,273 & 0,007 & 149 & 148,939 & 0,000 \\
\hline 50 & 50,255 & 0,005 & 150 & 149,986 & 0,000 \\
\hline 60 & 60,172 & 0,003 & 160 & 159,966 & 0,000 \\
\hline 70 & 70,110 & 0,002 & 170 & 169,928 & 0,000 \\
\hline 71 & 71,249 & 0,004 & 180 & 179,850 & 0,001 \\
\hline 72 & 72,172 & 0,002 & 190 & 189,825 & 0,001 \\
\hline 73 & 73,228 & 0,003 & 200 & 199,775 & 0,001 \\
\hline
\end{tabular}

Tabela C.11: Valores de raios conhecidos, valores de raios caracterizados e erros na medida dos raio, para a escala 1,5 submetida ao valor de nível de ruído zero, para o primeiro estudo. 
Apêndice D

Estudos de caso com amostras de papéis hidrossensíveis 


\section{Estudo de caso com amostras do papel hidrossensível \#2}

\section{Primeira amostra}

A figura D.1 apresenta a imagem da primeira amostra do segundo papel hidrossensível, ampliada 5 vezes em relação ao seu tamanho original.

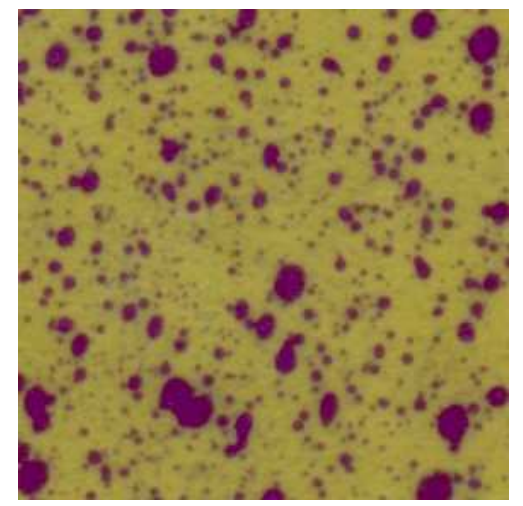

Figura D.1: Primeira amostra do segundo papel hidrossensível, ampliada 5 vezes em relação ao seu tamanho original.

Na figura D.2 pode ser visto o histograma apresentando a distribuição dos tamanhos das gotas contidas na primeira amostra do segundo papel hidrossensível.

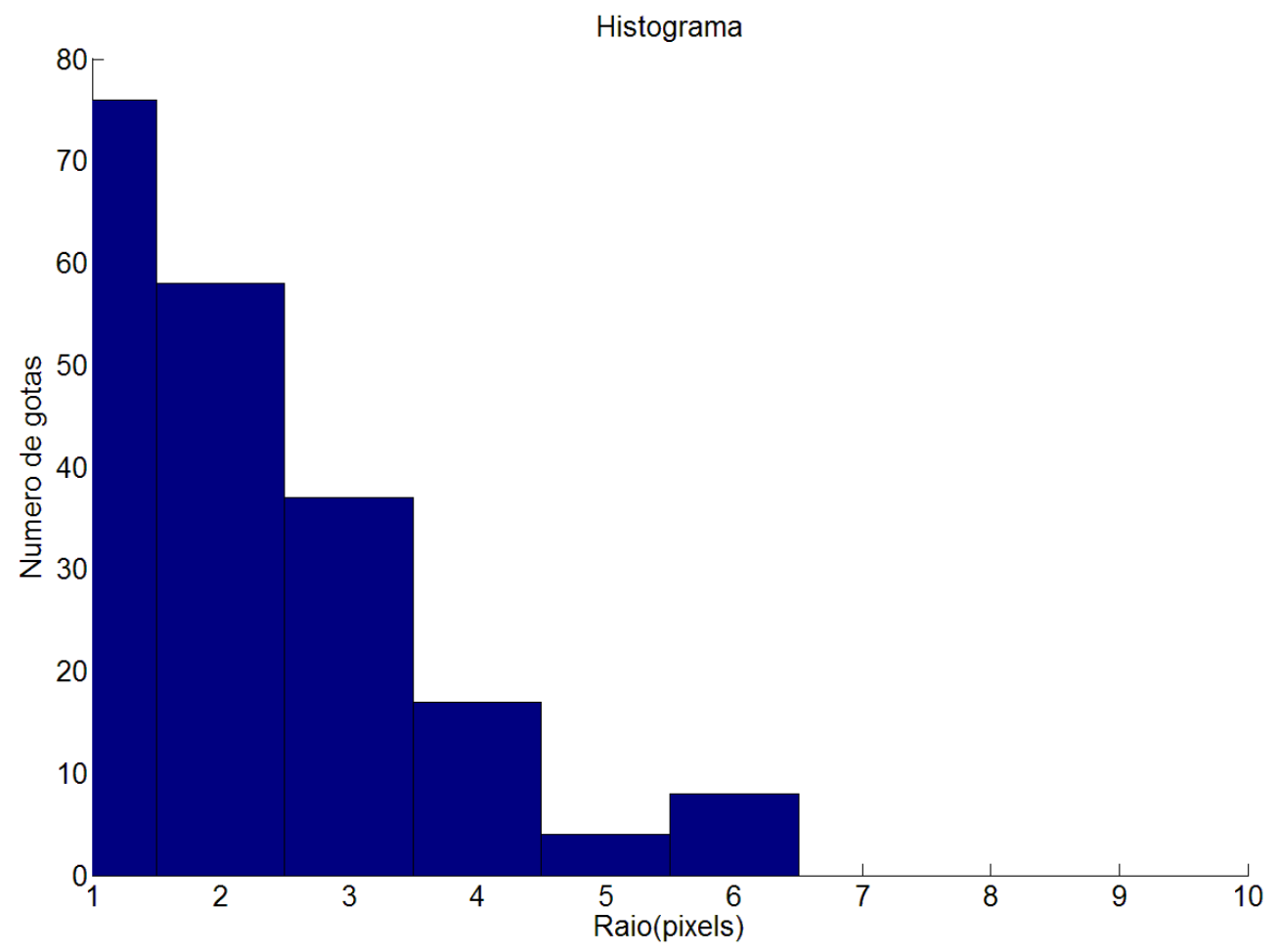

Figura D.2: Histograma apresentando a distribuição dos tamanhos das gotas contidas na primeira amostra do segundo papel hidrossensível. 


\section{Segunda amostra}

A figura D.3 apresenta a imagem da segunda amostra do segundo papel hidrossensível, ampliada 5 vezes em relação ao seu tamanho original.

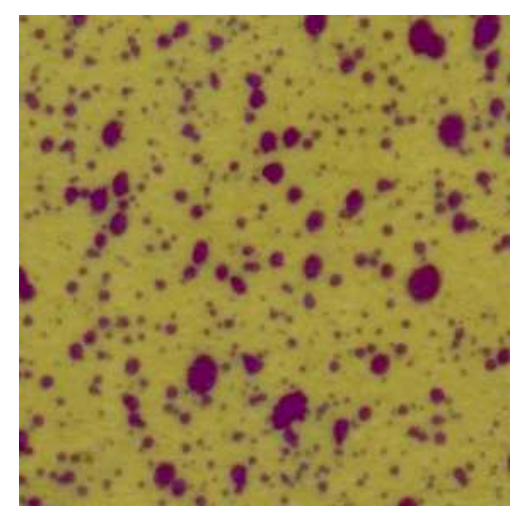

Figura D.3: Segunda amostra do segundo papel hidrossensível, ampliada 5 vezes em relação ao seu tamanho original.

Na figura D.4 pode ser visto o histograma apresentando a distribuição dos tamanhos das gotas contidas na segunda amostra do segundo papel hidrossensível.

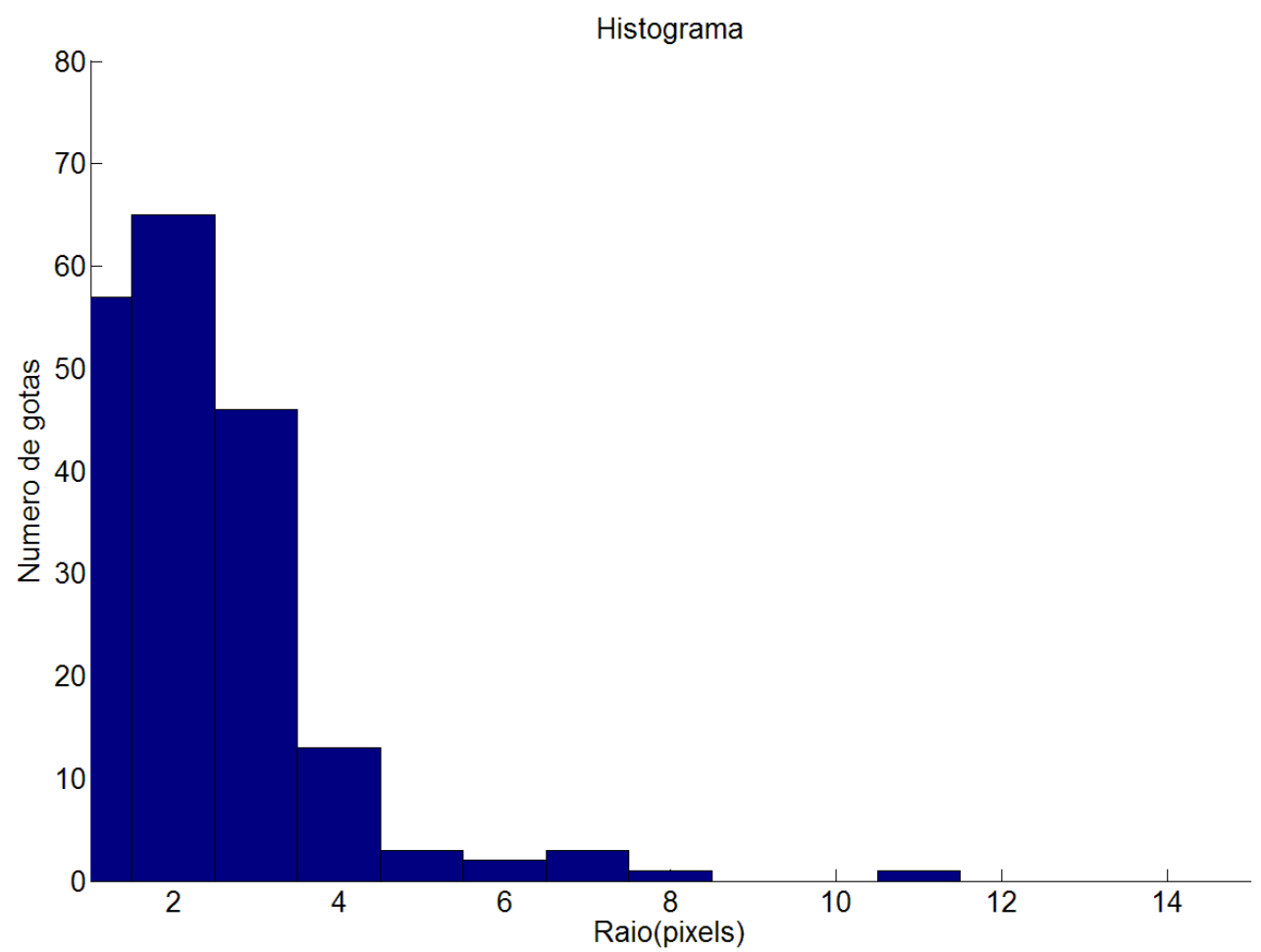

Figura D.4: Histograma apresentando a distribuição dos tamanhos das gotas contidas na segunda amostra do segundo papel hidrossensível. 


\section{Terceira amostra}

A figura D.5 apresenta a imagem da terceira amostra do segundo papel hidrossensível, ampliada 5 vezes em relação ao seu tamanho original.

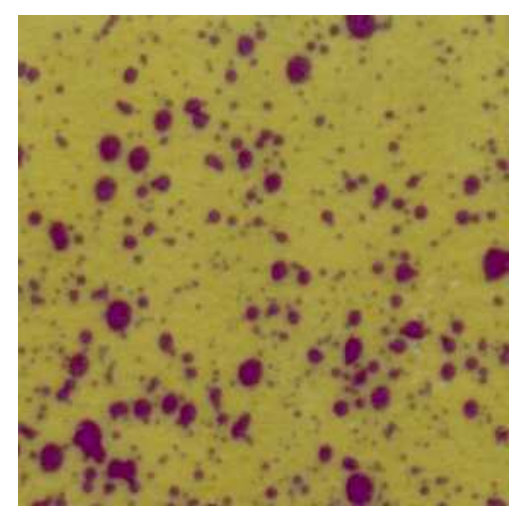

Figura D.5: Terceira amostra do segundo papel hidrossensível, ampliada 5 vezes em relação ao seu tamanho original.

Na figura D.6 pode ser visto o histograma apresentando a distribuição dos tamanhos das gotas contidas na terceira amostra do segundo papel hidrossensível.

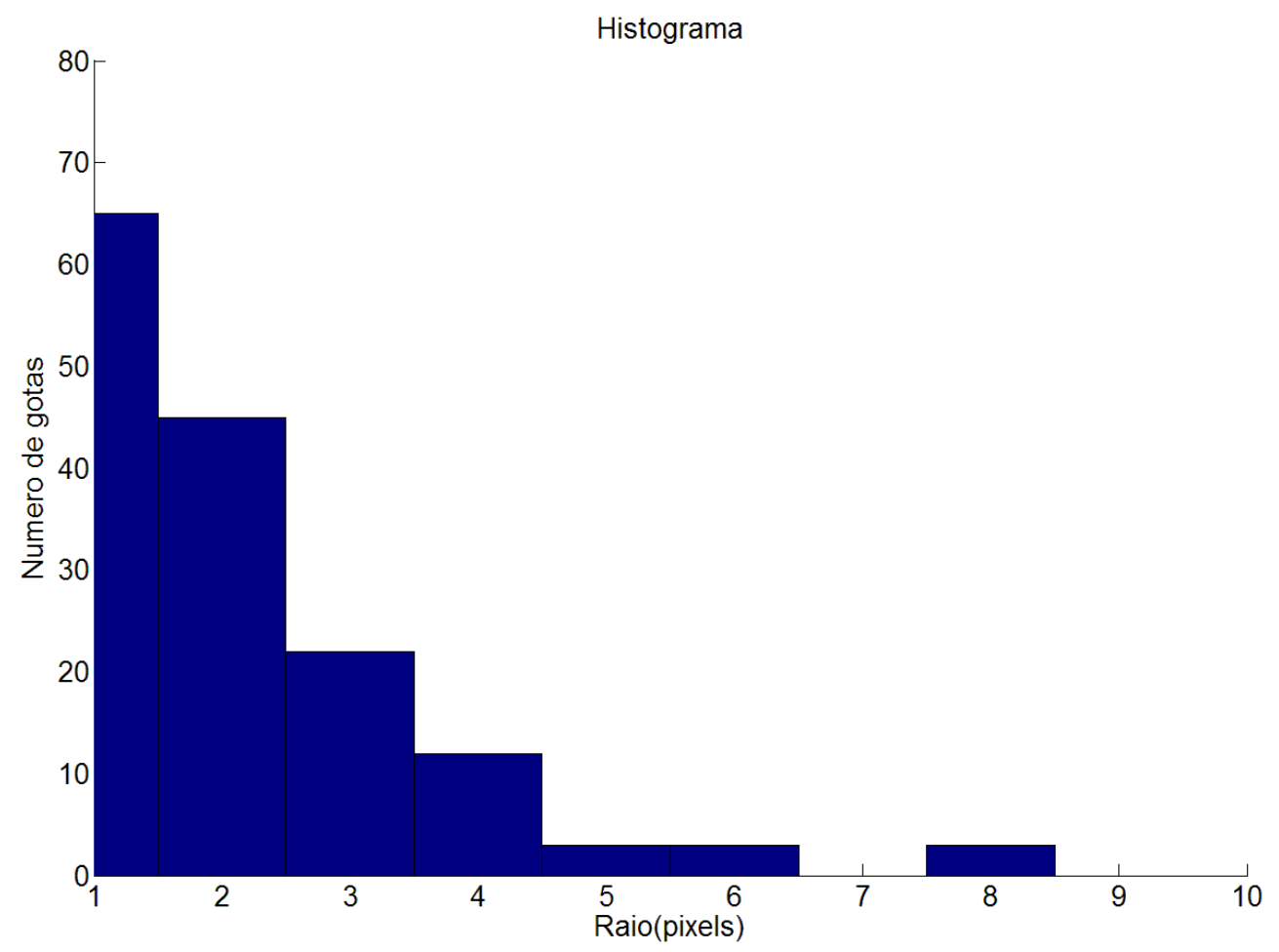

Figura D.6: Histograma apresentando a distribuição dos tamanhos das gotas contidas na terceira amostra do segundo papel hidrossensível. 


\section{Estudo de caso com amostras do papel hidrossensível \#3}

\section{Primeira amostra}

A figura D.7 apresenta a imagem da primeira amostra do terceiro papel hidrossensível, ampliada 5 vezes em relação ao seu tamanho original.

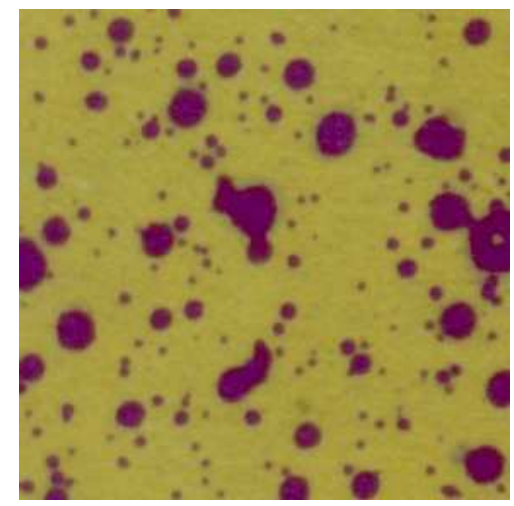

Figura D.7: Primeira amostra do terceiro papel hidrossensível, ampliada 5 vezes em relação ao seu tamanho original.

Na figura D.8 pode ser visto o histograma apresentando a distribuição dos tamanhos das gotas contidas na primeira amostra do terceiro papel hidrossensível.

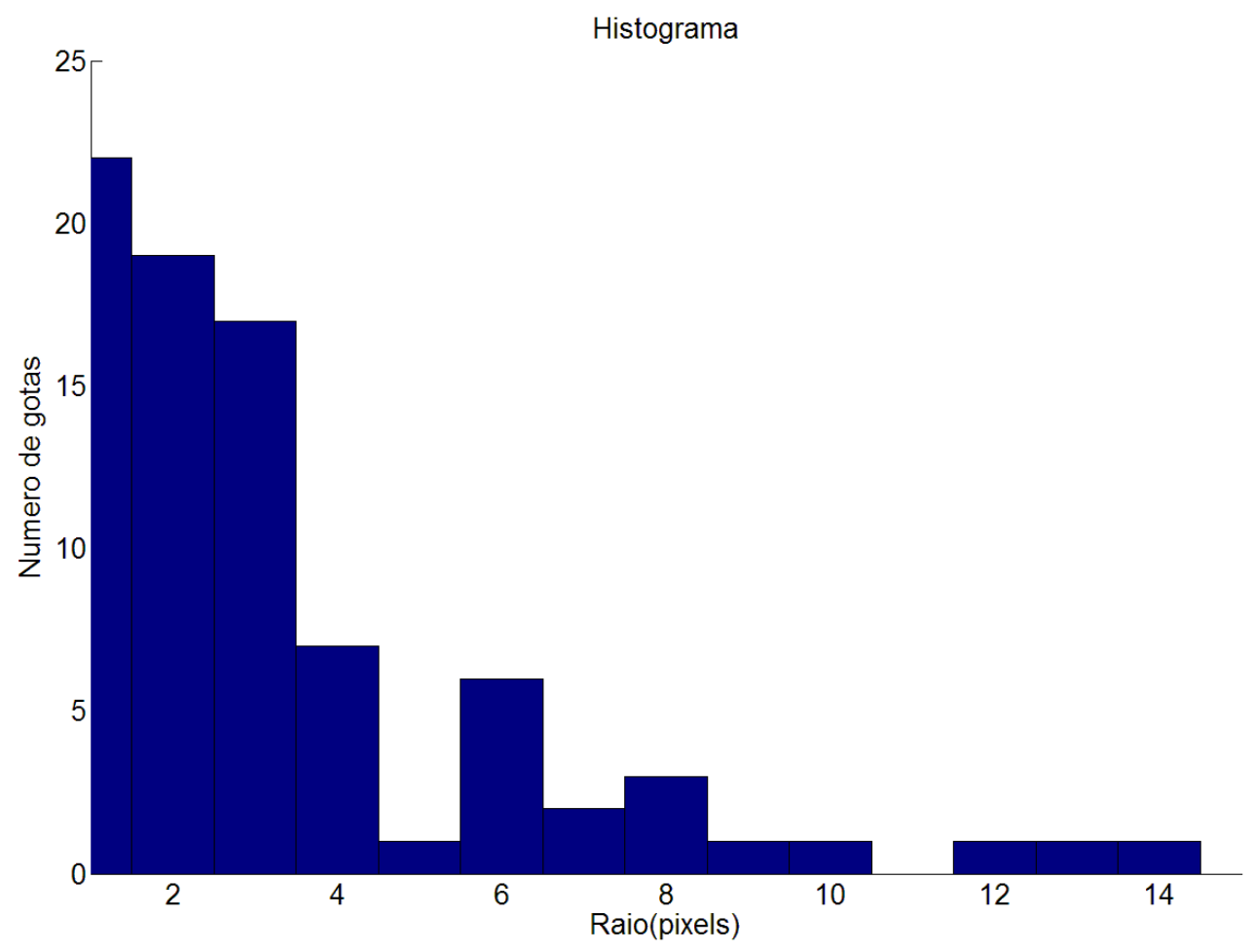

Figura D.8: Histograma apresentando a distribuição dos tamanhos das gotas contidas na primeira amostra do terceiro papel hidrossensível. 


\section{Segunda amostra}

A figura D.9 apresenta a imagem da segunda amostra do terceiro papel hidrossensível, ampliada 5 vezes em relação ao seu tamanho original.

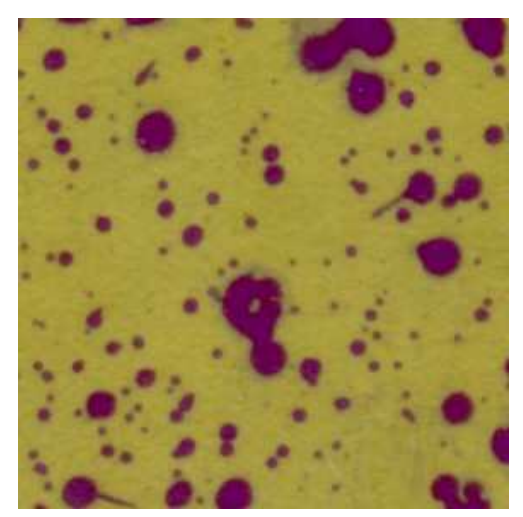

Figura D.9: Segunda amostra do terceiro papel hidrossensível, ampliada 5 vezes em relação ao seu tamanho original.

Na figura D.10 pode ser visto o histograma apresentando a distribuição dos tamanhos das gotas contidas na segunda amostra do terceiro papel hidrossensível.

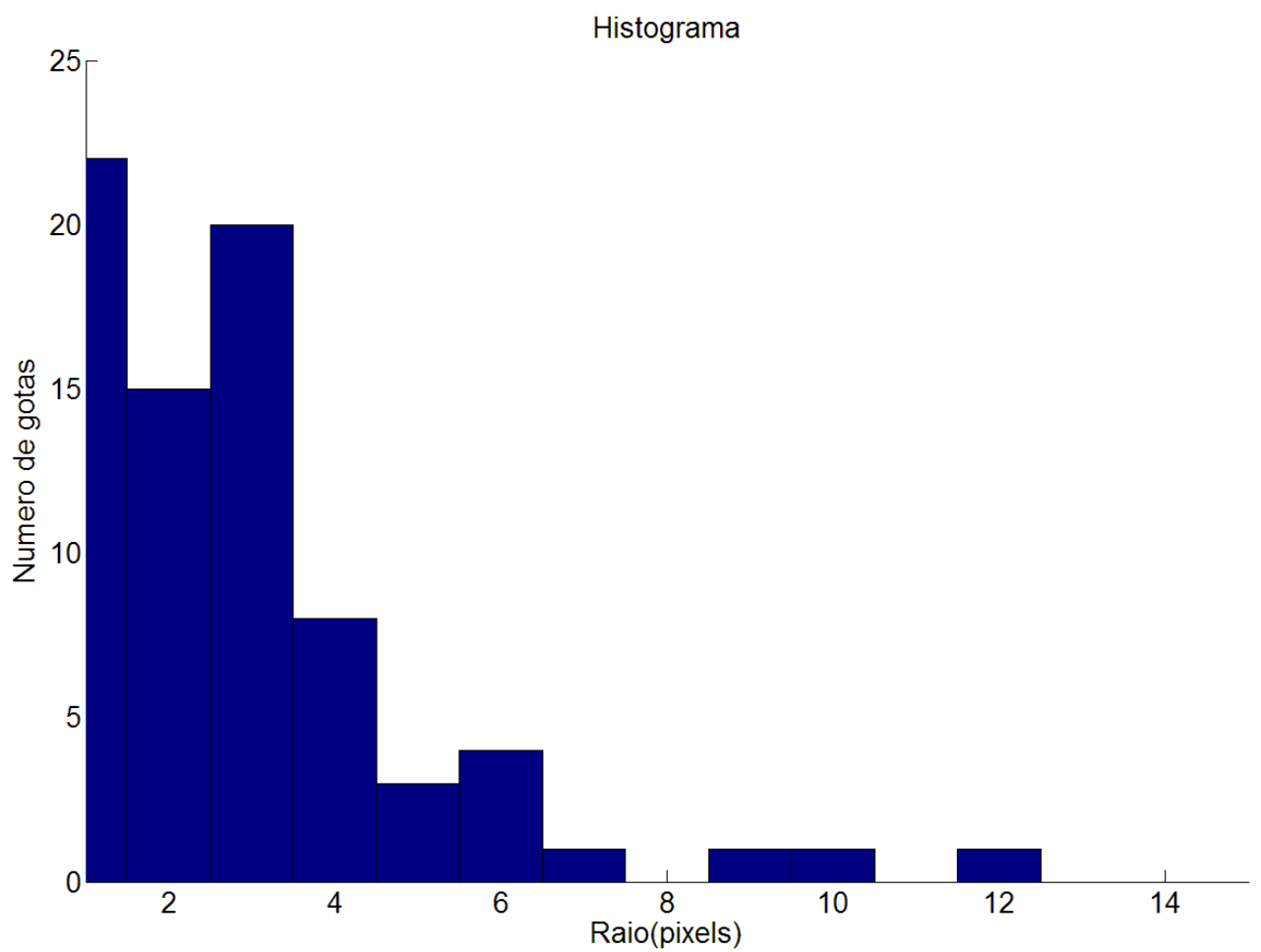

Figura D.10: Histograma apresentando a distribuição dos tamanhos das gotas contidas na segunda amostra do terceiro papel hidrossensível. 


\section{Terceira amostra}

A figura D.11 apresenta a imagem da terceira amostra do terceiro papel hidrossensível, ampliada 5 vezes em relação ao seu tamanho original.

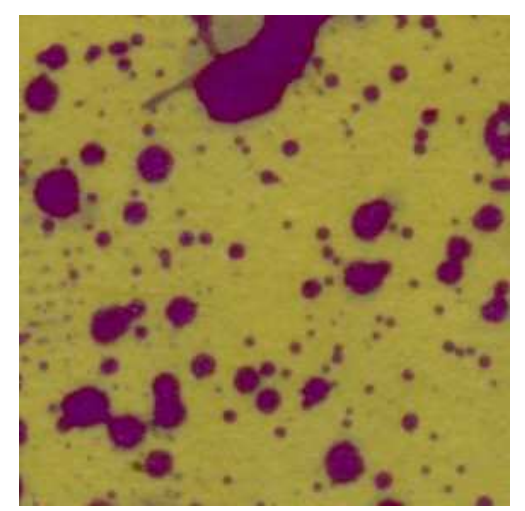

Figura D.11: Terceira amostra do terceiro papel hidrossensível, ampliada 5 vezes em relação ao seu tamanho original.

Na figura D.12 pode ser visto o histograma apresentando a distribuição dos tamanhos das gotas contidas na terceira amostra do terceiro papel hidrossensível.

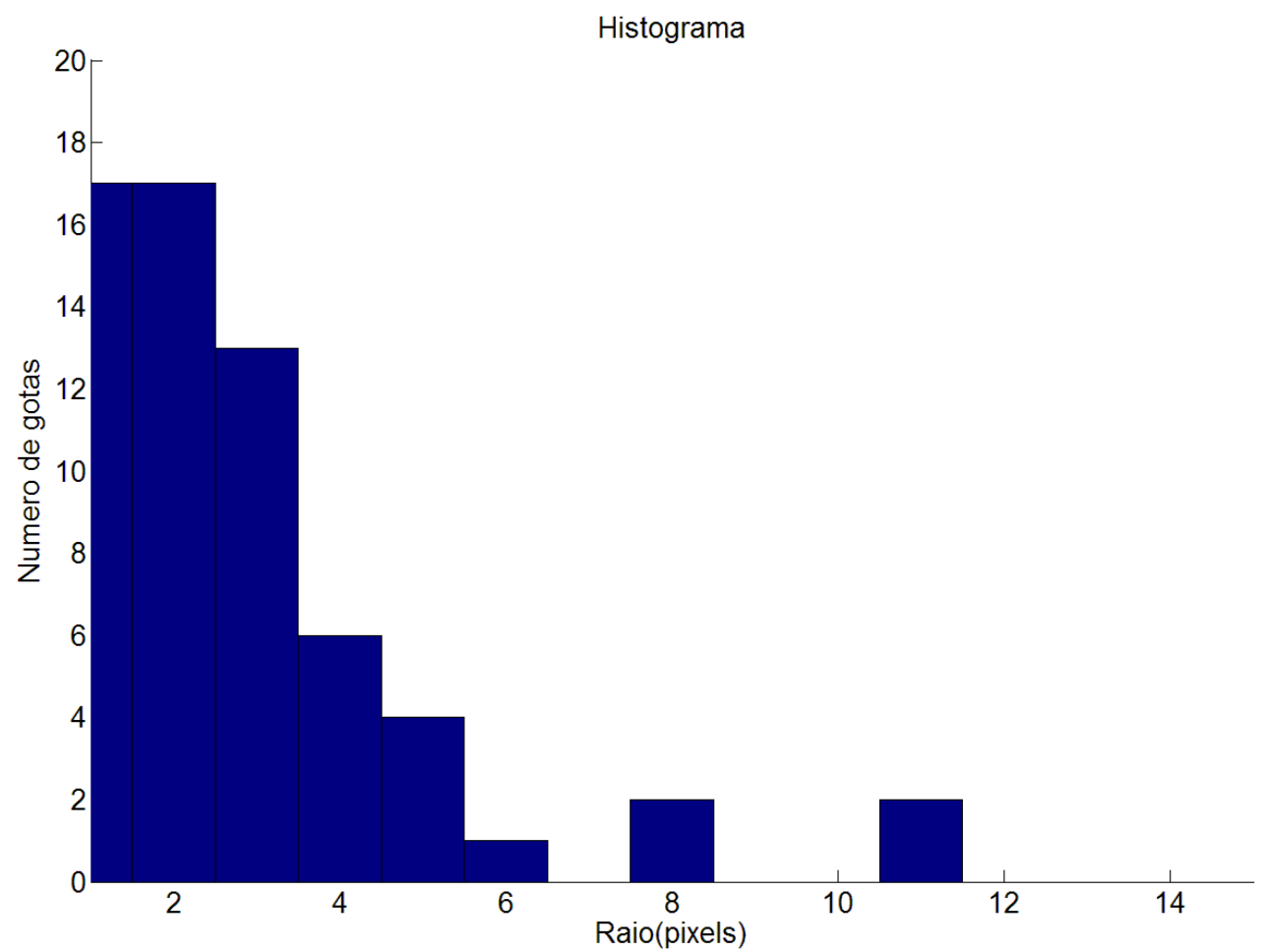

Figura D.12: Histograma apresentando a distribuição dos tamanhos das gotas contidas na terceira amostra do terceiro papel hidrossensível. 


\section{Estudo de caso com amostras do papel hidrossensível \#4}

\section{Primeira amostra}

A figura D.13 apresenta a imagem da primeira amostra do quarto papel hidrossensível, ampliada 5 vezes em relação ao seu tamanho original.

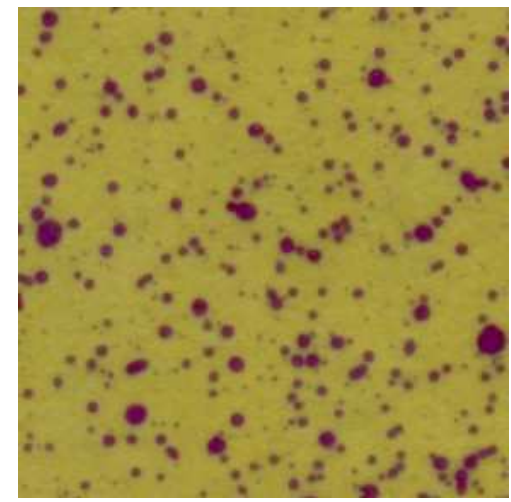

Figura D.13: Primeira amostra do quarto papel hidrossensível, ampliada 5 vezes em relação ao seu tamanho original.

Na figura D.14 pode ser visto o histograma apresentando a distribuição dos tamanhos das gotas contidas na primeira amostra do quarto papel hidrossensível.

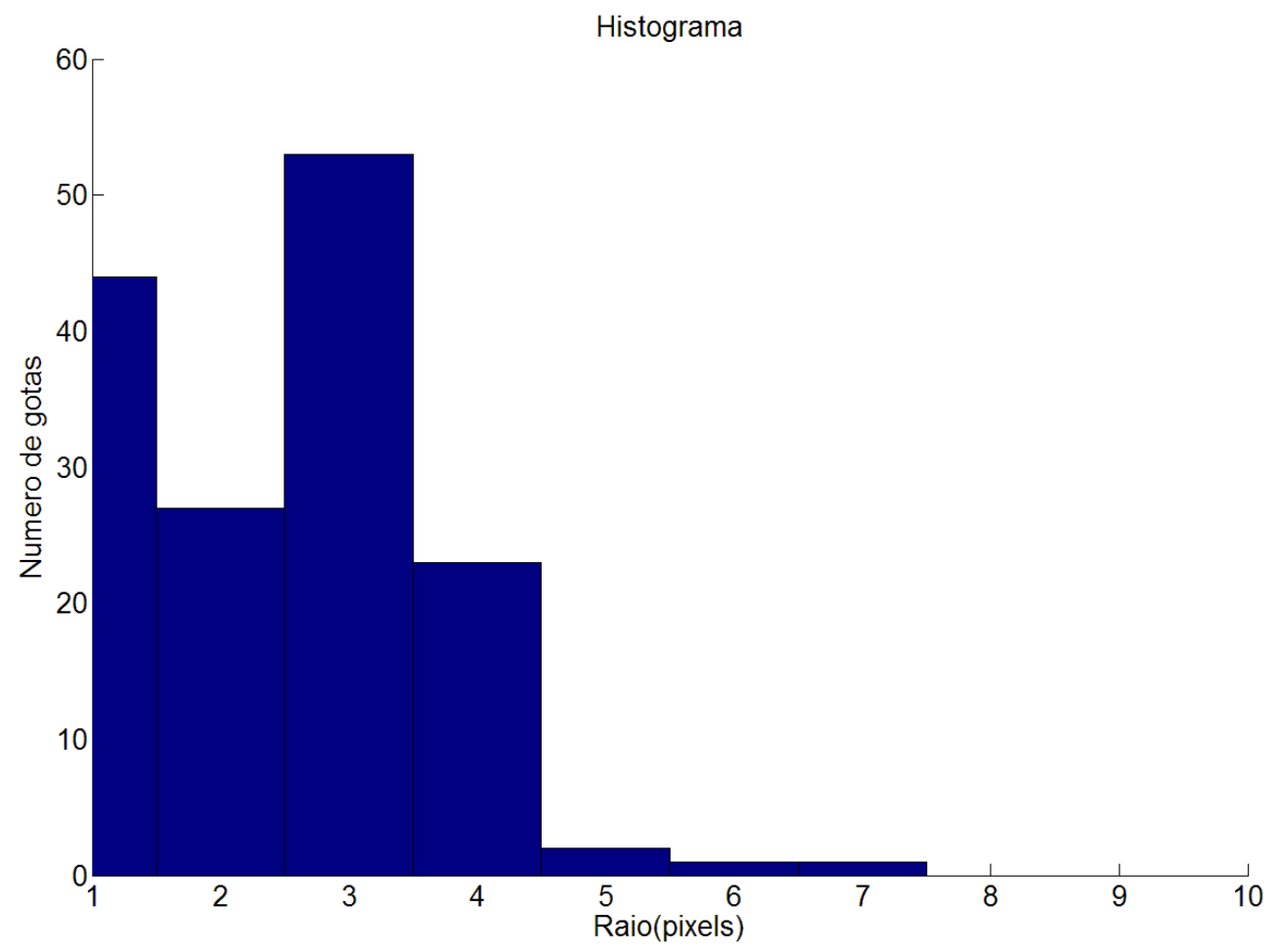

Figura D.14: Histograma apresentando a distribuição dos tamanhos das gotas contidas na primeira amostra do quarto papel hidrossensível. 


\section{Segunda amostra}

A figura D.15 apresenta a imagem da segunda amostra do quarto papel hidrossensível, ampliada 5 vezes em relação ao seu tamanho original.

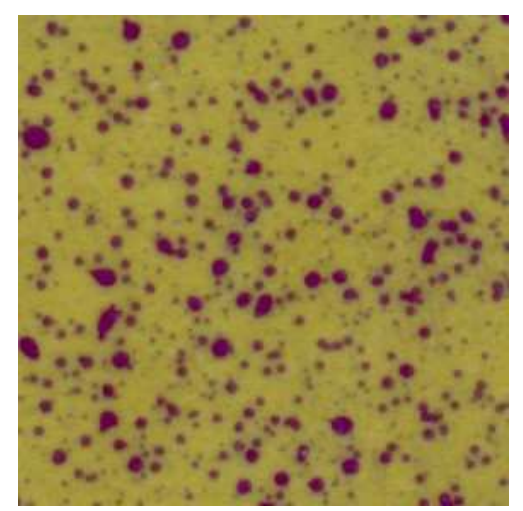

Figura D.15: Segunda amostra do quarto papel hidrossensível, ampliada 5 vezes em relação ao seu tamanho original.

Na figura D.16 pode ser visto o histograma apresentando a distribuição dos tamanhos das gotas contidas na segunda amostra do quarto papel hidrossensível.

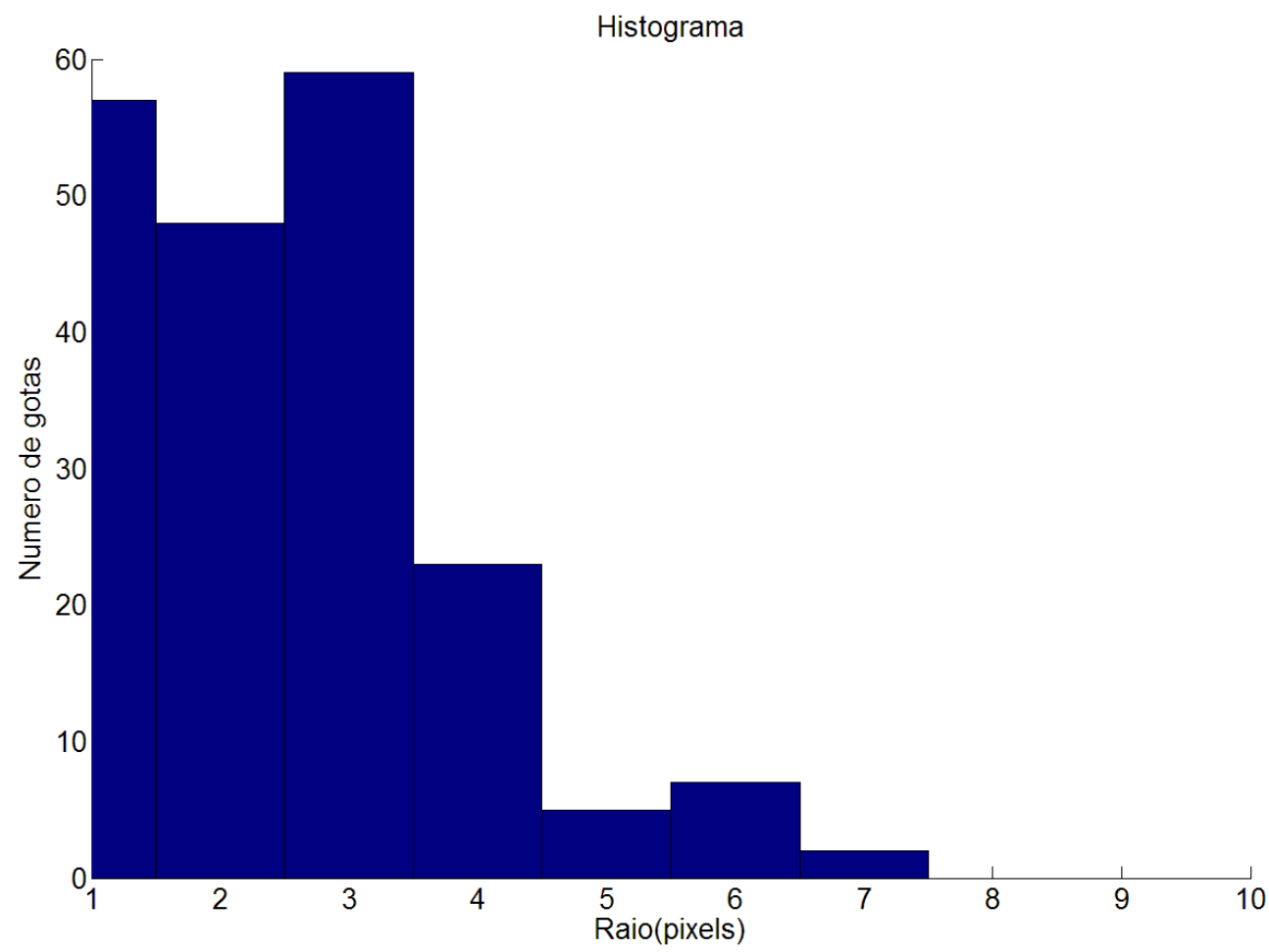

Figura D.16: Histograma apresentando a distribuição dos tamanhos das gotas contidas na segunda amostra do quarto papel hidrossensível. 


\section{Terceira amostra}

A figura D.17 apresenta a imagem da terceira amostra do quarto papel hidrossensível, ampliada 5 vezes em relação ao seu tamanho original.

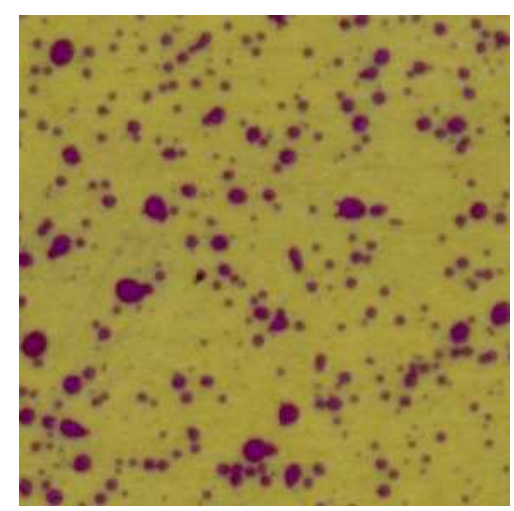

Figura D.17: Terceira amostra do quarto papel hidrossensível, ampliada 5 vezes em relação ao seu tamanho original.

Na figura D.18 pode ser visto o histograma apresentando a distribuição dos tamanhos das gotas contidas na terceira amostra do quarto papel hidrossensível.

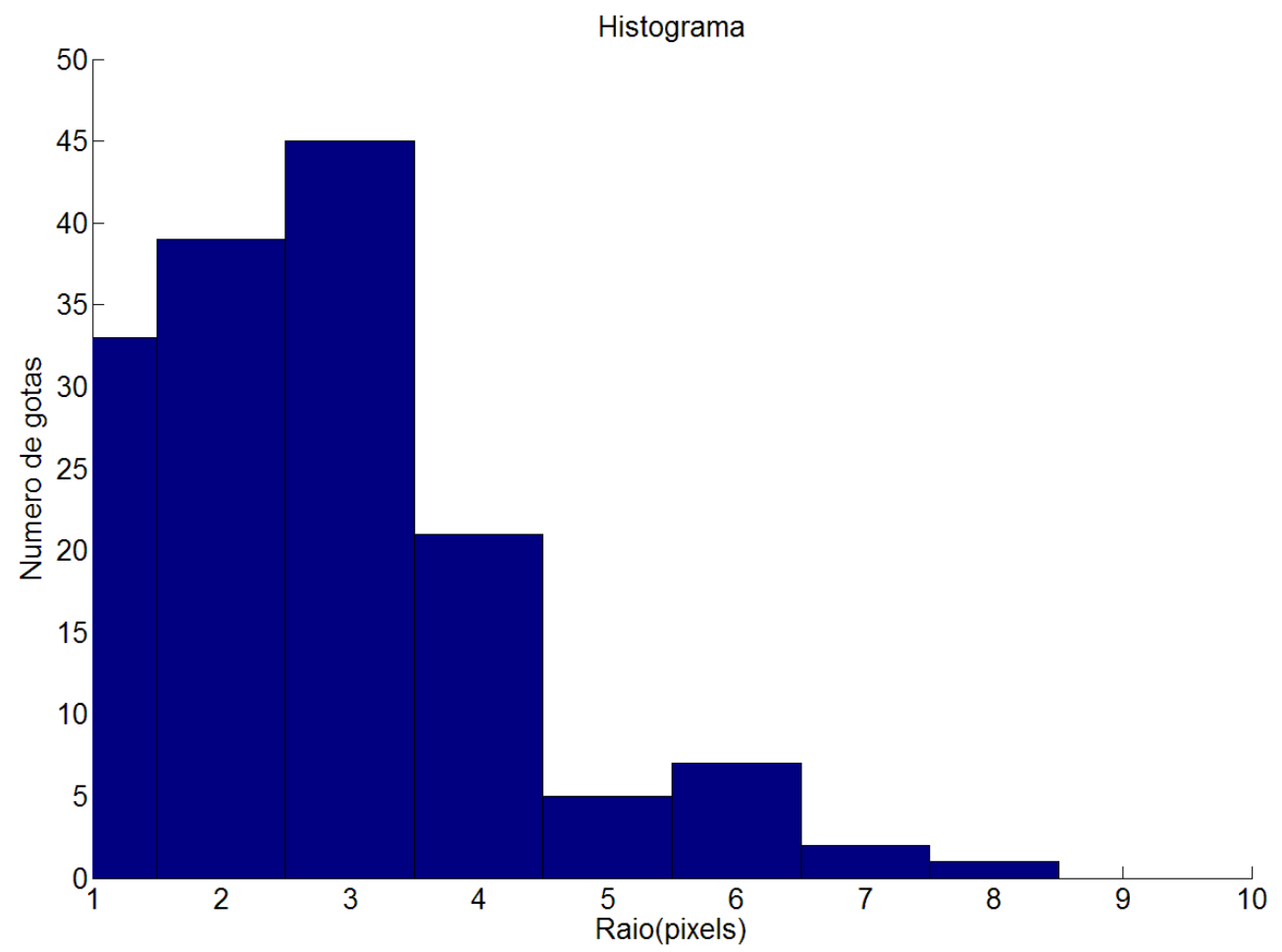

Figura D.18: Histograma apresentando a distribuição dos tamanhos das gotas contidas na terceira amostra do quarto papel hidrossensível. 


\section{Estudo de caso com amostras do papel hidrossensível \#5}

\section{Primeira amostra}

A figura D.19 apresenta a imagem da primeira amostra do quinto papel hidrossensível, ampliada 5 vezes em relação ao seu tamanho original.

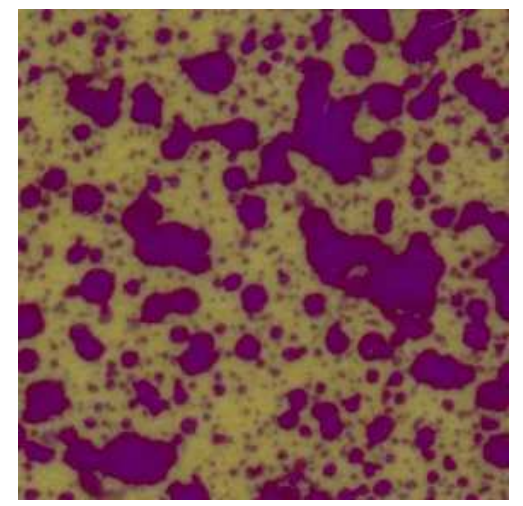

Figura D.19: Primeira amostra do quinto papel hidrossensível, ampliada 5 vezes em relação ao seu tamanho original.

Na figura D.20 pode ser visto o histograma apresentando a distribuição dos tamanhos das gotas contidas na primeira amostra do quinto papel hidrossensível.

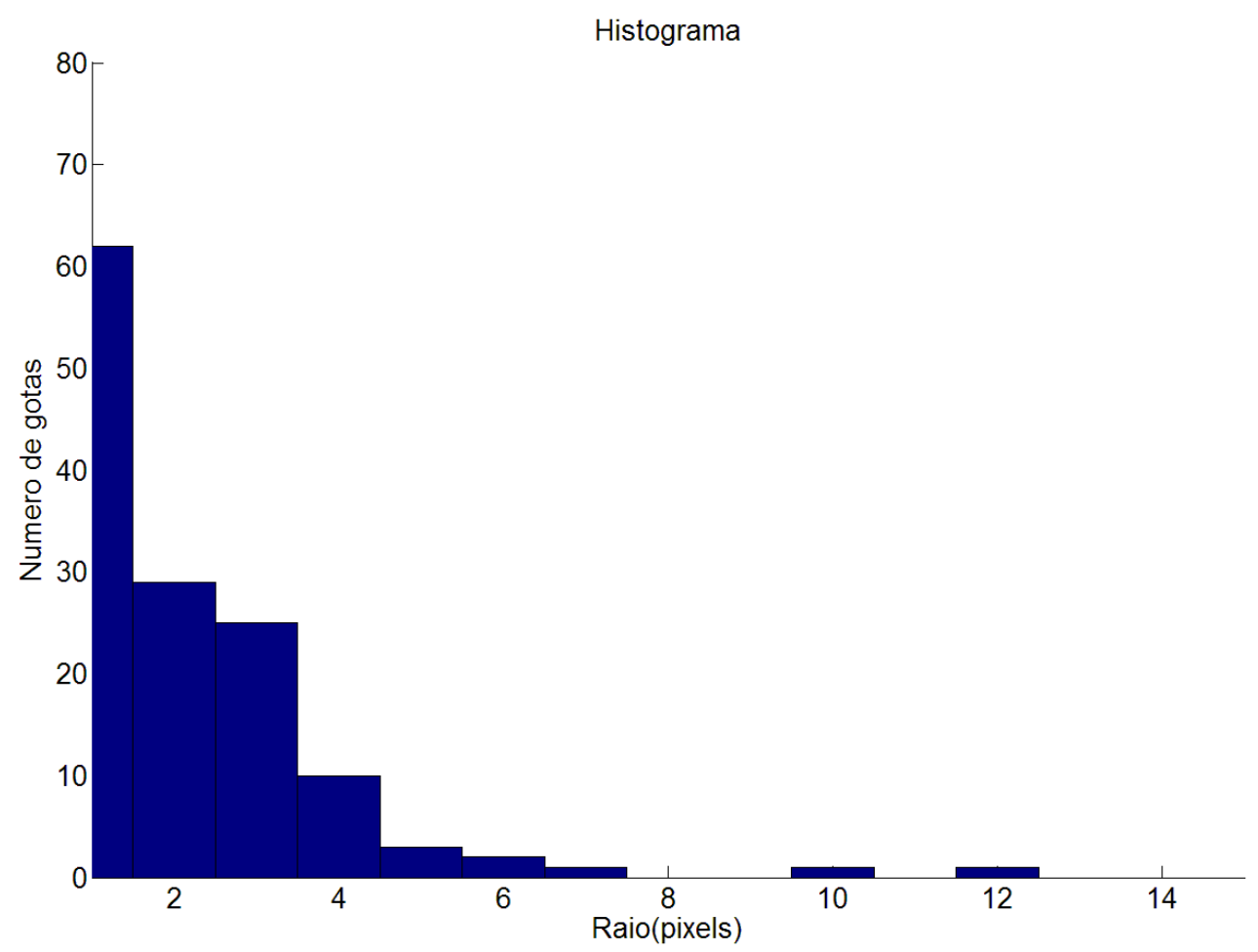

Figura D.20: Histograma apresentando a distribuição dos tamanhos das gotas contidas na primeira amostra do quinto papel hidrossensível. 


\section{Segunda amostra do quinto papel hidrossensível}

A figura D.21 apresenta a imagem da segunda amostra do quinto papel hidrossensível, ampliada 5 vezes em relação ao seu tamanho original.

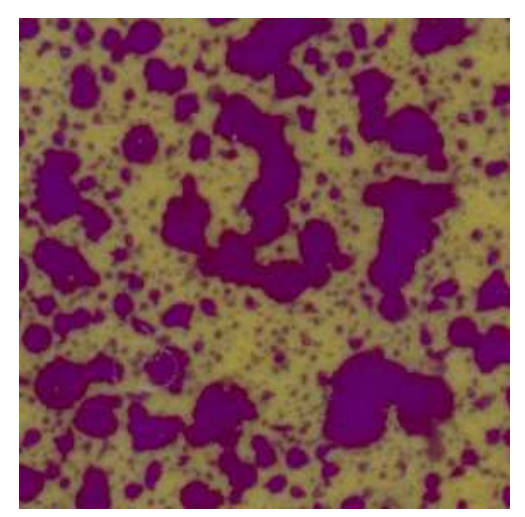

Figura D.21: Segunda amostra do quinto papel hidrossensível, ampliada 5 vezes em relação ao seu tamanho original.

Na figura D.22 pode ser visto o histograma apresentando a distribuição dos tamanhos das gotas contidas na segunda amostra do quinto papel hidrossensível.

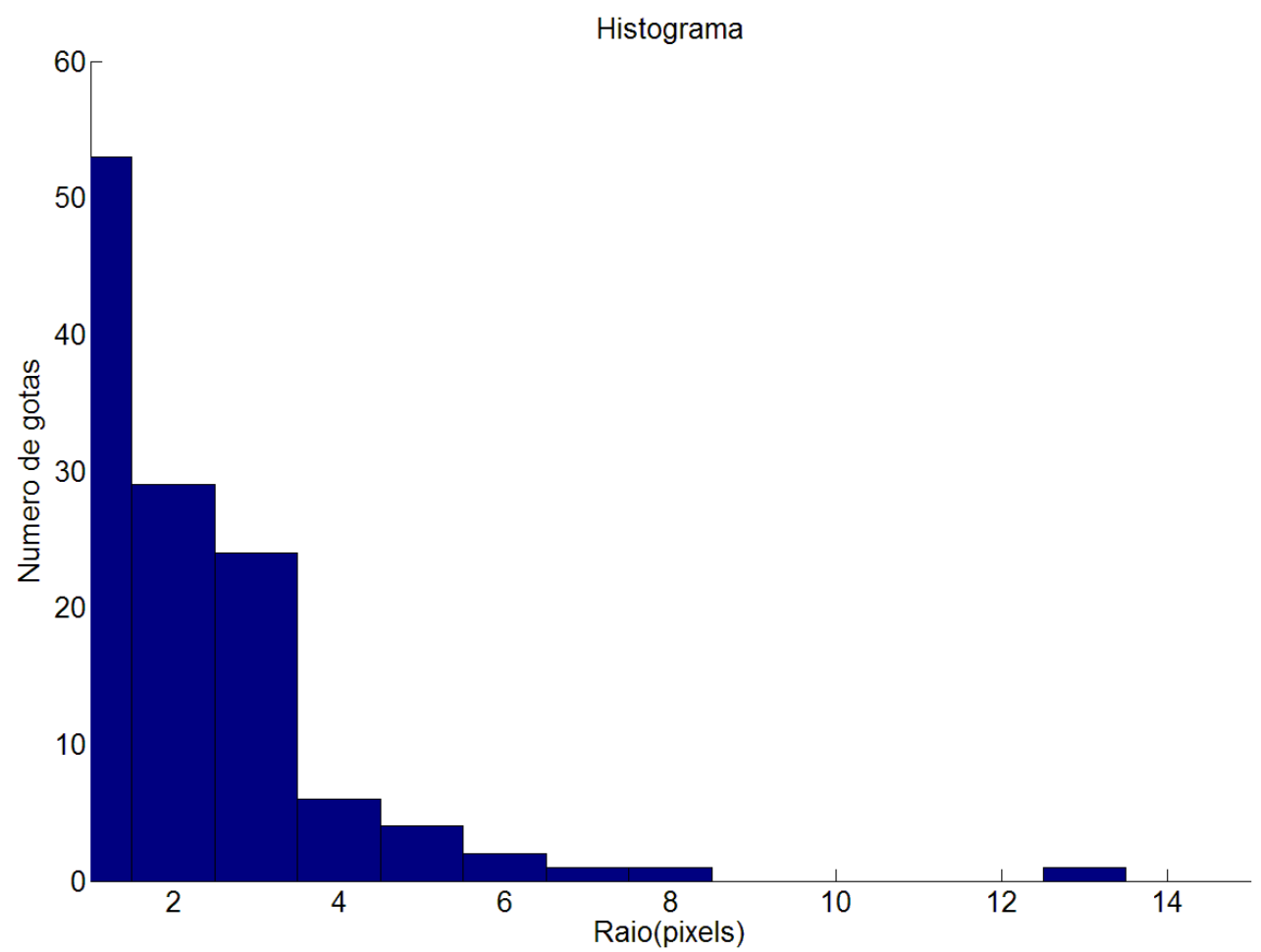

Figura D.22: Histograma apresentando a distribuição dos tamanhos das gotas contidas na segunda amostra do quinto papel hidrossensível. 


\section{Terceira amostra}

A figura D.23 apresenta a imagem da terceira amostra do quinto papel hidrossensível, ampliada 5 vezes em relação ao seu tamanho original.

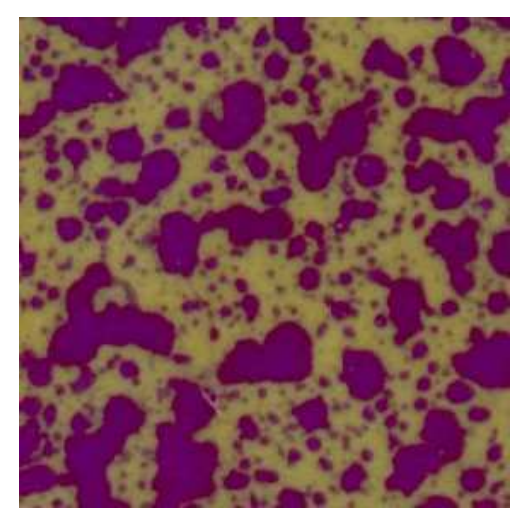

Figura D.23: Terceira amostra do quinto papel hidrossensível, ampliada 5 vezes em relação ao seu tamanho original.

Na figura D.24 pode ser visto o histograma apresentando a distribuição dos tamanhos das gotas contidas na terceira amostra do quinto papel hidrossensível.

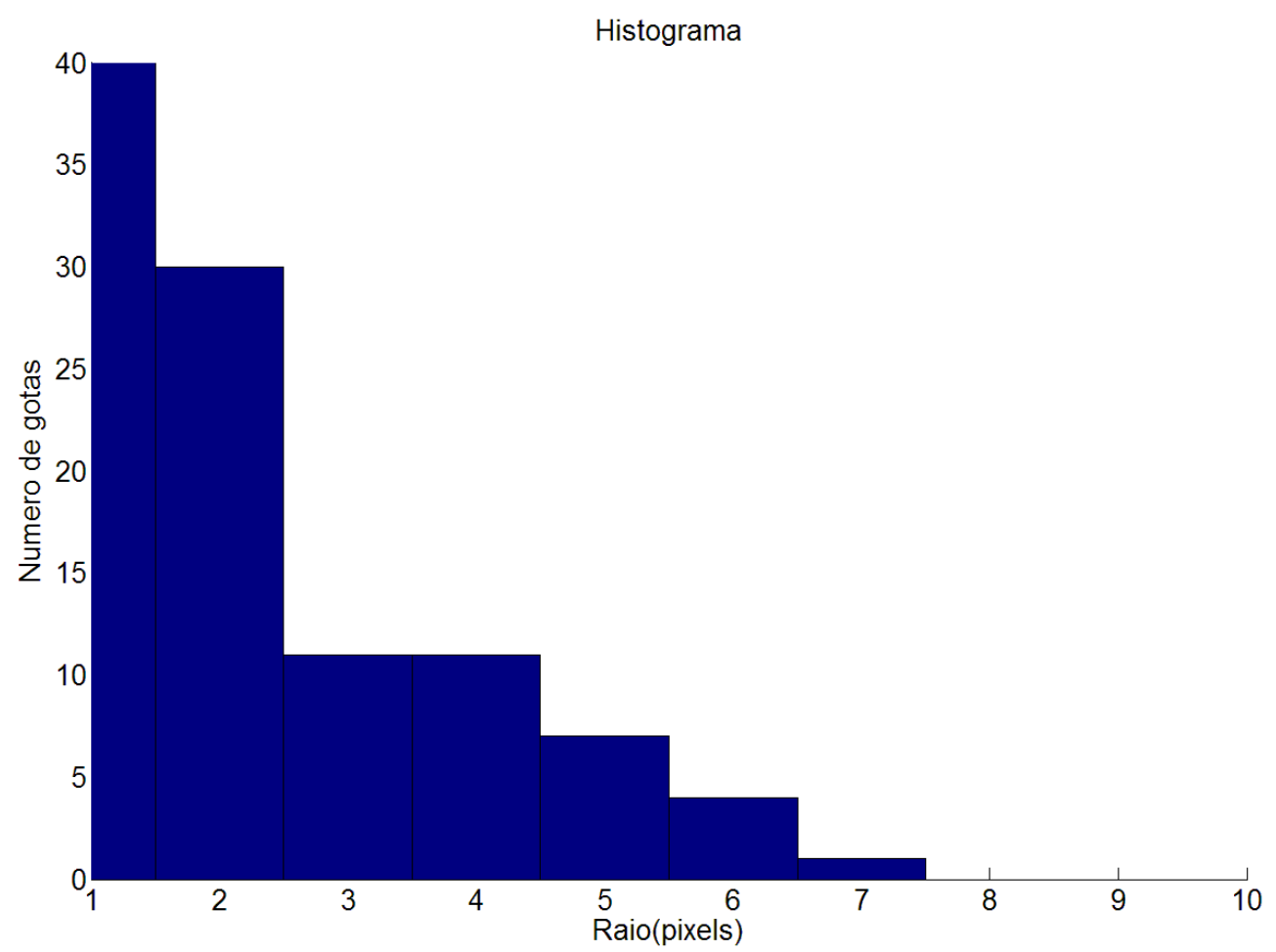

Figura D.24: Histograma apresentando a distribuição dos tamanhos das gotas contidas na terceira amostra do quinto papel hidrossensível. 


\section{Estudo de caso com amostras do papel hidrossensível \#6}

\section{Primeira amostra}

A figura D.25 apresenta a imagem da primeira amostra do sexto papel hidrossensível, ampliada 5 vezes em relação ao seu tamanho original.

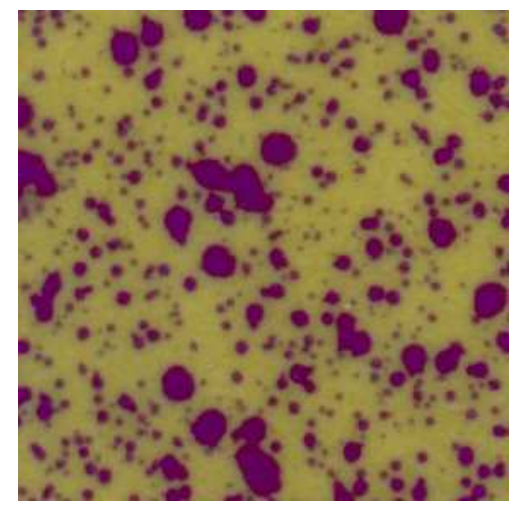

Figura D.25: Primeira amostra do sexto papel hidrossensível, ampliada 5 vezes em relação ao seu tamanho original.

Na figura D.26 pode ser visto o histograma apresentando a distribuição dos tamanhos das gotas contidas na primeira amostra do sexto papel hidrossensível.

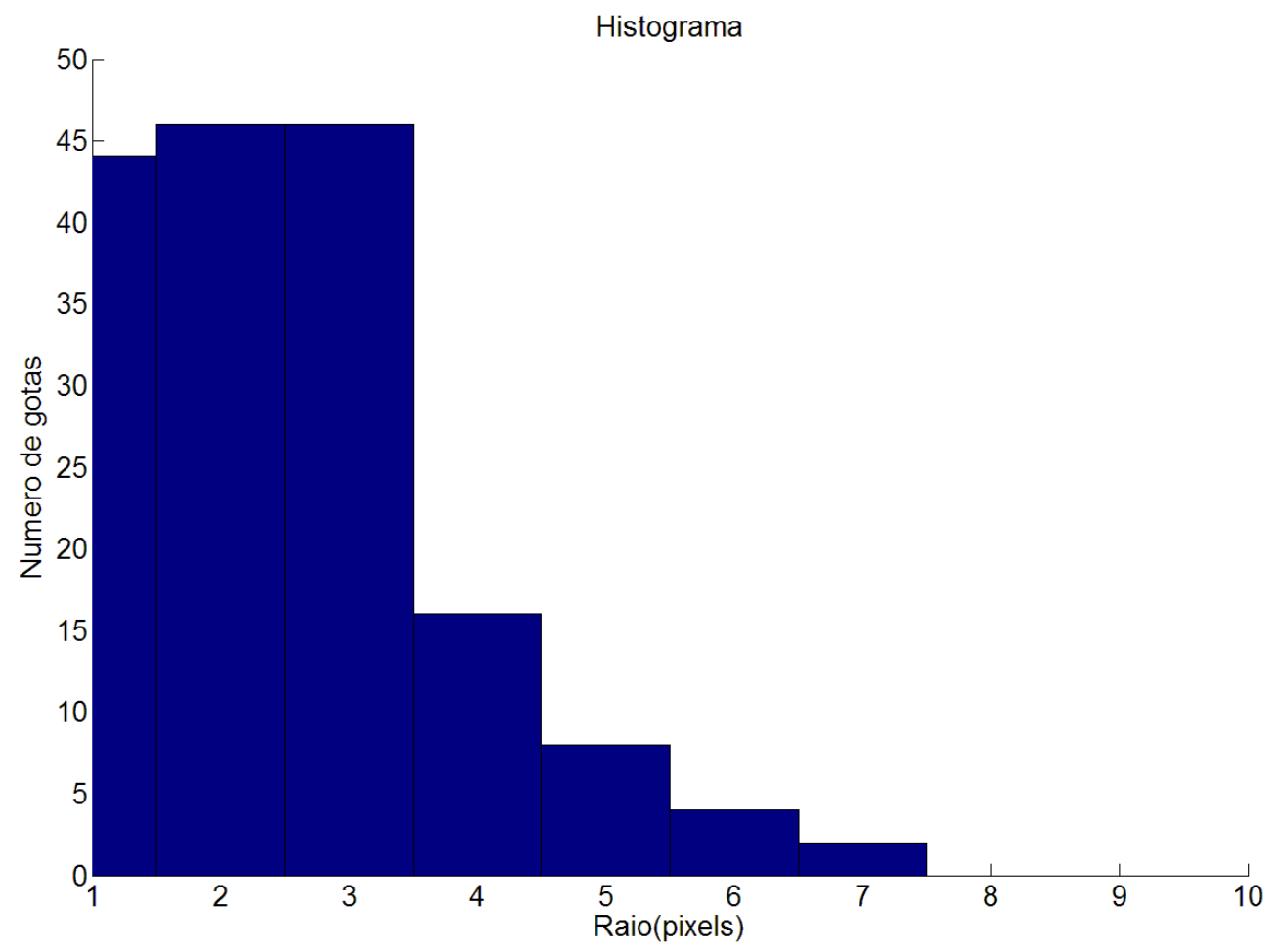

Figura D.26: Histograma apresentando a distribuição dos tamanhos das gotas contidas na primeira amostra do sexto papel hidrossensível. 


\section{Segunda amostra}

A figura D.27 apresenta a imagem da segunda amostra do sexto papel hidrossensível, ampliada 5 vezes em relação ao seu tamanho original.

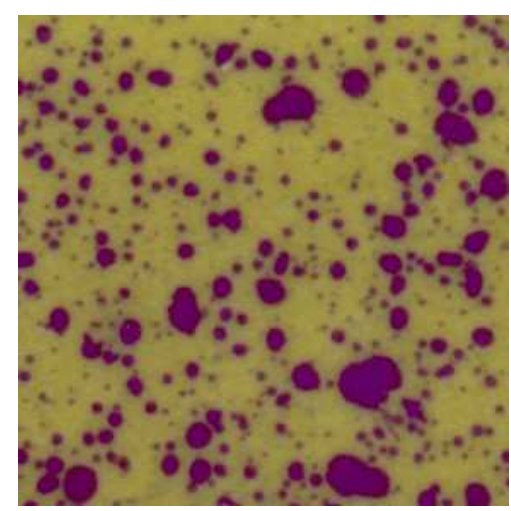

Figura D.27: Segunda amostra do sexto papel hidrossensível, ampliada 5 vezes em relação ao seu tamanho original.

Na figura D.28 pode ser visto o histograma apresentando a distribuição dos tamanhos das gotas contidas na segunda amostra do sexto papel hidrossensível.

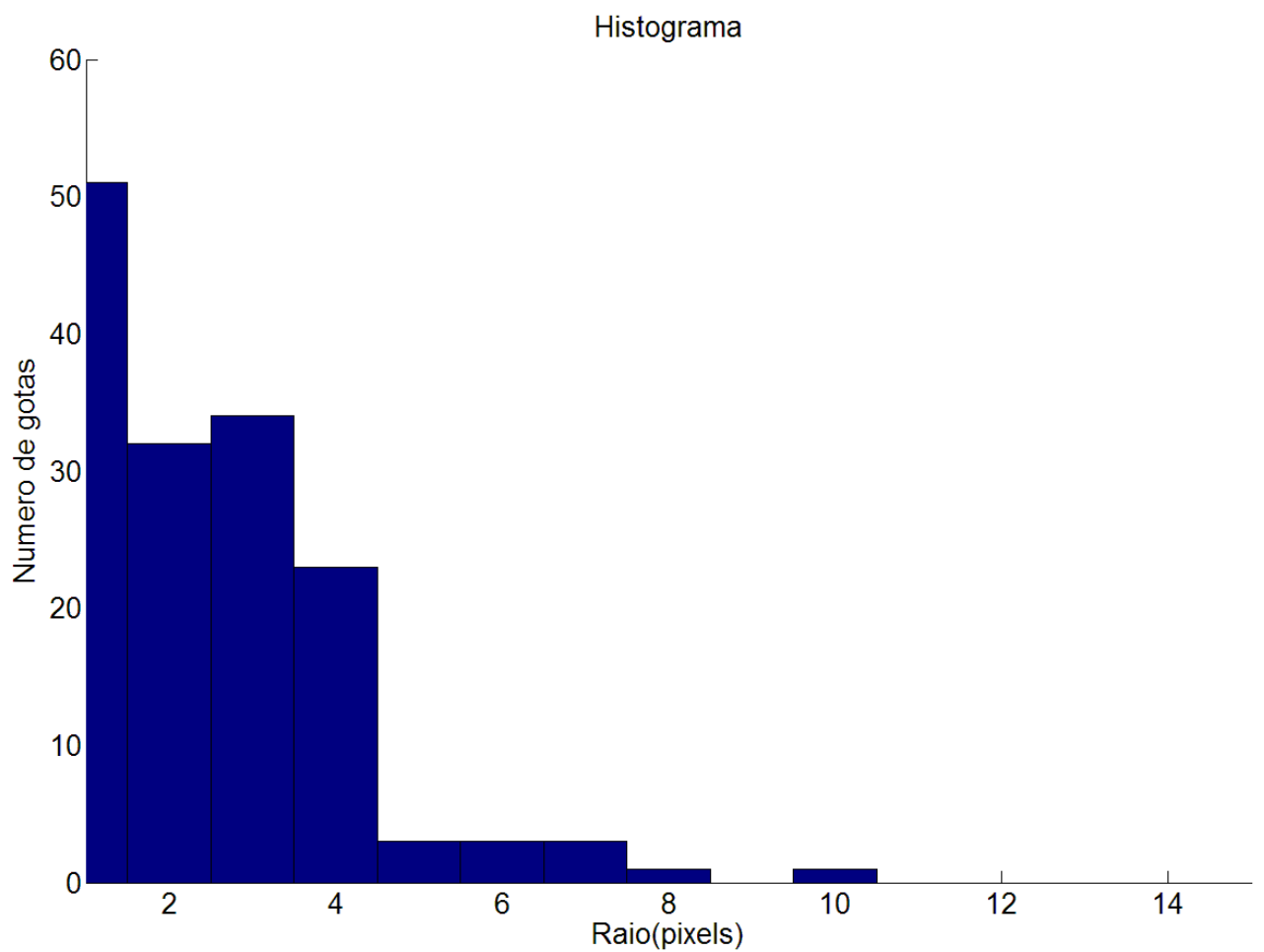

Figura D.28: Histograma apresentando a distribuição dos tamanhos das gotas contidas na segunda amostra do sexto papel hidrossensível. 


\section{Terceira amostra}

A figura D.29 apresenta a imagem da terceira amostra do sexto papel hidrossensível, ampliada 5 vezes em relação ao seu tamanho original.

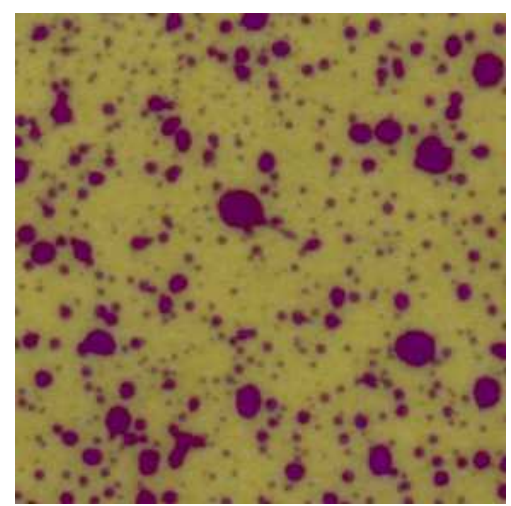

Figura D.29: Terceira amostra do sexto papel hidrossensível, ampliada 5 vezes em relação ao seu tamanho original.

Na figura D.30 pode ser visto o histograma apresentando a distribuição dos tamanhos das gotas contidas na terceira amostra do sexto papel hidrossensível.

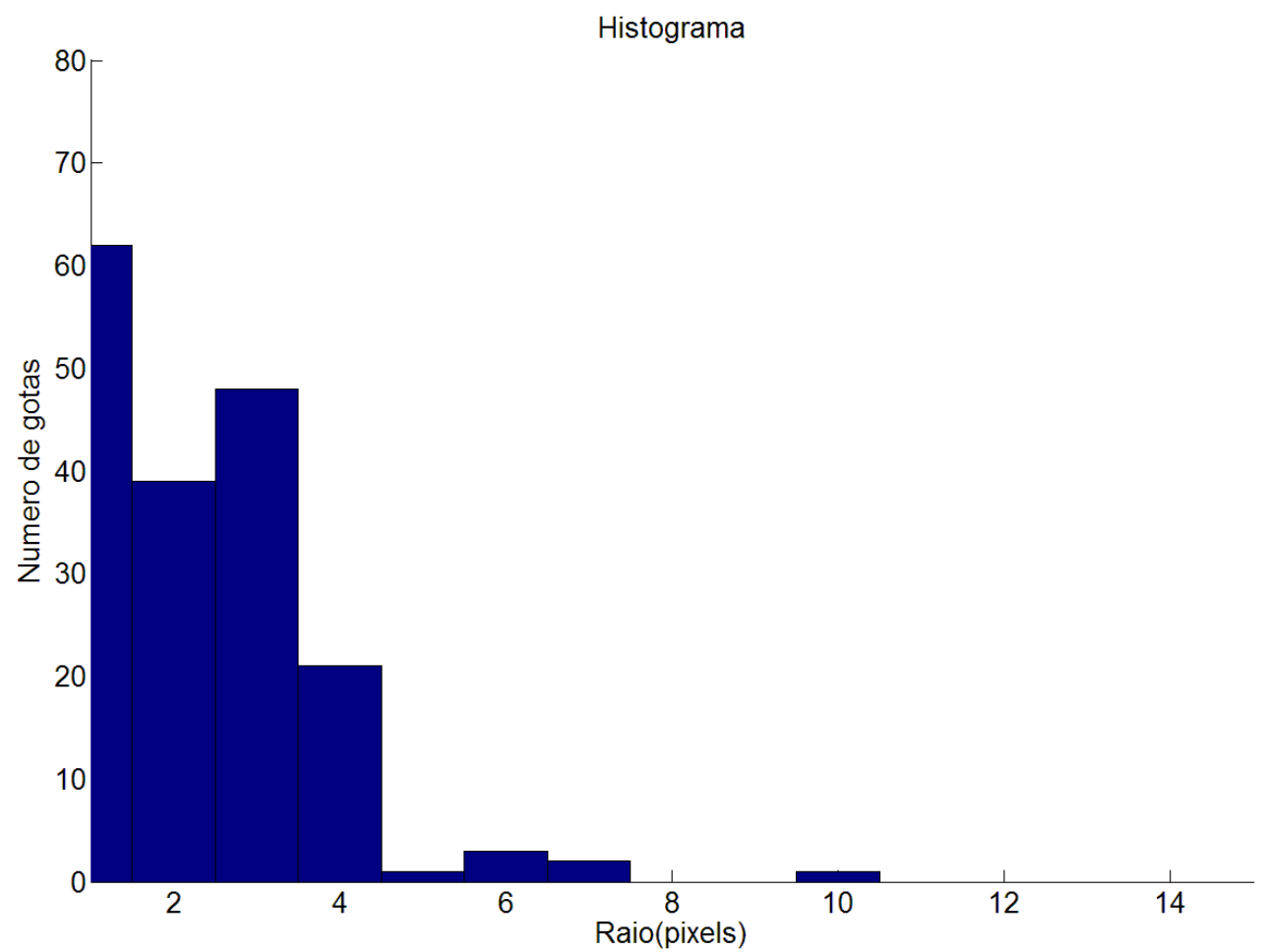

Figura D.30: Histograma apresentando a distribuição dos tamanhos das gotas contidas na terceira amostra do sexto papel hidrossensível. 


\section{Estudo de caso com amostras do papel hidrossensível \#7}

\section{Primeira amostra}

A figura D.31 apresenta a imagem da primeira amostra do sétimo papel hidrossensível, ampliada 5 vezes em relação ao seu tamanho original.

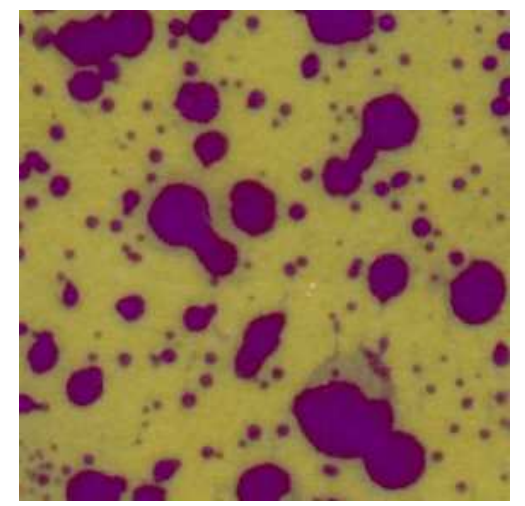

Figura D.31: Primeira amostra do sétimo papel hidrossensível, ampliada 5 vezes em relação ao seu tamanho original.

Na figura D.32 pode ser visto o histograma apresentando a distribuição dos tamanhos das gotas contidas na primeira amostra do sétimo papel hidrossensível.

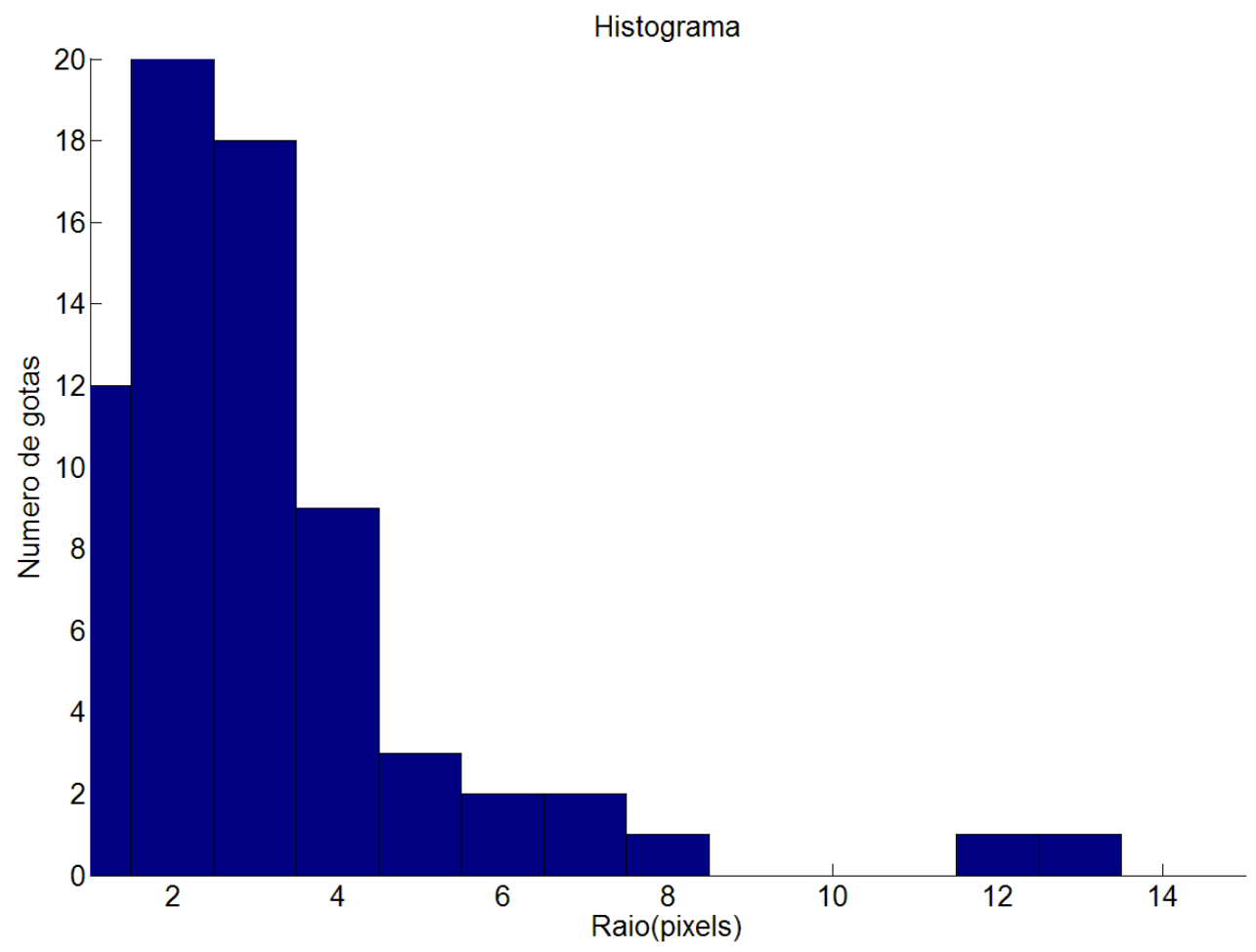

Figura D.32: Histograma apresentando a distribuição dos tamanhos das gotas contidas na primeira amostra do sétimo papel hidrossensível. 


\section{Segunda amostra}

A figura D.33 apresenta a imagem da segunda amostra do sétimo papel hidrossensível, ampliada 5 vezes em relação ao seu tamanho original.

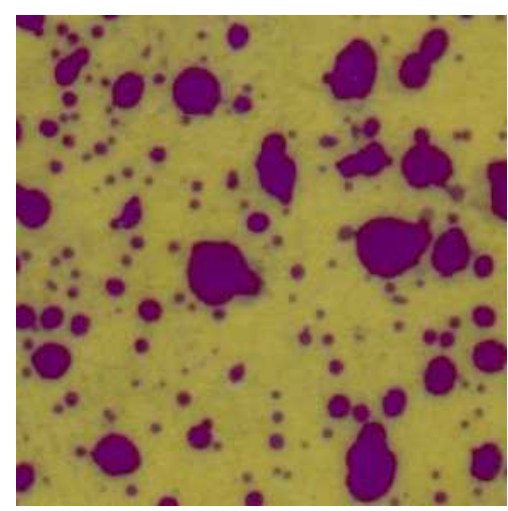

Figura D.33: Segunda amostra do sétimo papel hidrossensível, ampliada 5 vezes em relação ao seu tamanho original.

Na figura D.34 pode ser visto o histograma apresentando a distribuição dos tamanhos das gotas contidas na segunda amostra do sétimo papel hidrossensível.

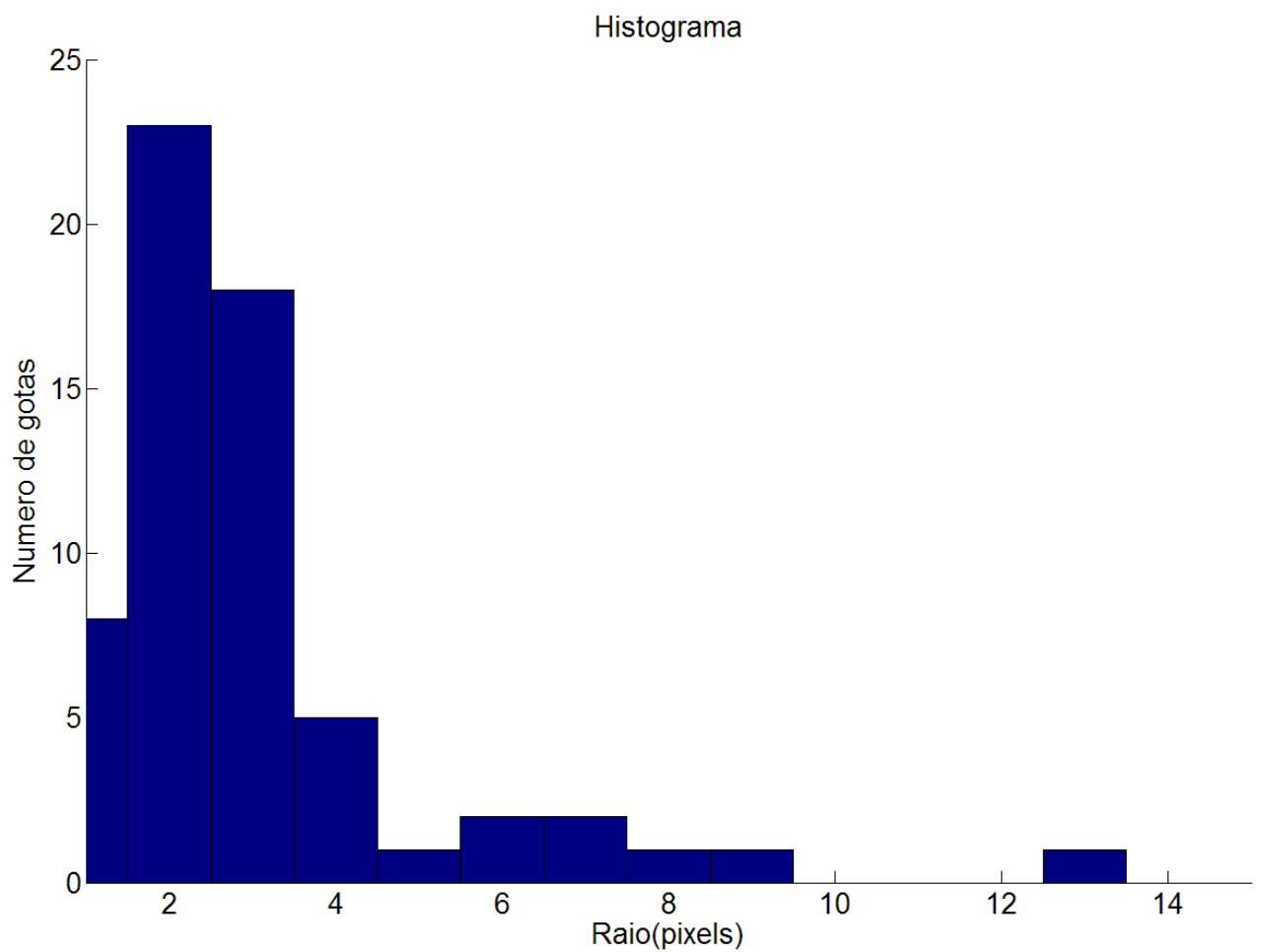

Figura D.34: Histograma apresentando a distribuição dos tamanhos das gotas contidas na segunda amostra do sétimo papel hidrossensível. 


\section{Terceira amostra}

A figura D.35 apresenta a imagem da terceira amostra do sétimo papel hidrossensível, ampliada 5 vezes em relação ao seu tamanho original.

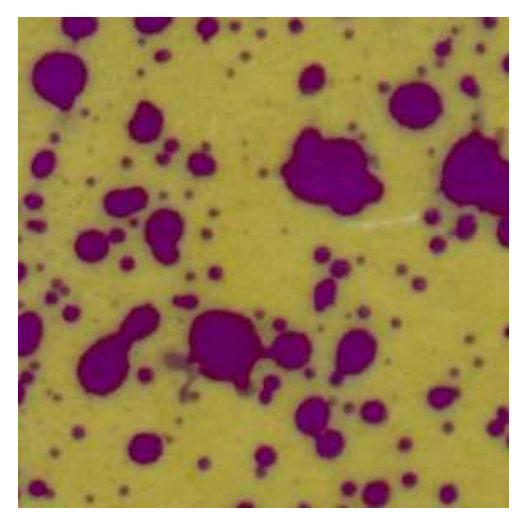

Figura D.35: Terceira amostra do sétimo papel hidrossensível, ampliada 5 vezes em relação ao seu tamanho original.

Na figura D.36 pode ser visto o histograma apresentando a distribuição dos tamanhos das gotas contidas na terceira amostra do sétimo papel hidrossensível.

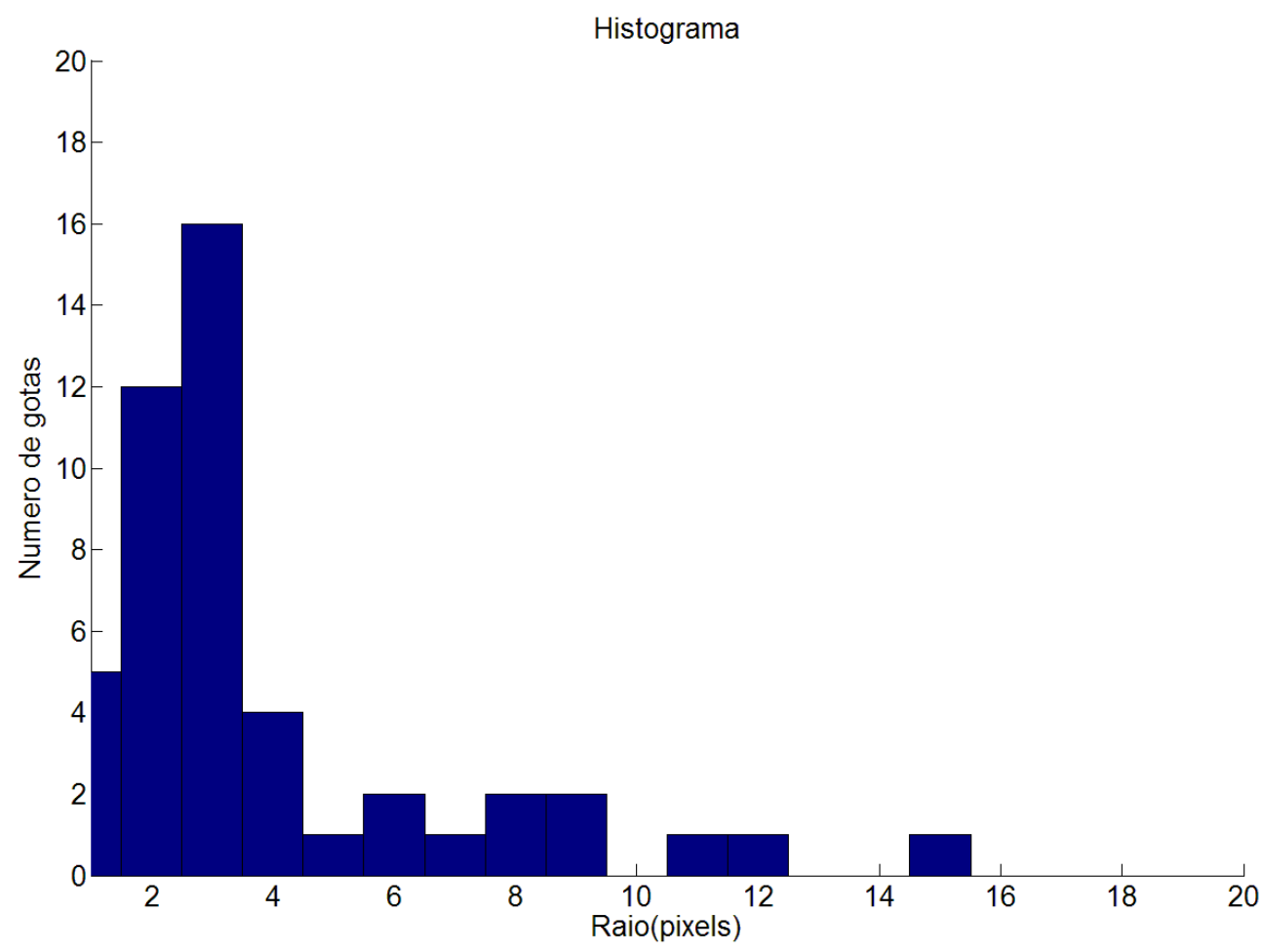

Figura D.36: Histograma apresentando a distribuição dos tamanhos das gotas contidas na terceira amostra do sétimo papel hidrossensível. 


\section{Estudo de caso com amostras do papel hidrossensível \#8}

\section{Primeira amostra}

A figura D.37 apresenta a imagem da primeira amostra do oitavo papel hidrossensível, ampliada 5 vezes em relação ao seu tamanho original.

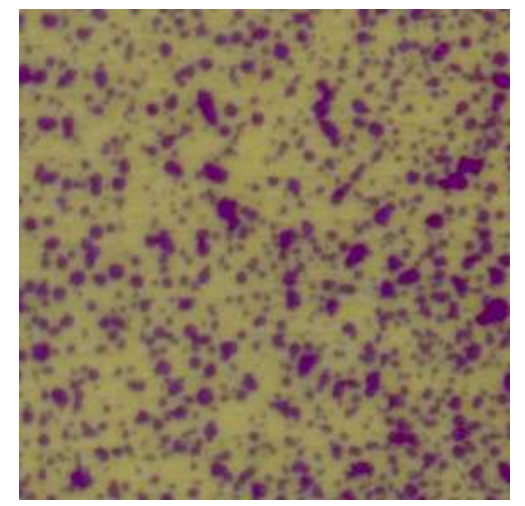

Figura D.37: Primeira amostra do oitavo papel hidrossensível, ampliada 5 vezes em relação ao seu tamanho original.

Na figura D.38 pode ser visto o histograma apresentando a distribuição dos tamanhos das gotas contidas na primeira amostra do oitavo papel hidrossensível.

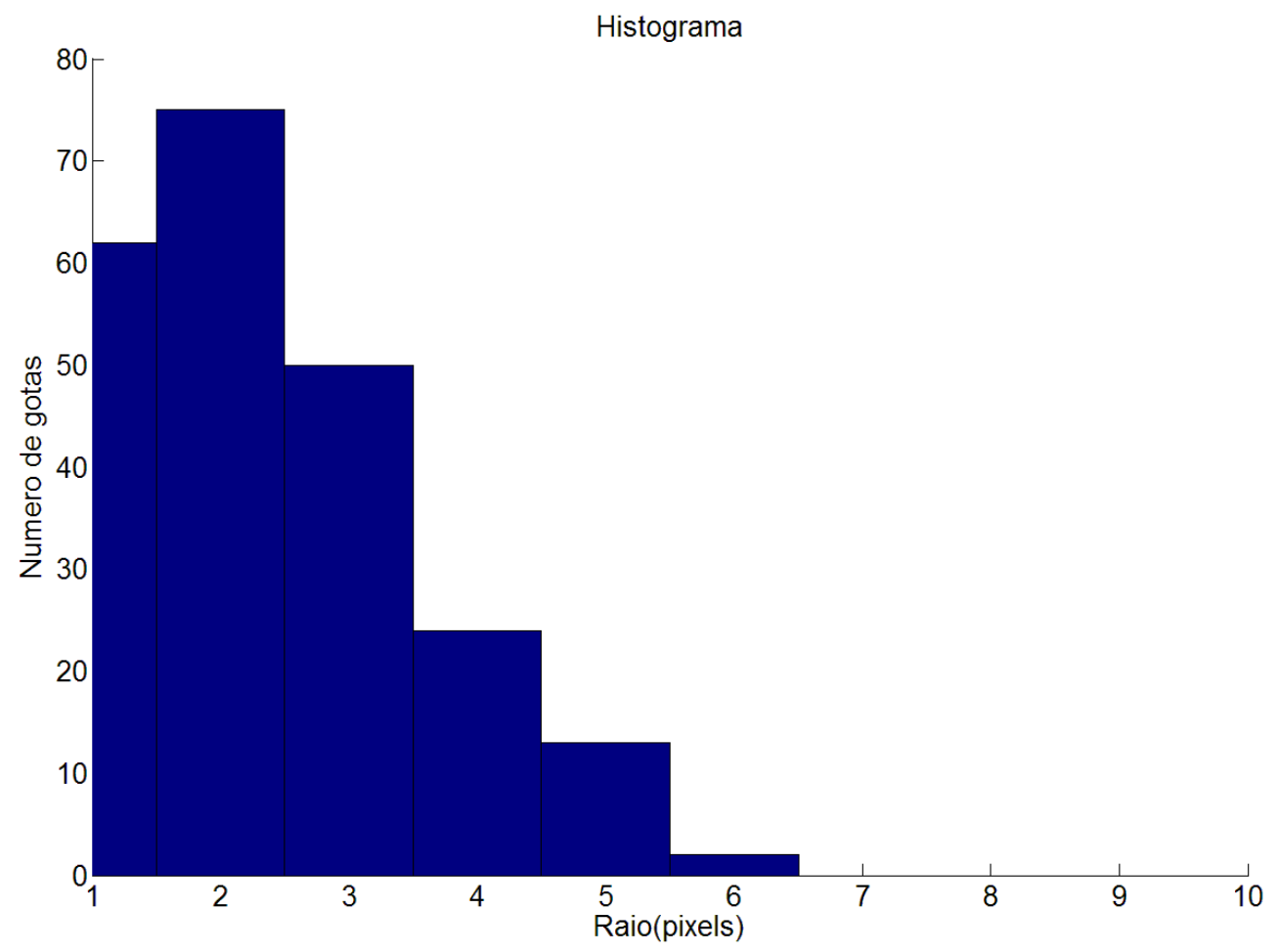

Figura D.38: Histograma apresentando a distribuição dos tamanhos das gotas contidas na primeira amostra do oitavo papel hidrossensível. 


\section{Segunda amostra}

A figura D.39 apresenta a imagem da segunda amostra do oitavo papel hidrossensível, ampliada 5 vezes em relação ao seu tamanho original.

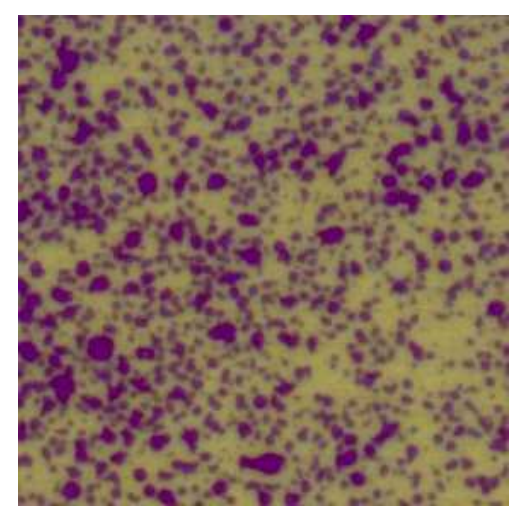

Figura D.39: Segunda amostra do oitavo papel hidrossensível, ampliada 5 vezes em relação ao seu tamanho original.

Na figura D.40 pode ser visto o histograma apresentando a distribuição dos tamanhos das gotas contidas na segunda amostra do oitavo papel hidrossensível.

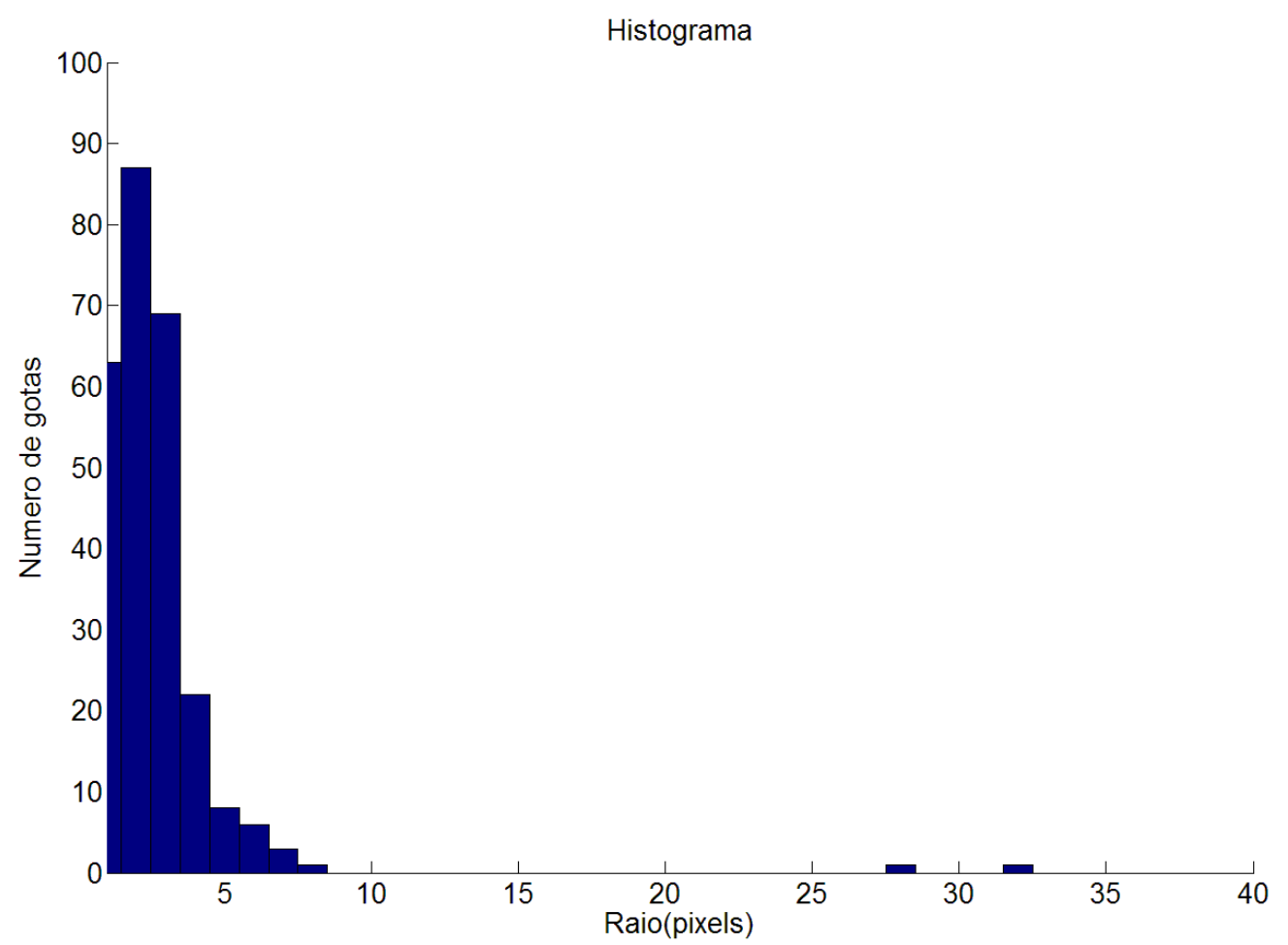

Figura D.40: Histograma apresentando a distribuição dos tamanhos das gotas contidas na segunda amostra do oitavo papel hidrossensível. 


\section{Terceira amostra}

A figura D.41 apresenta a imagem da terceira amostra do oitavo papel hidrossensível, ampliada 5 vezes em relação ao seu tamanho original.

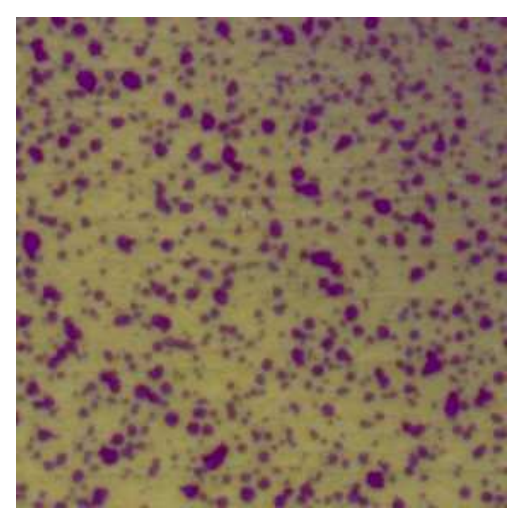

Figura D.41: Terceira amostra do oitavo papel hidrossensível, ampliada 5 vezes em relação ao seu tamanho original.

Na figura D.42 pode ser visto o histograma apresentando a distribuição dos tamanhos das gotas contidas na terceira amostra do oitavo papel hidrossensível.

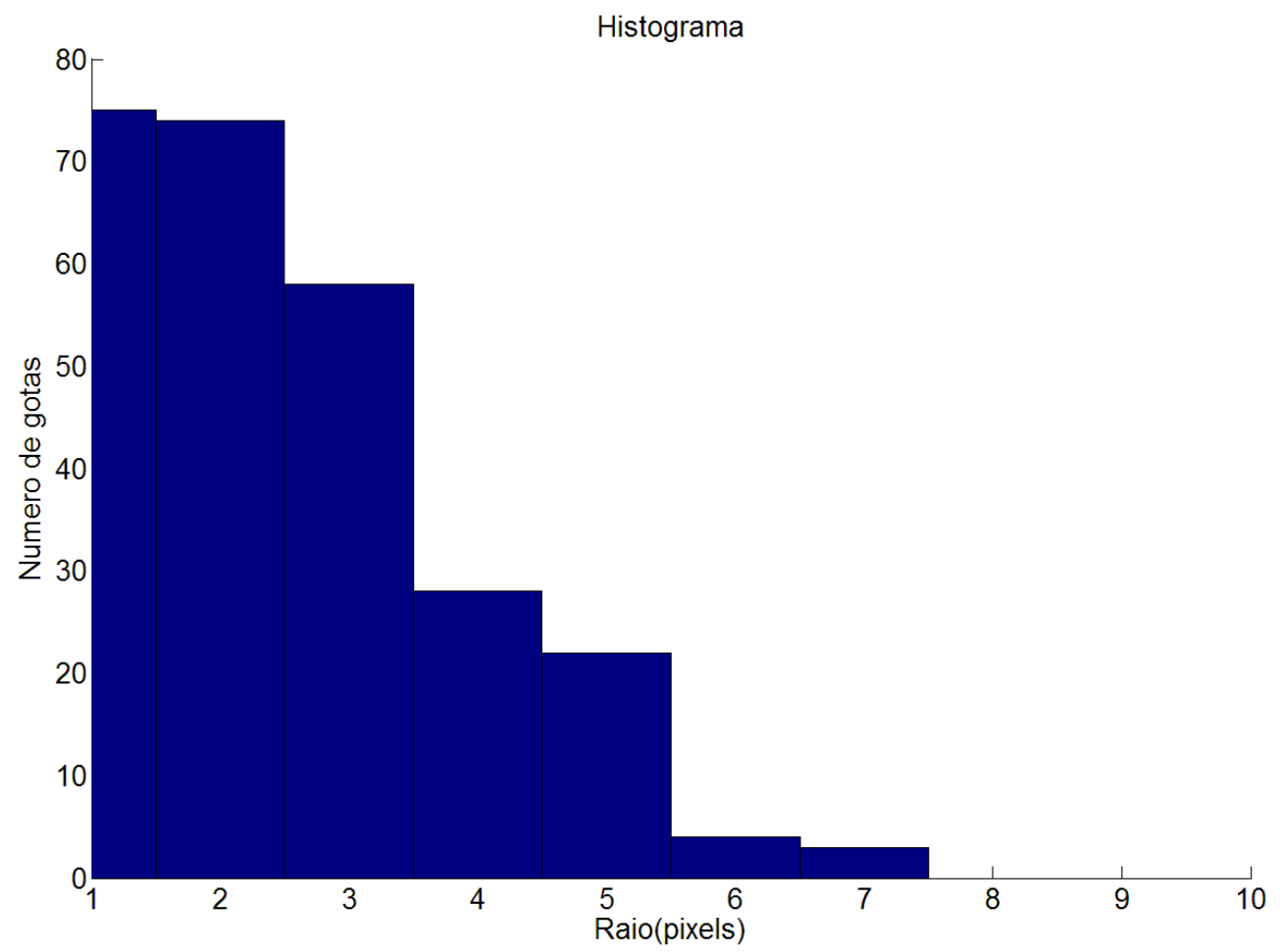

Figura D.42: Histograma apresentando a distribuição dos tamanhos das gotas contidas na terceira amostra do oitavo papel hidrossensível. 


\section{Estudo de caso com amostras do papel hidrossensível \#9}

\section{Primeira amostra}

A figura D.43 apresenta a imagem da primeira amostra do nono papel hidrossensível, ampliada 5 vezes em relação ao seu tamanho original.

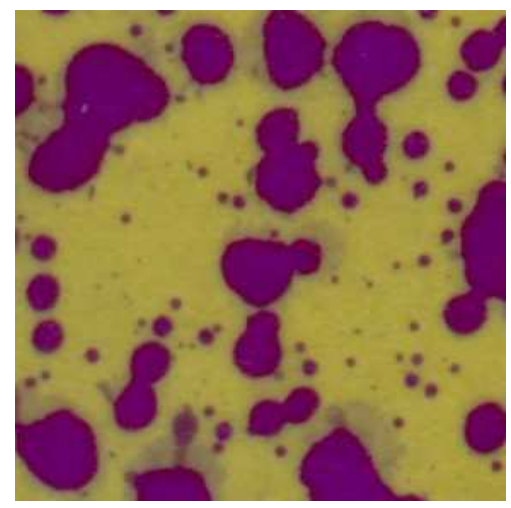

Figura D.43: Primeira amostra do nono papel hidrossensível, ampliada 5 vezes em relação ao seu tamanho original.

Na figura D.44 pode ser visto o histograma apresentando a distribuição dos tamanhos das gotas contidas na primeira amostra do nono papel hidrossensível.

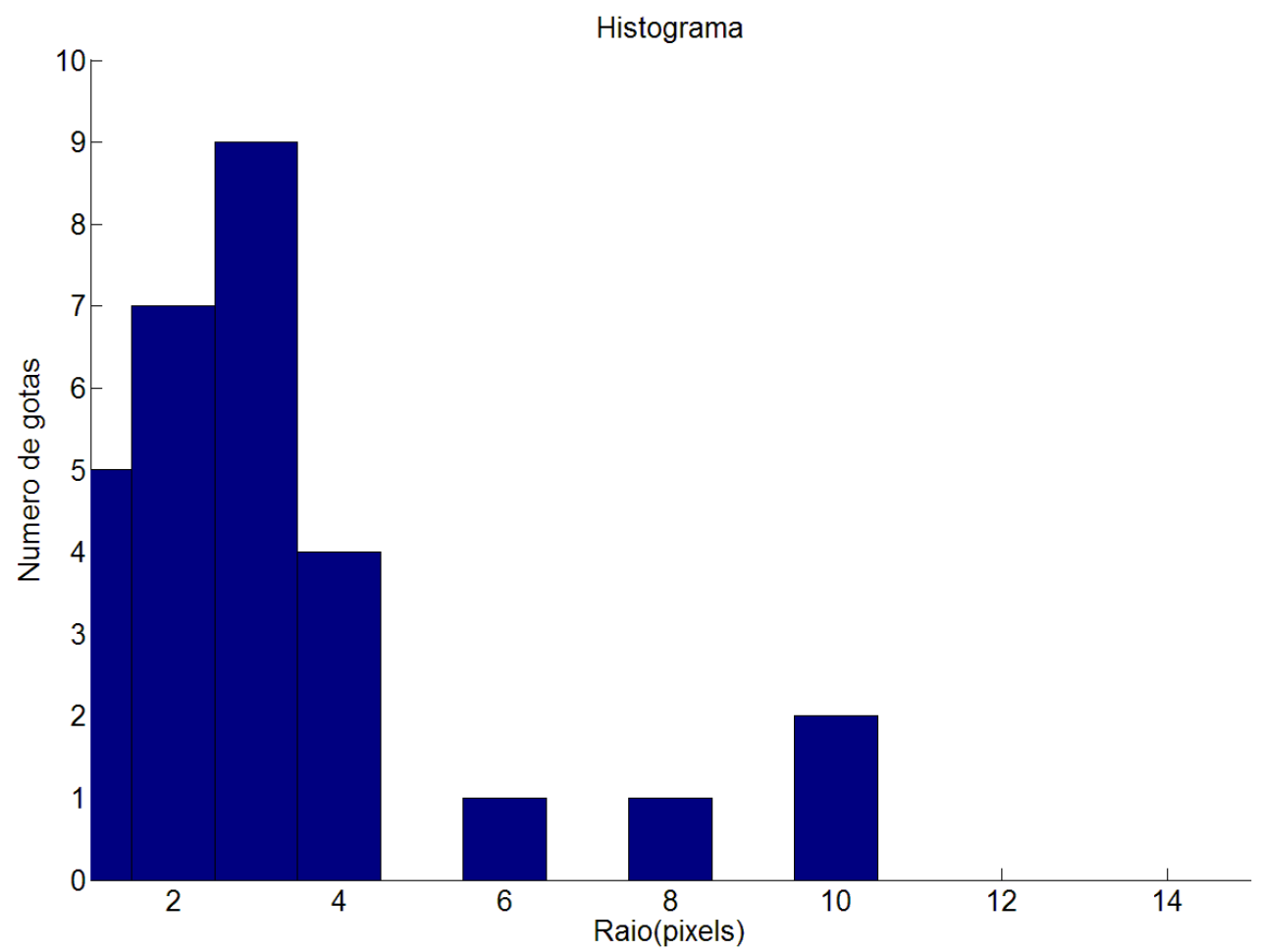

Figura D.44: Histograma apresentando a distribuição dos tamanhos das gotas contidas na primeira amostra do nono papel hidrossensível. 


\section{Segunda amostra}

A figura D.45 apresenta a imagem da segunda amostra do nono papel hidrossensível, ampliada 5 vezes em relação ao seu tamanho original.

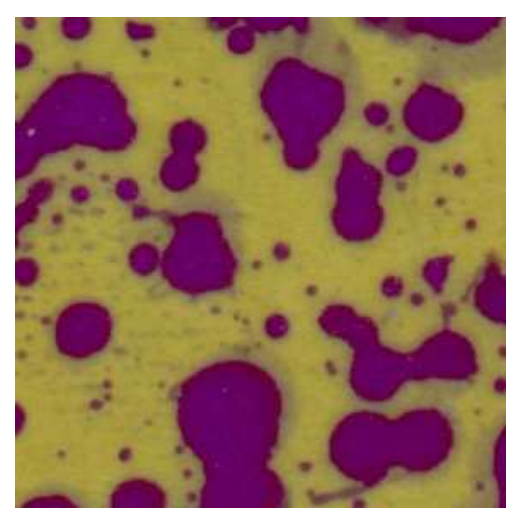

Figura D.45: Segunda amostra do nono papel hidrossensível, ampliada 5 vezes em relação ao seu tamanho original.

Na figura D.46 pode ser visto o histograma apresentando a distribuição dos tamanhos das gotas contidas na segunda amostra do nono papel hidrossensível.

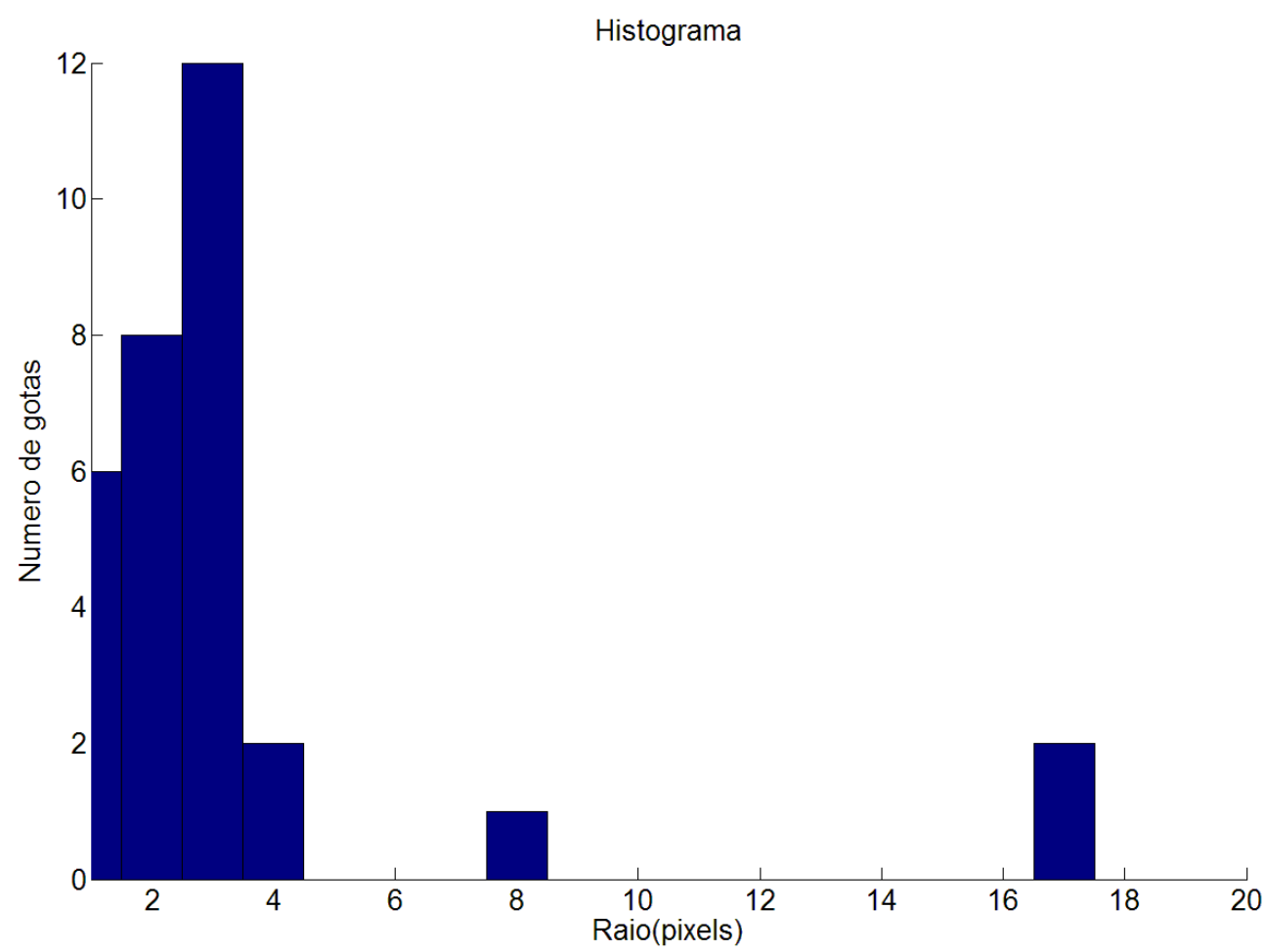

Figura D.46: Histograma apresentando a distribuição dos tamanhos das gotas contidas na segunda amostra do nono papel hidrossensível. 


\section{Terceira amostra}

A figura D.47 apresenta a imagem da terceira amostra do nono papel hidrossensível, ampliada 5 vezes em relação ao seu tamanho original.

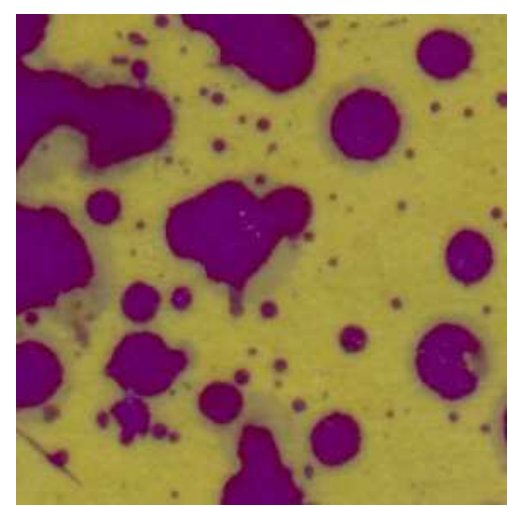

Figura D.47: Terceira amostra do nono papel hidrossensível, ampliada 5 vezes em relação ao seu tamanho original.

Na figura D.48 pode ser visto o histograma apresentando a distribuição dos tamanhos das gotas contidas na terceira amostra do nono papel hidrossensível.

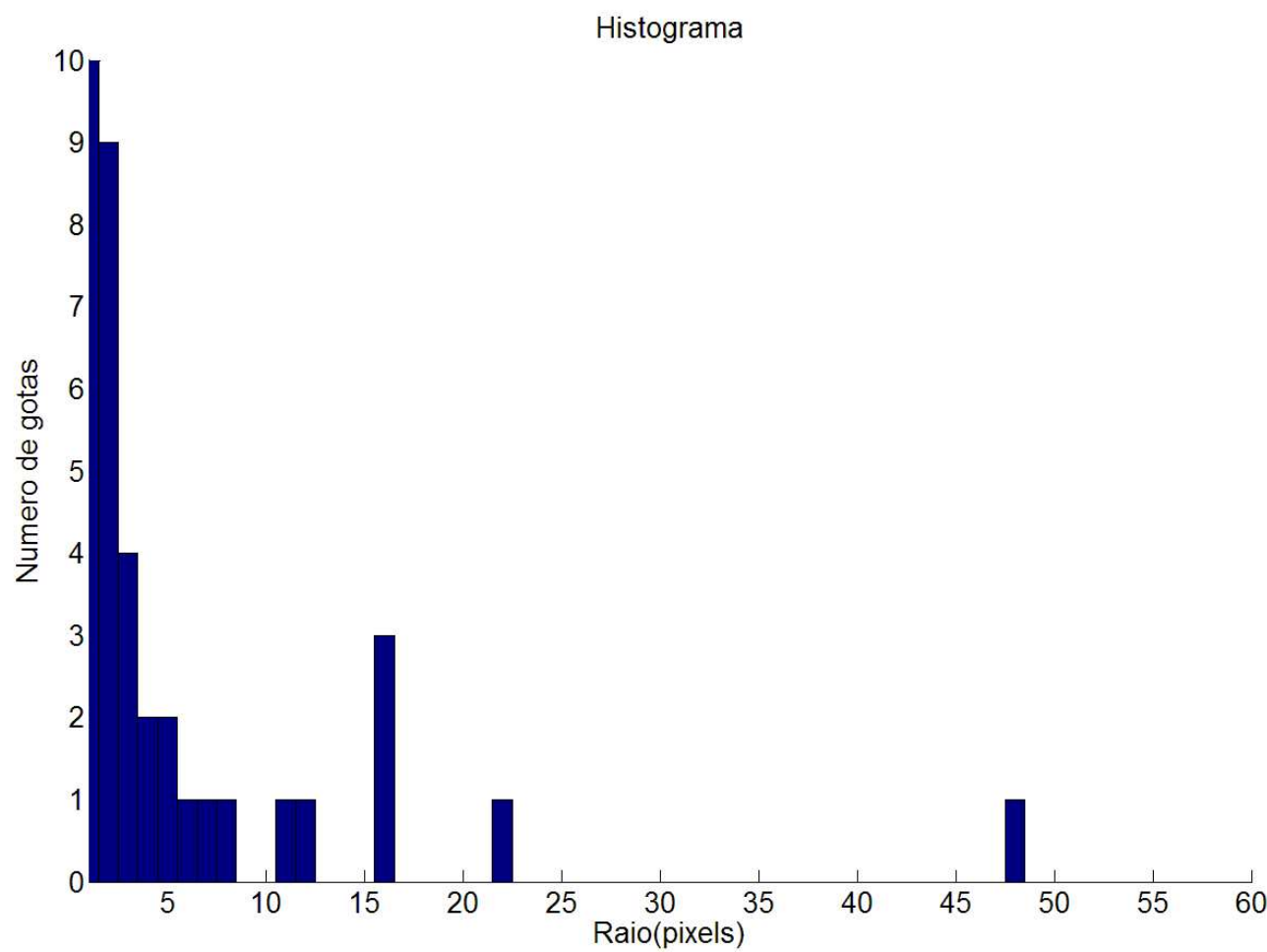

Figura D.48: Histograma apresentando a distribuição dos tamanhos das gotas contidas na terceira amostra do nono papel hidrossensível. 


\section{Referências Bibliográficas}

ANTUNiASSE, U. R. Técnicas Básicas para Aplicação de Defensivos. Botucatu - SP, 2003.

ATTNEAVE, F. Some informational aspects of visual perception. Psychological Review, v. 61, p. 183-193, 1954.

BEZERRA, F.; ANGELOCCI, L.; MINAMI, K. Deficiência hídrica em vários estádios de desenvolvimento da batata. Revista Brasileira de Engenharia Agrícola em Ambiental, DEAg/UFPB, Campina Grande-PB, v. 2, n. 2, p. 119-123, 1998.

BOWIE, I. Y. J. W. J. An analisys technique for biological shape i. Information and Control, v. 25, p. 357-370, 1974.

BOWIE, J.; YOUNG, I. An analysis technique for biological shape - ii. Acta Cytologica, v. 3, n. 21, p. 455-464, 1977.

BRIGHAM, E. The Fast Fourier Transform. NJ: Englewod-Cliffs Prentice Hall, 1974.

CALVACHE, A.; REICHARDT, K.; MALAVOLTA, E. Efeito da deficiência hídrica e da adubação nitrogenada na produtividade e na eficiência do uso de água em uma cultura de feijão. Scientia Agricola, ESALQ-USP, v. 54, n. 3, p. 232-240, Dezembro 1997.

CARMONA-POYATO, A.; FERNÁNDEZ-GARCÍA, N.; MEDINA-CARNICER, R.; MADRID-CUEVAS, F. Dominant point detection: A new porposal. Image and Vision Computing, Elsevier Science, v. 23, n. 1, p. 1226-1236, Julho 2005.

CESAR, R. J. Análise Multi-Escala de Formas Bidimensionais. 229 p. Tese (Doutorado) - IFSC - Instituto de Física de São Carlos da USP - Universidade de São Paulo, São Carlos - Brasil, 1997.

CESAR, R. J.; COSTA, L. Piecewise linear segmentation of digital contours in $\mathrm{o}(\mathrm{n} \cdot \log (\mathrm{n}))$ through a technique base don effective digital curvature estimation. Real-Time Imaging, p. 1: 409-417, 1995.

CESAR, R. J.; COSTA, L. Towards effective planar shape representation with multiscale digital curvature analysis based on signal processing techniques. Patern Reconittion, p. 29(9):1559-1569, 1996.

CESAR, R. J.; COSTA, L. The application and assesment of multiscale bending energy for morphometric characterization of neural cells. Review of Scientific Instruments, p. 1 68(5):2177-2186, May 1997. 
COSTA, L. F.; CESAR, R. J. Shape Analysis and Recognition: Theory and Practice. Boca Raton, USA: CRC Press, 2000.

CRUSCIOL, C.; ARF, O.; SORATTO, R. Manejo de irrigação por aspersão com base no "kc"e adubação mineral na cultura de arroz de terras altas. Bragantia, Campinas-SP, v. 62, n. 3, p. 465-475, 2003.

CRUVinel, P. E.; CRESTANA, S.; JORGE, L. A. C. Métodos e Aplicações do Processamento de Imagens Digitais. [S.l.]: EMBRAPA-SPI Brasília, 1996. 91-151 p.

CRUVINEL, P. E.; MARTINEZ, A. C.; KOENIGKAN, L. Estudo comparativo entre análise de correlação no domínio da frequência e transformada rápida de hough para determinação do volume de gotas de chuva. Congresso Brasileiro de Engenharia Agrícola,32-CONBEA, Goiânia, p. [CD-ROM], 2003.

CRUVINEL, P. E.; MINATEL, E. R.; MUCHERONI, M. L.; VIEIRA, S. R.; CRESTANA, S. An automatic method based on image processing for measurements of drop size distribution from agricultural sprinklers. In: SIBGRAPI, Simpósio Brasileiro de Computação Gráfica e Processamento De Imagens. Caxambu,MG: SBC/UFMG, 1996. v. 9, p. 39-46.

CRUVINEL, P. E.; VIEIRA, S. R.; CRESTANA, S.; MINATEL, E. R.; MUCHERONI, M. L.; NETO, A. T. Image processing in automated measurements of raindrop size and distribution. Computers and Eletronics in Agriculture, Amsterdam, v. 23, p. 205-217, 1999.

CUNHA, J.; TEIXEIRA, M.; VIEIRA, R.; FERNANDES, H. Avaliação do espectro de gotas dep ontas de pulverização hidáulicas utilizando a técnica da difração do raio laser. III Sintag - Simpósio Internacional de Tecnologia de Plaicação de Agrotóxicos, v. 1, n. 3, p. CD-ROM, Outubro 2004.

DAVIS, S. Understanding shapes: Angles and sides. IEEE Transactions on Computers, v. 26, n. 3, p. 236-242, march 1977.

EIGEL, J. D.; MORE, I. D. A simplified technique for measuring raindrop size and distribution. Transactions of the ASAE, v. 26, p. 1079-1084, 1983.

FELINTO, A. Visão Estéreo utilizando a Curvatura como Medida de Similaridade. 139 p. Tese (Doutorado) — IFSC - Instituto de Física de São Carlos da USP Universidade de São Paulo, São Carlos - Brasil, 2001.

FERNANDES, A.; R.SANTINATO; LESSI, R.; YAMADA, A.; SILVA, V. Deficiência hídrica e uso de granulados em lavoura cafeeira irrigada por gotejamento. Revista Brasileira de Engenharia Agrícola e Ambiental, DEAg/UFPB, Campina Grande-PB, v. 4, n. 3, p. 376-381, Maio 2000.

GONZALEZ, R. C.; WOODS, R. E. Digital Image Processing. [S.l.]: Addison-Wesley Publishing Company, Inc., 1993.

HALL, M. J. Use of the stain method in determining of the drop-size distribution of coarse liquid sprays. Transactions of the ASAE, v. 13, n. 1, p. 33-37, 1970.

JOHNSTON, E.; ROSENFELD, A. Angle detection on digital curves. IEEE Transactions on Computing, v. 22, n. 7, p. 875-878, 1973. 
KASHDAN, J.; SHRIMPTON, J.; WHYBREW, A. Two-phase flow characterization by automated digital image analysis. part 2: Application of pdia for sizing sprays. Particle and Particle Systems Characterization, WILEY-VCH Verlag GmbH and Co., v. 1, n. 21, p. 15-23, 2004.

KOHL, R. A. Drop size distribution from medium-sized agricultural sprinklers. Transactions of the ASAE, v. 17, n. 4, p. 690-693, 1974.

LOVICH, J.; MOUZA, A.; PARAS, S.; LYE, G.; ANGELI, P. Drop size distribution in highly conecentrated liquid-liquid dispersions using a light back scattering method. Journal of Chemical Technology and Biotechnology, Society of Chemical Industry, v. 1 , n. 80 , p. 545-552, Março 2005.

MAROUELLI, W.; SILVA, W.; MORETTI, C. Desenvolvimento de plantas, produção e qualidade de bulbos de alho sob condições de deficiência de água no solo. Horticultura Brasileira, v. 20, n. 3, p. 470-473, Setembro 2002.

MARTINEZ, A. C. Um novo método para medidas de gotas de chuva com técnicas do processamento digital de imagens. 194 p. Dissertação (Mestrado) - EESC/USP, São Carlos-SP, 2002.

MARTINEZ, A. C.; CRUVINEL, P. E. Uso de transformada rápida de hough na determinação do volume de gotas de chuva natural ou artificial. Congresso Brasileiro de Engenharia Agrícola,31-CONBEA, Salvador, p. 1454-1457, 2002.

MCCOOL, D. K. Personal communication. USDA-ARS, Agricultural Engineering Department, Washington State Univ., Pullman, 1982.

MUNEM, M.; FOULIS, D. Cálculo. Rio de Janeiro: Guanabara Dois S.A., 1982. Trad: A.L. Cordeiro et al.

OTTERLOO, P. van. A contour-Oriented Approach to Shape Analysis. NJ:

Prentice-Hall, 1991.

PAPOULIS, A. The Fourier Integral and its Applications. [S.l.]: McGraw-Hill, 1962.

PESSOA, M. C. P. Y.; CHAIM, A.; HERMES, L. C. Gota 5: programa computacional para estimar uniformidade de gota e volume de deposição de calda pulverizada. Jaguariúna, 1999. 31 p.

RAMOS, H.; DEMÉTRIUS; ARAÚJO; LIMA, J. de; BETTINE, P.; YANAI, K.; JR., C. G.; MINATEL, E. Acurácia de um programa de computador na determinação de parâmetros da pulverização sobre papeis hidrossensíveis. SINTAG III - Simpósio Internacional de Tecnologia de Aplicação de Agrotóxicos, FEPAF, Botucatu - SP, v. 1, n. 3, p. 1-4, Outubro 2004.

RAMOS, H. H. Perdas ligadas à má aplicação de agrotóxicos. II Simpósio Internacional de Tecnologia de Aplicação de Agrotóxicos: Eficiência, Economia e Preservação da Saúde Humana e do Ambiente, IAC - Instituto Agronômico de Campinas, Jundiaí - Brasil, 2001.

RODRIGUES, O.; LHAMBY, J.; DIDONET, A.; MARCHESE, J.; SCIPIONI, C. Efeito da deficiência hídrica na produção de trigo. Revista Pesquisa Agropecuária Brasileira, Embrapa, v. 33, n. 6, p. 839-846, Junho 1998. 
ROELS, J. M. Personal communication. Netherlands: Lab. Physical Geography, Geographical Institut, Univ.,Utrecht, 1981.

ROMAN, E.; VARGAS, L.; RBEIRO, M.; LUIZ, A. Influência do orvalho e volume de calda de aplicação na eficácia do glyphosate na dessecacão de brachiaria plantaginea. Revista Planta Daninha, Viçosa-MG, v. 22, n. 3, p. 479-482, 2004.

SABER, E.; XU, Y.; TEKALP, A. Partial shape recognition by sub-matrix matching for partial matching guided image labeling. Pattern Recognition, Elsevier Science, v. 38, n. 1, p. 1560-1573, Março 2005.

SCHLEUSENER, P. E. Drop Size Distribution and Energy of Falling Raindrops From a Medium Pressure Irrigation Sprinkler. Tese (Doutorado) - Michigan State University, East Lansing, 1967.

SONG, Q.; ZHANG, G.; QIU, Z. Review of drop analysis technology for liquid property study. Opto-Eletronics Review, v. 1, n. 13, p. 1-8, 2005. 